\title{
ANÁLISE NUMÉRICA DO COMPORTAMENTO ESTRUTURAL E DA RESISTÊNCIA DE TERÇAS DE AÇO RESTRINGIDAS PELAS TELHAS
}

Dissertação apresentada à Escola de Engenharia de São Carlos da Universidade de São Paulo como parte dos requisitos necessários à obtenção do título de Mestre em Engenharia de Estruturas.

Orientador: Prof. Associado Maximiliano Malite 

À minha esposa Ciça. 



\section{AGRADECIMENTOS}

Ao dom da vida e à fé que tenho.

Aos meus pais que com muito carinho me apoiaram nos meus passos me dando educação para a vida sendo os grandes responsáveis pela pessoa que sou hoje.

Aos meus familiares que sempre se preoucuparam comigo tios, primos, avós e a família de minha esposa. Em especial minha avó Maria e meu avô Américo.

À minha esposa que com muito amor compreendeu os meus defeitos, a minha ausência em vários momentos e mesmo assim me apoiou, aconselhou e garantiu inúmeros momentos de alegria.

Ao meu orientador de iniciação científica e amigo Roberto Buchaim, por ter me direcionado ao meio acadêmico o que hoje me proporciona imenso prazer e orgulho de estar inserido.

Ao meu orientador Maximiliano Malite que de forma no minímo exemplar me orientou com persistência e confiança.

À ótima orientação de Ben Schafer que da mesma forma confiou no meu trabalho, ofereceu oportunidades e me ensinou muito além de estruturas.

Aos colegas dos EUA Cris, Yared, Mina, Vahid e Rachel, pela compreensão e ajuda. Zak que me acolheu em sua casa e sua namorada Heather. Em especial aos meus amigos Cris e Zak que me "adotoram" e se preoucupavam não só com o meu trabalho mas também com meu bem estar e a minha imersão na cultura americana.

Aos meus amigos do departamento que compartilharam seus conhecimentos e amizade: André, Daniela, Dênis, Edson, Gustavo Chodraui, Iara, Karenina, Klaus Thöni, Raimundo, Ronaldo, Saulo, Tatianne Kotinda, Toledo e Wanderson. $\mathrm{E}$ àqueles que me deram além de muitas gargalhadas o prazer de uma amizade mais profunda: Pedro pela paciência com minhas brincadeiras, Marlos e Gustavo pelo companherismo constante, Lívia pela amizade sincera e Filipe pela grande amizade que dificilmente temos a chance de ter.

À USIMINAS e CNPQ pelos recursos financeiros concedidos. 



\begin{abstract}
RESUMO
Vieira Jr., L. C. M. Análise numérica do comportamento estrutural e da resistência de terças de aço restringidas pelas telhas. 125p. Dissertação (Mestrado) - Escola de Engenharia de São Carlos, Universidade de São Paulo, São Carlos, 2007.

Terças e longarinas metálicas são geralmente projetadas no Brasil desconsiderando a interação com as telhas, ou seja, como barras isoladas, apesar da norma brasileira NBR 14762:2001 apresentar um procedimento de cálculo que leva em consideração tal interação (método do fator $\mathrm{R}$ ). $\mathrm{O}$ comportamento estrutural do sistema terça-telha é complexo e a análise completa deve considerar a nãolinearidade geométrica e física, bem como a influência do contato e da conexão terçatelha.

Foram analisados modelos numéricos propostos na literatura e desenvolvido um modelo via método dos elementos finitos (MEF) que incorpora as não-linearidades e o contato terça-telha. O modelo foi calibrado com resultados experimentais e posteriormente foi realizada uma análise paramétrica, a qual permitiu gerar expressões que relacionam a força (vento de sucção) com os deslocamentos.

Foi também analisada a viabilidade da aplicação do método da resistência direta (MRD) ao dimensionamento de terças restringidas pela telha, empregando o método das faixas finitas (MFF) para a análise de estabilidade elástica, em que a restrição promovida pela telha foi modelada por meio de vínculos elásticos na mesa conectada com a telha. Foram considerados dois casos de distribuição de tensões normais: (i) tensões oriundas somente da flexão e (ii) tensões oriundas da flexão e torção. Em ambos os casos o momento resistente apresentou diferenças relativamente elevadas em relação ao obtido pelo método do fator $\mathrm{R}$, refletindo a necessidade de uma abordagem específica do método para o sistema terça-telha.
\end{abstract}

Palavras-chave: estruturas de aço, perfis formados a frio, terças de aço, terça-telha, método da resistência direta. 



\begin{abstract}
Vieira Jr., L. C. M. Numerical analysis of cold-formed purlin-sheeting systems focused on the structural behavior and strength. 125p. Dissertation (Master) Escola de Engenharia de Sao Carlos, Universidade de Sao Paulo, Sao Carlos, 2007.

The structural behavior of purlin-sheeting system is complex and the complete analysis should consider the physical and geometrical nonlinearity, as well as the influence of the purlin-sheeting contact and connection. The Brazilian code NBR 14762:2001 provides a design procedure to consider the interaction between a purlin or girt connected to the sheeting (factor R method). In Brazil purlins and girts are typically designed as isolated beams, without consideration for this purlin-sheeting combination.
\end{abstract}

Numerical models proposed in the literature were analyzed and a finite element model (FEM) was developed considering nonlinearities and the contact between purlin and sheeting. The model was validated through experimental results and then implemented in a parametrical analysis. Expressions were generated using the parametrical results to relate the loading (wind uplift) to the displacements.

The Direct Strength Method (DSM) was analyzed to the designed of purlins restrained by sheeting. The finite strip method (FSM) was used for elastic buckling determination. The restraint applied to the sheeting was modeled using an elastic foundation on the flange connected to the sheeting. Two stress distributions were considered: (i) bending stresses and (ii) bending and warping stresses. In both cases the nominal flexural strength presented considerable differences compared to the factor R design method, reflecting the necessity of a specific study to evaluate the viability of the DSM approach for purlin design.

Keywords: steel structures, cold-formed steel structures, steel purlin, purlin- sheeting combination, direct strength method. 



\section{SUMÁRIO}

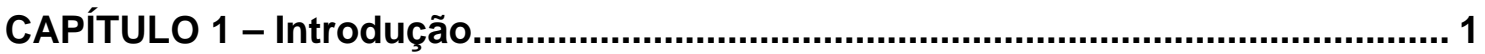

CAPÍTULO 2 - Revisão Bibliográfica.................................................................... 5

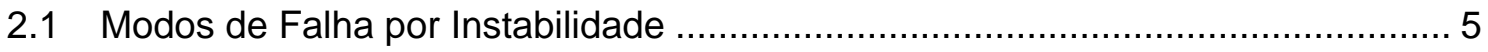

2.2 Comportamento Estrutural do Sistema Terça-Telha ........................................ 6

2.3 Aplicação da Teoria da Flexo-Torção ao Sistema Terça-Telha .......................... 10

2.4 Modelo Proposto por Trahair (1993) (Flambagem por Flexo-Torção) ................ 15

2.5 Modelo de Peköz e Soroushian (Cornell University) ..................................... 19

2.5.1 Ensaio Padronizado pelo AISI (1996)............................................... 28

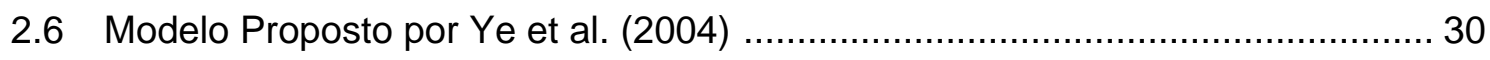

2.7 Modelo de LaBoube (University of Missouri-Rolla)............................................ 34

2.8 Calibração do fator R, segundo Hancock e Johnston (1994) .............................. 37

2.9 Método das Faixas Finitas Utilizado por Ye et al. (2002) .................................. 39

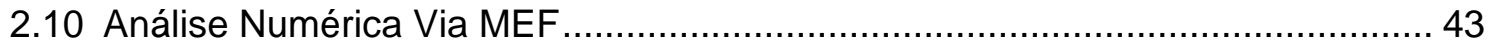

2.10.1 Modelo Completo, Lucas et al.(1997a)......................................... 43

2.10.2 Modelo Simplificado, Lucas et al.(1997b)...................................... 47

2.10.3 Modelo Desenvolvido por Baságlia (2004) ...................................... 50

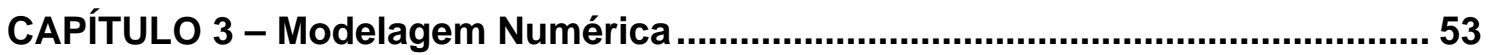

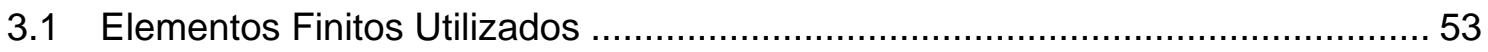

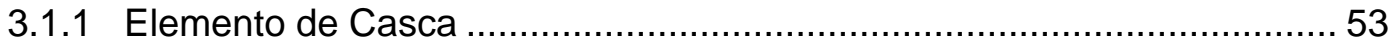

3.1.2 Elementos de Contato, TARGE170 e CONTA173 …............................ 54

3.1.3 Elementos de Mola, COMBIN39.................................................. 55

3.2 Critérios Utilizados Para a Análise Não-Linear.................................................... 55

3.2.1 Não-Linearidade do Contato ..................................................... 55

3.2.2 Modelo Adotado Para Considerar a Não-Linearidade do Material ........... 56

3.2.3 Aspectos Referentes à Análise Não-Linear Geométrica ......................... 57

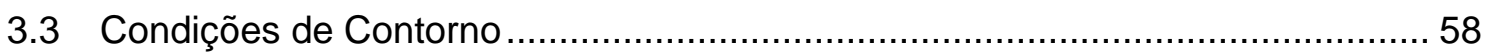

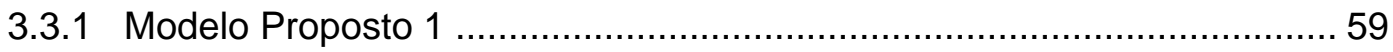

3.3.2 Modelo Completo Proposto por Lucas et al. (1997a) ............................. 65

3.3.3 Modelo Para Avaliação da Rigidez à Rotação ......................................... 66

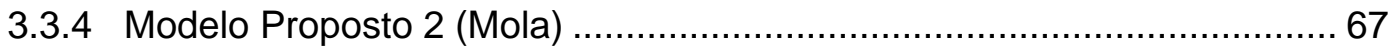

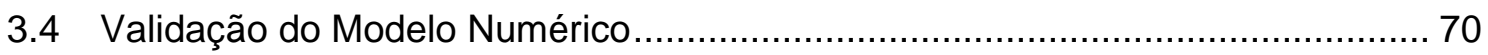




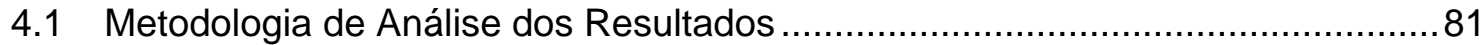

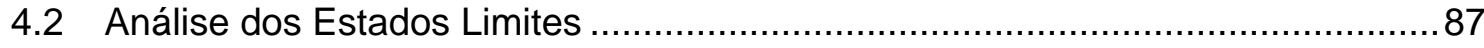

4.2.1 Estado Limite de Serviço .............................................................. 88

4.2.2 Estado Limite Último .....................................................................93

CAPÍTULO 5 - Método da Resistência Direta (MRD) Aplicado ao Sistema TerçaTelha .95

5.1 Prática Atual para o Cálculo de Terças Utilizando o Método da Resistência Direta 96

5.2 Estudo das Tensões Atuantes na Seção Transversal 98

5.2.1 Modelo de Winter para a Determinação das Tensões Atuantes em Fase Elástica 100

5.2.2 Modelo Proposto para a Distribuição de Tensões Considerando as Restrições Impostas pela Telha (Modelo de Winter Modificado)................................. 102

5.2.3 Estudo dos Coeficientes de Redução $\alpha_{B}$ e $\alpha_{M}$ do Modelo Proposto ........106

5.3 Aplicação do Método da Resistência Direta com Base nas Tensões $\sigma_{M}$ e $\sigma_{B} 110$ 5.3.1 Apresentação dos Resultados de Todas as Simulações pelo MRD .......112 


\section{INTRODUÇÃO}

As terças são elementos estruturais que servem de elo entre as telhas de cobertura e as tesouras, assim sendo, transmitem o carregamento aplicado nas telhas às tesouras (ou estrutura principal). O mesmo elemento recebe a denominação de longarina quando apóiam as telhas de fechamento lateral e transmitem o carregamento aos pilares. Estas denominações definem a transmissão dos carregamentos ao longo da estrutura como pode ser evidenciado no seguinte esquema:

$$
\begin{gathered}
\text { Telhas } \rightarrow \text { Terças } \rightarrow \text { Tesoura (ou Estrutura Principal) } \rightarrow \text { Pilares } \rightarrow \text { Fundação } \\
\text { Telhas } \rightarrow \text { Longarinas }
\end{gathered}
$$

As telhas podem ser fixadas às terças por meio de ganchos (ou pinos) e parafusos auto-atarraxantes (screws). A Figura 1.1 ilustra os modos de fixação das telhas às terças.

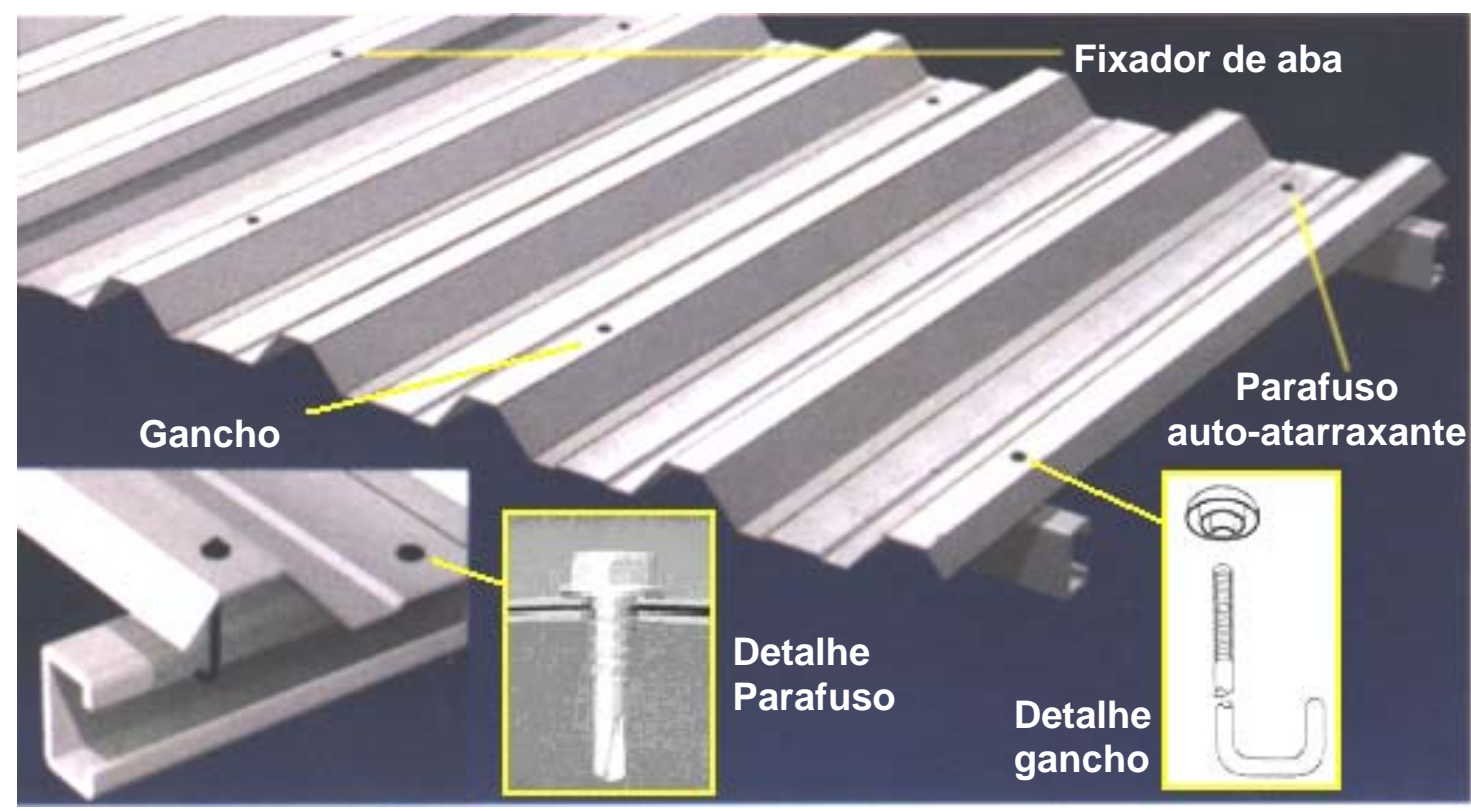

Figura 1.1 - Modos de fixação das telhas às terças. Fonte: Baságlia (2004). 
Os ganchos são encaixados na aba inferior das terças ou no enrijecedor da mesa superior da terça e fixados às ondulações superiores das telhas, já os parafusos de rosca soberba, também conhecidos como parafusos auto-atarraxantes (screws) fixam as ondulações inferiores das telhas às mesas superiores das terças.

As terças metálicas empregadas no Brasil até o final da década de 60 , eram produzidas pela CSN - Companhia Siderúrgica Nacional e atendia o padrão americano de perfis $U$ laminados. A partir da década de 70 foi iniciada a produção de terças em perfis formados a frio, as quais apresentavam maior variedade de dimensões e relação inércia/peso superior à dos perfis laminados.

Com o desenvolvimento das telhas metálicas (aço zincado e alumínio), as telhas mais pesadas (fibrocimento) entraram em desuso e conseqüentemente os ganchos foram substituídos pelos parafusos auto-atarraxantes que não necessitam de furação prévia. Além do mais, o uso dos parafusos auto-atarraxantes proporcionam a interação entre telha e terça, conferindo maior estabilidade lateral à terça, contudo, outros mecanismos de falha passam a atuar diferentemente dos mecanismos clássicos da Teoria da Estabilidade Elástica.

Os projetistas, ao tentar considerar o aumento da resistência das terças ao serem fixadas às telhas, deparam-se com procedimentos que não deixam claro o que foi considerado, como é o caso da utilização do fator $\mathrm{R}$, adotado pelas especificações do AISI desde 1991 e pela norma brasileira NBR 14762:2001 (Anexo F). Nesse método, não se sabe o que deu origem a estes coeficientes, deslocamentos excessivos, plastificação da seção ou instabilidade do perfil.

Deparam-se também com procedimentos que são complexos e necessitam de coeficientes de mola para simular a influência das telhas, os quais não estão disponíveis e necessitam de ensaios para sua avaliação. Assim, diante da complexidade de se utilizar estes procedimentos deixa de se compreender o foco principal de um projeto, ou seja, o comportamento estrutural do perfil.

Nos últimos anos, diversos pesquisadores têm analisado e sugerido modelos para o dimensionamento de vigas conectadas a painéis, com base em modelos teóricos e experimentais. Cabe ressaltar Peköz \& Soroushian (1982) que deram as bases ao procedimento adotado pelo Eurocode 3 - parte 1.3 (1996), LaBoube (1988, 1991 e 1992) desenvolveu o método incorporado pelo AISI a partir de 1991, Ye (2004) apresenta em suas pesquisas modelos importantes para a compreensão dos modos de instabilidade, além de outros pesquisadores que tem proposto métodos de análise numérica como Teoria 
Generalizada de Vigas (GBT), Método das Faixas Finitas (MFF) e Método dos Elementos Finitos (MEF).

Em Baságlia (2004) modelou-se o sistema terça-telha via MEF utilizando o programa ANSYS com grande refinamento e conseguiu reproduzir satisfatoriamente os resultados experimentais obtidos em Javaroni (1999), no entanto, o tempo de processamento necessário para realizar o estudo paramétrico seria inviável.

Desta forma, o presente trabalho propõe modelos numéricos que viabilizam o estudo paramétrico do comportamento estrutural de terças biapoiadas em perfil $U_{\mathrm{e}}(\mathrm{U}$ enrijecido) e também analisa a viabilidade da utilização do método da resistência direta para o dimensionamento de terças.

Os parâmetros propostos a serem analisados são o vão e a seção da terça e telha. Será também utilizado neste trabalho o programa de elementos finitos ANSYS. Para o estudo da viabilidade do dimensionamento de terças via método da resistência direta será utilizado o programa de faixas finitas freeware CU-FSM - Cornell University - Finite Strip Method. 



\section{REVISÃO BIBLIOGRÁFICA}

Os perfis formados a frio apresentam relação largura/espessura que conduzem a modos de falha por instabilidade, sendo sensível a contribuição das telhas para a estabilidade lateral das terças e, conseqüentemente, para a resistência aos carregamentos aplicados. A partir destas informações o próximo item visa elucidar os modos de instabilidade.

\subsection{Modos de Falha por Instabilidade}

Os perfis formados a frio estão sujeitos a modos de falha por instabilidade local, global incluindo distorcional, que geralmente conduzem a resistências estruturais inferiores a plastificação da seção transversal. O modo de instabilidade está condicionado às propriedades geométricas, às condições de contorno e aos carregamentos aplicados. $\mathrm{A}$ Figura 2.1 ilustra o comportamento de um perfil $U_{e}(U$ enrijecido), submetido à flexão simples, relacionando a tensão de flambagem com o comprimento de meia onda.

O ponto 1 caracteriza a flambagem local, ou seja, as arestas permanecem na mesma posição e os ângulos entre elementos permanecem inalterados, no entanto, os elementos comprimidos apresentam deslocamentos perpendiculares ao seu plano. A flambagem local é dominante em perfis com paredes esbeltas (elevadas relações larguraespessura) e baixa esbeltez global.

O ponto 2 caracteriza a flambagem distorcional, na qual ocorre a rotação do conjunto mesa-enrijecedor de borda em relação à alma, os ângulos entre elementos são alterados e conseqüentemente há a translação da aresta posicionada na junção da mesa com o enrijecedor. 


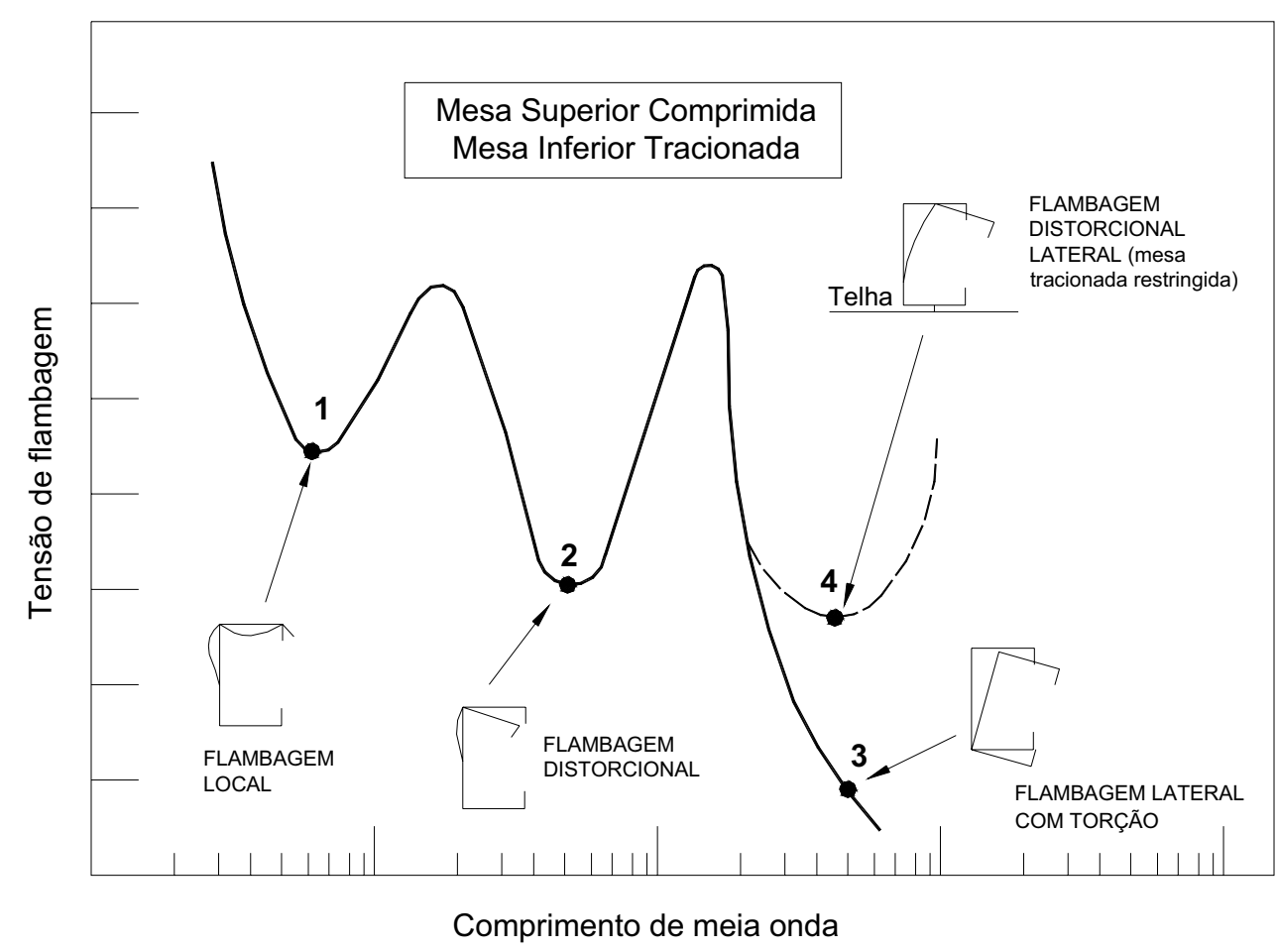

Figura 2.1 - Tensão de flambagem elástica versus comprimento de meia onda para um perfil $U_{e}$. Fonte: Adapt. Hancock et al.(2001).

O ponto 3 caracteriza a flambagem lateral com torção, ou seja, flambagem global, onde ocorre a torção do perfil acompanhada de um deslocamento lateral.

Finalmente, o ponto 4 caracteriza particularmente o caso de perfis com a mesa tracionada restringida, que é o caso da interação terça-telha sob o efeito de vento de sucção. O efeito conhecido como flambagem distorcional lateral é o resultado do acoplamento do efeito da flexão transversal da alma (flambagem distorcional) com o deslocamento lateral da mesa comprimida.

\subsection{Comportamento Estrutural do Sistema Terça-Telha}

Os sistemas terça-telha podem estar submetidos a carregamentos gravitacionais e de sucção. O carregamento gravitacional é transferido para a terça pelo contato existente entre a telha e a terça, ou seja, uma carga distribuída por área, a qual por simplificação é substituída por uma carga distribuída linearmente na posição da conexão da terça com a telha. Já o carregamento de sucção é transferido da telha para a terça somente pelo conector, assim novamente para efeito de simplificação ao invés de considerar cargas 
concentradas no ponto onde é instalado o conector considera-se uma carga distribuída linearmente ao longo da linha de conecção.

O carregamento gera tensões normais (flexão e flexo-torção) e tensões de cisalhamento (flexão, torção livre e flexo-torção). Analisando o perfil $U_{e}$ submetido à carregamento gravitacional ou de sucção aplicado paralelo à alma (Figura 2.2a) ocorrerá flexão simples e, portanto deslocamento perpendicular à mesa do perfil. Como o carregamento não está aplicado no centro de torção irá ocorrer a flexo-torção e o fluxo de tensões de cisalhamento poderá gerar a distorção do perfil.
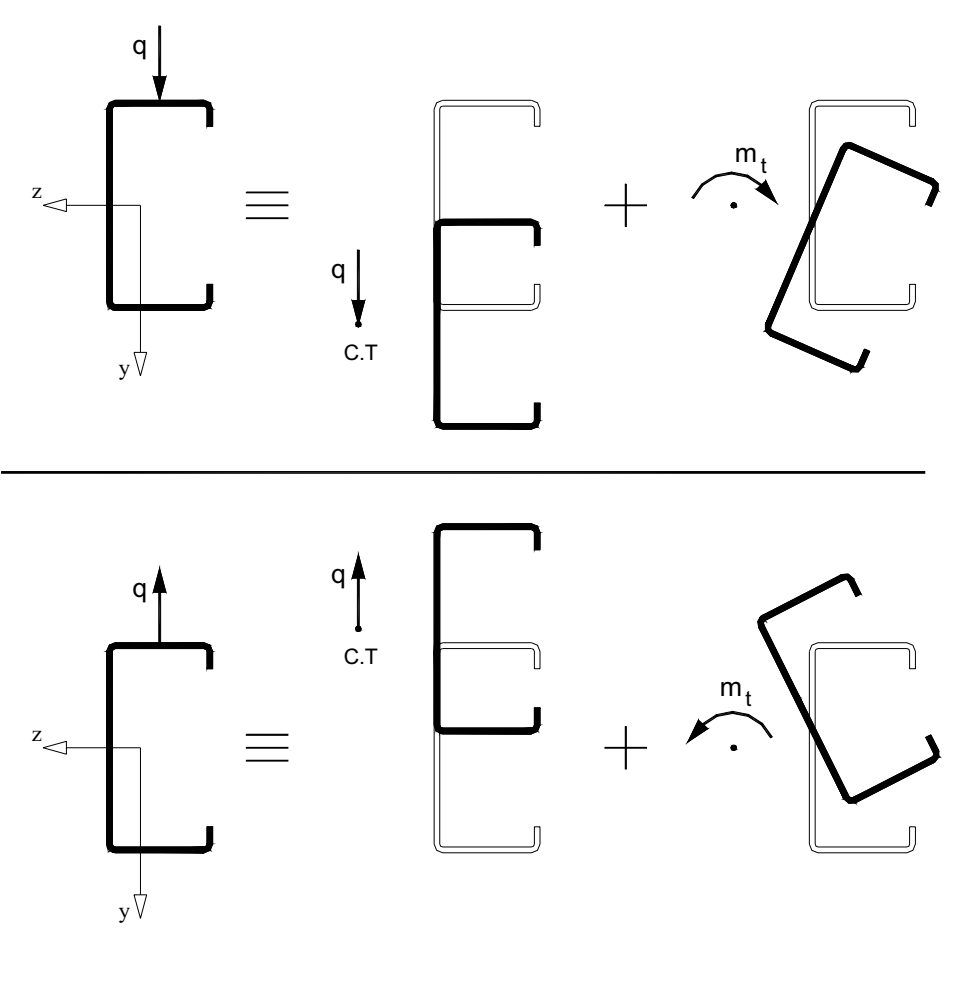

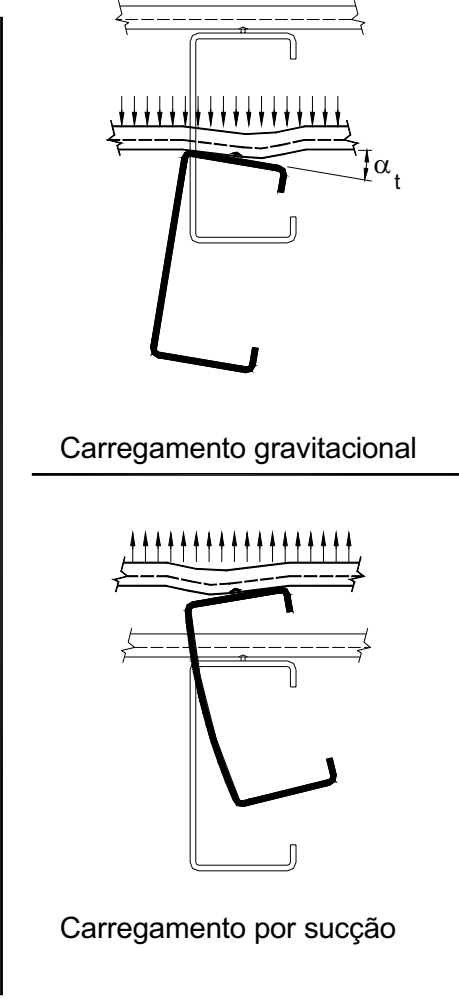

b) Perfil Ue conectado à telha

a) Perfil Ue sem restrição à rotação

Figura 2.2 - Comportamento estrutural do perfil $U_{e}$ sem restrição à rotação e conectado à telha. Fonte: Baságlia (2004).

Tal fato foi confirmado pela modelagem numérica desenvolvida em Baságlia (2004) para os sistemas sujeitos à carregamento de sucção (Figura 2.3). No modelo desenvolvido, o deslocamento lateral $w$ foi desmembrado em duas parcelas: uma proveniente da flexo-torção $(\delta)$ e outra da distorção lateral $(\beta)$. 

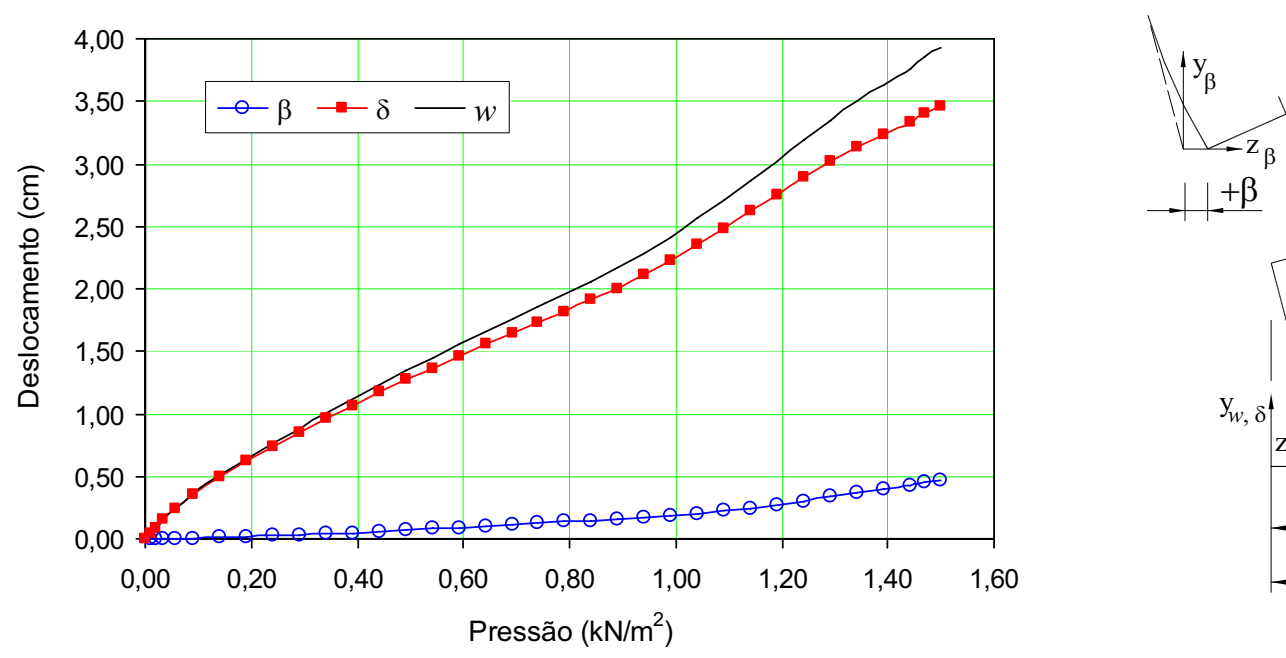

Figura 2.3 - Deslocamentos Característicos de Perfis U. Fonte: Baságlia (2004).

Já no perfil $Z_{90}\left(Z\right.$ enrijecido a $\left.90^{\circ}\right)$ submetido à carregamento gravitacional ou de sucção aplicado paralelo à alma (Figura 2.4a) ocorre a torção proveniente do carregamento não estar aplicado no centro de torção, assim como no perfil $U_{e}$.

Devido à posição dos eixos principais de inércia z e y (Figura 2.4) ocorrerá flexão oblíqua no perfil. A flexão oblíqua pode ser decomposta em uma flexão perpendicular à alma e uma paralela, assim sendo, o perfil terá um deslocamento paralelo à alma, $v$, e outro perpendicular, $u$, no entanto, ao se deslocar perpendicularmente à alma, a telha irá restringir apenas uma das mesas, com isto, ocorrerá a distorção do perfil, que poderá ser ampliada ou reduzida pelo fluxo de tensões cisalhantes.

Da mesma forma, Baságlia (2004) confirmou o comportamento estrutural dos perfis $Z_{90}$ (Figura 2.5) sujeitos a carregamentos de sucção e observou que a configuração deformada do perfil $Z_{90}$ possui dois estágios: o primeiro estágio caracteriza-se pela predominância dos efeitos do momento torçor, posteriormente, no segundo estágio, pelos efeitos da flexão oblíqua e do fluxo das tensões cisalhantes.

Diante de tais fenômenos, a análise estrutural do sistema terça-telha apresenta na literatura duas abordagens, a primeira analisa somente os efeitos da flexão e de torção (Modelo de Flexo-Torção - MFT) não admitindo a alteração da forma inicial da seção, já a segunda considera também o efeito da distorção (Modelo de Flexo-Torção com Distorção - MFTD). 

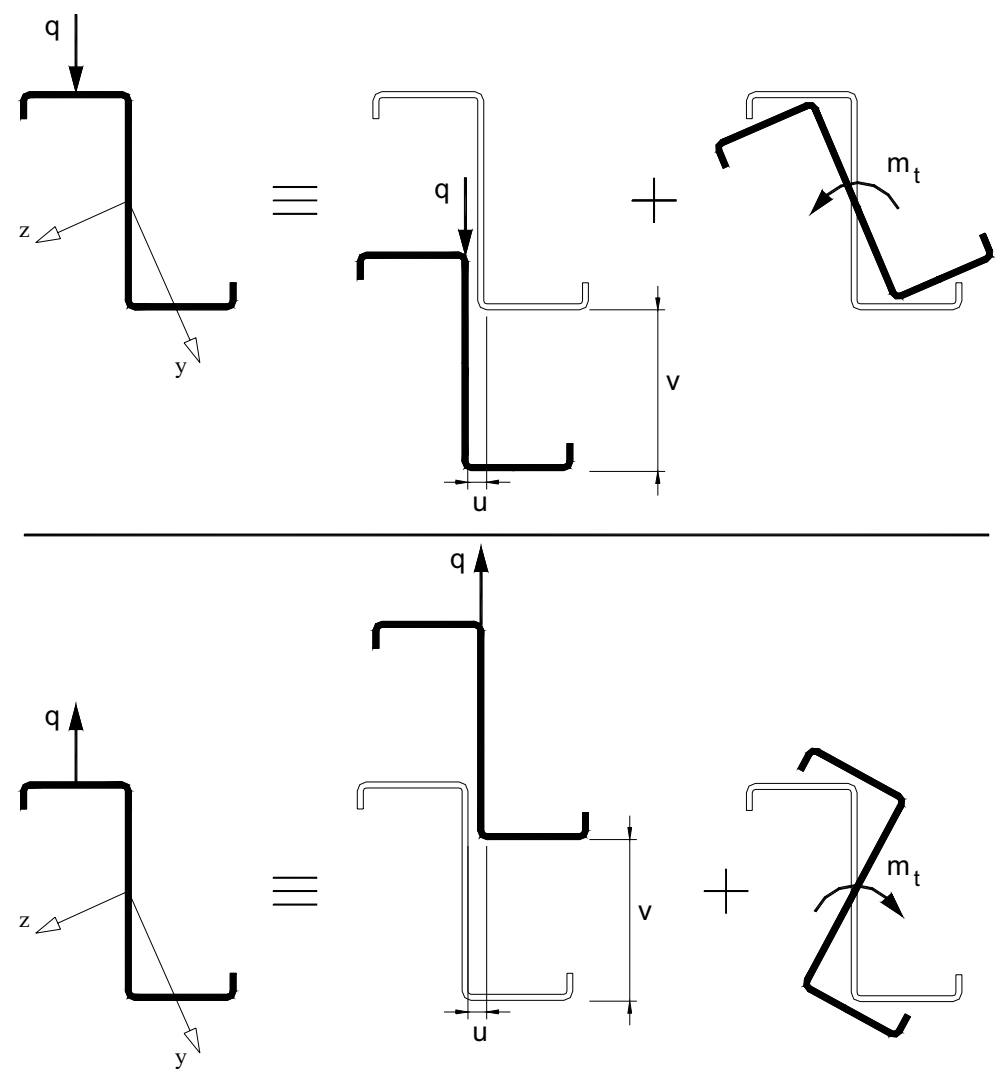

a) Perfil $Z_{90}$ sem restrição à rotação

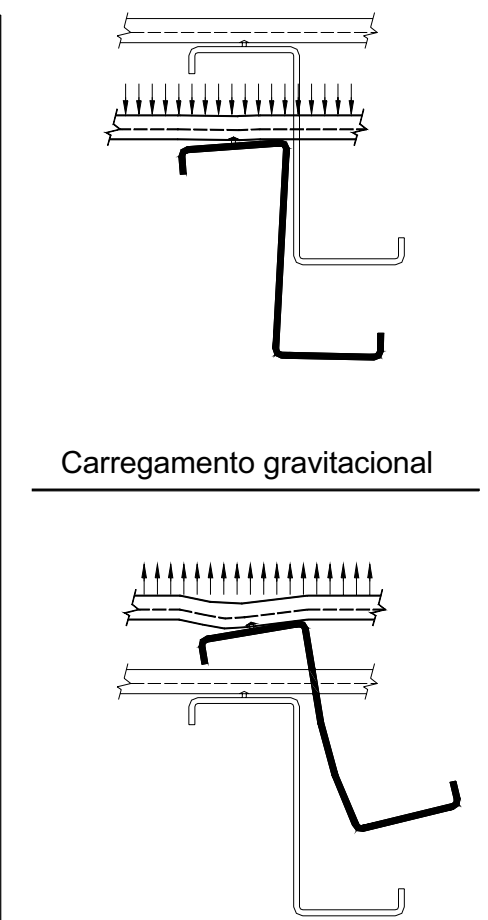

Carregamento por sucção

Figura 2.4 - Comportamento estrutural do perfil $Z_{90}$ sem restrição à rotação e conectado à telha. Adapt. Baságlia (2004).
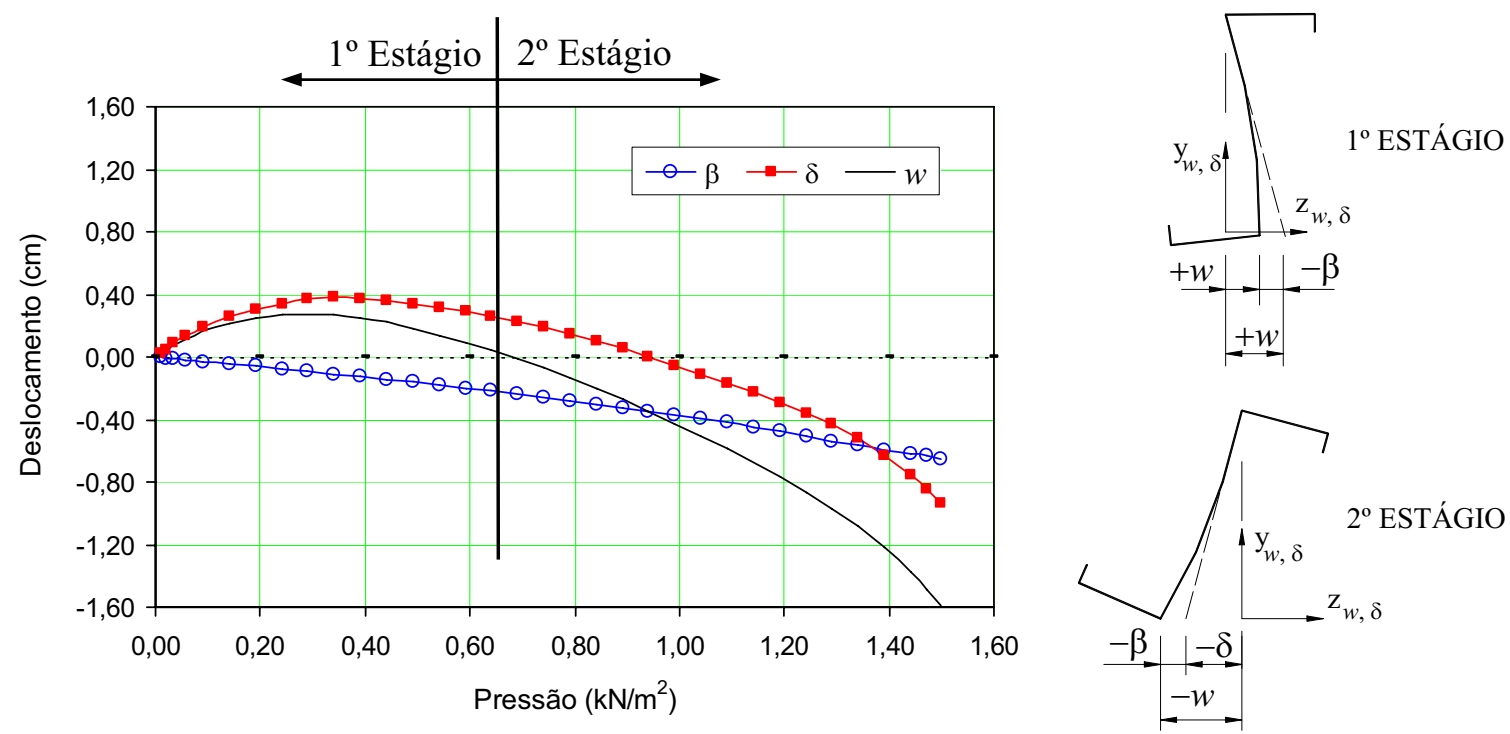

Figura 2.5 - Deslocamentos Característicos de Perfis Z $Z_{90 .}$ Fonte: Baságlia (2004). 


\subsection{Aplicação da Teoria da Flexo-Torção ao Sistema Terça-Telha}

A teoria da flexo-torção distingue-se da teoria da torção livre ou de SaintVenant por admitir deslocamentos longitudinais (empenamento) e portanto tensões normais à seção transversal. Em Vlasov (1961) é apresentado o estudo de flexo-torção desenvolvido para barras com seções transversais abertas e paredes delgadas. Essas barras além de possuírem espessura pequena em relação às outras dimensões apresentam também as dimensões da seção transversal pequenas ao serem comparadas ao comprimento da barra.

Dentre as hipóteses adotadas em Vlasov (1961) para o desenvolvimento da formulação cabe ressaltar: (i) após a deformação da barra, a seção transversal projetase indeformada no seu plano, ou seja, não ocorre distorção da seção transversal, (ii) somente são admitidos deslocamentos longitudinais, denominados "empenamento" da seção transversal.

Adotando as hipóteses (i) e (ii) assume-se que toda a seção transversal é contida por diafragmas transversais rígidos em toda a extensão da barra. Os diafragmas não permitem a distorção da seção transversal, porém permitem a rotação e translação da seção transversal como um todo. Estas considerações são feitas para que seja possível substituir um carregamento externo por um sistema de forças estaticamente equivalente e assim desenvolver a teoria proposta.

Ao se restringir os deslocamentos longitudinais, como conseqüência, aparecem tensões normais longitudinais $\sigma_{x}$ adicionais. Para encontrar a tensão normal longitudinal $\sigma_{x}$ em Vlasov (1961) foi introduzida uma nova grandeza, o bimomento, que conduz a forças auto-equilibradas e desempenha para a flexo-torção a mesma função que o momento fletor para a flexão.

Para entender a grandeza bimomento considere a Figura 2.6.a onde é mostrada uma viga engastada em uma das extremidades e submetida a uma força normal à seção transversal $(\mathrm{P})$. O sistema mostrado na Figura 2.6.a é dado pelo teoria de flexão simples equivalente a superposição da Figura 2.6.b (tração), Figura 2.6.c (flexão em torno do eixo y), Figura 2.6.d (flexão em torno do eixo $x$ ).

Porém, analisando-se mais detalhadamente na Figura 2.6.b o balanço das forças em relação ao eixo x e ao eixo y são simétricos, no entanto ao considerar-se a Figura 2.6.c o balanço das forças é simétrico em relação ao eixo $y$, mas inversamente 
simétricos em relação ao eixo x, enquanto na Figura 2.6.d são simétricos em relação ao eixo $\mathrm{x}$ e inversamente simétricos em relação ao eixo y. Devido à simetria inversa um conjunto de forças é necessário para completar a decomposição, sendo esse indicado na Figura 2.6.e.

A Figura 2.6.e ilustra um conjunto de forças que é inversamente simétrico nos eixos $\mathrm{x}$ e $\mathrm{y}$, o conjunto de forças irá resultar em um momento responsável por girar as mesas no seu plano. As mesas irão girar com mesma intensidade, porém direções opostas, esse fenômeno é conhecido como empenamento da seção transversal. O esforço solicitante que conduz a forças auto-equilibradas é apresentado em Vlasov (1961) como bimomento, o qual é responsável pelo empenamento da seção transversal.

a)

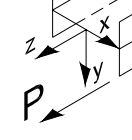

b)

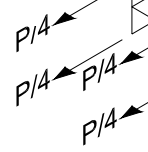

c)

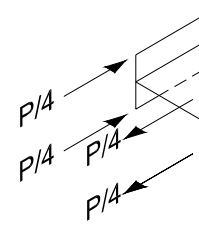

d)

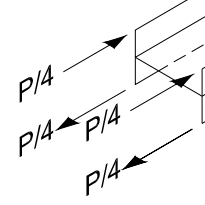

e)

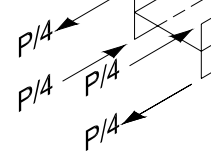

Figura 2.6 - Sistema equivalente de forças.

A tensão normal longitudinal $\sigma_{x}$ é composta por três parcelas: a primeira corresponde à tensão gerada pelo esforço normal, $\mathrm{N}$, sobre a área $\mathrm{A}$, enquanto a segunda corresponde à tensão gerada pelos momentos fletores $M_{z}$ e $M_{y}$, e a terceira corresponde à tensão proveniente do bimomento, $B$, assim tem-se:

$$
\sigma_{x}= \pm \frac{N}{A} \pm \frac{M_{z}}{I_{z}} \cdot y \pm \frac{M_{y}}{I_{y}} \cdot z \pm \frac{B}{I_{\omega}} \cdot \omega
$$

Onde: 
$I_{\omega}:$ momento de inércia setorial;

$\omega$ : área setorial.

Utilizando-se do conceito de momento de torção uniformemente distribuído, $m$, é possível definir a equação diferencial da flexo-torção em função do bimomento, equação (2.2), ou em função do giro, equação (2.3).

$$
\begin{aligned}
& r^{2} \cdot \frac{\partial^{2} B}{\partial x^{2}}-B=-r^{2} \cdot m \\
& r^{2} \cdot \frac{\partial^{4} \varphi}{\partial x^{4}}-\frac{\partial^{2} \varphi}{\partial x^{2}}=-\frac{m}{G \cdot I_{t}}
\end{aligned}
$$

Onde:

$\varphi$ : giro relativo entre as seções consideradas;

$G$ : módulo de elasticidade transversal;

$I_{t}$ : momento de inércia à torção.

$r=\sqrt{2(1+v) \frac{I_{\omega}}{I_{t}}}$

A convenção dos eixos e a simbologia a ser adotada no presente trabalho para os perfis $U_{\mathrm{e}}$ e $Z_{90}$ estão apresentadas na Figura 2.7 .

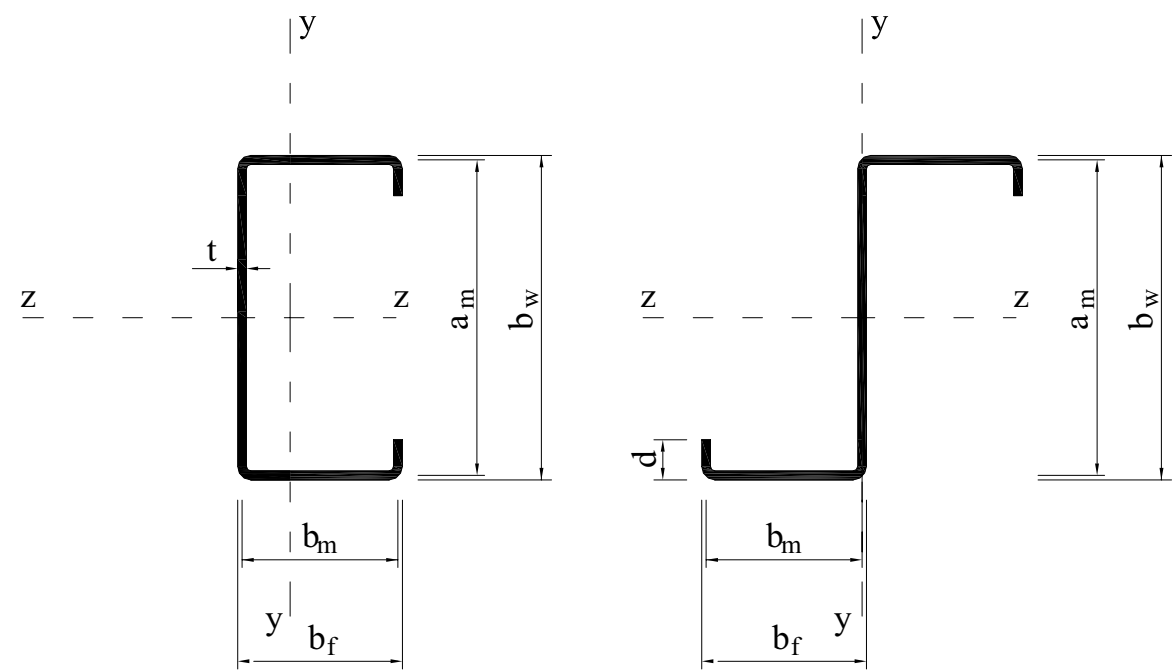

Figura 2.7 - Convenção dos eixos e simbologia para a seção. 
Onde:

$b_{w}:$ largura nominal da alma;

$b_{f}$ : largura nominal da mesa;

d: largura nominal do enrijecedor de borda do perfil;

t: espessura;

$a_{\mathrm{m}}$ : largura da alma referente à linha média da seção $\left(a_{m}=b_{w}-t\right)$;

$\mathrm{b}_{\mathrm{m}}$ : largura da mesa referente à linha média da seção $\left(b_{m}=b_{f}-t\right)$.

Hancock et al. (2001) apresentaram a partir da configuração deformada do modelo (Figura 2.8a) em que somente ocorre flexo-torção um sistema de equivalência estática do sistema terça-telha (Figura 2.8b) onde $q$ representa a força distribuída proveniente do carregamento de sucção enquanto $p$ representa a força distribuída provocada pela pressão de contato entre o perfil e a telha e $r$ representa a força distribuída devido à restrição lateral da telha ao deslocamento da mesa superior do perfil. A força distribuída $p$ depende da configuração deformada do sistema, sendo que nos perfis $Z_{90}$ encontra-se na junção da mesa com a alma, já nos perfis $U_{e}$ encontra-se na junção da mesa com o enrijecedor.

A Figura 2.8d apresenta a equivalência estática a partir da aplicação de forças, $r$ e $q$, e momento, $m$, no centro de torção do perfil. Sendo o momento $m$ dado pela equação (2.5) para perfis $Z_{90}$ e equação (2.6) para perfis $U_{e}$ :

$$
\begin{aligned}
& m=\frac{p \cdot b_{m}}{2}-\frac{r \cdot a_{m}}{2}+\frac{q \cdot b_{m}}{2} \\
& m=\frac{p \cdot b_{m}}{2}-\frac{r \cdot a_{m}}{2}-\frac{q \cdot b_{m}}{2}-q \cdot d_{z}
\end{aligned}
$$

As equações (2.5) e (2.6) permitem a seguinte conclusão: para simplificação considere que o perfil não gire, então $r=0$, para que $m$ seja igual a zero a parcela do carregamento de sucção, $\frac{q \cdot b_{m}}{2}$, para perfis $Z_{90} \mathrm{e},-\frac{q \cdot b_{m}}{2}-q \cdot d_{z}$, para perfis $\mathrm{U}_{\mathrm{e}}$ deve ser contrabalanceada pela parcela devido à pressão de contato da terça com a telha, $\frac{p \cdot b_{m}}{2}$, assim sendo, a pressão de contato nos perfis $\cup_{\mathrm{e}}$ é maior do que nos perfis 
$Z_{90}$, pois a parcela a ser contrabalanceada é maior.
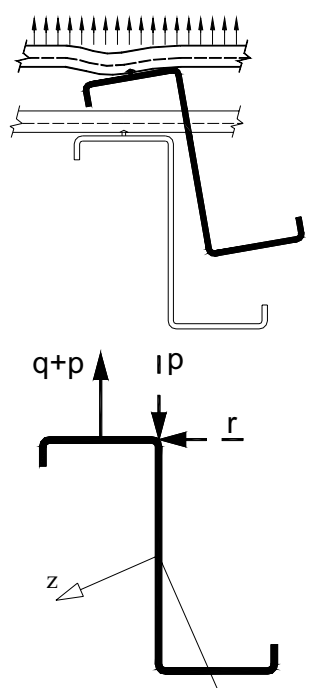

y

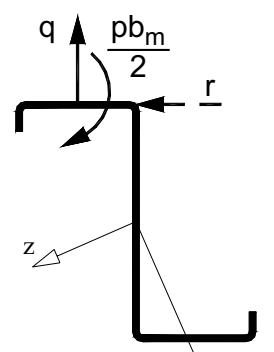

y

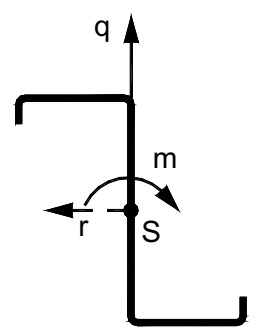

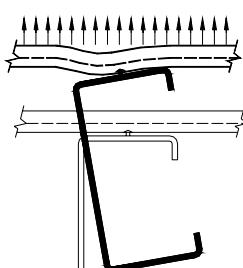

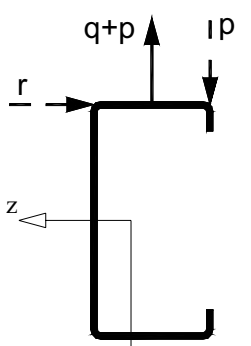

y
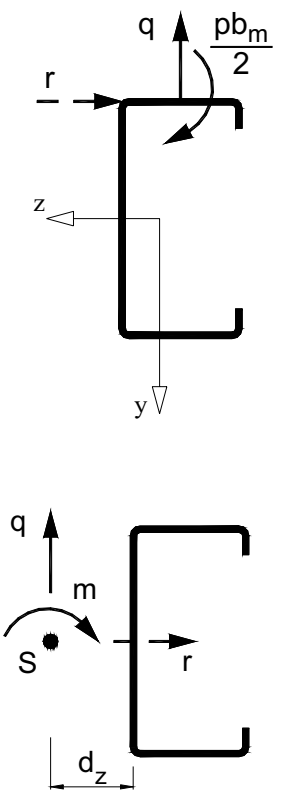

a) Configuração deformada

b) Equivalência estática

c) Equivalência estática de (b) por meio de momento

d) Equivalência estática de (c) com momento e forças aplicadas no centro de torção

Figura 2.8 - Forças e momentos atuantes nas terças.

Fonte: Baságlia (2004), Adapt. Hancock et al.(2001)

Baságlia (2004) constatou o mesmo fato utilizando-se de modelagem via método dos elementos finitos e considerando inclusive a distorção do perfil, no entanto a constatação deu-se a partir dos deslocamentos. Na Figura 2.9 é comparado o perfil $Z_{90}$ $250 \times 85 \times 25 \times 2,65$ (Z2-B0) e $U_{e} 250 \times 85 \times 25 \times 2,65$ (U2-B0), como a reação de contato entre a telha e a terça nos perfis $U_{e}$ é maior, o momento gerado será maior e portanto maiores serão os deslocamentos. 


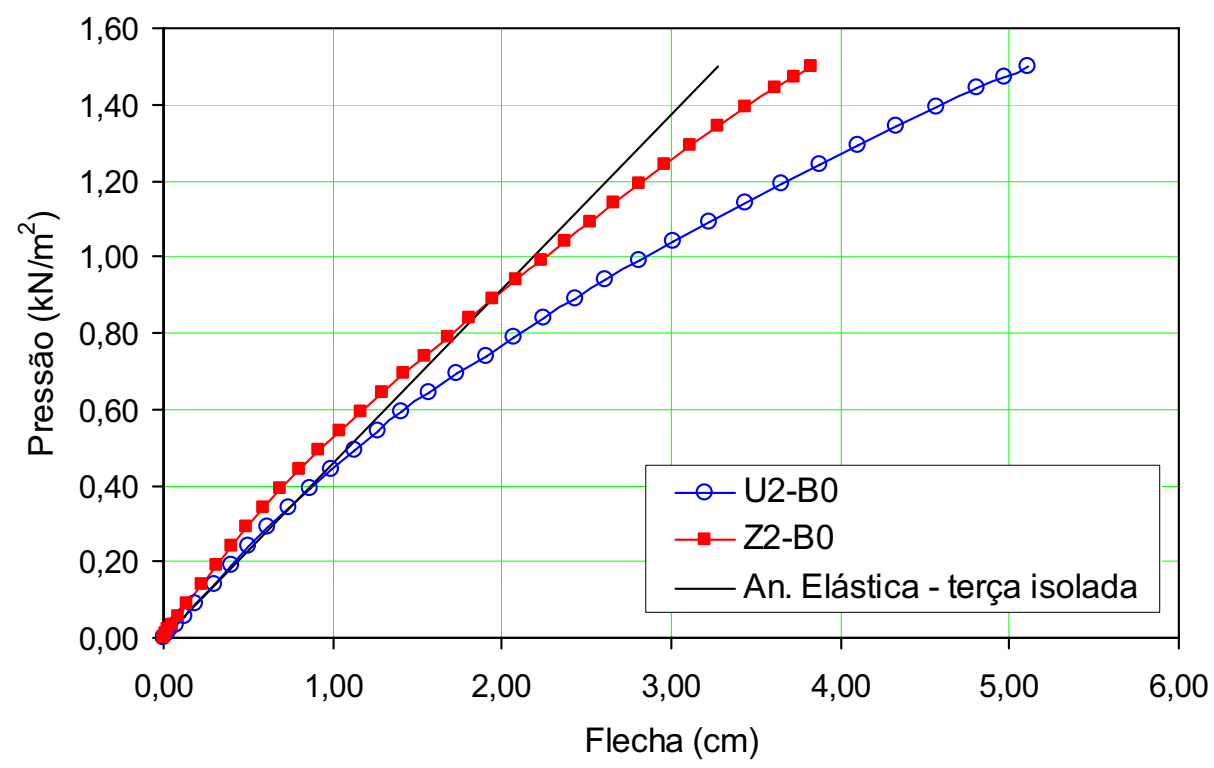

Figura 2.9 - Flecha em função da pressão para os modelos. Fonte: Baságlia (2004).

\subsection{Modelo Proposto por Trahair (1993) (Flambagem por Flexo-Torção)}

Trahair (1993) dedicou-se ao estudo da flambagem por flexo-torção de vigas restringidas continuamente, vale ressaltar que o estudo deu-se de forma geral ao estudo de vigas e não somente terças restringidas por telhas.

Segundo Trahair (1993) (Figura 2.10c) uma viga pode ser contida: (i) por uma restrição lateral de rigidez $\alpha_{t}$ a qual atua a uma distância $y_{t}$ do centro de gravidade, (ii) por uma restrição à rotação em torno do eixo de menor inércia de rigidez $\alpha_{r y}$ que atua a uma distância $y_{r}$ do centro de gravidade, (iii) por restrição à torção de rigidez $\alpha_{r z}$ e (iv) por uma restrição ao empenamento $\alpha_{w}$. Sendo que estas restrições podem ser substituídas por ações no centro de torção (Figura 2.10b) com isto pode-se definir o vetor das ações $\{r\}$ e o vetor dos deslocamentos $\{d\}$, assim como a relação existente entre eles:

$$
\begin{aligned}
& \{r\}=\left\{f_{t}, m_{r y}, m_{r z}, B_{z}\right\}^{T} \\
& \{d\}=\left\{u, u^{\prime}, \phi, \phi^{\prime}\right\} \\
& \{r\}=\left[\alpha_{b}\right]\{d\}
\end{aligned}
$$


Onde:

$B_{z}$ : é o bimomento por unidade de comprimento;

$\left[\alpha_{b}\right]$ : é a matriz de rigidez das restrições, sendo:

$$
\left[\alpha_{b}\right]=\left[\begin{array}{cccc}
\alpha_{t} & 0 & -\alpha_{t}\left(y_{t}-y_{0}\right) & 0 \\
0 & \alpha_{r y} & 0 & -\alpha_{r y}\left(y_{r}-y_{0}\right) \\
-\alpha_{t}\left(y_{t}-y_{0}\right) & 0 & \left\{\alpha_{t}\left(y_{t}-y_{0}\right)^{2}+\alpha_{r z}\right\} & 0 \\
0 & -\alpha_{r y}\left(y_{r}-y_{0}\right) & 0 & \left\{\alpha_{r y}\left(y_{r}-y_{0}\right)^{2}+\alpha_{w}\right\}
\end{array}\right]
$$

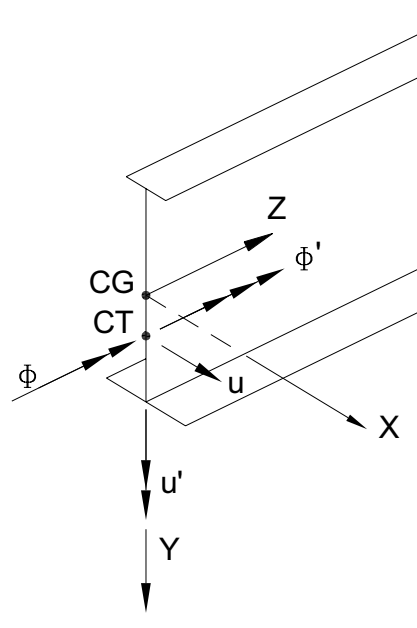

a) Deformações

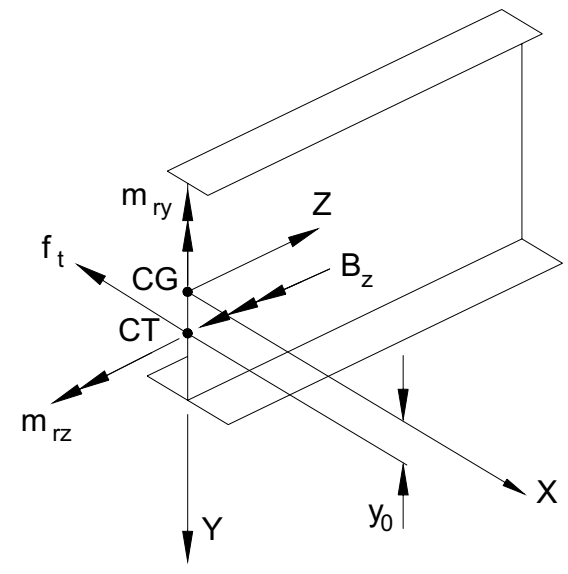

b) Ações no Centro de Torção

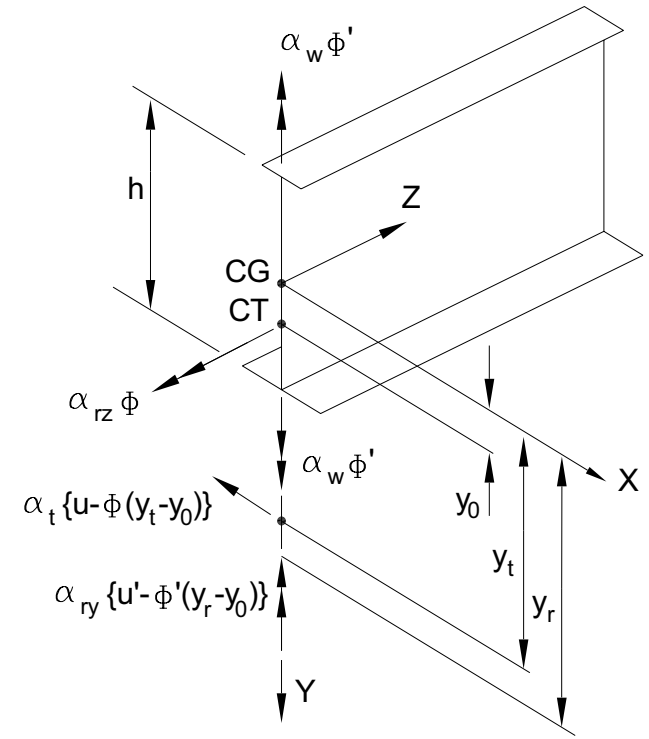

c) Ações provenientes das restrições

Figura 2.10 - Ações em vigas continuamente restritas. 
A natureza das ações fica evidente na Figura 2.11, onde o perfil analisado está sujeito a uma restrição translacional, $f_{t}$, restrição ao cisalhamento, $m_{r y}$, e a restrição proveniente da resistência à rotação, $m_{r z}$.
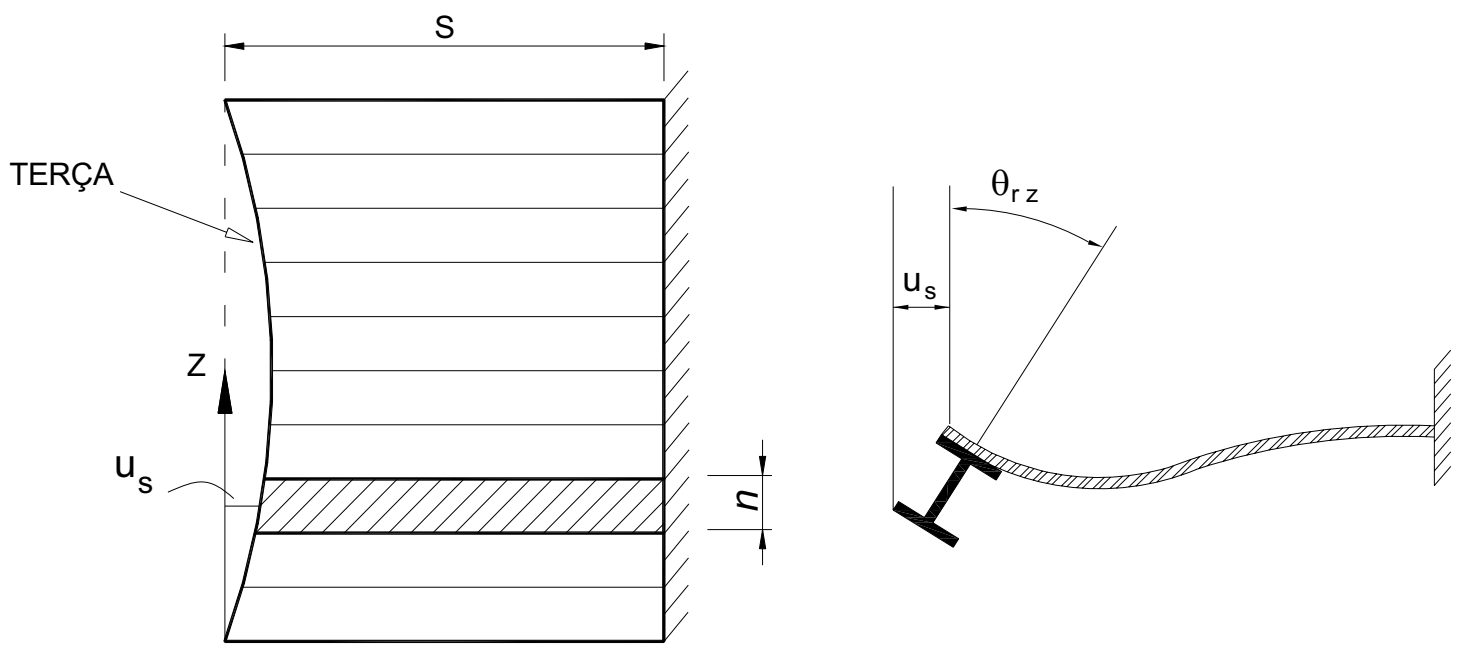

a) Plano do Telhado

b) Elevação do Telhado

$\mathrm{n}$

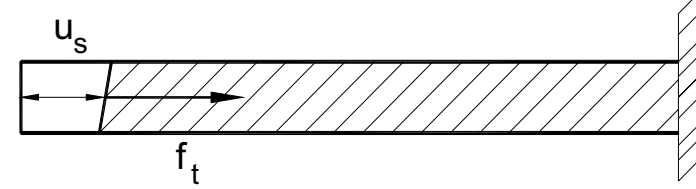

$$
\alpha_{t}=\frac{f_{t}}{u_{s}}
$$

c) Força de membrana, $f_{t}$, vista em planta

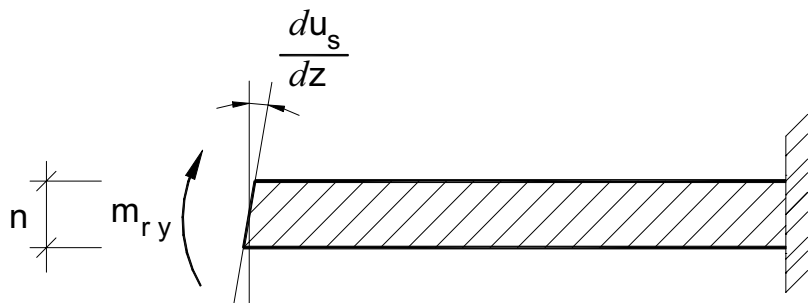

$$
\alpha_{r y}=m_{r y} / \frac{d u_{s}}{d z}
$$

d) Rigidez ao cisalhamento da telha $\left(\alpha_{r y}\right)$, vista em planta

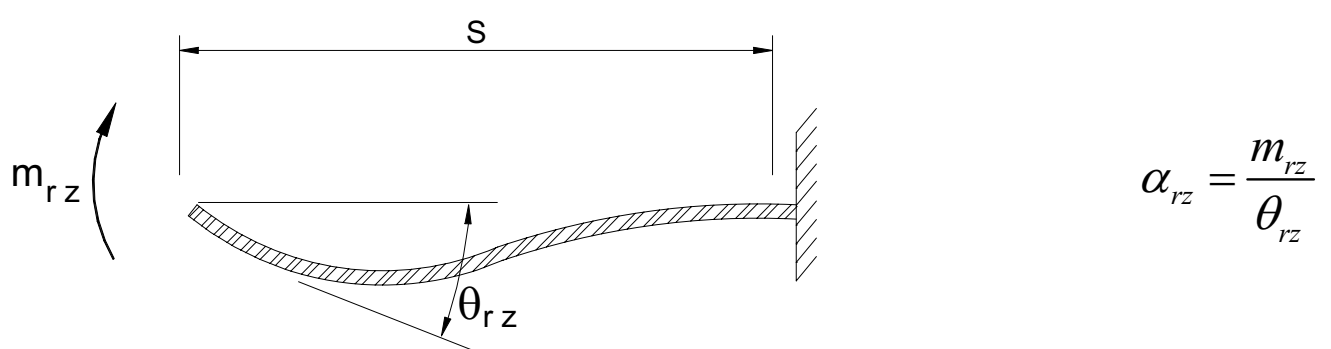

e) Rigidez à rotação $\left(\alpha_{r z}\right)$, vista em elevação

Figura 2.11 - Natureza das ações em vigas restringidas lateralmente. 
As restrições podem ser particularizadas para os sistemas terça-telha em que a telha não está restringida por uma contenção lateral como no caso analisado na Figura 2.11. Será utilizado o índice $k$ ao invés de $\alpha$ quando referir-se especificamente a este sistema terça-telha. A rigidez $\alpha_{t}$ não possui nenhuma rigidez conjugada, já que é admitido que a terça ao se deslocar lateralmente é acompanhada pela adjacente.

Por outro lado, a rigidez $\alpha_{r y}$ tem efeito similar à rigidez $k_{r y}$, assim como, $\alpha_{r z}$ tem efeito similar a $k_{r z}$ também conhecidos como $k_{r s}$ e $k_{f s}$, onde os subíndices são relativos respectivamente à rigidez à rotação, "rotational stiffness", e à rigidez à flexão "flexural stiffness".

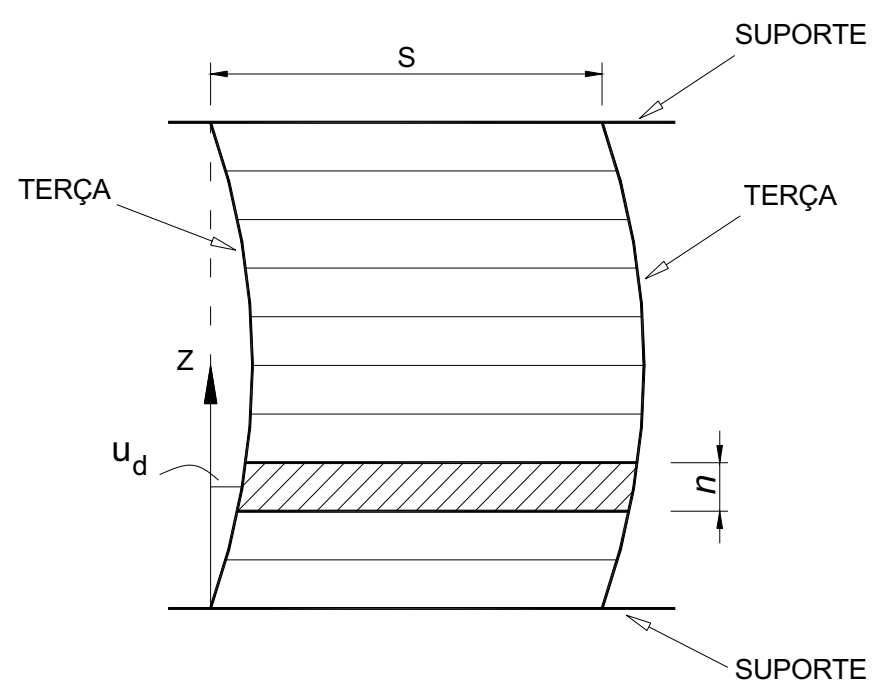

a) Plano do Telhado

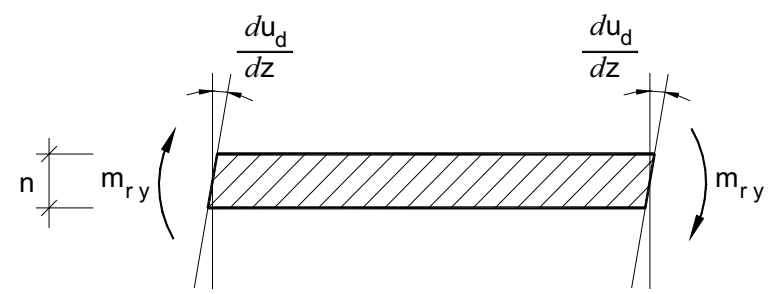

$$
k_{r y}=m_{r y} / \frac{d u_{d}}{d z}
$$

b) Rigidez ao cisalhamento da telha $\left(k_{r y}\right)$, vista em planta

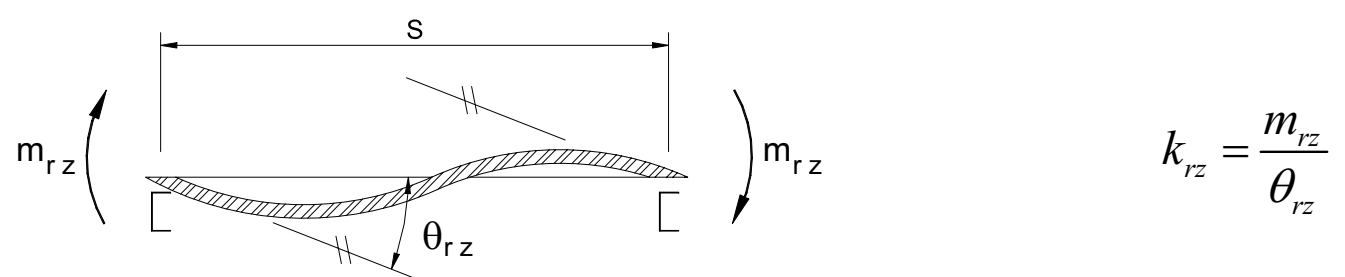

d) Rigidez à rotação $\left(k_{r z}\right)$, vista em elevação

Figura 2.12 - Rigidez do sistema terça-telha. Fonte: Baságlia (2004). 
Em grande parte dos problemas que envolvem vigas restringidas, o carregamento crítico não pode ser determinado analiticamente, assim Trahair (1993) utilizou-se do método da conservação de energia para encontrar a solução, sendo que, a energia de deformação do sistema é definida como a soma das parcelas de energia devido à rigidez do perfil mais a energia proveniente da rigidez das restrições:

$$
\frac{1}{2} \delta^{2} U=\frac{1}{2} \int_{0}^{L}\left\{E I_{y} u^{\prime \prime 2}+E I_{w} \phi^{\prime 2}+G I_{t} \phi^{\prime 2}\right\} d z+\frac{1}{2} \int_{0}^{L}\{d\}^{t}\left[\alpha_{b}\right]\{d\} d z
$$

Trahair (1993) dentre os casos analisados apresenta os resultados para vigas simplesmente apoiadas com vínculos de garfo, ou seja, $u_{0, L}=\phi_{0, L}=0, u^{\prime \prime}{ }_{0, L}=\phi^{\prime \prime}{ }_{0, L}=0$ e carga uniformemente distribuída. Dentre as conclusões de Trahair (1993) vale ressaltar a pequena importância nos valores encontrados para a carga crítica de flambagem devido à rigidez à torção imposta pela telha, $\alpha_{r z}$, ao contrário da rigidez ao cisalhamento, $\alpha_{r y}$, que é determinante para a mesma.

Os estudos de Trahair (1993) são de grande importância no entendimento das restrições impostas pela telha ao sistema, no entanto, não considera a distorção da seção.

\subsection{Modelo de Peköz e Soroushian (Cornell University)}

Tendo em vista as dificuldades de se aplicar a teoria de flexo-torção ao sistema terça-telha, Peköz e Soroushian (1982) propuseram um modelo de cálculo para terças de perfil $U$ e $Z$ associadas às telhas metálicas e sujeitas aos esforços de sucção, ou seja, mesa tracionada restringida pela telha e mesa comprimida livre. O modelo foi validado por ensaios em caixa de sucção realizados pelos autores e por empresas, sendo que os resultados obtidos foram considerados satisfatórios.

Analisando o modelo proposto por Peköz e Soroushian (1982) pode-se determinar a tensão máxima de compressão que ocorre, geralmente, na junção da mesa com a alma.

Para a compreensão do modelo é importante ressaltar que ao se analisar a rotação de um perfil $U_{e}$ conectado a um painel, o centro de rotação do mesmo ocorre na junção da mesa superior com o enrijecedor, enquanto nos perfis $Z_{90} 0$ centro de rotação 
encontra-se na junção da mesa superior com a alma (Figura 2.13).
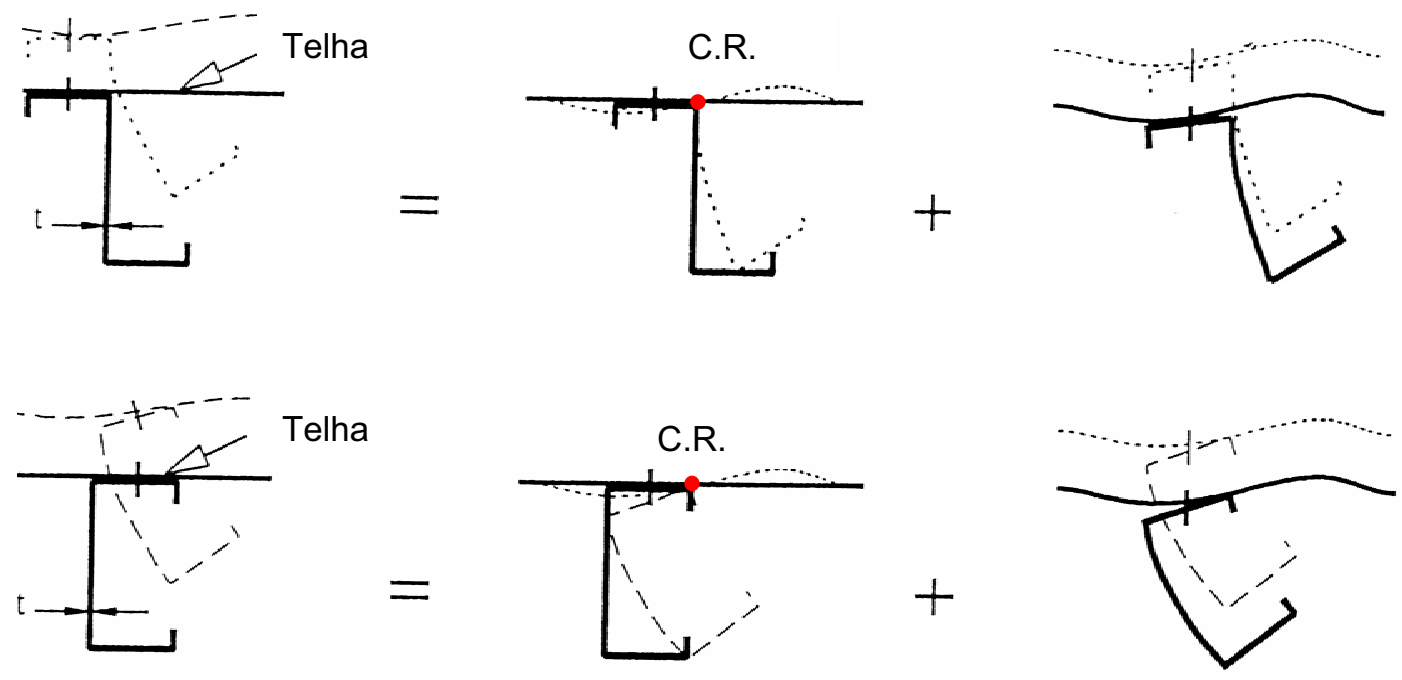

Estágio Final

Rotação

Deslocamento Vertical

Figura 2.13 - Idealização do comportamento dos perfis sob efeito de sucção. Fonte: Baságlia (2004).

O modelo analítico proposto é subdividido em dois estágios: o primeiro refere-se à flexão e o segundo à torção. A flexão é analisada admitindo-se flexão simples, porém o momento de inércia é reduzido devido à rotação e o deslocamento lateral da seção.

A rigidez à rotação pode ser idealizada por uma mola rotacional posicionada no centro de rotação da terça, no entanto pode-se admitir a simplificação desta por uma mola linear elástica posicionada na junção da alma com a mesa comprimida (Figura 2.14).
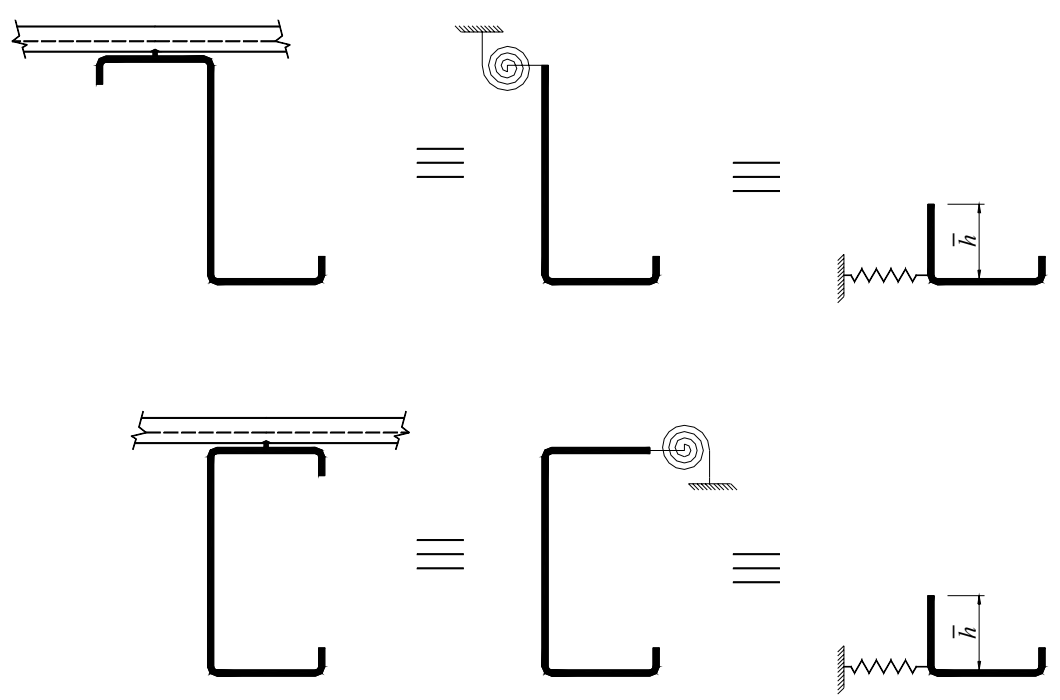

Figura 2.14 - Idealização da rigidez rotacional. Fonte: Baságlia (2004). 
O modelo proposto para a análise consiste na idealização do conjunto mesa comprimida, enrijecedor e parcela da alma $(\bar{h})$ sujeito a um carregamento lateral distribuído $\left(q_{z}(x)\right)$ e um carregamento axial distribuído $(p(x))$. A parcela da alma $(\bar{h})$ da seção idealizada é dada no Eurocode 3 - parte 1.3 (1996) como $\bar{h}=b_{w} / 6$.

O conjunto é apoiado em uma base elástica ao longo do vão e nas extremidades por apoios do segundo e primeiro gênero (Figura 2.15).

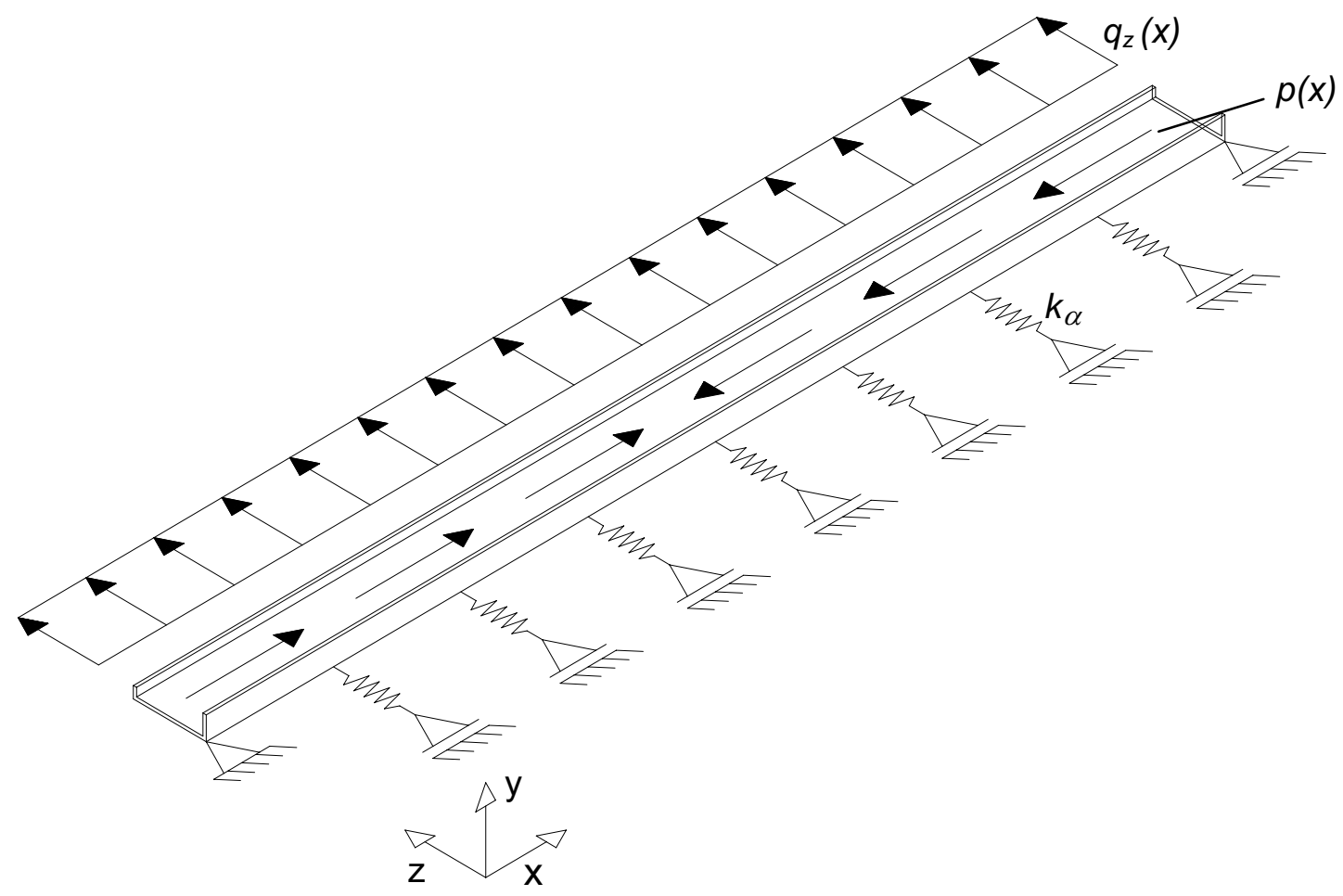

Figura 2.15 - Modelo idealizado sobre a base elástica e sujeita ao carregamento lateral fictício.

O carregamento lateral $\left(q_{z}(x)\right)$ é resultado do fluxo de tensões cisalhantes na seção. No caso de terças $Z_{90}$ como o centro de rotação encontra-se na junção da mesa superior com a alma o fluxo de tensões de cisalhamento na alma não produz momento torçor, no entanto o fluxo de tensões de cisalhamento na mesa inferior causa momento torçor sobre o centro de rotação. Já no caso de perfis $U_{e} \circ$ centro de rotação ocorre na junção da mesa superior com o enrijecedor, portanto o fluxo de tensões de cisalhamento na alma e na mesa inferior causam momento de torção. Assim, pode-se expressar o carregamento lateral como:

$q_{z}(x)=\frac{\text { Força Cortante na Mesa em }(x+d x)-\text { ForçaCortante na Mesa em }(x)}{d x}+\alpha q_{y}(x)$ 
O que representa:

$q_{z}(x)=q_{y}(x) \cdot\left(\frac{S_{m e} b_{f}}{2 I_{z, R}}+\alpha\right)$

Onde:

$q_{z}(x)$ : força fictícia lateralmente distribuída na direção horizontal, (eixo z);

$q_{y}(x)$ : força distribuída na direção vertical devido a solicitação por sucção (eixo y);

$S_{m e}:$ momento estático da mesa inferior e enrijecedor em relação ao eixo $z$ do perfil;

$b_{f}$ : largura da mesa;

$I_{z, R}:$ momento de inércia da seção rotacionada em relação ao eixo $z$;

$\alpha=\frac{b_{f}}{b_{w}}$ para seção $U$ e $\alpha=0$ para seção Z.

A primeira parcela da equação (2.12) representa o fluxo de força cortante na mesa e a segunda parcela representa o fluxo na alma, desta forma como em seções $Z_{90}$ o fluxo de tensões de cisalhamento na alma não produz momento torçor o coeficiente $\alpha$ é igual à zero.

O carregamento fictício axial $p(x)$ é considerado devido à variação da tensão de compressão ao longo da terça e pode ser expresso como:

$$
p(x)=\frac{\text { ForçaAxial em }(x+d x)-\text { Força Axial em }(x)}{d x}
$$

O que representa:

$$
p(x)=V_{y} \frac{S_{i d}}{I_{z}}
$$

Onde:

$V_{y}:$ força cortante;

$S_{i d}:$ momento estático da seção idealizada em relação ao eixo z;

$I_{z}:$ momento de inércia da seção em relação ao eixo principal $z$.

O momento de inércia em torno do eixo perpendicular à alma $\left(I_{z}\right)$ deve ser reduzido devido ao deslocamento lateral e vertical da seção transversal, resultando como já 
mencionado, no momento de inércia da seção rotacionada em relação ao eixo $z\left(I_{z, R}\right)$. Segundo os autores o momento de inércia pode ser aproximado pela expressão:

$$
I_{z, R}=I_{z} \cdot\left[1-\left(\frac{w}{b_{w}}\right)^{2}\right]
$$

Onde:

w : deslocamento horizontal (direção do eixo z) da mesa comprimida;

O valor da rigidez do apoio elástico do modelo $\left(k_{\alpha}\right)$ é determinado por meio de ensaio padronizado pelo AISI (1996) (Figura 2.16) que visa representar o tipo de ligação terça-telha, a rigidez à flexão da telha e a rigidez à torção do perfil. O ensaio resulta em um gráfico força versus deslocamento, assim admitindo-se um valor de $q_{y}(x)$ tem-se pela equação (2.13) o valor de $q_{z}(x)$ e então é definido no gráfico o valor de $k_{\alpha}$. O ensaio será detalhado no item 2.5.1.
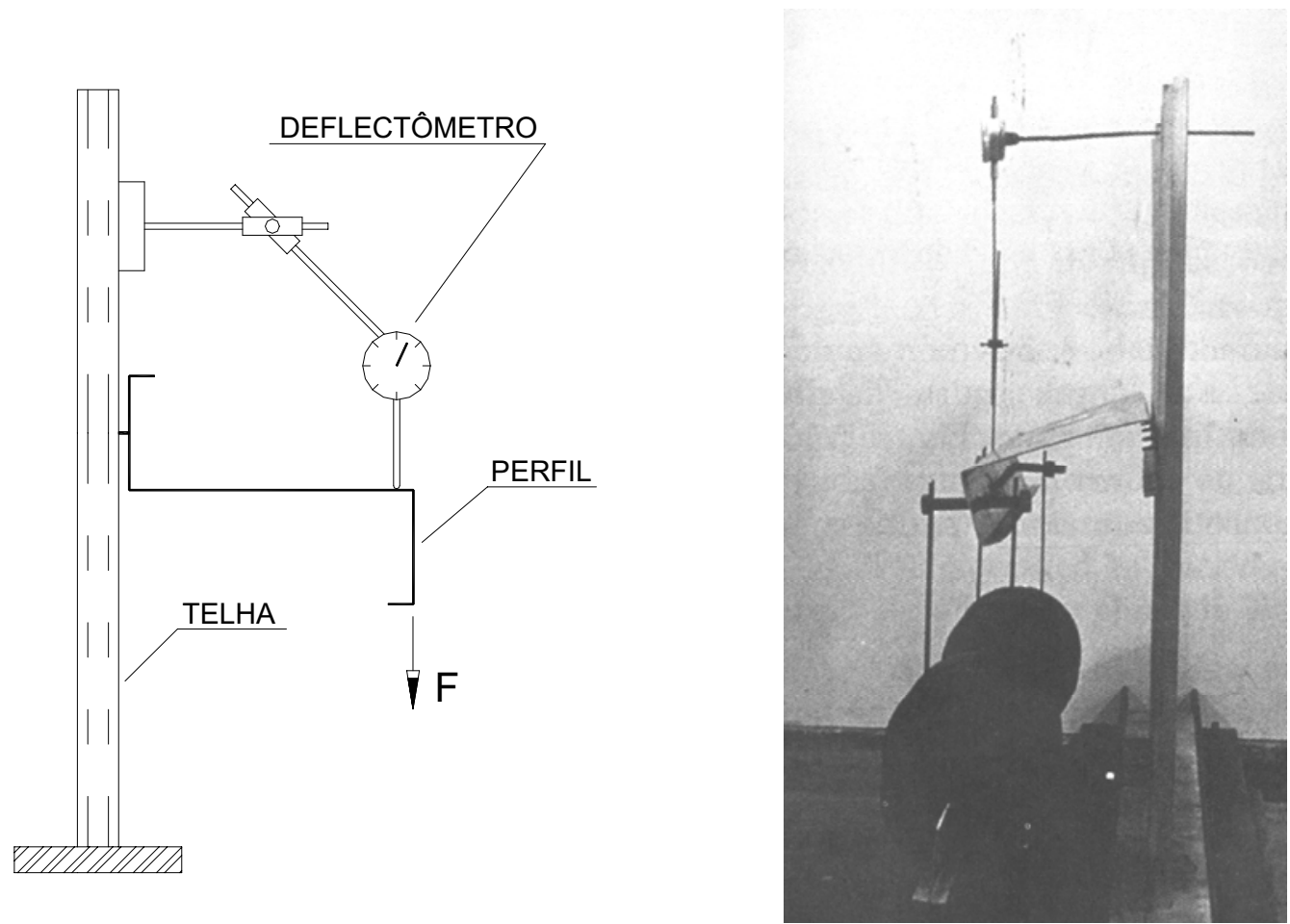

Fonte: Hancock et al. (2001).

Figura 2.16 - Ensaio padronizado pelo AISI para determinar o valor de $k_{\alpha}$. Fonte: Baságlia (2004).

O modelo consiste então na verificação da tensão máxima de compressão na seção idealizada quando submetida aos carregamentos $q_{z}(x)$ e $p(x)$ (Figura 2.15). A tensão máxima de compressão deve ser limitada à resistência ao escoamento $\left(f_{y}\right)$. 
A solução do problema é dada pelo método da conservação de energia, onde a energia total do sistema é subdividida em trabalho das forças reativas, ou energia de derformação $\left(U_{f}\right.$ e $\left.U_{k}\right)$ e trabalho das forças externas, ou energia potencial das ações $\left(U_{w}\right.$ e $\left.U_{p}\right)$. A energia potencial total $(U)$ é expressa por:

$U=U_{f}+U_{k}+U_{w}+U_{p}$

Sendo a energia de deformação $U_{f}$ e $U_{k}$ definida por:

$$
\begin{aligned}
& U_{f}=2 \int_{0}^{L / 2} \frac{E I_{y, i d}}{2}\left(\frac{\partial^{2} w}{\partial x^{2}}-\frac{\partial^{2} w_{0}}{\partial x^{2}}\right)^{2} d x \\
& U_{k}=2 \int_{0}^{L / 2} \frac{k_{\alpha}\left(w-w_{0}\right)^{2}}{2} d x
\end{aligned}
$$

Onde:

$I_{y, i d}:$ momento de inércia da seção idealizada em relação ao eixo central paralelo à alma;

$w_{0}$ : imperfeições iniciais horizontais da mesa.

$k_{\alpha}$ : rigidez da mola que define a base elástica do modelo, a determinação de $k_{\alpha}$ será descrita adiante.

E a energia potencial das ações $U_{w}$ e $U_{p}$ definida por:

$$
\begin{aligned}
& U_{w}=-2 \int_{0}^{L / 2} q_{z}(x)\left(w-w_{0}\right) d x \\
& U_{p}=-2 \int_{0}^{L / 2} p(x) \frac{1}{2}\left[\left(\frac{\partial w}{\partial x}\right)^{2}-\left(\frac{\partial w_{0}}{\partial x}\right)^{2}\right] d x
\end{aligned}
$$

Para a solução das equações é empregado o método de Ritz utilizando-se de funções trigonométricas as quais satisfaçam as condições de contorno. A seguir é descrita a solução para terças biapoiadas sem travamento lateral intermediário (linhas de corrente).

As funções dos deslocamentos podem ser expressas por meio das seguintes séries: 


$$
\begin{aligned}
& w=\sum_{n=1,3 \ldots} a_{n} \operatorname{sen} \frac{n \pi x}{L} \\
& w_{0}=\sum_{n=1,3 \ldots} a_{n 0} \operatorname{sen} \frac{n \pi x}{L}
\end{aligned}
$$

Nas equações $a_{n}$ representa a amplitude dos deslocamentos e $a_{n 0}$ é a medida das imperfeições iniciais no plano da mesa. Desde que os deslocamentos sejam simétricos podem ser tomados somente os valores negativos da série.

Pelo método de Ritz tem-se:

$$
a_{n}=\frac{4 q_{y}(x) L^{4}\left(\frac{S_{m e} b_{f}}{2 I_{z}}+\alpha\right)+a_{n 0}\left(n^{5} E I_{y, i d} \pi^{5}+n k_{\alpha} L^{4} \pi\right)}{E I_{y, i d} \pi^{5} n^{5}+k_{\alpha} L^{4} n \pi-4 \frac{S_{i d}}{I_{z}} q_{y}(x) L^{4} n \pi\left(0,206 n^{2}-0,063\right)}
$$

Onde:

$L$ : comprimento da terça.

Estudos numéricos comprovaram que a série utilizada pelo método de Ritz converge rapidamente, assim tomando-se apenas o primeiro termo da série os resultados conduzem a um erro no deslocamento horizontal $(w)$ inferior a $5 \%$. Portanto, pode-se obter:

$$
a_{1}=\frac{C_{1}\left(\frac{S_{i d} b_{f}}{2 I_{z, R}}+\alpha\right)+a_{10}}{1-0,45 C_{1} \frac{S_{i d}}{I_{z}}}
$$

Onde:

$$
C_{1}=\frac{1,27 q_{y}(x)}{\frac{94,41 E I_{y, i d}}{L^{4}}+k_{\alpha}}
$$

Deve ser notado que o deslocamento total da seção transversal é o resultado do deslocamento lateral $w$ e do deslocamento vertical $v$, que é expresso em função do deslocamento lateral por:

$$
v=\frac{x q_{y}(x)}{24 E I_{z, R}}\left(L^{3}-2 L x^{2}+x^{3}\right)+\frac{\Psi w^{2}}{2 b_{w}}
$$


Onde:

Y: fator de correção dos efeitos distorcionais da seção. $O$ fator pode ser determinado experimentalmente ou, segundo os autores, o valor $\Psi=3,4$ conduz a resultados satisfatórios.

É importante ressaltar que na equação (2.27) a primeira parcela é referente ao deslocamento devido à solicitação por sucção e a segunda é proveniente da distorção lateral da alma. Como se pode observar, a segunda parcela está em função do deslocamento horizontal.

A tensão máxima de compressão, $\sigma_{\text {máx,c, }}$, ocorrerá na junção da mesa comprimida e a alma do perfil. Esta é obtida pela superposição das tensões provocadas pela flexão em torno do eixo z (Figura 2.17a) e as tensões em torno do eixo y provenientes da seção fictícia idealizada (Figura 2.17b).

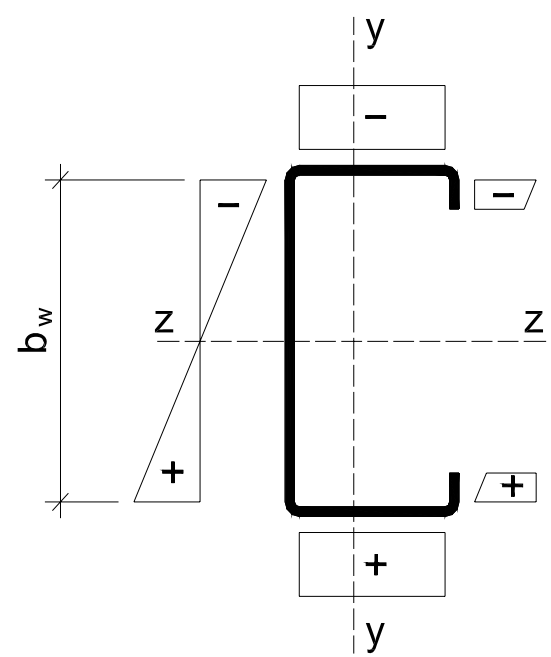

a) Tensões provenientes da flexão simples em torno do eixo z.

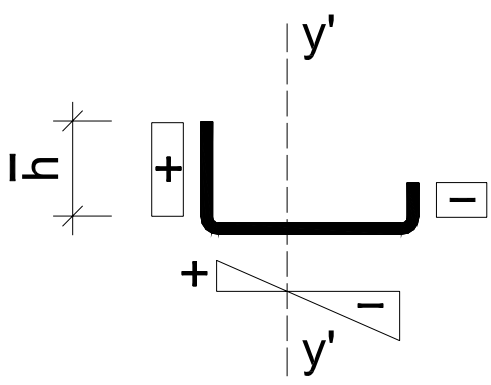

b) Tensões provenientes da flexão em relação ao eixo y' - seção idealizada.

Figura 2.17 - Tensões definidas por Peköz e Soroushian (1982) a serem sobrepostas. Nesta figura o sinal positivo representa compressão.

Desta forma, a tensão máxima de compressão, $\sigma_{\text {máx,c, }}$, é representada pela expressão:

$\sigma_{\text {max } x, c}=\frac{M_{z}}{W_{z}}+\frac{M_{y, i d}}{W_{y, i d}}$

Onde:

$M_{z}$ : momento fletor em torno do eixo z, devido à flexão simples; 
$W_{z}$ : módulo de resistência elástico da seção transversal da barra em relação ao eixo z, referente ao momento de inércia reduzido, $I_{z, R}$, como definido na expressão 2.16;

$M_{y, i d}:$ momento fletor na seção idealizada, em torno do eixo paralelo à alma (eixo y');

$W_{y, i d}$ : módulo de resistência elástico da seção transversal idealizada em relação ao eixo paralelo à alma (eixo y').

O momento fletor na seção idealizada $\left(M_{y, i d}\right)$ é dado por:

$$
\begin{aligned}
& M_{y, i d}=E I_{y, i d}\left(\frac{\partial^{2} w}{\partial x^{2}}-\frac{\partial^{2} w_{0}}{\partial x^{2}}\right) \\
& M_{y, i d}=\frac{E I_{y, i d} \pi^{2}}{L^{2}} \sum_{n=1,3 \ldots} n^{2}\left(a_{n}-a_{n 0}\right) \operatorname{sen} \frac{n \pi x}{L}
\end{aligned}
$$

Após análises numéricas os autores propuseram algumas simplificações no cálculo de $I_{y, i d}, S_{m e}$ e na relação $S_{i d} / I_{z}$, onde a parcela da alma da seção idealizada é desprezada e a largura da mesa $b_{f}$ é dada pela projeção da mesa e enrijecedor sobre o eixo z, assim tem-se:

$$
\begin{gathered}
I_{y, i d}=\frac{t b_{f}^{3}}{12} \\
S_{m e}=\frac{b_{f} t b_{w}}{2} \\
\frac{S_{i d}}{I_{z}}=\frac{b_{f} t b_{w}}{4 I_{z}}
\end{gathered}
$$

Substituindo as equações (2.31) a (2.33) em (2.25) e (2.26), tem-se:

$$
a_{1}=\frac{C_{1}\left(Z b_{f}+\alpha\right)+a_{10}}{1-0,9 Z C}
$$

Onde:

$$
Z=\frac{t b_{w} b_{f}}{4 I_{z}}
$$




$$
C=\frac{1,27 q_{y}(x)}{\frac{7,87 E t b_{f}^{3}}{L^{4}}+k_{\alpha}}
$$

Adotando as hipóteses simplificadoras a tensão máxima de compressão no perfil $Z$ continua atuando na junção da mesa com a alma, no entanto no perfil $U_{e} a$ tensão máxima de compressão passa a atuar na junção da mesa com o enrijecedor e é dada por:

$\sigma_{\text {máx. }, c}=\frac{b_{w} M_{z}}{2 I_{z, R}}+\frac{E b_{f} \pi^{2}}{2 L^{2}}\left(a_{1}-a_{10}\right)$

Assim sendo, o deslocamento vertical máximo é dado por:

$v_{\text {máx }}=\frac{5 q_{y}(x) L^{4}}{384 E I_{z, R}}+\frac{\Psi w^{2}}{2 b_{w}}$

É importante ressaltar que o modelo de Peköz e Soroushian (1982) não apresenta um carregamento crítico e sim a tensão máxima de compressão, ou seja, a estabilidade é verificada por meio da tensão máxima de compressão.

O Eurocode 3 - parte 1.3 (1996), item 10.1, adotou como procedimento base para as suas recomendações o modelo desenvolvido por Peköz e Soroushian (1982) devido às relações satisfatórias com os resultados experimentais e por apresentar uma formulação fechada (analítica) para a solução do problema.

No entanto, o modelo apresenta como dificuldade a necessidade de ensaio para a determinação de $k_{\alpha}$. Diante desta dificuldade o Eurocode apresenta uma expressão para determinação deste coeficiente sem que seja necessário algum tipo de ensaio. Já o AISI (1996) apesar de não apresentar o procedimento de Peköz e Soroushian (1982) no corpo da norma, padronizou o ensaio para a determinação das rigidezes de mola para a eventual utilização de tal procedimento, ensaio o qual é descrito no próximo item.

\subsubsection{Ensaio Padronizado pelo AISI (1996)}

O ensaio padronizado pelo AISI (1996) visa determinar o coeficiente $\mathrm{K}$ que consiste do acoplamento da: (a) rigidez lateral do perfil, $K_{a}$, que está em função da geometria do perfil e da ligação terça-telha, (b) a rigidez local da ligação, $K_{b}$, que é afetada pelo tipo de parafuso atarraxante, pelo espaçamento e a geometria dos elementos 
conectados e por fim (c) pela rigidez à flexão do painel, $\mathrm{K}_{\mathrm{c}}$, que é função do momento de inércia do painel, espaçamento entre terças e localização da terça (extremidade ou intermediária).

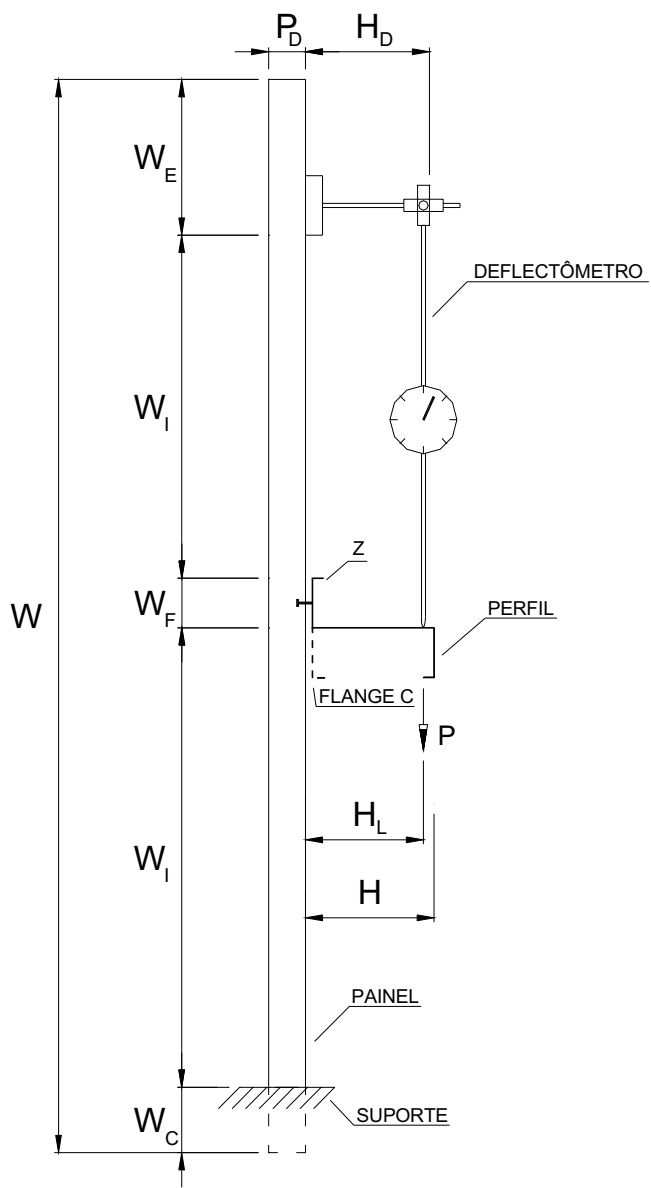

a) Elevação Lateral

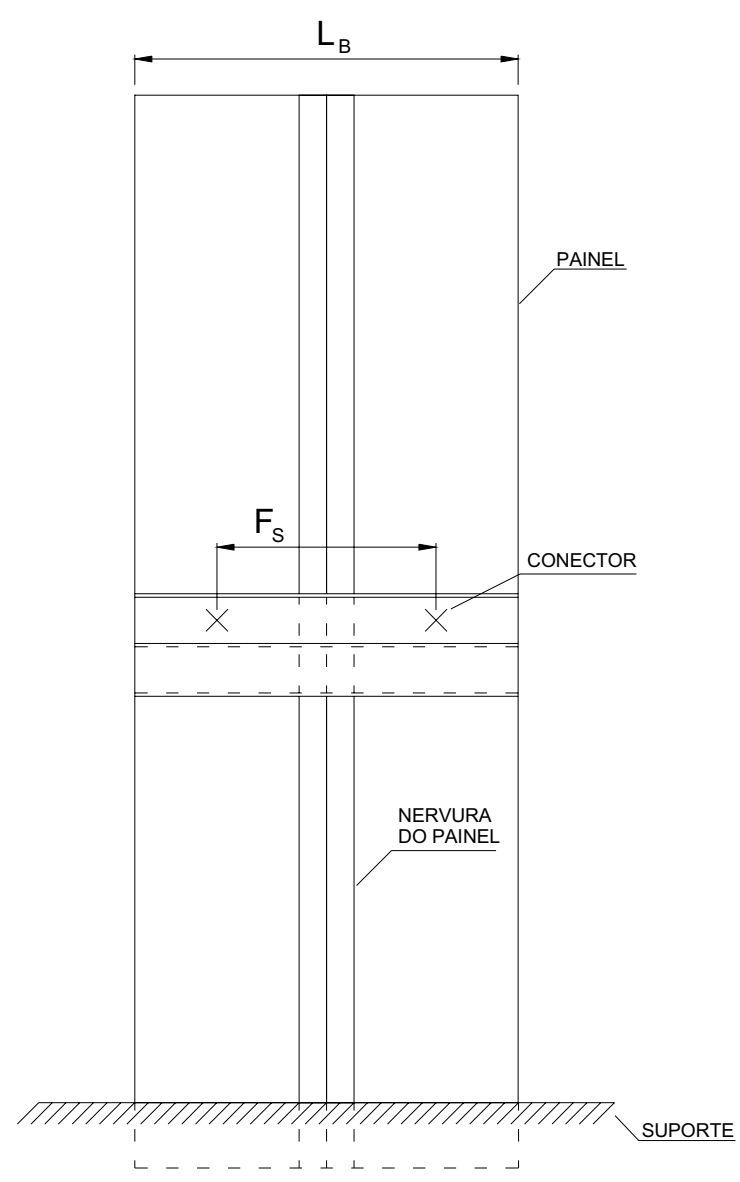

b) Elevação Frontal

Figura 2.18- Ensaio padronizado pelo AISI (1996).

O ensaio constitui em um painel fixado em uma de suas extremidades e com o perfil conectado ao mesmo (Figura 2.18).

Algumas restrições quanto às dimensões são dadas tais como: I) $W_{1}$ deve ser maior que: (a) 1,5 vezes $\mathrm{P}_{\mathrm{D}}$, (b) $\mathrm{W}_{\mathrm{F}}$, (c) $\mathrm{F}_{\mathrm{S}}$ e para telhas corrugadas (d) 2 vezes a largura de contato entre o perfil e a telha. II) $W_{C}$ deve ser maior que 2 vezes a altura da telha mas não maior que $50 \mathrm{~mm}$. III) $\mathrm{W}_{\mathrm{E}}$ deve ser o suficiente para conectar o deflectômetro. IV) $L_{B}$ deve ser maior que: (a) 2 vezes $F_{S}$ e (b) largura nominal de cobertura do painel. $A$ ligação terça-telha deve conter ao menos dois conectores.

A rigidez $\mathrm{K}$ é dada pela força aplicada dividida pelo comprimento do painel, $L_{B}$, dividido pelo deslocamento $D$ medido pelo deflectômetro, assim tem-se a rigidez 
por unidade de comprimento do conjunto. No entanto $\mathrm{K}$ inclui o efeito da rigidez do perfil $\left(\mathrm{K}_{\mathrm{a}}\right)$ e a rigidez da conexão telha-terça $\left(\mathrm{K}_{\mathrm{b}}\right)$ porém exclui a rigidez à flexão do painel $\left(\mathrm{K}_{\mathrm{c}}\right)$. Apesar do AISI (1996) indicar uma forma analítica para a determinação de $\mathrm{K}_{c}$, o próprio AISI (1996) ressalta ser desprezível esta contribuição.

O AISI (1996) apresenta um ensaio alternativo para a determinação da rigidez K (Figura 2.19), de forma a incluir a rigidez à flexão do painel, no entanto, salienta que este método é conservativo quando comparado ao método analítico para determinação de $\mathrm{K}_{c}$, uma vez que resultará em uma estrutura mais flexível que a real onde tem-se a continuidade da telha que está fixada as outras terças.

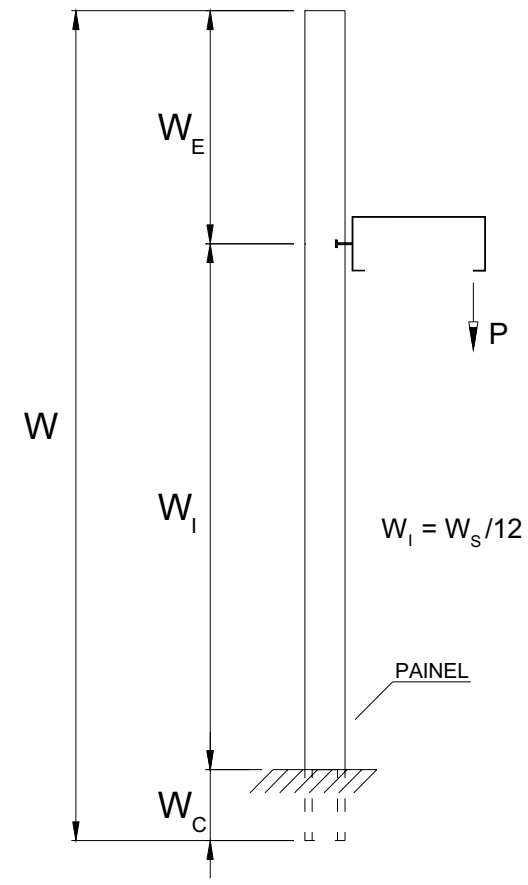

a) Elevação

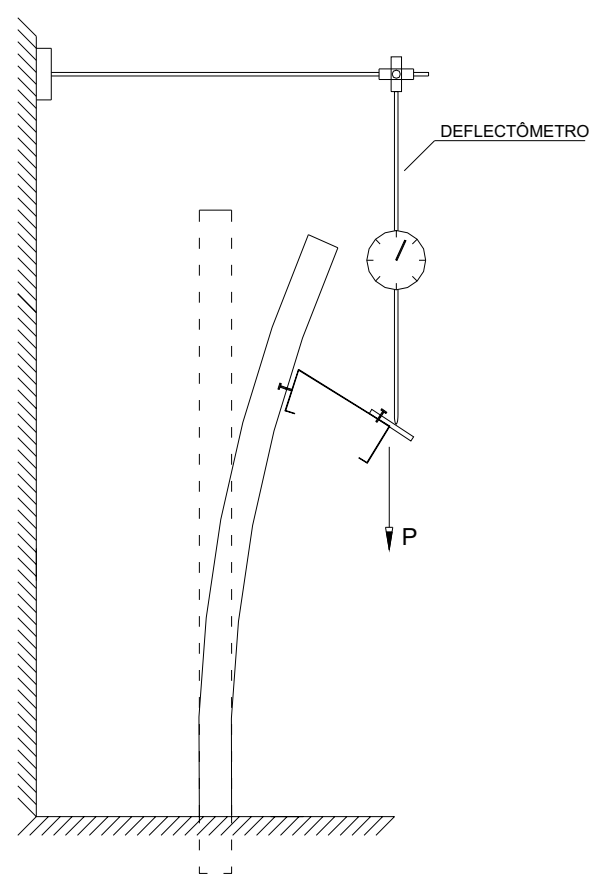

b) Disposição do ensaio

Figura 2.19 - Ensaio alternativo para a determinação do fator $K$.

\subsection{Modelo Proposto por Ye et al. (2004)}

Ye et al. (2004) propõem um modelo analítico para a análise da interação terça-telha sujeita a carregamento de sucção em perfis $Z$, as restrições impostas pela telha à terça são simuladas por meio do uso de duas molas, sendo uma translacional e outra rotacional e o carregamento é admitido uniformemente distribuído ao longo do eixo de fixação como mostrado na Figura 2.20. 


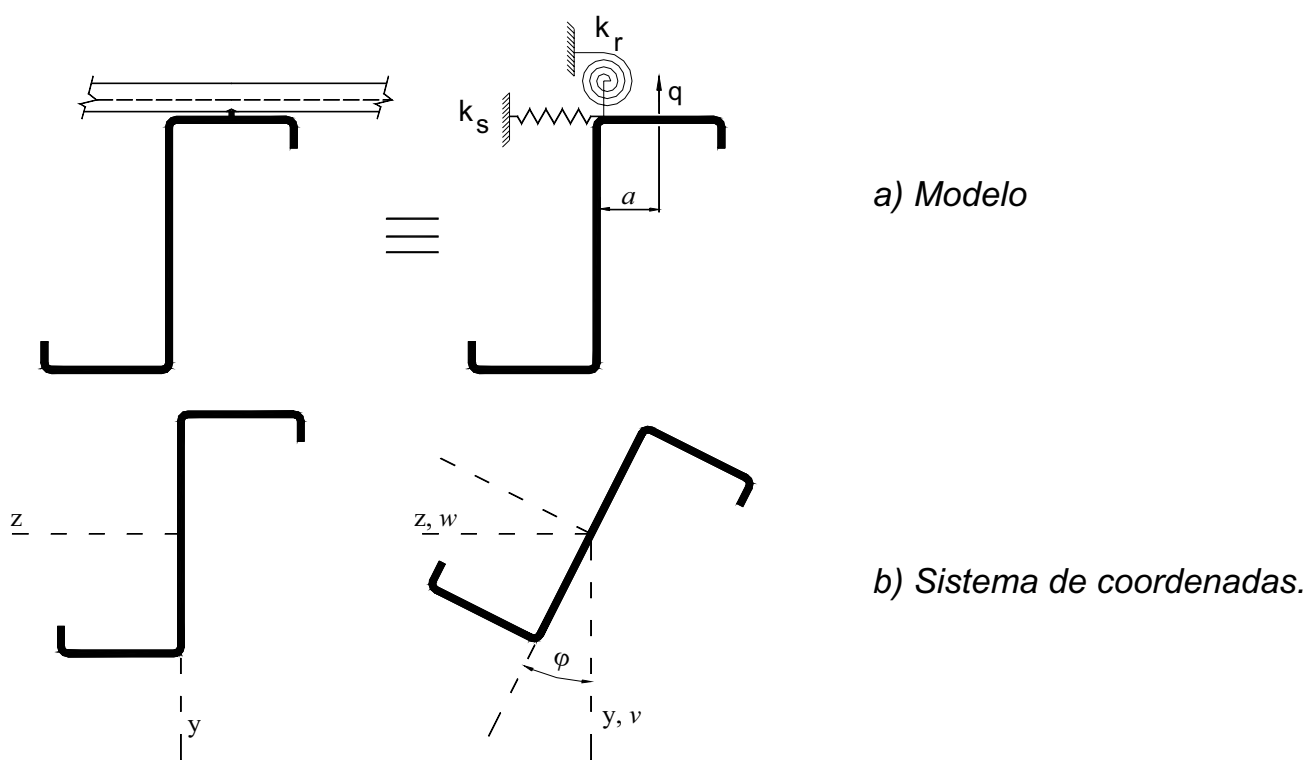

Figura 2.20 - Modelagem do sistema terça-telha, segundo Ye et al. (2004). Fonte: Baságlia (2004).

Estabelecendo como a origem do sistema de coordenadas o centro de gravidade do perfil (Figura 2.20) a relação entre o momento fletor e o raio de curvatura pode ser expressa como:

$\left\{\begin{array}{l}M_{y} \\ M_{z}\end{array}\right\}=E \cdot\left[\begin{array}{cc}I_{y} & I_{y z} \\ I_{z y} & I_{z}\end{array}\right] \cdot\left\{\begin{array}{c}\frac{1}{R_{z}} \\ \frac{1}{R_{y}}\end{array}\right\}$

Onde para problemas lineares o raio de curvatura em termos de deslocamentos é dado por:

$\frac{1}{R_{z}}=-\frac{\partial^{2} \mathrm{w}}{\partial \mathrm{x}^{2}}, \quad \frac{1}{R_{y}}=-\frac{\partial^{2} \mathrm{v}}{\partial \mathrm{x}^{2}}$

Sendo $w$ e $v$ os deslocamentos na direção $z$ e y respectivamente como mostrado na Figura 2.20.

A partir das equações de equilíbrio tem-se o momento fletor em função das forças distribuídas:

$$
\begin{aligned}
& \frac{\partial^{2} \mathrm{M}_{\mathrm{y}}}{\partial \mathrm{x}^{2}}=-\mathrm{q}_{\mathrm{z}}, \frac{\partial^{2} \mathrm{M}_{\mathrm{z}}}{\partial \mathrm{x}^{2}}=-\mathrm{q}_{\mathrm{y}} \\
& \text { Onde } q_{y} \text { e } q_{z} \text { são as forças distribuídas nas direções } \mathrm{y} \text { e } \mathrm{z}
\end{aligned}
$$
respectivamente. 
Substituindo as equações (2.41) e (2.40) em (2.39) tem-se:

$\left\{\begin{array}{c}\frac{\partial^{4} w}{\partial x^{4}} \\ \frac{\partial^{4} v}{\partial x^{4}}\end{array}\right\}=\frac{1}{E\left(I_{y} I_{z}-I_{y z}^{2}\right)}\left[\begin{array}{cc}I_{z} & -I_{y z} \\ -I_{z y} & I_{y}\end{array}\right]\left\{\begin{array}{c}q_{z} \\ q_{y}\end{array}\right\}$

A tensão longitudinal gerada pelo momento fletor $\left(\sigma_{x m}\right)$ em qualquer ponto da seção transversal, pode ser calculada baseada na formulação desenvolvida para a flexão:

$\sigma_{x m}=\frac{M_{z} I_{y}-M_{y} I_{y z}}{I_{y} I_{z}-I_{y z}^{2}} y+\frac{M_{y} I_{z}-M_{z} I_{y z}}{I_{y} I_{z}-I_{y z}^{2}} z$

Além da flexão, a barra encontra-se sujeita à torção provida pela mola rotacional e pelos carregamentos aplicados fora do centro de cisalhamento da terça, sendo a equação de flexo-torção escrita por:

$-\frac{\partial \mathrm{M}_{\mathrm{t}}(\mathrm{x})}{\partial \mathrm{x}}=\mathrm{EC}_{\mathrm{w}} \frac{\partial^{4} \varphi}{\partial \mathrm{x}^{4}}-\mathrm{GI}_{\mathrm{t}} \frac{\partial^{2} \varphi}{\partial \mathrm{x}^{2}}$

A tensão longitudinal gerada pela flexo-torção $\left(\sigma_{x w}\right)$ é calculada como:

$\sigma_{x w}=\frac{B}{I_{\omega}} \omega$

Onde:

$B$ : bimomento;

$I_{\omega}:$ momento de inércia setorial;

$\omega$ : área setorial principal, variável na seção transversal.

Considerando que o carregamento aplicado é dado por:

$\mathrm{q}_{\mathrm{y}}=\mathrm{q}, \quad \mathrm{q}_{\mathrm{z}}=-\mathrm{k}_{\mathrm{s}}\left(\frac{\mathrm{b}_{\mathrm{w}}}{2} \varphi+\mathrm{w}\right), \quad \frac{\partial \mathrm{M}_{\mathrm{t}}}{\partial \mathrm{x}}=\mathrm{k}_{\mathrm{s}}\left(\frac{\mathrm{b}_{\mathrm{w}}}{2} \varphi+\mathrm{w}\right) \frac{\mathrm{b}_{\mathrm{w}}}{2}+\mathrm{qa}+\mathrm{k}_{\mathrm{r}} \varphi$

Substituindo (2.46) em (2.42) e (2.44) tem-se:

$\gamma_{1} L^{4} \frac{d^{4} w_{\varphi}}{d x^{4}}-L^{2} \frac{d^{2} w_{\varphi}}{d x^{2}}+\frac{k_{s} \gamma_{2}}{E}\left(w_{\varphi}+w\right)+\frac{4 k_{r} \gamma_{2}}{E b_{w}^{2}} w_{\varphi}=-\frac{q \gamma_{3}}{E}$ 


$$
\begin{aligned}
& L^{4} \frac{d^{4} w}{d x^{4}}+\frac{k_{s} \lambda_{z}}{E}\left(w_{\varphi}+w\right)=-\frac{q \lambda_{y z}}{E} \\
& L^{4} \frac{d^{4} v}{d x^{4}}=\frac{k_{s} \lambda_{y z}}{E}\left(w_{\varphi}+w\right)+\frac{q \lambda_{y}}{E}
\end{aligned}
$$

Sendo:

$$
\begin{aligned}
& w_{\varphi}=\frac{\varphi b_{w}}{2}, \quad \gamma_{1}=\frac{E C_{w}}{G I_{t} L^{2}}, \quad \gamma_{2}=\frac{E\left(b_{w} L\right)^{2}}{4 G I_{t}}, \quad \gamma_{3}=\frac{a E b_{w} L^{2}}{2 G I_{t}} \\
& \lambda_{z}=\frac{I_{z} L^{4}}{I_{y} I_{z}-I_{y z}^{2}}, \quad \lambda_{y}=\frac{I_{y} L^{4}}{I_{y} I_{z}-I_{y z}^{2}}, \quad \lambda_{y z}=\frac{I_{y z} L^{4}}{I_{y} I_{z}-I_{y z}^{2}}
\end{aligned}
$$

Onde:

$k_{s}$ é a rigidez da mola de translação;

$k_{r}$ é a rigidez da mola de rotação;

$I_{z}, I_{y}$ : momentos de inércia da seção em relação aos eixos principais $\mathrm{z}$ e $\mathrm{y}$, respectivamente;

$I_{y z}:$ produto de inércia da seção em relação ao sistema de coordenadas yz;

$E C_{w}:$ rigidez ao empenamento;

$G I_{t}:$ rigidez à torção;

$a$ : distância entre o ponto de aplicação do carregamento e a linha de centro da alma;

$L$ : comprimento da barra;

$q$ : carregamento uniformemente distribuído;

$\varphi$ : ângulo de torção;

$v, w$ : deslocamento da barra nas direções y e z respectivamente.

A norma britânica BS5950 (1987) apud. Ye et al. (2004) utiliza-se de um caso particular, supondo que o perfil encontra-se totalmente restringido pela telha, ou seja, $k_{s}=k_{r}=\infty \mathrm{e}$, portanto $w=w_{\varphi}=0$, com isto tem-se: 
$L^{4} \frac{d^{4} v}{d x^{4}}=\frac{q}{E}\left(\frac{\lambda_{y} \lambda_{z}-\lambda_{y z}^{2}}{\lambda_{z}}\right)=\frac{q L^{4}}{E I_{z}}$

Com isto, a norma britânica BS5950 (1987) apresenta a formulação para flexão de vigas simétricas e verifica a flambagem local da mesa sujeita a compressão. No entanto, como a telha geralmente não garante restrição total $\left(k_{s} \neq 0, k_{r} \neq 0\right)$ o perfil estará submetido à flexão assimétrica e as tensões deveriam ser calculadas como tal, também deveria ser considerada a flexo-torção que gera além das tensões cisalhantes as tensões devido ao bimomento.

A formulação proposta por Ye et al. (2004) apresenta como dificuldade a necessidade de se determinar as constantes de rigidez das molas de translação $\left(k_{s}\right)$ e de rotação $\left(k_{r}\right)$. É importante ressaltar que Trahair (1993) utiliza para simular a rigidez ao cisalhamento da telha mola rotacional diferentemente de Ye et al. (2004), que como mostrado utiliza mola translacional.

É importante salientar que a formulação adotada para determinar a tensão normal (2.43) e (2.45), assim como as equações de equilíbrio (2.47) a (2.49), não consideram o efeito da distorção lateral do perfil.

\subsection{Modelo de LaBoube (University of Missouri-Rolla)}

O Modelo de Laboube (1988, 1991 e 1992) consiste em um procedimento empírico de análise em caixa de sucção (Figura 2.21). O dispositivo da caixa de sucção é composto pelo conjunto telha-terça a ser ensaiada, sujeita a uma diferença de pressão interna e externa provocada pela retirada do ar contido no interior da caixa. 


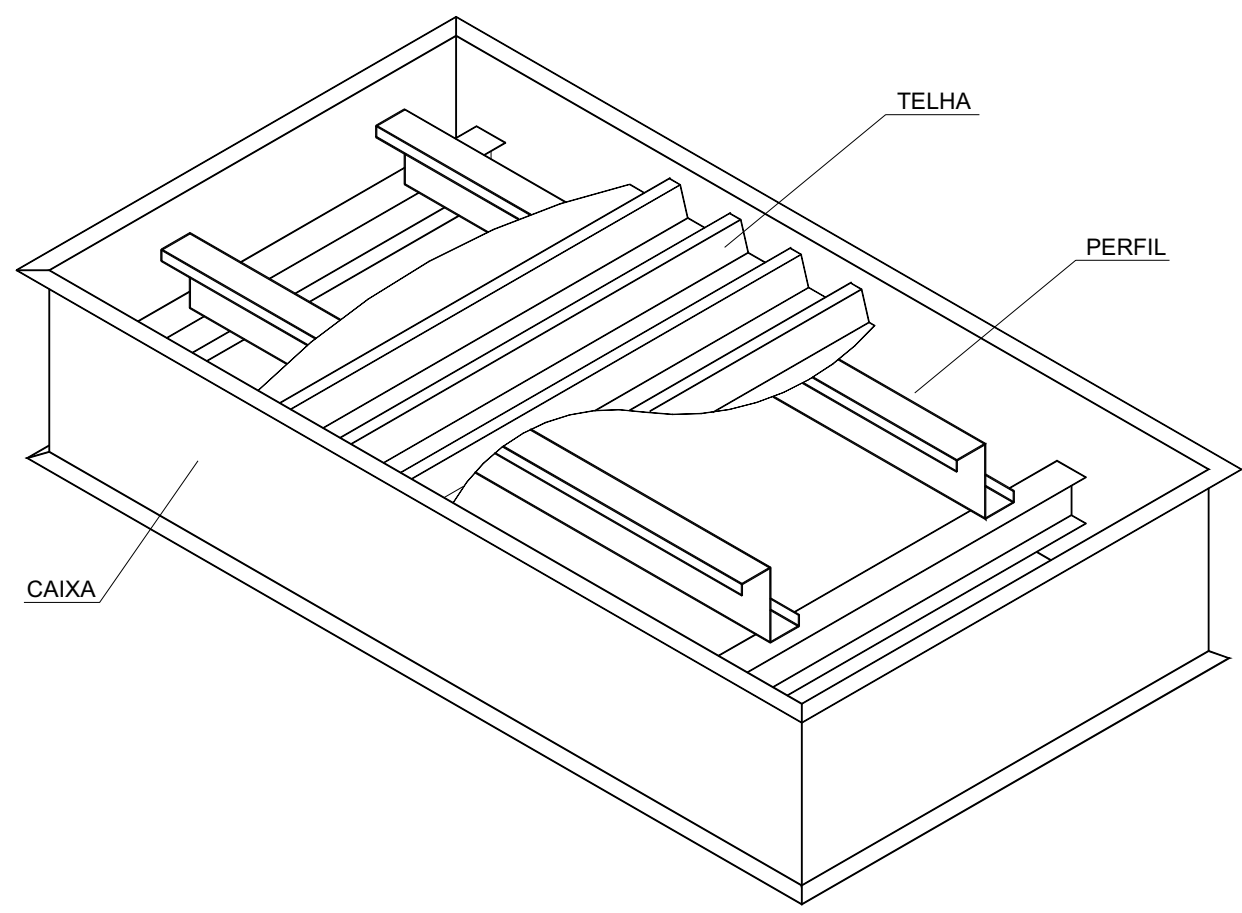

Figura 2.21 - Caixa de sucção invertida. Fonte: Baságlia (2004).

O momento fletor máximo observado no ensaio é relacionado com o momento fletor de início de escoamento da seção efetiva, obtendo-se um fator de redução $R$.

$$
M_{R}=R \cdot W_{e f} \cdot f_{y}
$$

Onde:

$M_{R}:$ momento fletor resistente (valor limite estabelecido no ensaio);

$R$ : fator de redução;

$W_{e f}$ : módulo de resistência elástico da seção efetiva referente ao início de escoamento da seção efetiva;

$f_{y}$ : resistência ao escoamento do aço.

Foram realizados 19 ensaios, sendo que 14 ensaios utilizaram perfis $Z_{\mathrm{e}}$ ( $Z$ enrijecido) enquanto 5 ensaios utilizaram perfis $U_{e}$. Os parâmetros foram: (i) a largura da mesa (50,8 a 76,2mm), (ii) a altura da alma (165 a 254mm), (iii) a espessura $(1,42$ a $2,57 \mathrm{~mm}$ ), (iv) a inclinação dos enrijecedores de borda $\left(42^{\circ}\right.$ a $\left.90^{\circ}\right)$, (v) comprimento do traspasse $^{*}(76,2$ a $183 \mathrm{~mm})$ e (vi) vão $(6,1$ a $9,1 \mathrm{~m})$. O painel utilizado foi padronizado em

\footnotetext{
* A continuidade nos apoios é obtida por traspasse (sobreposição) das terças.
} 
todos os ensaios, conectado por parafusos auto-atarraxantes fixados a cada $30,5 \mathrm{~cm}$.

Os valores médios do fator de redução $R$ encontrados por LaBoube (1988) e adotado pelo AISI (1991) são mostrados na Tabela 2-1. Estes mesmos valores são adotados pela norma brasileira NBR 14762:2001 (Anexo F).

Tabela 2-1 - Valores do fator de redução $R$ encontrados por LaBoube (1988).

\begin{tabular}{|c|c|c|}
\hline Seção & Sistema & $\boldsymbol{R}$ \\
\hline$U_{e}$ & (biapoiado, sem linhas de corrente) & 0,40 \\
\hline$Z_{e}$ & (biapoiado, sem linhas de corrente) & 0,50 \\
\hline$U_{e}$ & (contínuo, sem linhas de corrente) & 0,60 \\
\hline$Z_{e}$ & (contínuo, sem linhas de corrente) & 0,70 \\
\hline
\end{tabular}

LaBoube determinou como restrições ao emprego destes valores:

a) Altura máxima do perfil igual a $25,5 \mathrm{~cm}$;

b) Os perfis devem possuir enrijecedores efetivos;

c) A relação altura-espessura do perfil deve estar compreendida entre $60 \mathrm{e}$ 170 ;

d) A relação altura-largura do perfil deve estar compreendida entre 2 e 5;

e) A relação largura plana da mesa/espessura do perfil deve estar compreendida entre 16 e 43.

Após a revisão do AISI(1996) o AISI (2001) adotou para terças biapoiadas outros valores para o fator $R$, em que há a variação do mesmo em função da altura do perfil, já que em terças de menor altura o efeito da distorção lateral é menor. $O$ fator $R$ continua o mesmo para terças com altura entre 216 e $292 \mathrm{~mm}$, porém é alterado para perfis $\mathrm{U}_{\mathrm{e}}$ e $\mathrm{Z}_{\mathrm{e}}$ de altura inferior a $216 \mathrm{~mm}$ (Tabela 2-2).

Tabela 2-2 - Valores do fator de $R$ adotados nas recomendações do AISI(2001).

\begin{tabular}{|c|c|c|}
\hline \multicolumn{3}{|c|}{ Tercas biapodas sem linhas de corrente } \\
\hline Seção & Altura do perfil $(\mathbf{m m})$ & $\boldsymbol{R}$ \\
\hline $\mathrm{U}_{\mathrm{e}}$ ou $\mathrm{Z}_{\mathrm{e}}$ & $\mathrm{b}_{\mathrm{w}} \leq 165$ & 0,70 \\
\hline $\mathrm{U}_{\mathrm{e}}$ ou $\mathrm{Z}_{\mathrm{e}}$ & $165<\mathrm{b}_{\mathrm{w}} \leq 216$ & 0,65 \\
\hline $\mathrm{Z}_{\mathrm{e}}$ & $216<\mathrm{b}_{\mathrm{w}} \leq 292$ & 0,50 \\
\hline $\mathrm{U}_{\mathrm{e}}$ & $216<\mathrm{b}_{\mathrm{w}} \leq 292$ & 0,40 \\
\hline
\end{tabular}




\subsection{Calibração do fator $R$, segundo Hancock e Johnston (1994)}

Tendo em vista os resultados obtidos pelo modelo LaBoube, Hancock e Johnston (1994) procuraram por meio de ensaios em caixa de sucção calibrar os valores do fator de redução $R$ para os sistemas terça-telha comumente utilizados na Austrália.

Foram analisadas terças sujeitas a carregamentos de sucção simplesmente apoiadas e contínuas de 2 e 3 vãos restringidas por linhas de correntes $(0,1$ e 2 linhas de corrente), além de sistemas contínuos de 3 vãos sujeitos a carregamentos gravitacionais.

Os ensaios mostraram que para terças simplesmente apoiadas e contínuas de 3 vãos o fator $R$ médio encontrado foi de 0,79 com desvio padrão de 0,04 , também foram realizadas verificações nas regiões dos apoios utilizando a verificação combinada da solicitação por esforços cortantes e momentos fletores, equação (2.54), onde encontrou-se o valor médio do fator $R$ médio de 0,83 , ou seja maior que o anteriormente encontrado, portanto este valor não é preponderante no dimensionamento. Todos os ensaios apresentaram falha por instabilidade local no centro do vão para terças simplesmente apoiadas e nas proximidades do centro dos vãos externos para terças contínuas de 3 vãos.

$\left\{\frac{V}{V_{R}}\right\}^{2}+\left\{\frac{M}{M_{R}}\right\}^{2} \leq 1,0$

Onde:

$V$ : esforço cortante solicitante;

$V_{R}:$ esforço cortante resistente;

$M$ : momento fletor solicitante;

$M_{R}:$ momento fletor resistente.

Para terças simplesmente apoiadas e contínuas de 3 vãos com uma linha de correntes o fator $R$ médio encontrado foi de 0,89 com desvio padrão de 0,024 e novamente a verificação na região de traspasse (apoios internos) não foi preponderante e apresentaram falhas por instabilidade local nas mesmas regiões do ensaio anterior.

Já com 2 linhas de corrente o fator $R$ médio encontrado foi de 1,09 com desvio padrão de 0,082 , no entanto em alguns casos a verificação na região de traspasse 
foi preponderante e em um dos ensaios, diferentemente dos ensaios anteriores, a falha ocorreu no final da região de traspasse.

Para terças com dois vãos os valores médios do fator $R$ encontrados foram de 0,67, 0,76 e 0,88 para respectivamente nenhuma,uma e duas linhas de corrente, sendo que a verificação na região de traspasse não foi preponderante em nenhum dos casos.

Para carregamentos gravitacionais como dito anteriormente, somente foram analisadas terças contínuas de três vãos. O valor médio do fator $R$ encontrado foi de 0,91 com desvio padrão de 0,057 , vale ressaltar que o número de linhas de corrente não interfere nos resultados, pois restringe as mesas tracionadas e a verificação na região de traspasse não foi preponderante apesar de alguns ensaios apresentarem falha na região final do traspasse.

Com base nesses resultados a norma AS/NZS 4600 (1996) adotou os seguintes valores para o fator $R$ :

\section{Carregamento de Sucção}

Terças contínuas de três vãos ou mais em perfil $Z_{e}$ e simplesmente apoiadas ${ }^{*}$ em $U_{e}$ e $Z_{e}$ fixadas com parafusos auto-atarraxantes

(i) Sem linhas de corrente $R=0,75$

(ii) Uma linha de corrente em todos os vãos $R=0,85$

(iii) Duas linhas de corrente ${ }^{\dagger}$ nos vãos extremos e uma ou mais nos $R=0,95$ vãos intermediários

(iv) Duas linhas de corrente em terças simplesmente apoiadas $R=1,00$

Terças contínuas de dois vãos em perfil $Z_{e}$

(i) Sem linhas de corrente $R=0,60$

(ii) Uma linha de corrente por vão $R=0,70$

(iii) Duas linhas de corrente por vão $R=0,80$

\section{Carregamento Gravitacional}

Terças contínuas de três vãos ou mais em perfil $Z_{e}$

(i) Qualquer número de correntes

$R=0,85$

\footnotetext{
*Quando as terças não forem conectadas com parafusos auto-atarraxantes devem ser utilizados os valores do AISI (1991).

${ }^{\dagger}$ Deve ser verificado o efeito combinado da flexão e cisalhamento na sobreposição (traspasse).
} 
É importante ressaltar que a ligação telha-terça foi feita na crista (onda alta) das telhas, detalhe normalmente empregado na Austrália, diferentemente do Brasil onde o painel é conectado ao perfil pela onda inferior.

A recomendação adotada pela norma australiana de conectar o perfil à onda superior tem a finalidade de evitar problemas de estanqueidade e corrosão na região de ligação na onda inferior por onde escoa a água pluvial.

\subsection{Método das Faixas Finitas Utilizado por Ye et al. (2002)}

O método das faixas finitas foi inicialmente desenvolvido por Cheung e empregado por Hancock e Schafer para perfis formados a frio. O método semi-analítico de análise por faixas finitas permite que cada elemento do perfil a ser analisado seja subdivido em faixas longitudinais, desta forma somente a seção transversal do perfil deve ser discretizada (Figura 2.22). Cada faixa finita encontra-se livre para deformar-se em seu plano (deslocamentos de membrana) e fora de seu plano (deslocamentos de flexão). A análise dos deslocamentos de membrana é regida por funções polinomiais enquanto os deslocamentos fora do plano são regidos por funções harmônicas (formato de uma meia onda senoidal - Figura 2.23).

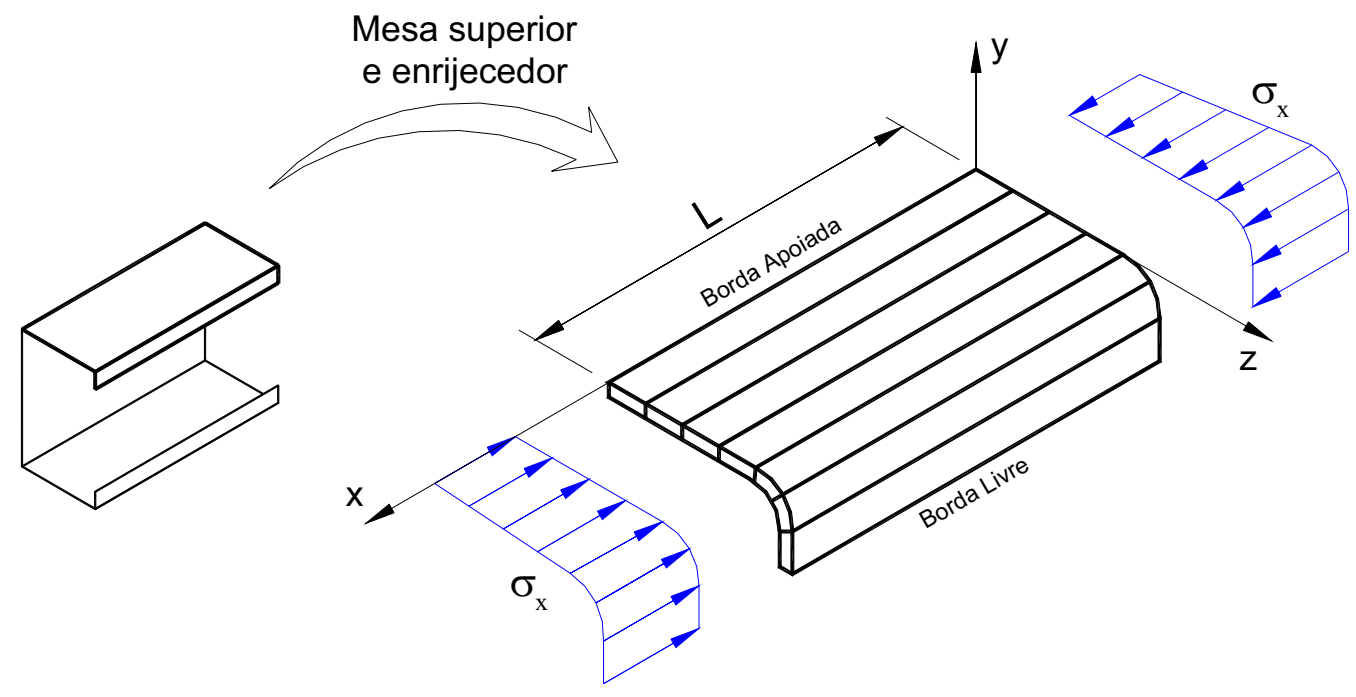

Figura 2.22 - Discretização parcial do perfil via MFF. Fonte: Baságlia (2004). 


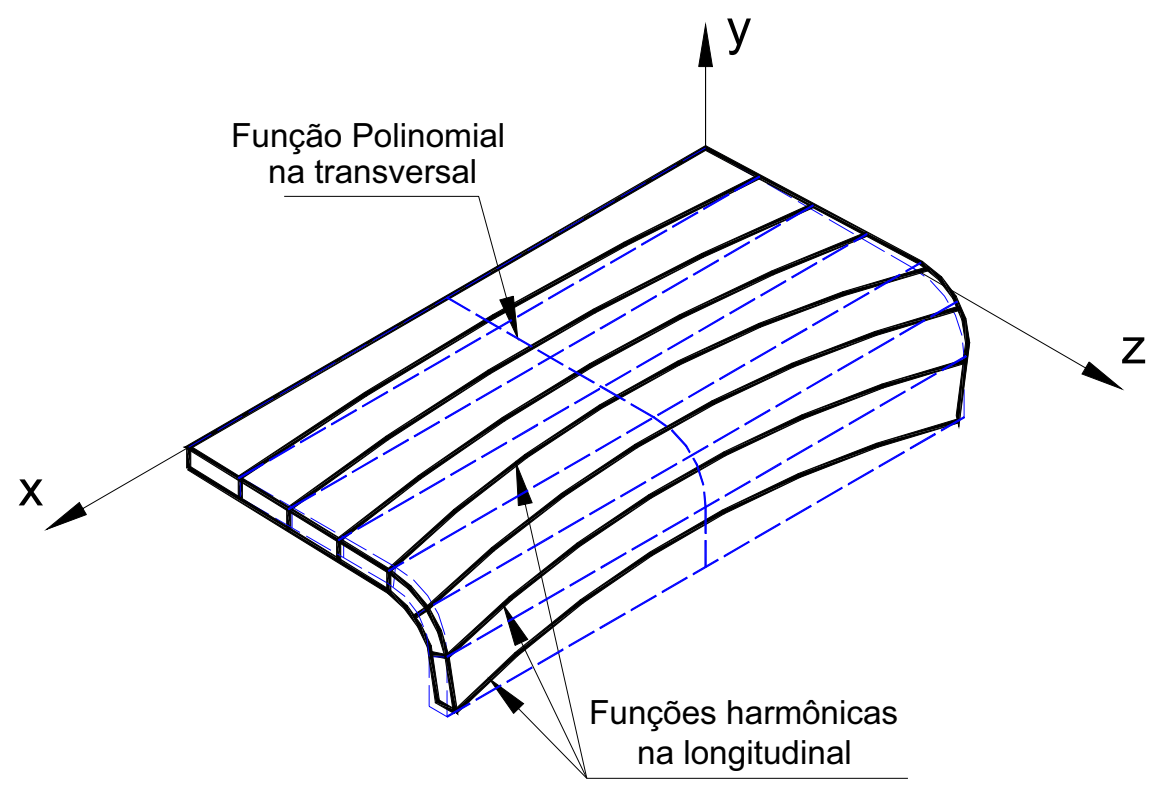

Figura 2.23 - Deslocamentos dos elementos da discretização via MFF. Fonte: Adapt. Baságlia (2004).

A equação para análise de flambagem linear elástica pode ser obtida pelo método da conservação de energia e que resulta em um problema de auto-valor, equação (2.55):

$\left(\left[K_{p}\right]+\left[K_{s}\right]-\lambda\left[K_{g}\right]\right)\{\delta\}=\{0\}$

Onde:

$\left[K_{p}\right]$ : matriz de rigidez da terça, onde o subíndice $p$ é relativo a purlins (terças);

$\left[K_{s}\right]$ : matriz de rigidez das molas, onde o subíndice $s$ é relativo a springs (molas);

$\left[K_{g}\right]$ : matriz de rigidez geométrica;

$\lambda$ : fator de proporcionalidade entre as tensões $\sigma$ e $\sigma_{0}$, onde $\sigma$ representa a tensão crítica de flambagem elástica, resultado de $\sigma=\lambda \sigma_{0}$, sendo $\sigma_{0}$ a tensão de referência utilizada;

$\{\delta\}$ : vetor de deslocamentos que descreve o modo de flambagem (auto-vetor).

A matriz de rigidez geométrica, $\left[K_{g}\right]$, trás indexado o valor das duas rigidezes de mola, translacional $\left(\mathrm{k}_{\mathrm{s}}\right)$ e rotacional $\left(\mathrm{k}_{\mathrm{r}}\right)$ onde os subíndices $s$ e $r$ são relativos respectivamente a shear e rotational, como mostradas na Figura 2.24. Vale ressaltar que as rigidezes das molas têm influência na distribuição e no valor das tensões atuantes (Figura 2.25). 


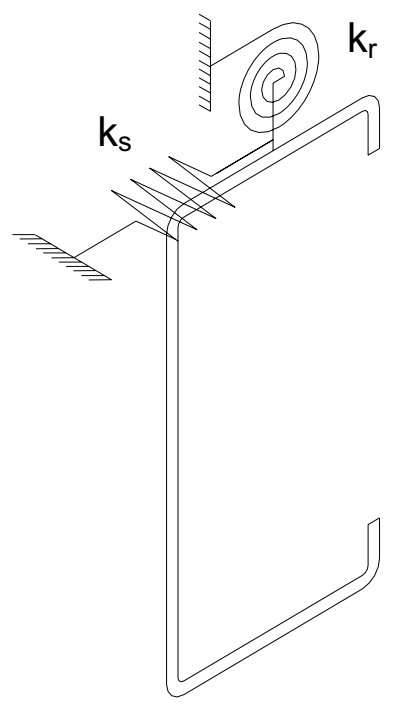

Figura 2.24 - Natureza das molas de restrição, segundo Ye et al. (2002).

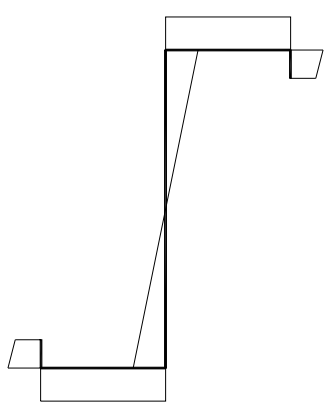

a) $k_{s}=k_{r}=\infty$

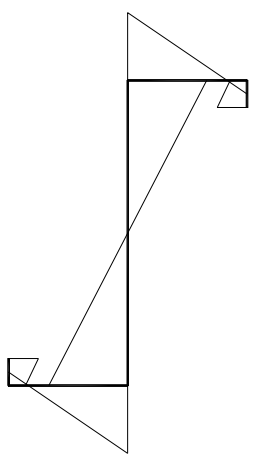

b) $k_{s}=0, k_{r}=\infty$

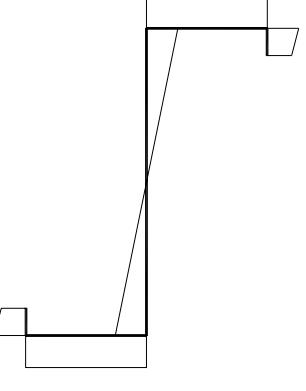

c) $k_{s}=\infty, k_{r}=0$

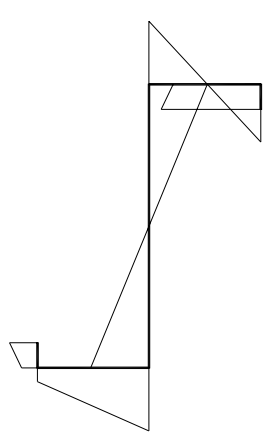

d) $k_{s}=0, k_{r}=0$

Figura 2.25 - Distribuição de tensões para diferentes rigidezes de mola (Molas posicionadas no centro da mesa superior, configuração para vão de cinco metros).

Ye et al. (2002) investigaram a influência das rigidezes de mola (Figura 2.26). Os resultados mostram que para flambagem local $k_{s}$ tem influência significante enquanto $k_{r}$ quase não apresenta influência. No entanto para flambagem lateral com torção $\mathrm{k}_{\mathrm{r}}$ apresenta maior influência que $\mathrm{k}_{\mathrm{s}}$. Para flambagem por distorção as influências são mistas e as rigidezes interferem uma nas outras. 


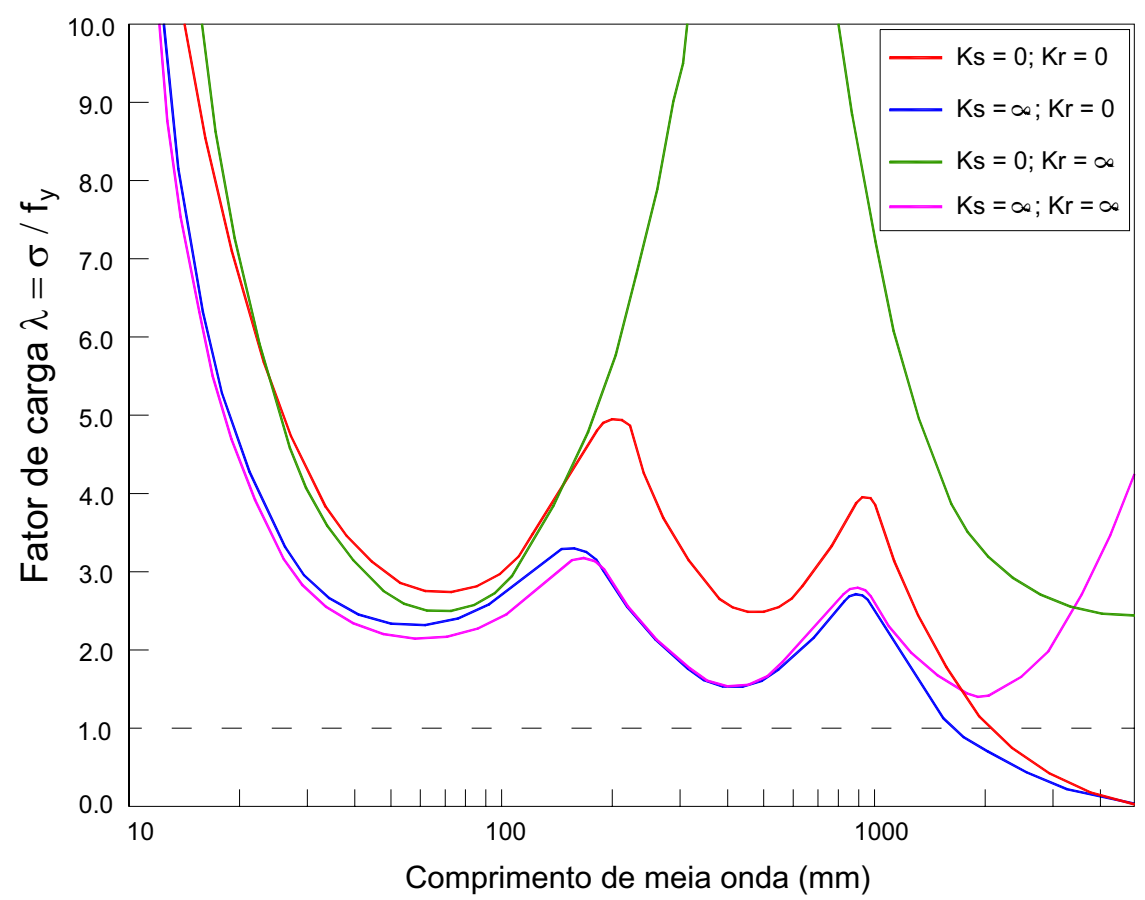

Figura 2.26 - Curva de flambagem do perfil $Z_{90}$ para valores extremos das rigidezes $k_{s}$ e $k_{r}$. Fonte: $Y e$ et al.(2002).

No entanto algumas observações devem ser feitas:

a) O programa só admite esforço constante ao longo da seção, assim sendo, deve-se considerar a ação variável do momento fletor na terça com a utilização do coeficiente de equivalência de momentos na flexão $\left(C_{b}\right)$;

b) Não é possível simular o efeito de travamentos intermediários, assim é necessário ajustar os resultados por meio da redução do comprimento de flambagem;

c) As rigidezes de mola a serem empregadas devem ser obtidas por meio de ensaios ou simulações e podem ser tabeladas para estudos posteriores;

d) A maior dificuldade consiste em determinar as tensões longitudinais de referência atuantes na seção transversal, este tópico é abordado detalhadamente no capítulo 5 . 


\subsection{Análise Numérica Via MEF}

O método dos elementos finitos (MEF) visa discretizar o domínio de integração, contínuo, em um número finito de elementos. Com isto, pode-se admitir funções contínuas que representem o campo de deslocamentos no domínio de um elemento e com isto determinar o estado de deformações, subseqüentemente, de posse das relações constitutivas dos materiais, pode-se definir o estado de tensões do elemento.

Lucas et al. (1997a,b), iniciaram os estudos dos modos de instabilidade dos sistemas terça-telha via MEF, propondo um modelo de análise não-linear. As suas publicações foram subdivididas em duas partes: uma baseada no modelo denominado completo e outra baseada no modelo simplificado.

Baságlia (2004) desenvolveu a análise numérica via MEF do sistema terça-telha empregando um modelo refinado de análise não-linear considerando também material elasto-plástico, porém utilizando elemento de contato entre a telha e a terça. $A$ seguir é comentado cada modelo.

\subsubsection{Modelo Completo, Lucas et al.(1997a)}

O modelo completo desenvolvido em Lucas et al. (1997a) utilizando o programa de elementos finitos ANSYS incorpora o sistema terça-telha discretizado por elementos de casca (Figura 2.27). O modelo visa representar a distorção da seção transversal da terça e as restrições de membrana e rotação impostas pela telha. Analisa-se a falha da seção transversal por instabilidade ou escoamento da seção.

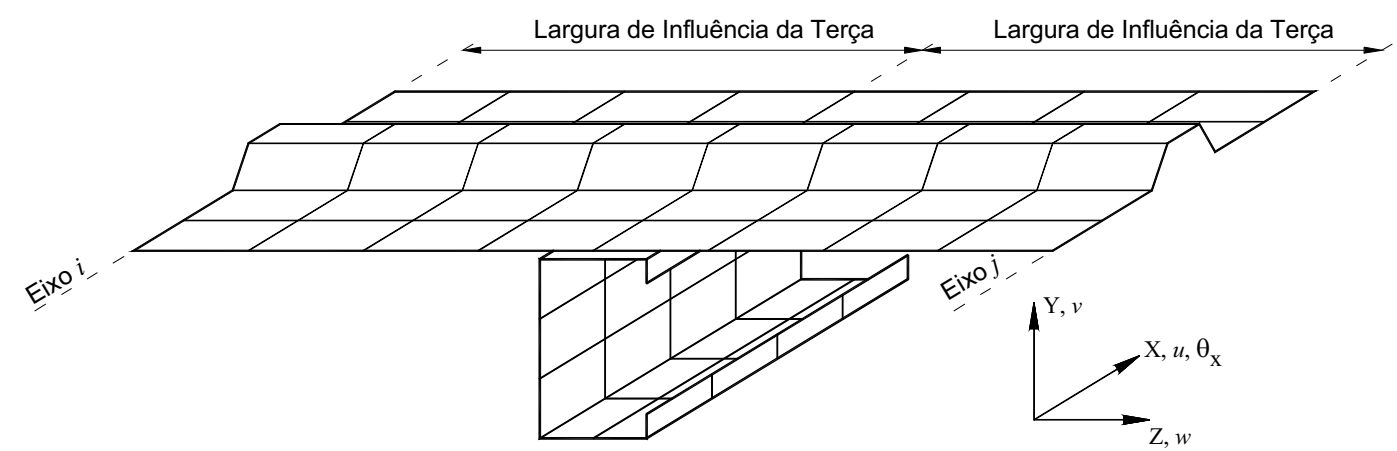

Figura 2.27 - Malha de Elementos utilizada por Lucas et al.(1997a). Fonte: Baságlia (2004).

Foram realizados modelos e ensaios de sistemas com um, dois e três vãos submetidos a carregamentos gravitacionais e de sucção e comparado com resultados 
experimentais desenvolvidos na Universidade de Sidney. Deve ser ressaltado novamente o fato de na Austrália ser utilizado o sistema de cobertura com fixação das telhas pela crista (onda alta) por meio de parafusos (Figura 2.28) diferentemente do Brasil, assim os modelos são fiéis aos padrões australianos.

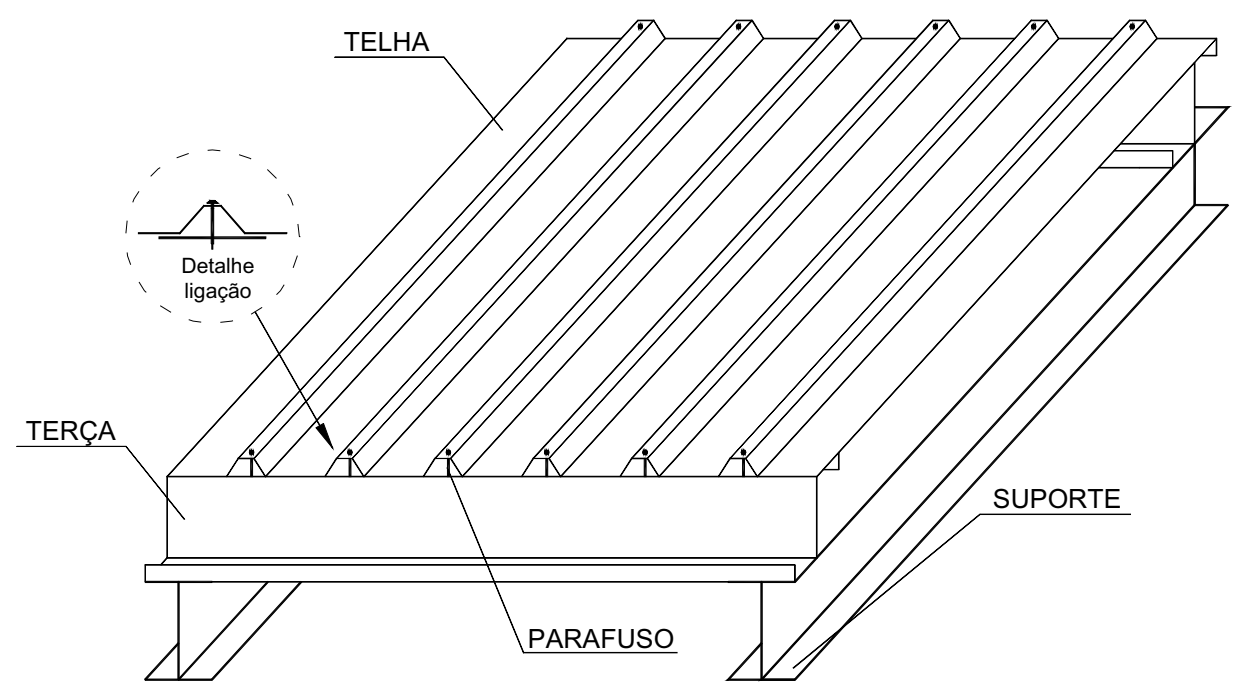

Figura 2.28 - Sistema de cobertura que utiliza pinos na conexão entre terças e telhas.

Fonte: Baságlia (2004).

Os ensaios de sucção mostraram a falha por escoamento na junção da mesa livre com a alma, no enrijecedor da mesa livre ou ao longo de toda a mesa livre. Já nos ensaios com cargas gravitacionais todos apresentaram falha local no final do traspasse entre terças. Em nenhum dos casos a flambagem por flexo-torção foi visivelmente determinante, confirmando o fato de segundo Lucas et al. (1997a) o modo local, distorcional e o escoamento serem os fenômenos preponderantes, entretanto, nos modelos, somente a plastificação da seção foi o fator limitante.

Lucas et al. (1997a) procuraram modelar com o acoplamento de deslocamentos e rotação entre nós o comportamento físico do sistema de terça-telha, Tabela 2-3, onde o contato foi reproduzido acoplando o nó da terça com o nó da telha que entrará em contato (Figura 2.29). 


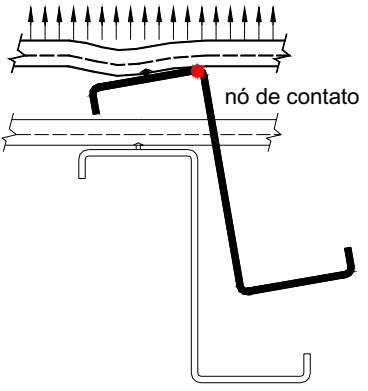

a) Perfil $Z_{90}$

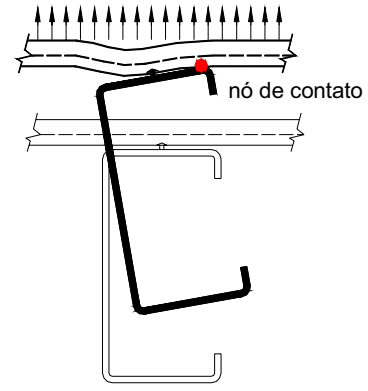

b) Perfil U enrijecido

Figura 2.29 - Configuração deformada de terças sujeita a carregamento de sucção.

Baseado na Figura 2.30 a Tabela 2-3 apresenta os acoplamentos nodais utilizados:

Tabela 2-3 - Acoplamentos nodais segundo Lucas et al.(1997a).

\begin{tabular}{|l|l|}
\hline \multicolumn{2}{|c|}{$\underline{\text { Seção: }} \mathrm{U}_{\mathrm{e}}$} \\
\hline Centro da mesa superior & $v_{p}=v_{s}, \theta_{p}=\theta_{s}, w_{p}=w_{s}+\theta_{s} d$ \\
\hline Junção da mesa com o enrijecedor & $v_{p}=v_{s}$ \\
\hline & $\underline{\text { Seção: }} \mathrm{Z}_{90}$ \\
\hline Centro da mesa superior & $v_{p}=v_{s}, w_{p}=w_{s}+\theta_{s} d$ \\
\hline Junção da mesa com a alma & $v_{p}=v_{s}$ \\
\hline
\end{tabular}

Onde:

$v_{p}, v_{s}:$ deslocamento vertical dos pontos $P$ e $S$ respectivamente;

$\theta_{p}, \theta_{s}:$ rotação da mesa superior e da telha respectivamente;

$w_{p}, w_{s}$ : deslocamento horizontal dos pontos $P$ e $S$ respectivamente;

$d$ : distância entre a mesa superior do perfil e a crista da telha. 


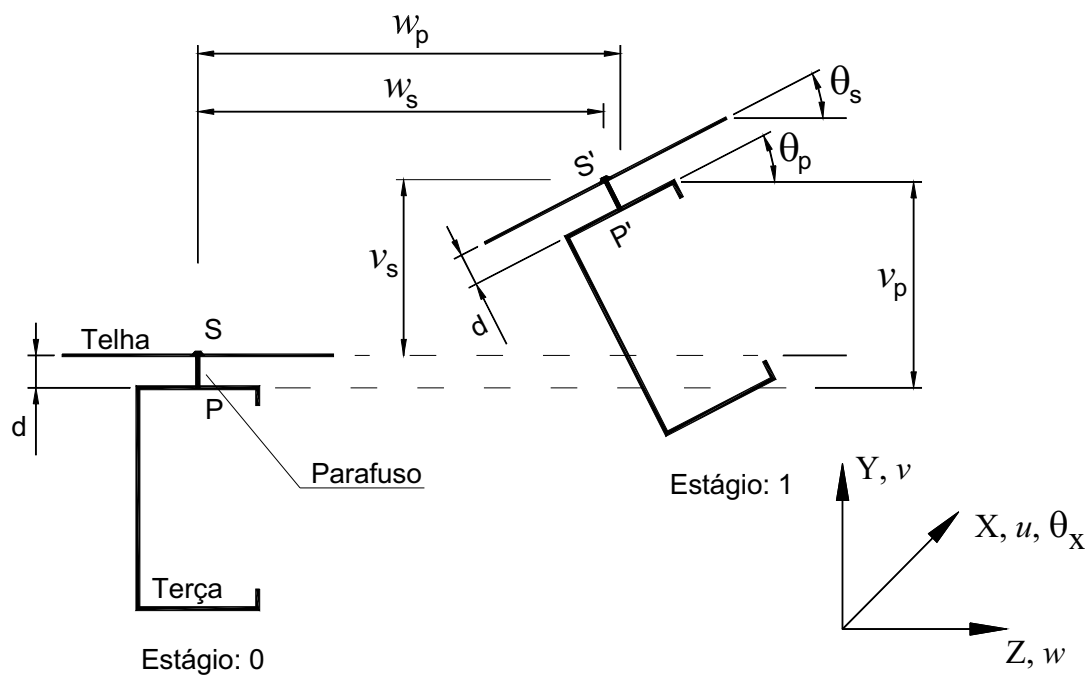

Figura 2.30 - Nomenclatura para restrições nodais segundo Lucas et al.(1997a).

Fonte: Baságlia (2004).

No entanto, como pode ser visto na Figura 2.31, a rotação da mesa superior do perfil ficou inibida pela presença da telha. Segundo Lucas et al. (1997a) este fato pode ser proveniente do deslocamento da mesa inferior ser relativamente muito maior que o da mesa superior. Baságlia (2004) utilizando uma análise mais refinada com elementos de contato entre a terça a telha encontrou maiores deslocamentos nesta região.

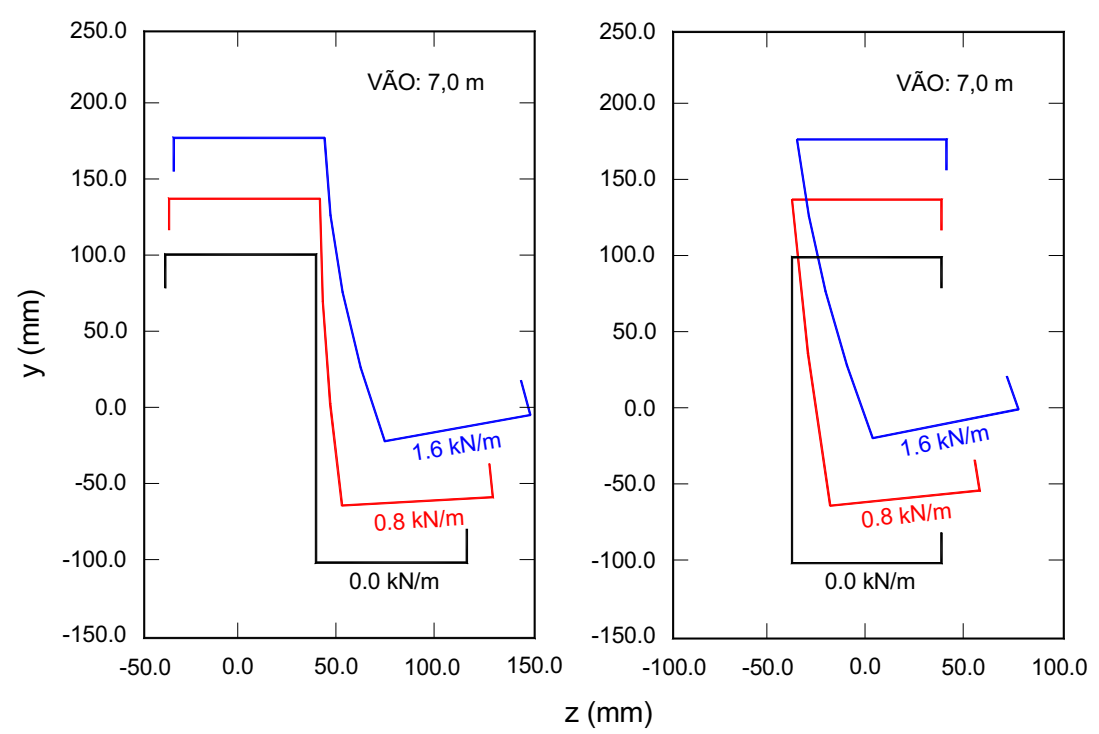

Figura 2.31 - Resultados obtidos por Lucas et al.(1997a). Fonte: Baságlia.(2004).

Lucas et al.(1997a) discretizaram o modelo de um telhado contínuo utilizando-se da simetria, assim o sistema terça-telha representa a respectiva largura de influência (Figura 2.32). Para simular o efeito da restrição imposta pela continuidade do sistema algumas condições de contorno foram empregadas, tais como: 
$v_{L, i}=v_{R, i}$

$w_{L, i}=w_{R, i}$

$\theta_{x, L, i}=\theta_{x, R, i}=0$

$\theta_{y, L, i}=\theta_{y, R, i}=0$

Onde $v$ representa deslocamento vertical, $w$ representa deslocamento horizontal, o subíndice $L$ representa à esquerda (Left) e $R$ à direita (Right) e $i$ representa os nós em que estarão dispostos na longitudinal (eixo x).

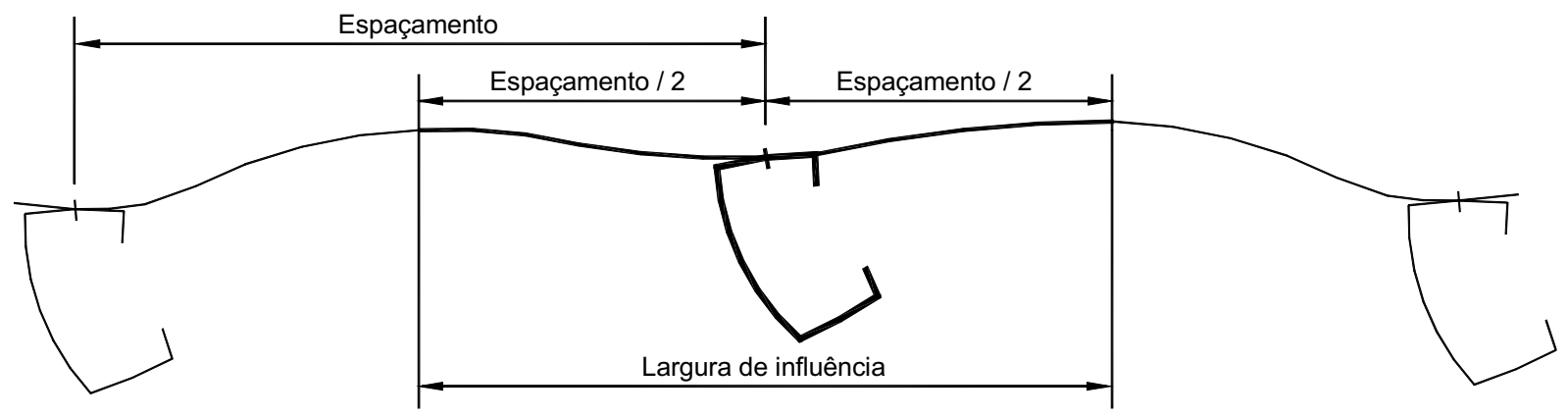

Figura 2.32 - Seção do sistema terça-telha. Fonte: Baságlia (2004).

\subsubsection{Modelo Simplificado, Lucas et al. (1997b)}

Lucas et al.(1997b) visando diminuir os esforços computacionais e o tempo de processamento, propuseram um modelo simplificado utilizando-se do sistema de molas que restringem as terças. O modelo não necessita de dados experimentais, no entanto, são necessários modelos para determinar a rigidez ao cisalhamento, $k_{r y}$, e à rigidez à rotação, $k_{r x}$ (Figura 2.33), impostas pela ligação e pela telha. 


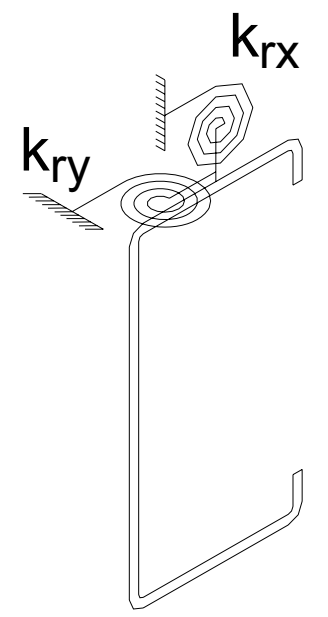

Figura 2.33 - Posicionamento e natureza das molas de restrição.

Pincus (1963) apud Lucas et al.(1997b) desenvolveu uma metodologia de ensaio para a determinação da rigidez ao cisalhamento, $k_{r y}$, Double Beam Shear Test (DBST), a qual foi utilizada para a determinação de $k_{r y}$, no entanto poderia também ser empregado um modelo em elementos finitos. A rigidez ao cisalhamento pode ser determinada segundo os resultados do ensaio (Figura 2.34) utilizando a formulação:

$k_{r y}=\frac{4}{\pi} \frac{M_{0}}{\Delta}-\frac{\pi^{2} E I_{y}}{L^{2}}$

Onde:

$M_{0}=P . l$, ou seja, o momento uniforme no trecho analisado;

$\Delta$ : deslocamento a meio vão;

$E$ : módulo de elasticidade;

$I_{y}:$ momento de inércia em relação ao eixo y;

$L$ : comprimento do trecho considerado. 


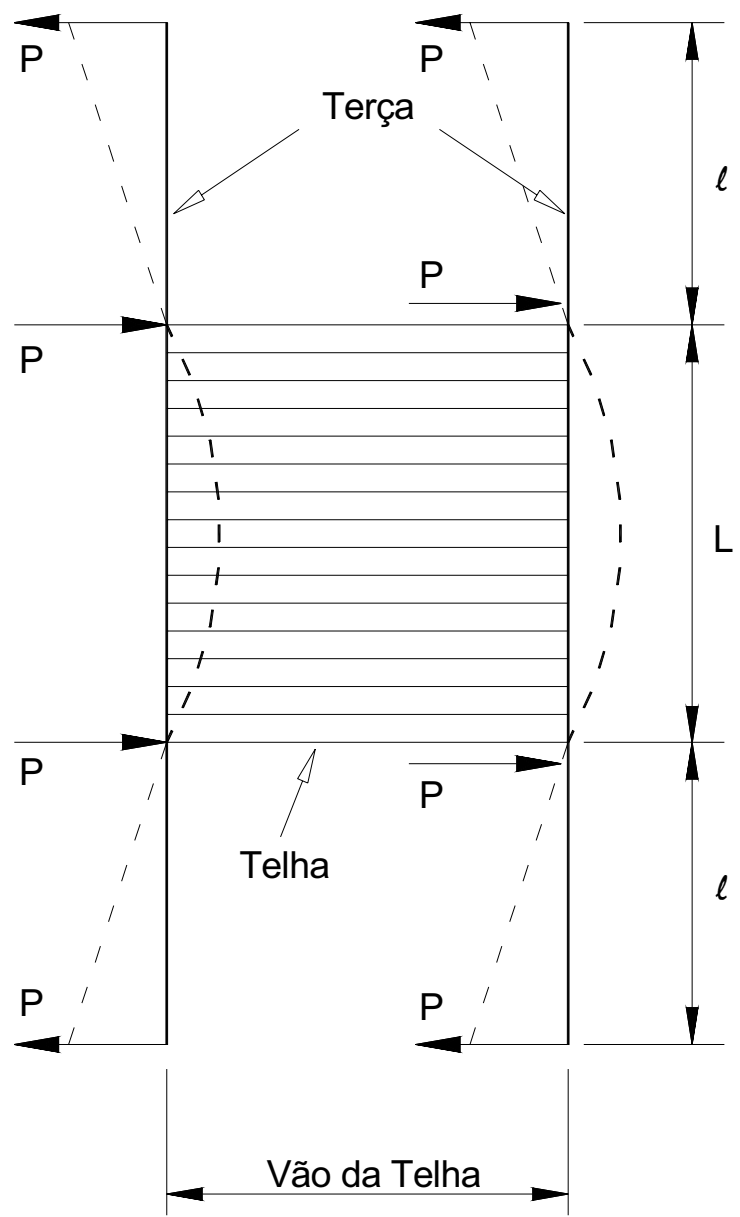

Figura 2.34 - Ensaio proposto por Pincus (Double beam shear test - DBST).

A partir dos resultados obtidos pode-se comprovar que a rigidez ao cisalhamento, $k_{r y}$, depende da seção transversal da telha e do espaçamento entre terças (vão da telha), sendo que quanto maior o vão e a rigidez da telha, maior a rigidez ao cisalhamento.

Foi constatado que a rigidez ao cisalhamento para os casos usuais variam de 300 a $1500 \mathrm{kN} / \mathrm{rad}$ e que as terças em perfil $Z_{90}$ e $U_{e}$ apresentaram sensibilidade desprezível a estes valores, desta forma, convencionou-se utilizar o valor de $1000 \mathrm{kN} / \mathrm{rad}$ para todos os modelos.

Segundo Lucas et al.(1997b) a rigidez à rotação, $k_{r x}$, varia de $200 \mathrm{~N} / \mathrm{rad}$ a $4000 \mathrm{~N} / \mathrm{rad}$ para os perfis de telhas comumente utilizados, e os perfis $U_{e}$ e $Z_{90}$ são sensíveis às alterações do valor da rigidez, portanto não poderá ser uniformizada como na rigidez ao cisalhamento.

A rigidez à rotação determinada pelo ensaio padronizado do AISI (1996) (Figura 2.18) é composta pela rigidez à distorção do perfil (rigidez à flexão da alma) mais a 
rigidez à rotação do conjunto (rigidez local da ligação e rigidez à flexão do painel), portanto, não é possível empregá-la no modelo simplificado como valor para o coeficiente de mola $\mathrm{k}_{\mathrm{rx}}$, já que é necessário o valor isolado da rigidez do conjunto.

Frente a este problema o ensaio do AISI (1996) foi modelado como no modelo completo, no entanto com a utilização de acoplamento de deslocamentos entre nós, de tal forma que a alma não apresentasse nenhuma distorção. Assim os resultados adquiridos puderam ser utilizados como valores para a rigidez à rotação $\left(k_{r x}\right)$ no modelo simplificado. O modelo desenvolvido é denominado Modelo de Restrição à Rotação (Rotational Restraint Model (RRM)).

A partir do modelo RRM a rigidez à rotação foi analisada segundo algumas variáveis: (i) vão da telha, (ii) terças $Z_{90}$ e $U_{e}$, (iii) perfil da telha e (iv) perfil da terça. O vão da telha influenciou em uma diferença de rigidezes de um por cento, considerada desprezível. Ao comparar as mesmas seções, porém no formato $Z_{90}$ ou $U_{e}$, a seção $Z_{90}$ apresentou sempre maior rigidez à rotação e as diferenças de rigidezes entre perfil de terça e telha empregados são consideráveis. Desta forma, foi necessário para cada combinação de perfil de telha e terça distintos determinar a rigidez à rotação.

O modelo simplificado apresentou ótima correlação com os ensaios em caixa de sucção, sendo que, o estado limite último no modelo simplificado deu-se essencialmente devido à plastificação na região próxima a junção da mesa inferior com a alma. No entanto, o deslocamento lateral no modelo simplificado apresentou-se mais sensível às alterações das restrições. Segundo Lucas et al.(1997b) as diferenças quanto ao deslocamento lateral podem ser decorrentes das imperfeições iniciais e das acomodações das conecções durante o carregamento.

\subsubsection{Modelo Desenvolvido por Baságlia (2004)}

Baságlia (2004) desenvolveu, via elementos finitos, o modelo do sistema terça-telha (Figura 2.35) considerando não-linearidade física, geométrica e a nãolinearidade do contato telha-terça. Para analisar o modelo estrutural foram escolhidos quatro tipos de elementos: (i) elemento de casca para discretizar a telha e a terça, (ii) elemento de barra para discretizar os tirantes, (iii) elemento de mola para simular as condições de apoio, (iv) elemento de contato para simular o contato da terça com a telha. 


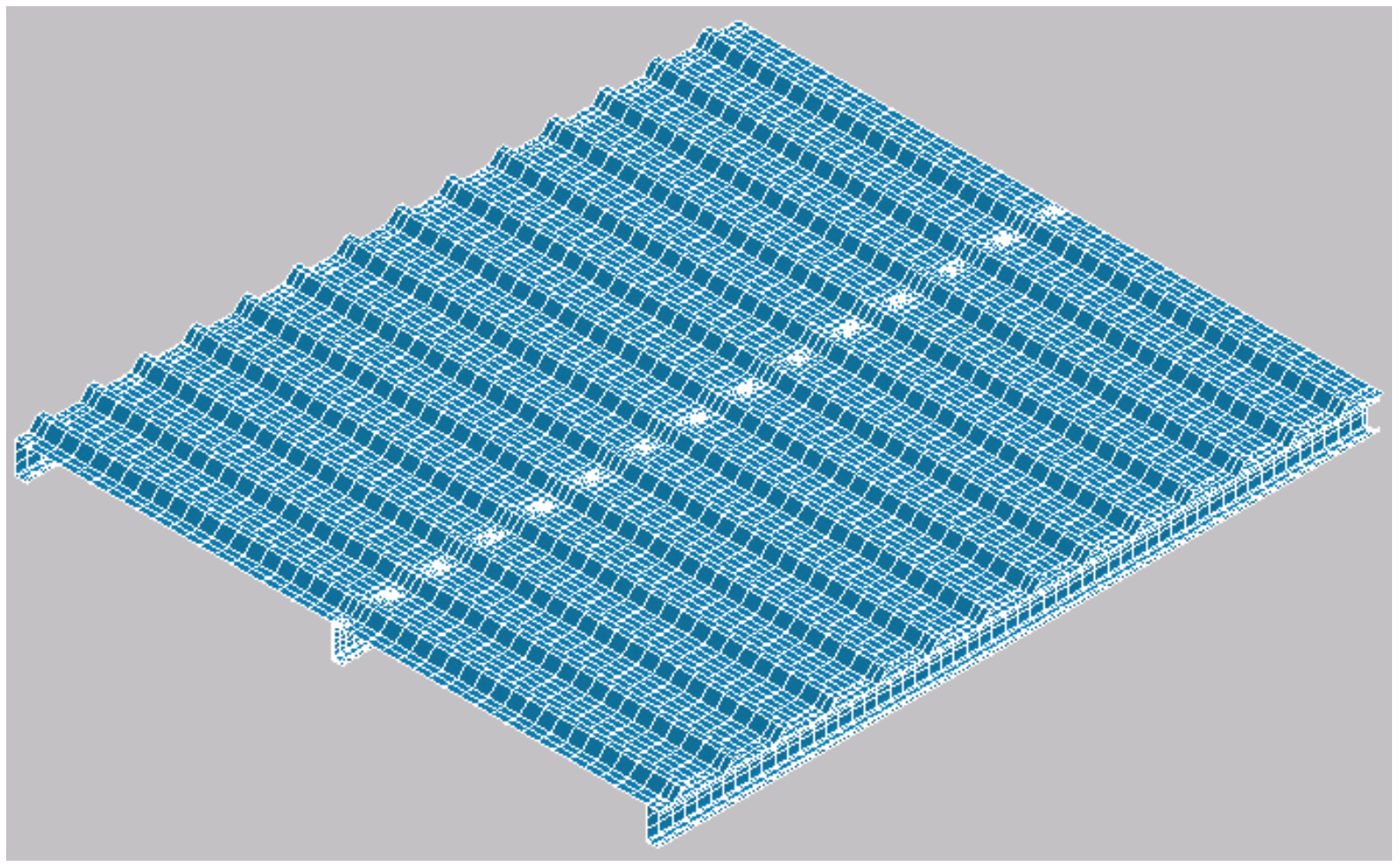

Figura 2.35 - Modelo idealizado por Baságlia (2004)

$O$ foco do trabalho foi o estudo de perfis $U_{e}$ e $Z_{90}$, sendo que foi analisado o comportamento estrutural, os modos de instabilidade, as deformações, deslocamentos e tensões. As variáveis consideradas no estudo foram a seção transversal do perfil, a presença de tirantes e o posicionamento dos tirantes. O modelo foi calibrado com os ensaios desenvolvidos em caixa de sucção por Javaroni (1999).

Os modelos apresentam espaçamento entre terças de 2,0 metros e vão de 6,80 metros, foi adotado o mesmo perfil de telha para todos os modelos e a telha é conectada em todas as ondas inferiores por parafusos auto-atarraxantes.

Algumas constatações foram explicitadas no decorrer da revisão bibliográfica, no entanto cabe ressaltar a análise efetuada do comportamento estrutural das terças com a presença de tirantes.

Para a constatação da eficiência dos tirantes é apresentada a Figura 2.36. Os dados provem da análise do perfil $U_{e} 250 \times 85 \times 25 \times 1,50$ e foram analisados casos sem correntes (U2-A0), casos com as linhas de corrente posicionadas a meia altura da alma, com uma ou duas linhas de corrente (respectivamente U2-A1meio e U2-A2meio) e uma ou duas linhas de corrente posicionadas na metade do terço inferior da altura da alma (respectivamente U2-A1inf e U2-A2inf). 

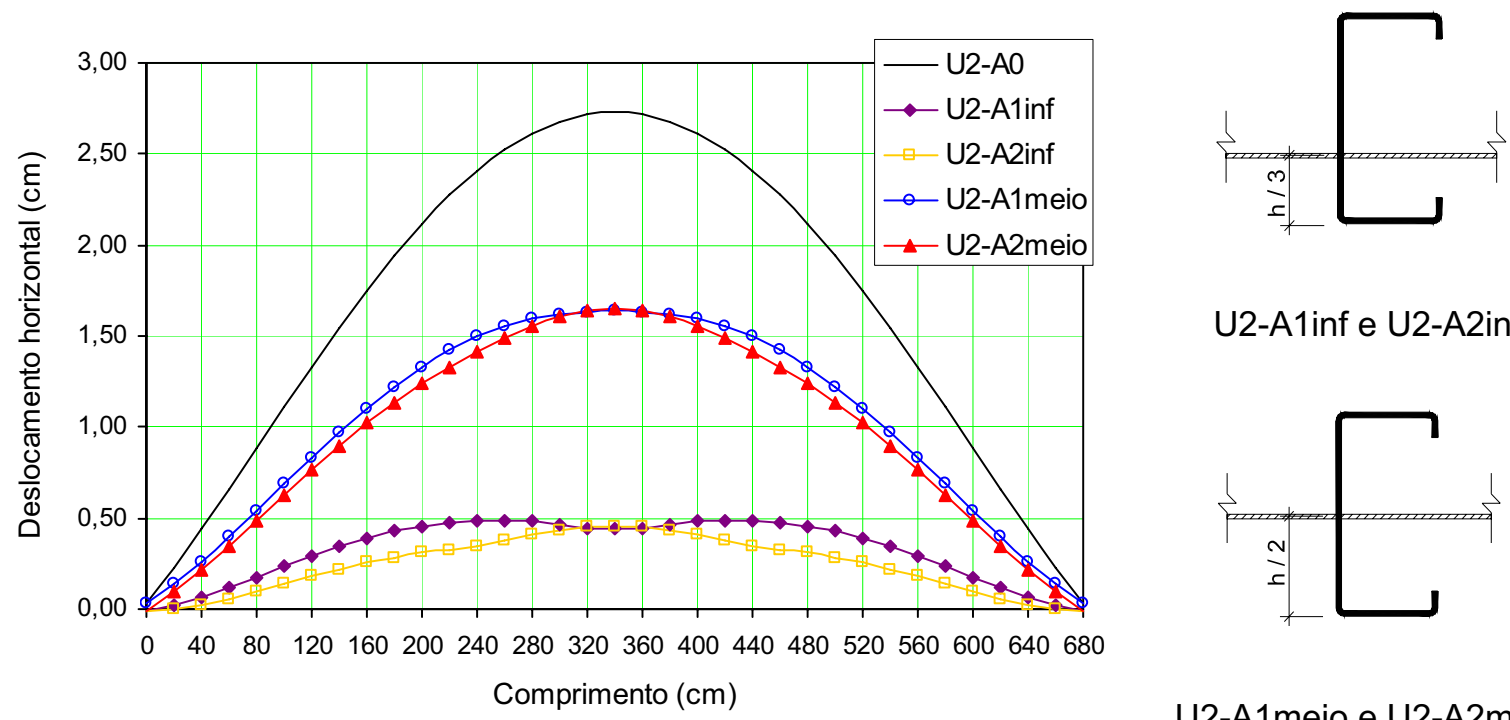

U2-A1inf e U2-A2inf

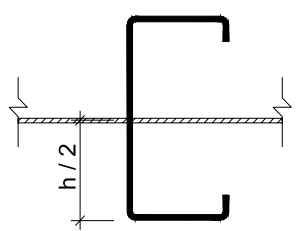

U2-A1meio e U2-A2meio

Figura 2.36 - Deslocamentos ao longo do comprimento da terça medido na junção alma e mesa inferior. Fonte: Adapt. Baságlia (2004).

A partir do gráfico é possível verificar que a presença dos tirantes diminui significativamente os deslocamentos horizontais. A presença de uma linha de corrente na metade do terço inferior é mais eficiente que duas linhas posicionadas a meia altura da alma. Nota-se que há pouca diferença na restrição provocada por uma ou duas linhas de corrente se forem posicionadas na mesma altura.

A Figura 2.37 mostra que o posicionamento do tirante na parte inferior da alma além de atenuar a rotação da seção transversal, diminui os efeitos da distorção lateral. Segundo Baságlia (2004) os tirantes além de restringirem os deslocamentos promovem um ganho de resistência.

a1

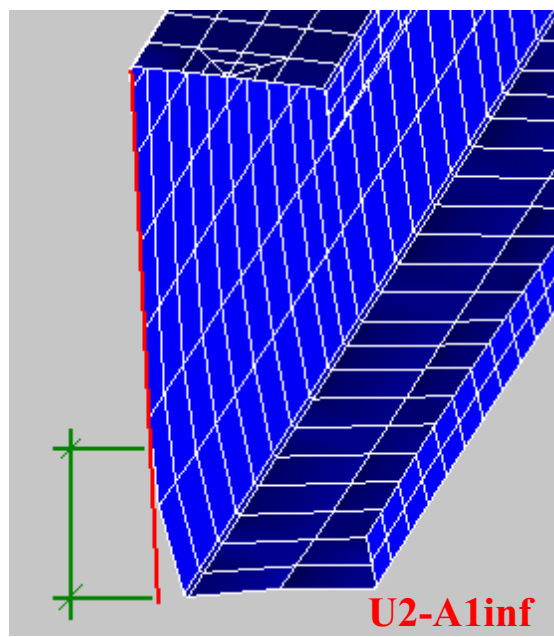

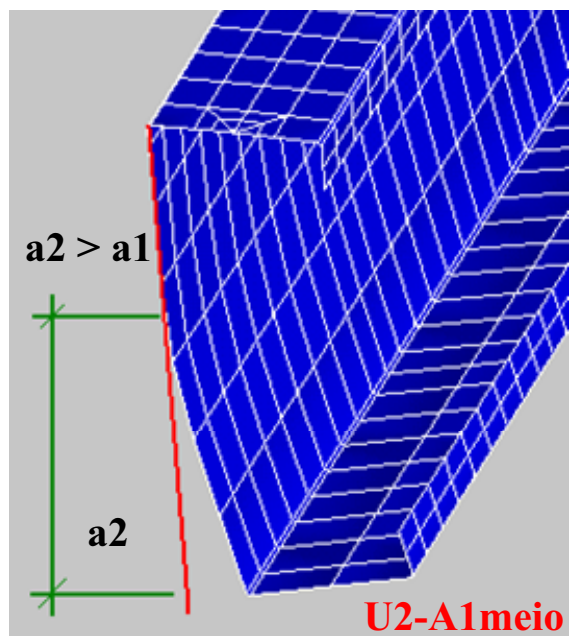

U2-A1meio

Figura 2.37 - Comparação entre a configuração deformada da terça variando o posicionamento do tirante. Fonte: Baságlia (2004) 


\section{MODELAGEM NUMÉRICA}

Os modelos numéricos foram desenvolvidos no programa ANSYS, via MEF, tendo por base a modelagem feita por Baságlia (2004) e calibrado com os resultados dos ensaios em caixa de sucção realizados por Javaroni (1999).

\subsection{Elementos Finitos Utilizados}

Para a representação dos ensaios foram utilizados quatro elementos que podem ser encontrados na biblioteca interna do ANSYS. Foi utilizado um elemento de casca denominado SHELL181, dois elementos de contato denominados TARGE170 e CONTA173 e um elemento de mola denominado COMBIN39. Os elementos serão apresentados a seguir:

\subsubsection{Elemento de Casca}

Foi utilizado para a modelagem da telha e terça o elemento de casca SHELL181 (Figura 3.1) que segundo as informações dadas pela biblioteca interna do ANSYS, é ideal para análise não-linear de cascas de pequena espessura sujeitas a grandes deformações e rotações.

O elemento possui quatro nós com seis graus de liberdade por nó, translação na direção dos eixos $x$, y e z e rotação em torno dos mesmos eixos. O elemento permite a utilização de materiais não-lineares. 


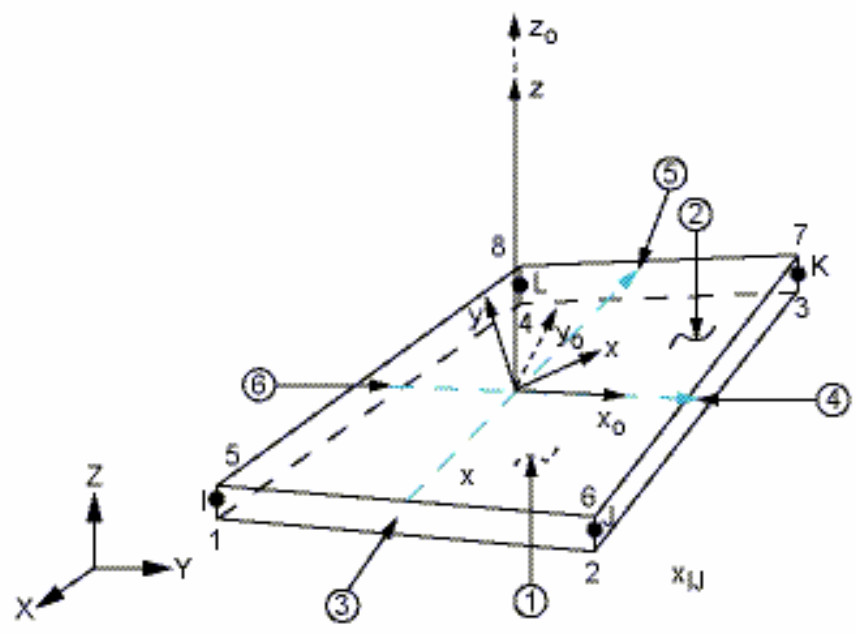

Figura 3.1 - Elemento finito SHELL181. (Fonte: Documentação do ANSYS)

\subsubsection{Elementos de Contato, TARGE170 e CONTA173}

São utilizados para representar o contato entre a terça e telha, ou seja, o contato entre dois elementos de casca. Os elementos de contato (Figura 3.2) podem ser utilizados em análises tridimensionais e simulam a pressão de contato entre a terça e a telha e permitem ao mesmo tempo o desprendimento dos mesmos, também consideram o atrito entre os dois elementos, apesar de pouco alterar os resultados para os casos analisados.

Nas análises numéricas realizadas o elemento TARGE170 que representa a superfície alvo (target), foi associado à crista inferior da telha enquanto o elemento CONTA173 foi associado à mesa superior do perfil.

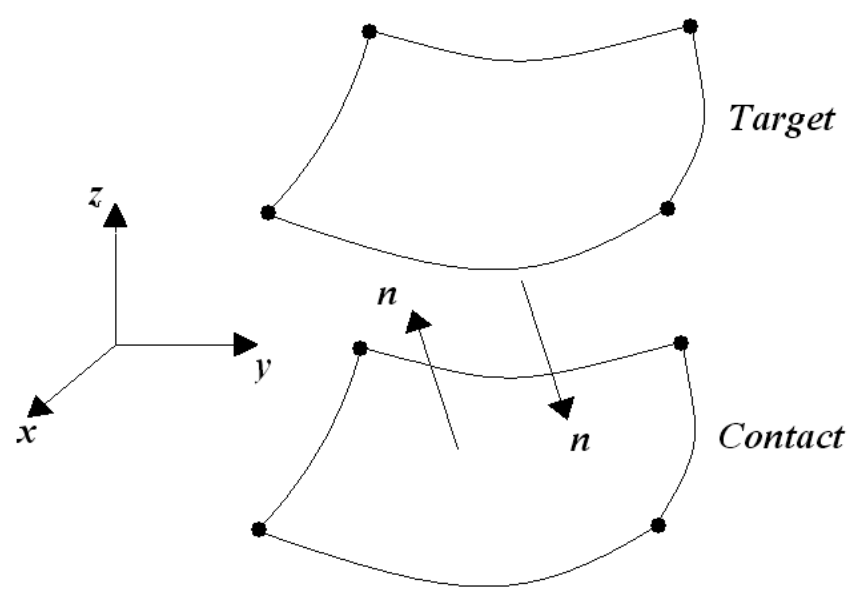

Figura 3.2 - Elementos finitos CONTA173 e TARGE170. (Fonte: Kotinda (2006)) 


\subsubsection{Elemento de Mola, COMBIN39}

O elemento de mola unidirecional COMBIN39 (Figura 3.3) possui dois nós ( $\underline{l}$ e $\underline{J}$ ) e possibilita a entrada de curvas força-deslocamento ou momento-rotação não-linear. Ao ser habilitada a curva força-deslocamento cada nó possui três graus de liberdade, sendo os deslocamentos na direção dos eixos x, y e z. Ao se habilitar a curva momento-rotação, cada nó também possui três graus de liberdade, no entanto são relativos à rotação em torno dos eixos $x, y$ e $z$.

O elemento de mola foi utilizado para simular a restrição dada pela cantoneira de apoio, item 3.3.1 (Figura 3.12 e Figura 3.13), e para simular a atuação da telha nos modelos em que a telha foi substituída por um conjunto de molas, item 3.3.4 (Figura 3.20 e Figura 3.21).

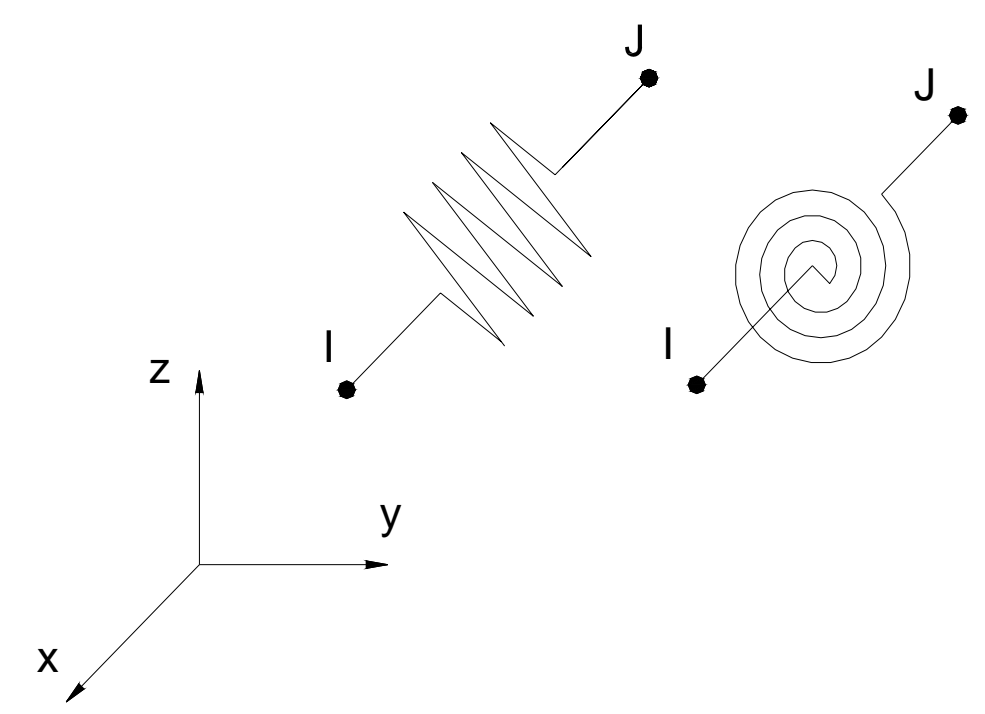

Figura 3.3 - Elemento finito COMBIN39, mola de rotação ou translação.

\subsection{Critérios Utilizados Para a Análise Não-Linear}

A resposta não-linear foi analisada admitindo-se o comportamento nãolinear da estrutura (geométrico), do material e do contato, os quais são descritos a seguir.

\subsubsection{Não-Linearidade do Contato}

A não-linearidade do contato deve-se ao fato de que ao contato ser 
solicitado à tração nenhum esforço é acrescentado ao conjunto terça-telha, porém ao ser solicitado à compressão, gera-se uma pressão no contato entre a terça e a telha.

Foram utilizados para definir o contato todos os valores pré-definidos no ANSYS, somente foi alterado o coeficiente de atrito entre as duas superfícies para 0,3. A norma NBR 8800:1986 define em seu corpo que o coeficiente de atrito entre superfícies zincadas é superior a 0,28, portanto, convencionou-se utilizar o valor 0,3.

\subsubsection{Não-Linearidade do Material}

Para a terça e a telha foi adotado o modelo constitutivo elasto-plástico multilinear com encruamento isótropo e critério de plastifificação de von Mises. A Figura 3.4 mostra a correlação existente entre o comportamento elasto-plástico com encruamento de aço trabalhado a frio (sem patamar de escoamento) e o modelo trilinear adotado.

A curva tensão-deformação limitou-se a três ramos como mostrado na Figura 3.4b, o primeiro tramo trata-se de um modelo elástico-linear considerando o módulo de elasticidade do aço $(E)$ até a tensão de proporcionalidade $\left(f_{p}\right)$ que equivale a $70 \%$ da tensão de escoamento, o segundo tramo segue retilíneo até o ponto referente à resisência ao escoamento $\left(f_{y}\right)$ e a deformação de $0,5 \%$, e, finalmente, segue retilíneo até o ponto equivalente à resistência à ruptura $\left(f_{u}\right)$ e deformação de $20 \%$.

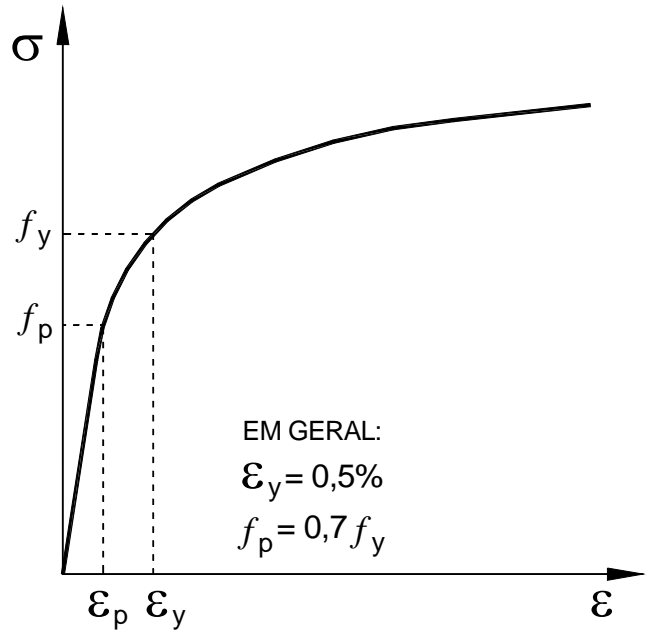

a) Comportamento elasto plástico com encruamento

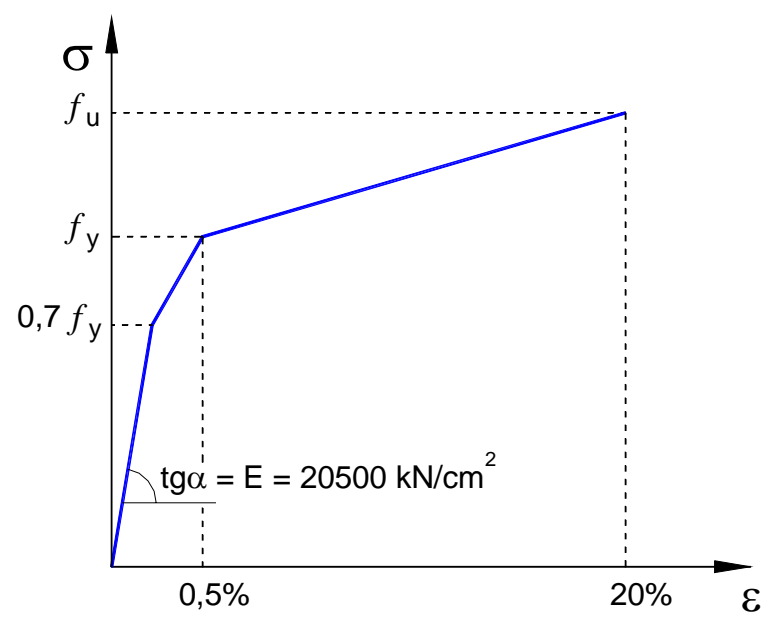

b)Modelo constitutivo trilinear

Figura 3.4 - Modelos Constitutivos (Fonte: Baságlia (2004)). 


\subsubsection{Não-Linearidade Geométrica}

Para a resolução do sistema não-linear foi utilizado o método iterativo e incremental Newton-Raphson Completo ("Newton-Raphson Full") que atualiza a matriz de rigidez tangente a cada iteração. Foi utilizada também em conjunto a ferramenta "Stress Stiffness". É importante salientar que em alguns modelos que apresentavam dificuldade de convergência foi utilizado na solução do sistema o método de Newton-Raphson Completo Assimétrico ("Full Newton-Raphson Unsymmetric").

O carregamento foi aplicado de forma incremental utilizando-se da ferramenta do ANSYS conhecida como "Automatic Load Stepping". Esta ferramenta faz com que o programa atualize automaticamente o incremento de força a ser acrescido. Segundo o manual do ANSYS, o incremento de força é diminuído se o número de iterações ultrapassarem o limite estabelecido pelo usuário (adotado 25), se ocorrer deslocamentos excessivos ou se o incremento de deformações plásticas ultrapassar 15\%.

Foi utilizado o critério de convergência em termos de deslocamentos. O critério de convergência verifica se a solução obtida possui a precisão julgada suficiente. Segundo Lourenço (1999), o critério de convergência em termos de deslocamentos é dado por $\|\underline{\delta u}\|<\beta\|\underline{u}\|$ em que $\underline{\delta u}$ são as correções iterativas dos deslocamentos, $\underline{u}$ são os deslocamentos totais e $\beta$ é a tolerância ou erro máximo admitido. No presente trabalho foi adotada basicamente como tolerância $(\beta)$ o valor $10^{-3}$. Em alguns casos foi necessário, para que houvesse a convergência dos modelos, reduzir este valor.

Esta alteração foi em todos os casos sempre seguida de cuidadosa avaliação, em modelos mais rígidos foi identificado ser desprezível a influência desta alteração, no entanto foi necessária uma avaliação mais cuidadosa em modelos mais flexíveis, como ilustrado na figura 3.5 pela simulação do perfil $U_{e} 200 \times 75 \times 20 \times 2$, vão de $7182 \mathrm{~mm}$, telha de $25 \mathrm{~mm}$ de altura e espessura de $0,43 \mathrm{~mm}$. 


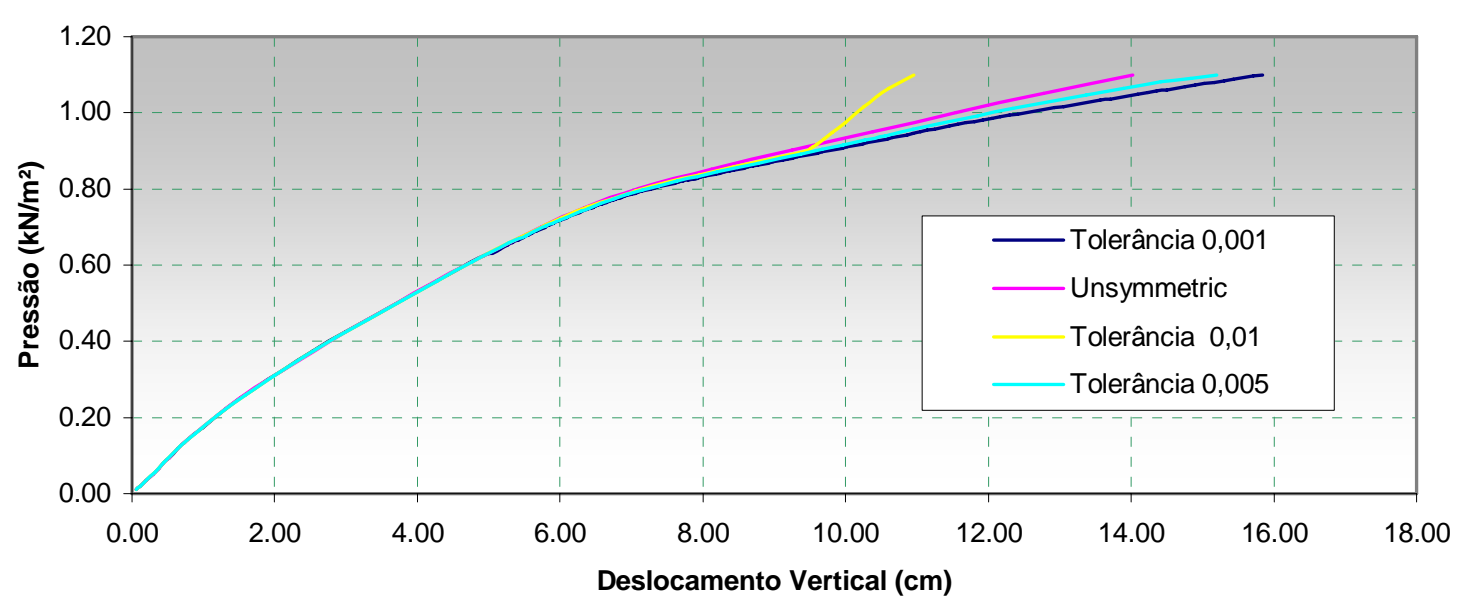

Figura 3.5 - Gráfico pressão x deslocamento vertical, alterando as ferramentas utilizadas.

A figura 3.5 mostra que utilizando o critério de convergência igual a 0,001 e 0,005 e a ferramenta de montagem da matriz considerando-a assimétrica, as diferenças são desconsideráveis, no entanto, ao aumentar a tolerância em deslocamentos para 0,01, por volta de $0,90 \mathrm{kN} / \mathrm{m}^{2}$ os resultados já não são mais confiáveis.

Visando melhorar a convergência do modelo foi utilizada a ferramenta "Line-Search", pois segundo Lourenço (1999) os processos incrementais-iterativos apresentam a limitação de serem convergentes para alguma solução do sistema de equações não-lineares a partir de praticamente qualquer solução inicial, assim utiliza-se a ferramenta "Line-Search" para atingir a estimativa de uma solução exterior ao raio de convergência do método Newton-Raphson. O método consiste em multiplicar o vetor de incremento de deslocamentos por um fator determinado pela minimização da energia do sistema.

\subsection{Condições de Contorno}

Os estudos se concentraram em torno de quatro modelos. O primeiro modelo possui grande similaridade com o modelo desenvolvido por Baságlia (2004) a não ser pelo fato da utilização de mais dois eixos de simetria. O segundo modelo foi baseado no trabalho de Lucas (1997a) que, diferentemente do de Baságlia (2004), não utiliza elementos de contato. O terceiro modelo baseado no artigo de Lucas (1997b) visa adquirir a rigidez à rotação imposta pela telha ao conjunto, modelo intitulado de "Rotational Restraint (RR) 
Model" e finalmente o último modelo é o modelo em que é simulada somente a terça que fica restrita por elementos de mola. A seguir são apresentados os modelos atentando-se as condições de contorno impostas.

\subsubsection{Modelo Proposto 1}

Baságlia (2004) adotou em suas simulações modelo idêntico ao ensaio de sucção realizado por Javaroni (1999), utilizando-se apenas de um eixo de simetria situado a meio vão (Figura 3.6).

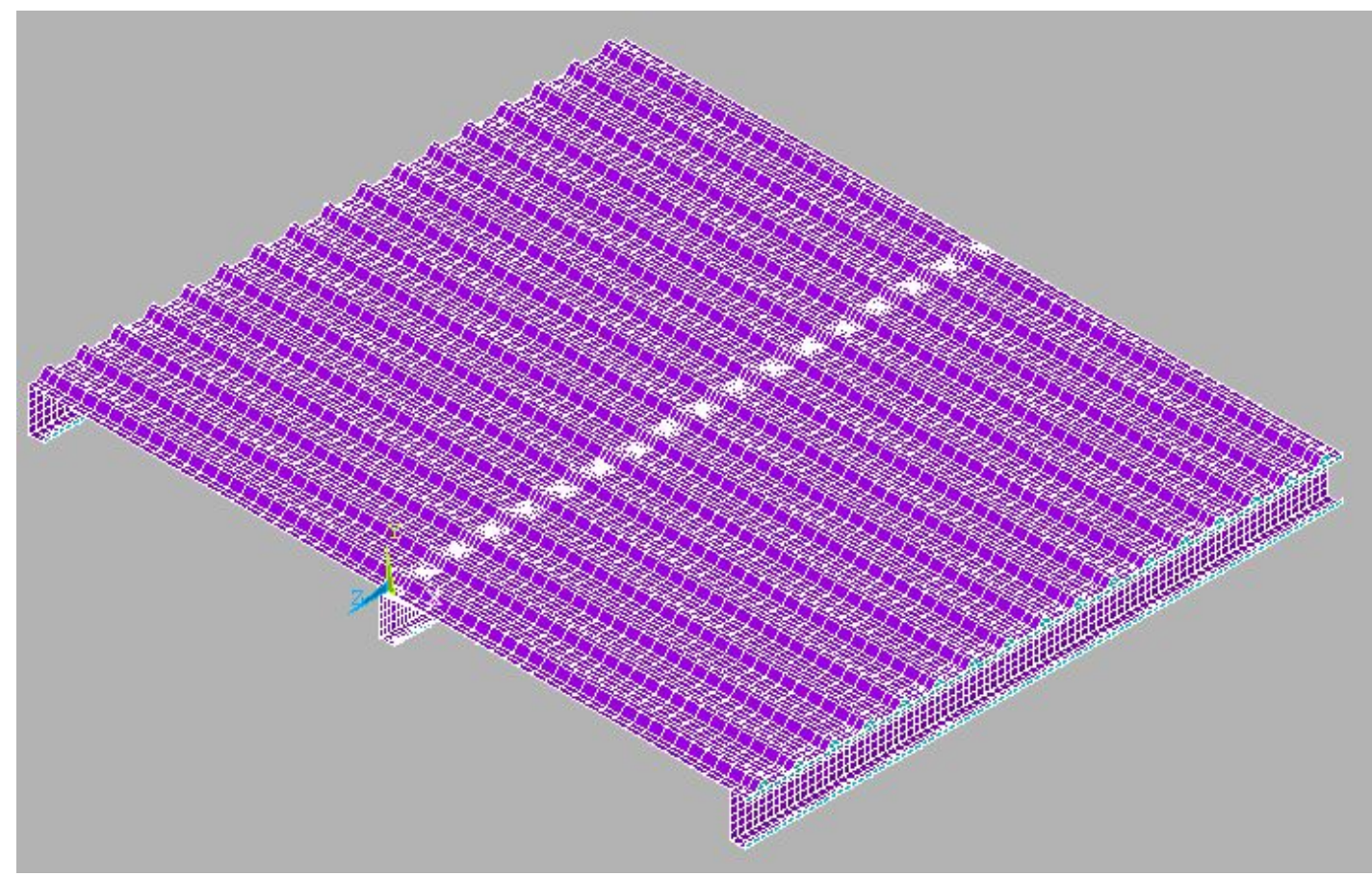

Figura 3.6 - Modelo utilizado para a simulação do ensaio de sucção adotado por Baságlia (2004).

(Fonte: Baságlia (2004)).

Como Baságlia (2004) verificou que as reações verticais das terças das extremidades variam de $45 \%$ a $55 \%$ do valor da reação vertical no apoio da terça intermediária, optou-se, no presente trabalho, por simular somente a terça intermediária e a telha contida na largura de influência e utilizar dois eixos de simetria localizados no meio do espaçamento entre terças (Figura 3.7). 


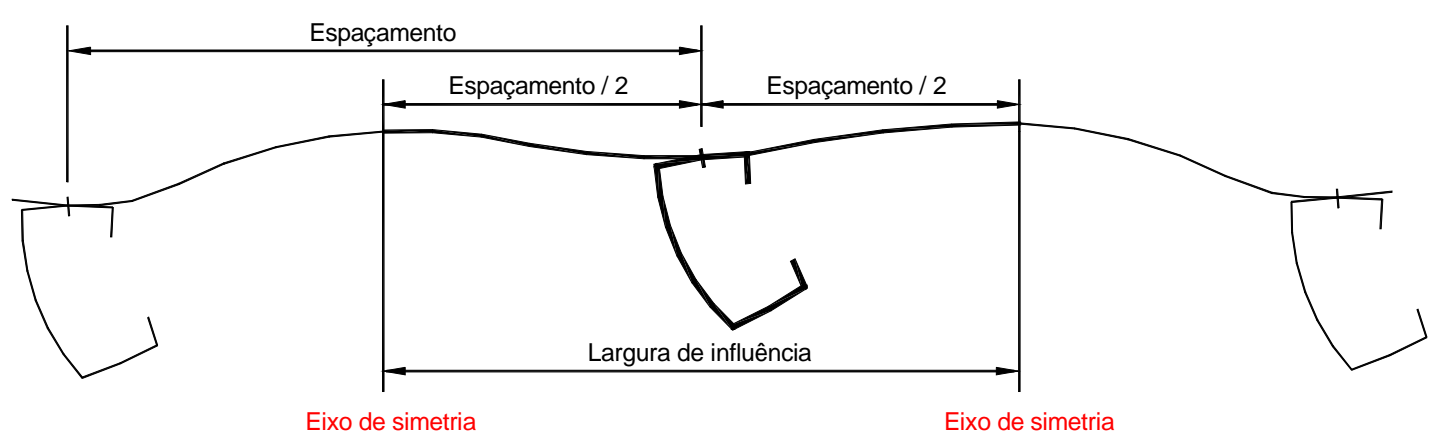

Figura 3.7 - Largura de Influência da Terça. (Fonte: Adapt. Baságlia (2004).

O modelo proposto é apresentado na Figura 3.8. O eixo de simetria na seção a meio vão da terça restringe segundo o eixo apresentado na figura o deslocamento na direção do eixo $z$ e as rotações em torno de $x$ e y $\left(u_{z}=\phi_{x}=\phi_{y}=0\right)$, já o eixo de simetria simulando a continuidade da telha restringe os deslocamentos na direção do eixo $\mathrm{x}$ e as rotações em torno dos eixos y e z $\left(u_{x}=\phi_{y}=\phi_{z}=0\right)$.

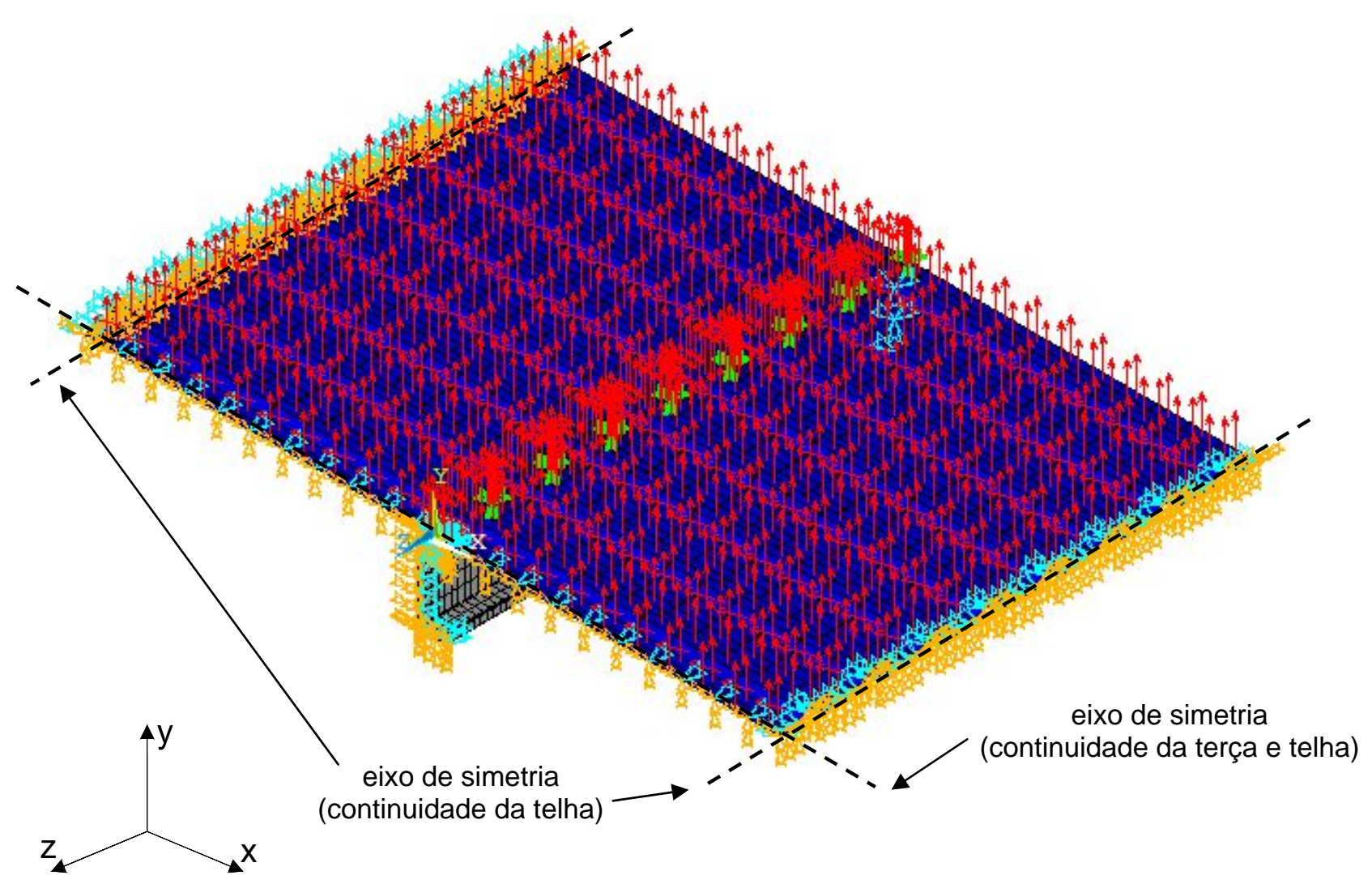

Figura 3.8 - Modelo proposto.

A união entre telha e terça é comumente dada a partir do uso de 
parafusos auto-atarraxantes como mostrado na Figura 3.9, onde a parte inferior da telha é conectada à mesa superior do perfil.

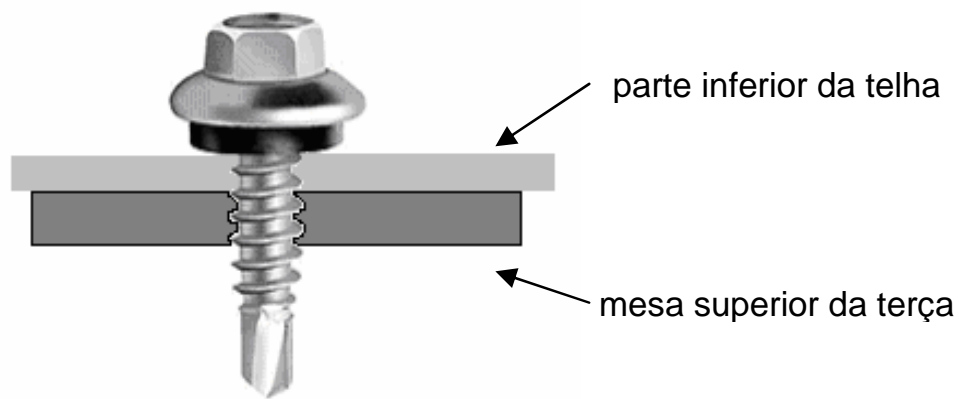

Figura 3.9 - Detalhe da ligação telha-terça com parafuso auto-atarraxante. (Fonte: Baságlia (2004)).

A partir deste detalhamento optou-se por acoplar os deslocamentos dos nós que delimitam a projeção do diâmetro do fuste do parafuso (Figura 3.10). Para simular esta ligação, a malha do modelo é recortada por um círculo com mesmo diâmetro do fuste do parafuso tanto no centro da parte inferior da telha quanto na mesa superior do perfil, e o perímetro de cada quadrante do círculo também foi dividido ao meio, resultando em nove nós a serem acoplados. Desta forma, a geometria da malha segue a recomendação do manual do ANSYS de sempre manter quatro nós para o elemento SHELL181.

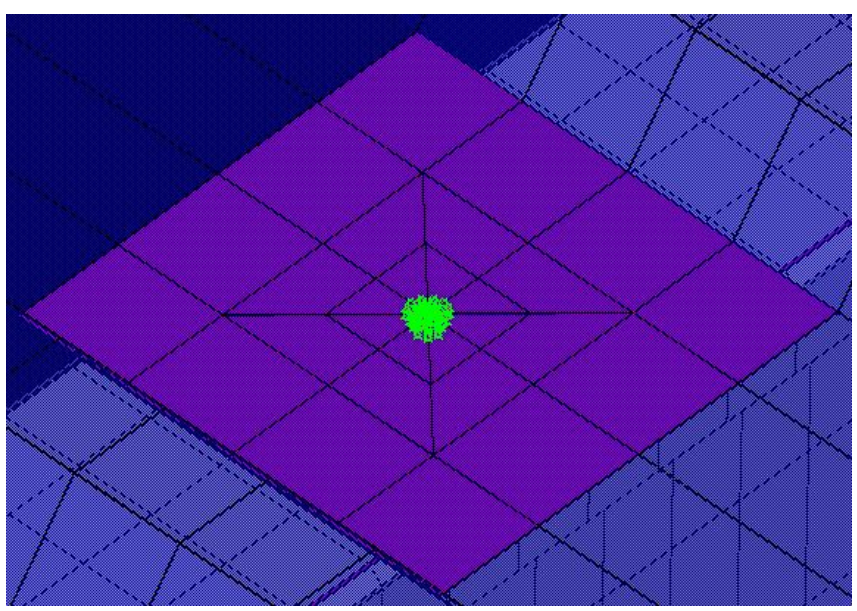

a) Localização da ligação terça-telha

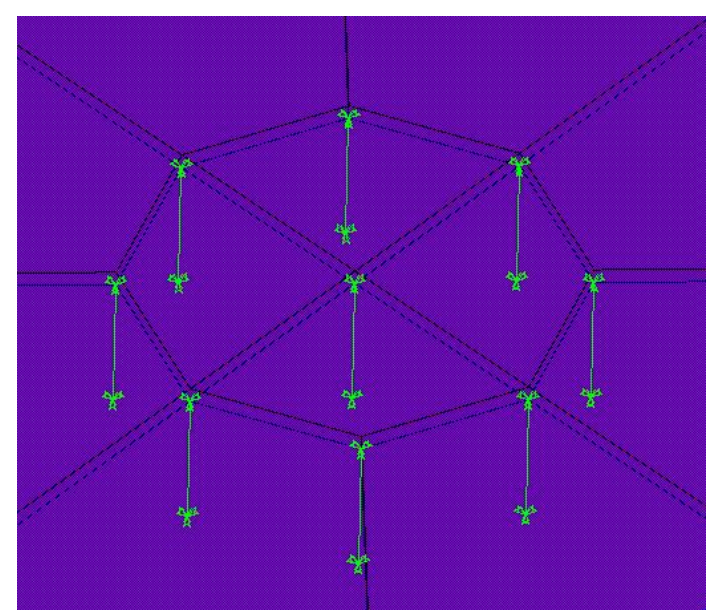

b) Detalhamento dos nós acoplados

Figura 3.10 - Modelagem do detalhamento da ligação terça-telha.

Os elementos de contato foram dispostos ao longo de toda a mesa superior do perfil mais as dobras (elemento CONTA173) e na parte inferior da telha (TARGE170) como mostrados na Figura 3.11. 


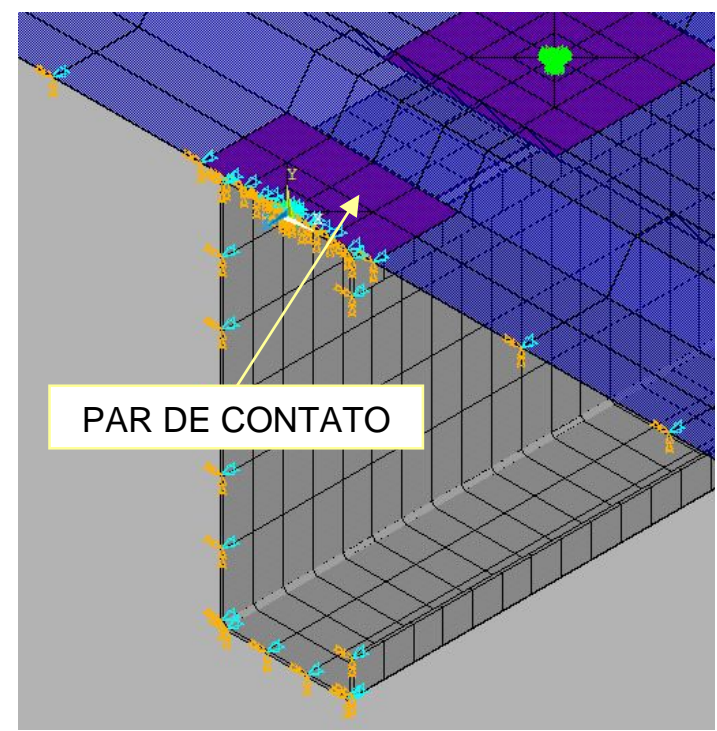

a) Localização do par de contato

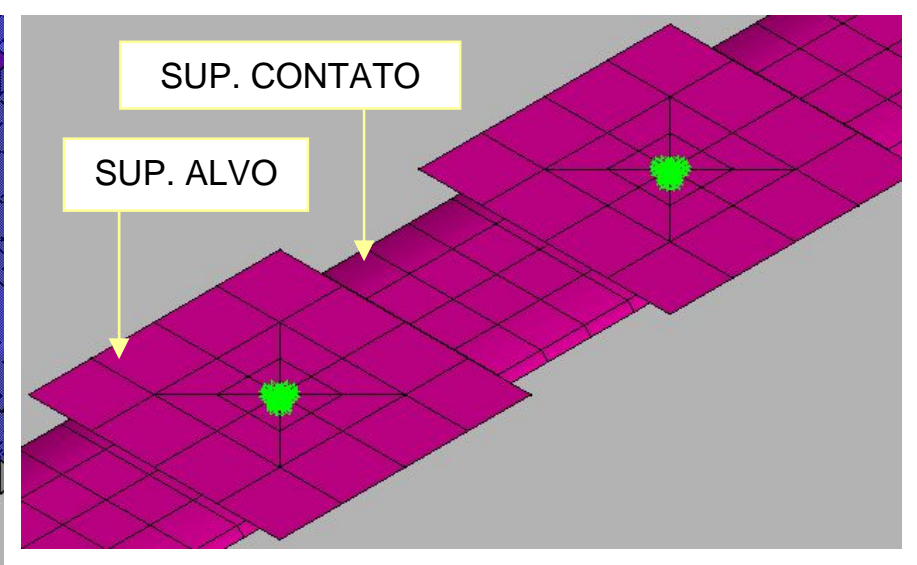

b) Pares de contato mostrados isoladamente

Figura 3.11 - Disposição dos elementos de contato.

A ligação da terça com a trave é dada pela fixação por parafusos a uma cantoneira de apoio e a cantoneira de apoio é fixada à trave por solda ou parafusos, como mostrado na Figura 3.12a.

Para simular os parafusos que ligam a terça à cantoneira de apoio foram restringidos todos os deslocamentos $\left(u_{x}=u_{y}=u_{z}=0\right)$ dos nós que se encontram posicionados no mesmo local dos respectivos parafusos. Na Figura 3.12b tem-se o exemplo de dois parafusos alinhados na vertical, igualmente espaçados.

A cantoneira de apoio, como ilustrado na Figura 3.13, restringe o deslocamento da mesa inferior do perfil no sentido de u negativo e não faz nenhuma restrição a u positivo. Para simular este efeito é utilizado o elemento de mola COMBIN39 que é configurado de tal forma que para u positivo (deslocamento) nenhuma restrição seja oferecida, porém tem rigidez infinita para deslocamento u negativo.

$\mathrm{Na}$ Figura 3.12b é mostrado o posicionamento do elemento de mola COMBIN39, no entanto não é possível visualiza-lo, isto se dá pelo fato do elemento estar posicionado entre dois nós que foram criados sobrepostos, sendo que um nó é o nó da seção do perfil e o outro é o nó criado. O nó criado é restringido na direção do deslocamento u para que a mola, apesar de infinitamente rígida, não apresente deslocamento de corpo rígido quando submetida à compressão. 


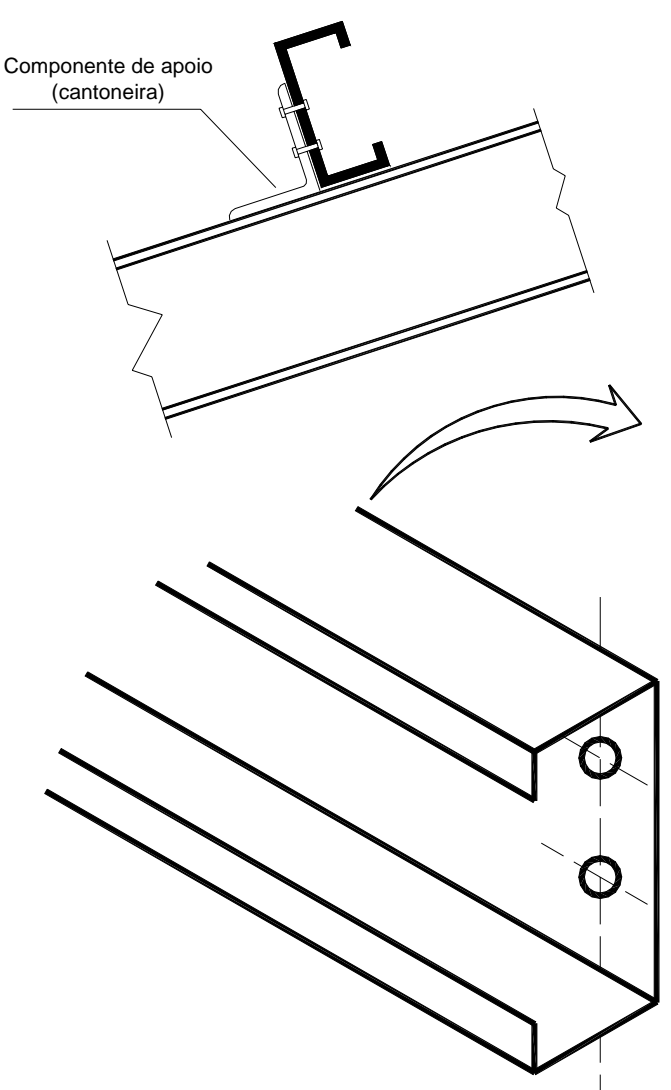

a) Detalhamento de ligação

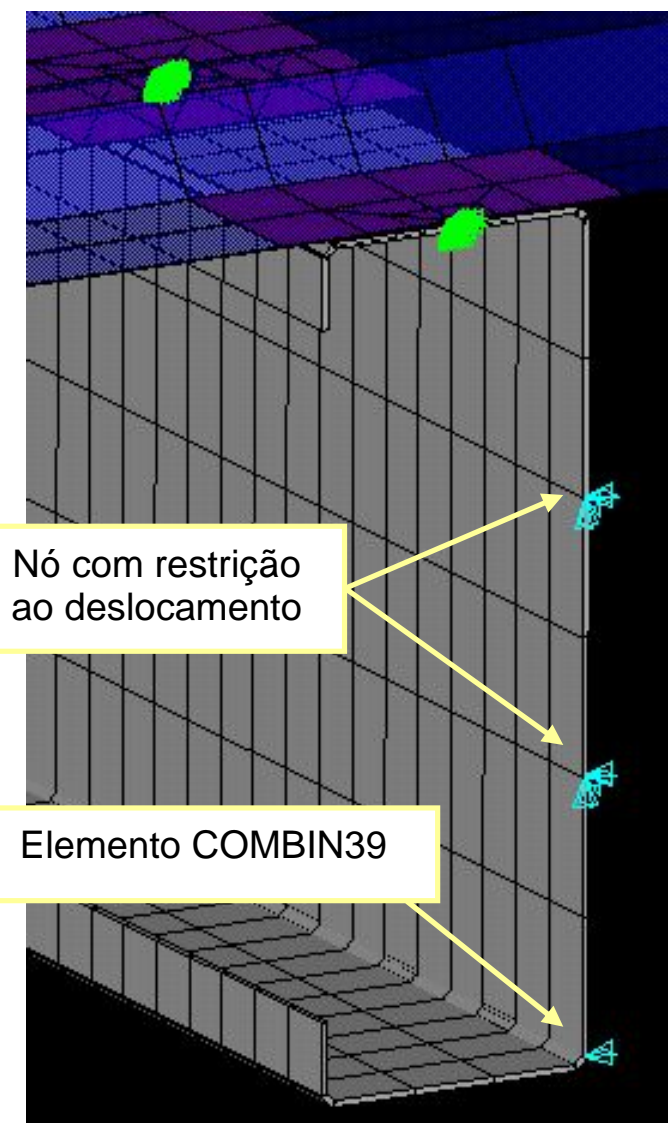

b) Modelagem da ligação

Figura 3.12 - Adaptação do detalhamento padrão de ligação à modelagem. (Fonte: Adapt. Baságlia (2004))

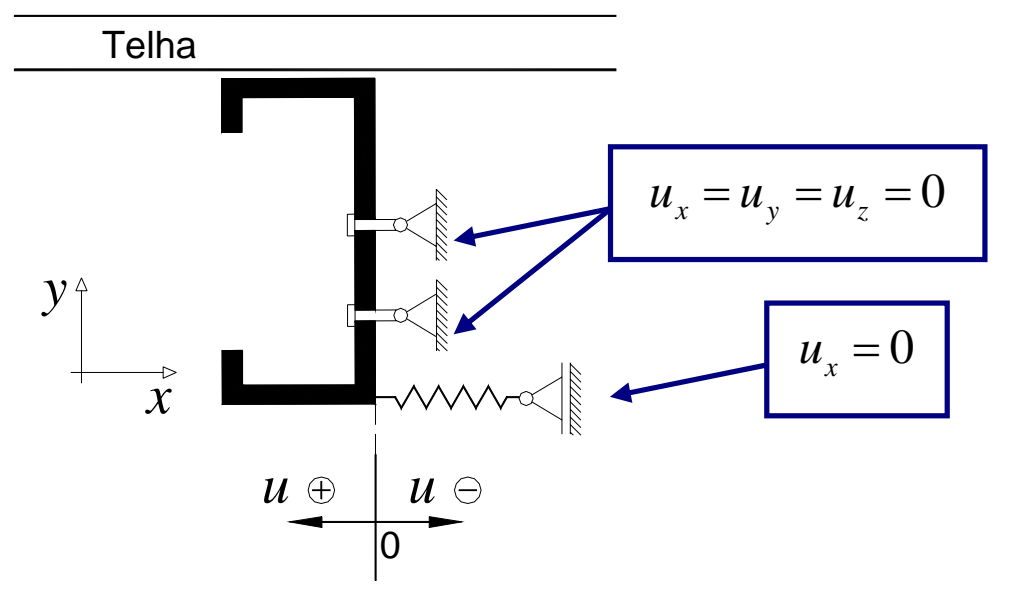

Figura 3.13 - Ilustração da modelagem da cantoneira de apoio. (Fonte: Adapt. Baságlia (2004))

A Figura 3.14 mostra a atuação do elemento de mola para o modelo $U_{e}$ 250x85x25×2 de vão igual a 6,5m e largura de influência de $2 \mathrm{~m}$, onde, é simulado o mesmo modelo com e sem mola e o deslocamento horizontal é medido no nó da seção transversal 
do perfil onde é colocado o elemento de mola. Pode-se notar que até aproximadamente a pressão de $0,8 \mathrm{kN} / \mathrm{m}^{2}$ os deslocamentos são coincidentes e a partir desta o modelo sem mola admite deslocamentos no sentido de u negativo enquanto o modelo com mola não admite.

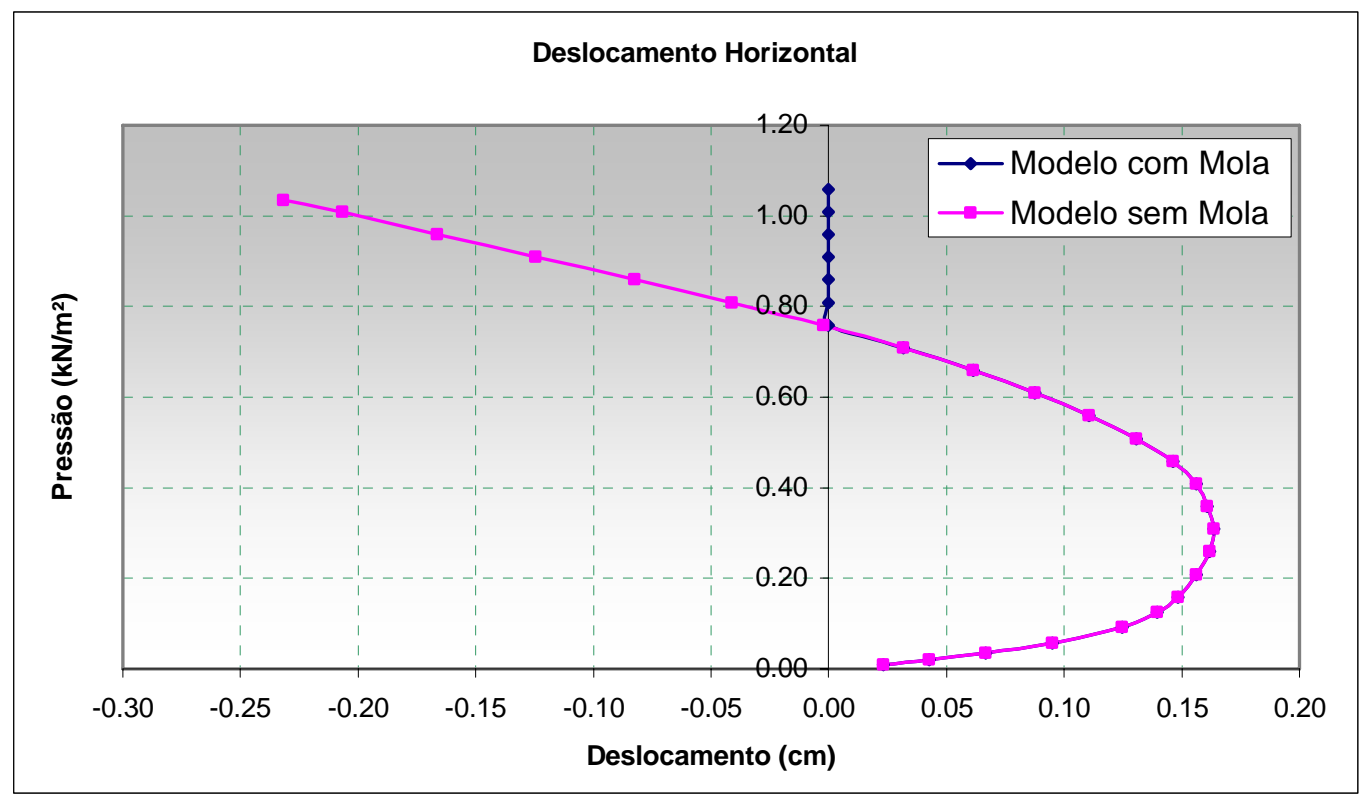

Figura 3.14 - Gráfico pressão x deslocamento para modelos com e sem mola.

A solicitação de sucção foi aplicada por meio de uma força distribuída uniformemente, perpendicular às faces da telha (Figura 3.15) e o peso próprio foi desconsiderado.

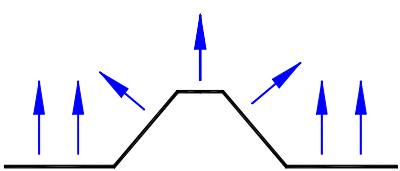

Pressão Uniforme

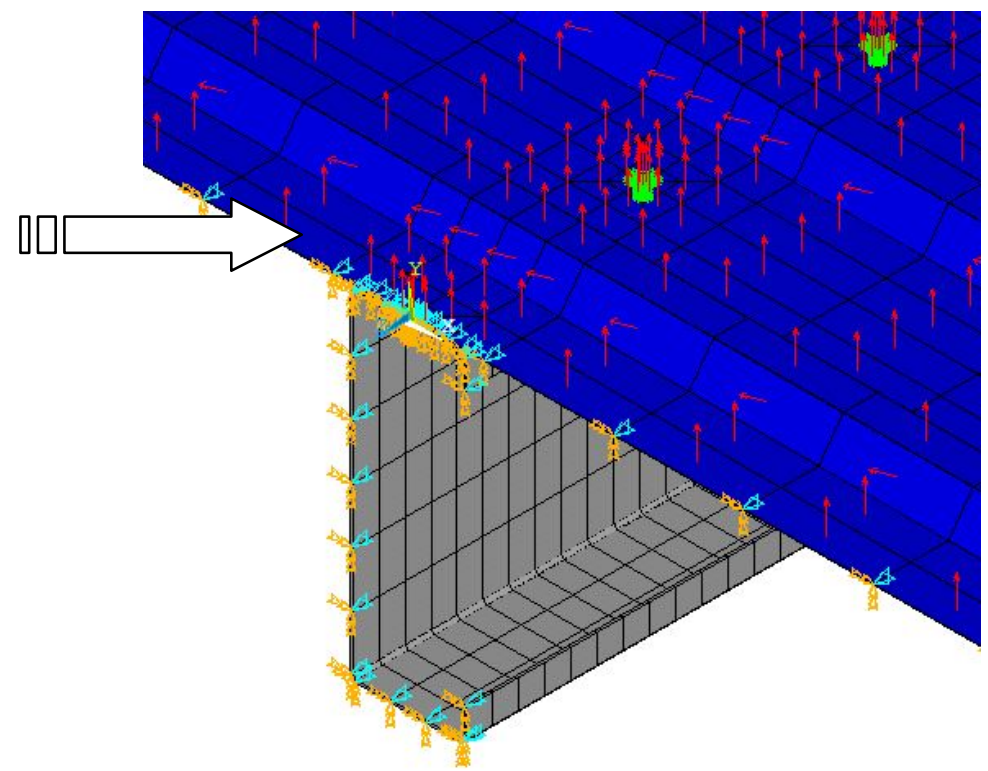

b) Modelagem

a) Ação de Sucção

Figura 3.15 - Modelagem da ação de sucção. 


\subsubsection{Modelo Completo Proposto por Lucas et al. (1997a)}

Esta simulação é baseada no modelo proposto por Lucas et al.(1997a), intitulado de "Full Model" (Figura 3.16). O modelo difere-se do anterior por não utilizar elementos de contato e por simular a continuidade da telha por meio de acoplamento de nós.

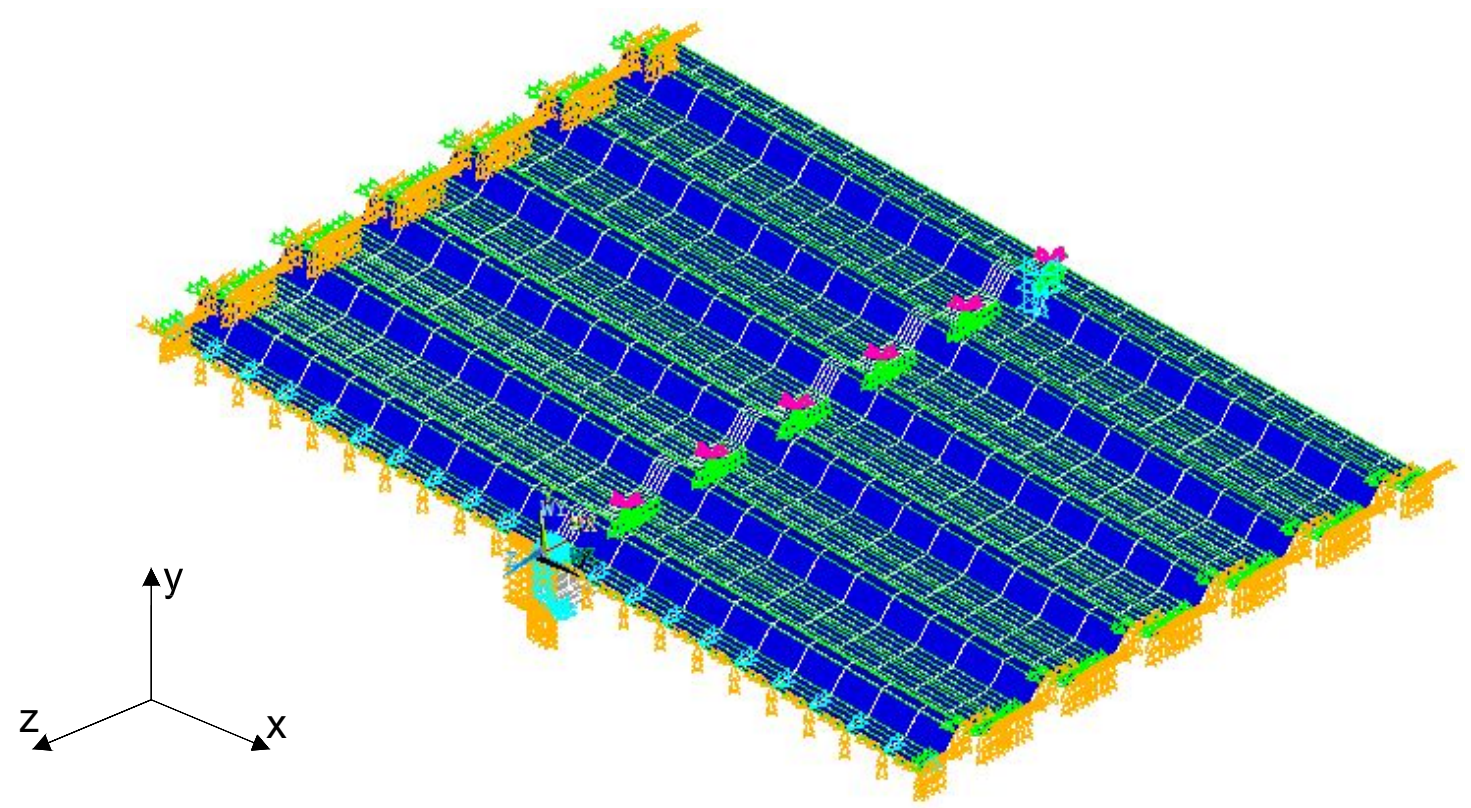

Figura 3.16 - Vista global do modelo baseado no trabalho de Lucas (1997a).

Como já relatado na revisão bibliográfica, nas condições de contorno mostradas na Figura 3.17, $v$ representa deslocamento vertical, $w$ o deslocamento horizontal, $\theta$ a rotação, $d$ a distância dada na modelagem entre a crista da telha e a mesa superior do perfil. O subíndice $L$ representa à esquerda (Left), $R$ à direita (Right), $p$ quando se refere ao nó da terça (purlin) e $s$ ao nó da telha (sheet) e $i$ representa os nós dispostos na longitudinal (eixo x).

Como o modelo não utiliza elementos de contato é previsto o contato da junção da mesa superior do perfil e enrijecedor com a parte inferior da telha por meio do acoplamento dos deslocamentos destes nós na vertical (Figura 3.17a).

Lucas et al.(1997a) propõem que os nós centrais onde se prevê a fixação da telha à terça sejam acoplados. No presente modelo (Figura 3.17b) foram empregados as mesmas condições de acoplamento, no entanto, optou-se por acoplar todos os nós ao longo de todo o fuste do parafuso. 


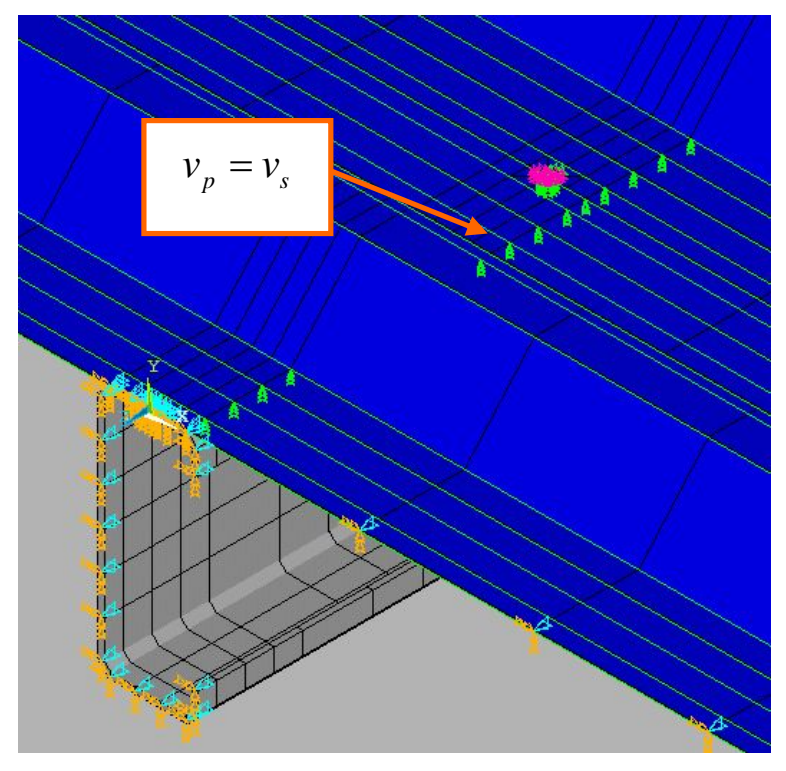

a) Acoplamento para simular o contato terça-telha

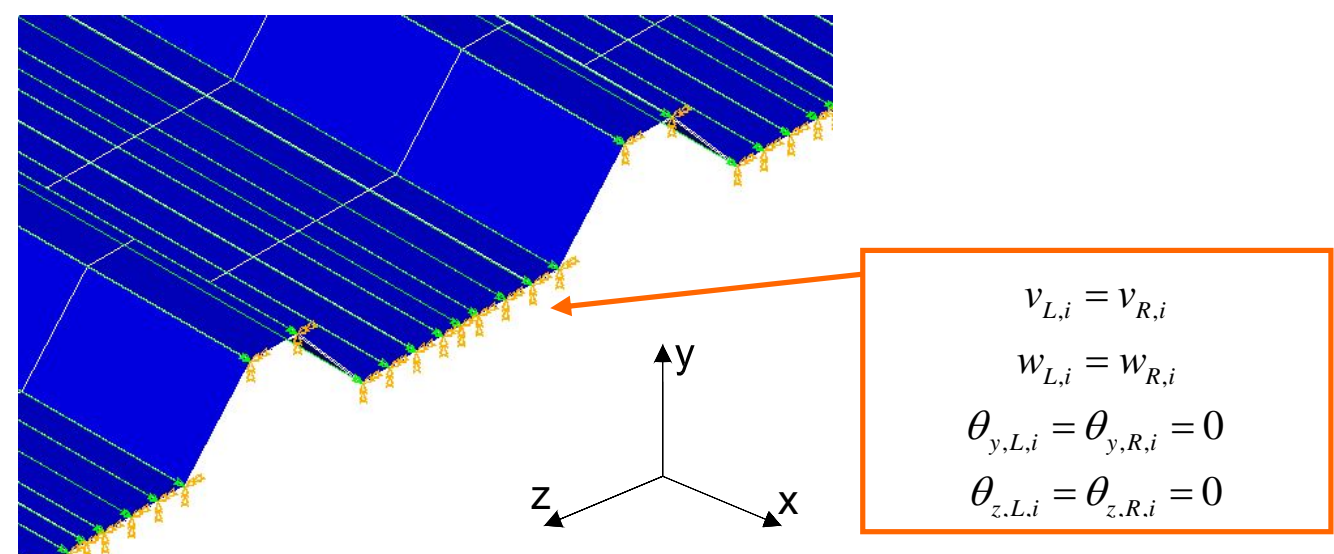

c) Acoplamento dos nós para simular a continuidade da telha

Figura 3.17 - Detalhamento do modelo baseado no artigo de Lucas (1997a).

Para simular a continuidade da telha em vez de utilizar eixos de simetria, como no modelo descrito anteriormente, Lucas et al.(1997a) propõem acoplar os deslocamentos horizontais e verticais dos nós a meio vão à direita aos nós a meio vão à esquerda (Figura 3.17c) e restringir as rotações em torno dos eixos y e z.

\subsubsection{Modelo Para Avaliação da Rigidez à Rotação}

Lucas et al.(1997b) propuseram um modelo baseado no ensaio "Torsional Restraint Test" padronizado pelo AISI (1996) para avaliação da rigidez à rotação imposta à 
terça. As mesmas condições de vinculação terça-telha proposta por Lucas et al.(1997a) são utilizadas. No entanto, para simular a base rígida necessária para realizar o ensaio, foram restringidos todos os deslocamentos e rotações (Figura 3.18). Todas as dimensões recomendadas pelo AISI (1996) foram respeitadas.

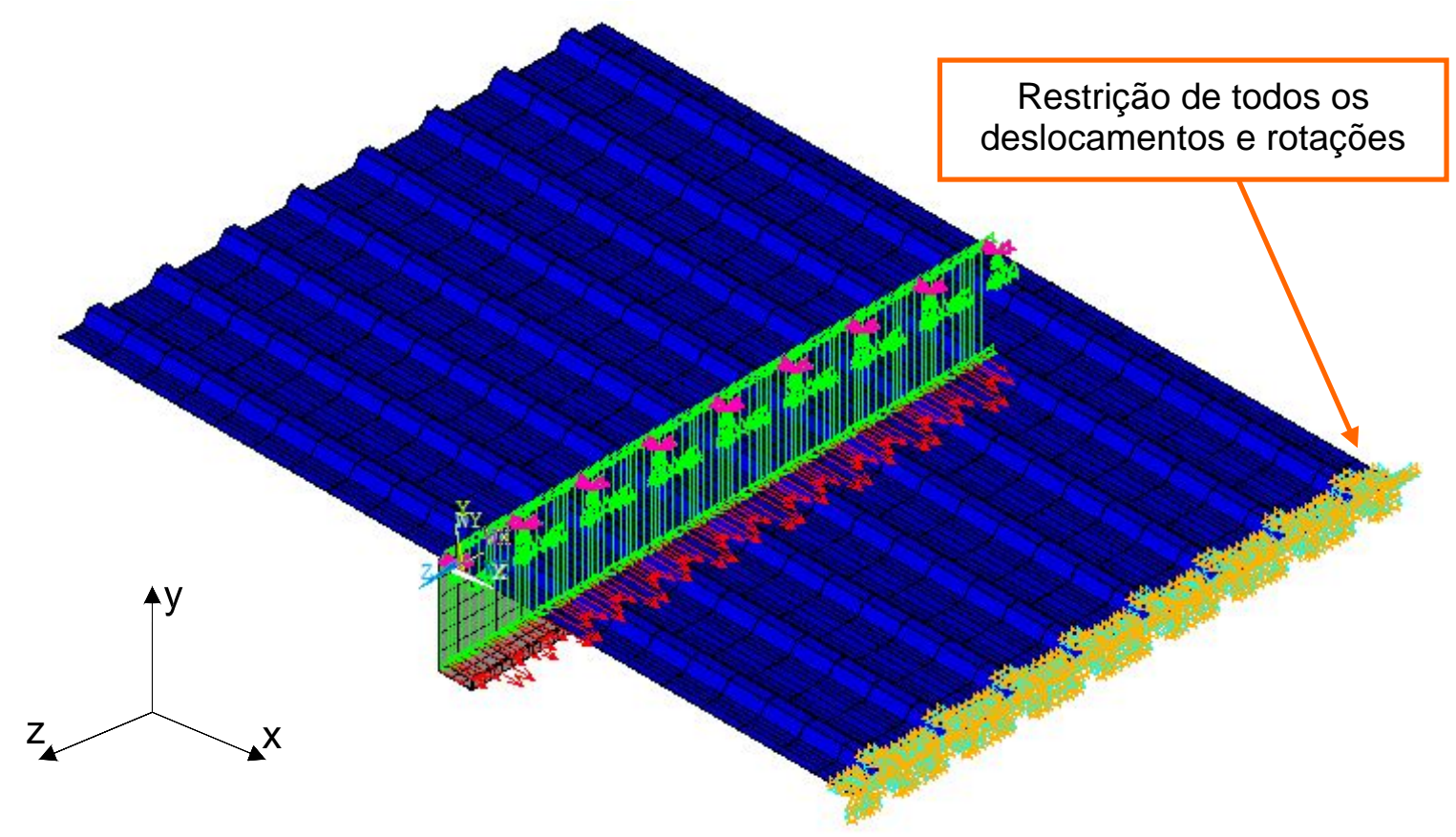

Figura 3.18 - Modelo para avaliação da rigidez à rotação.

Porém o ensaio padronizado pelo AISI (1996) considera a rigidez à rotação imposta pela conexão terça-telha e a rigidez da alma do perfil. Como se pretende modelar toda a terça e elementos de mola para simular somente a conexão terça-telha, Lucas et al.(1997b) propuseram acoplar a rotação dos nós extremos da alma do perfil, nó $i$ e nó $j$ (Figura 3.19) em torno do eixo z.

O carregamento é aplicado de forma incremental por meio de forças nodais. As forças nodais são aplicadas em cada nó segundo a largura de influência do mesmo. Dois são os fatores para interromper o carregamento: primeiro, se alguma instabilidade for detectada na telha ou no perfil e, segundo, se a resultante das forças nodais aplicadas ultrapassar a resultante da força distribuída aplicada à telha necessária para atingir o momento fletor resistente da terça $\left(M_{R}\right)$ baseado no escoamento da seção bruta, sendo $M_{R}=W \cdot f_{y}$. 


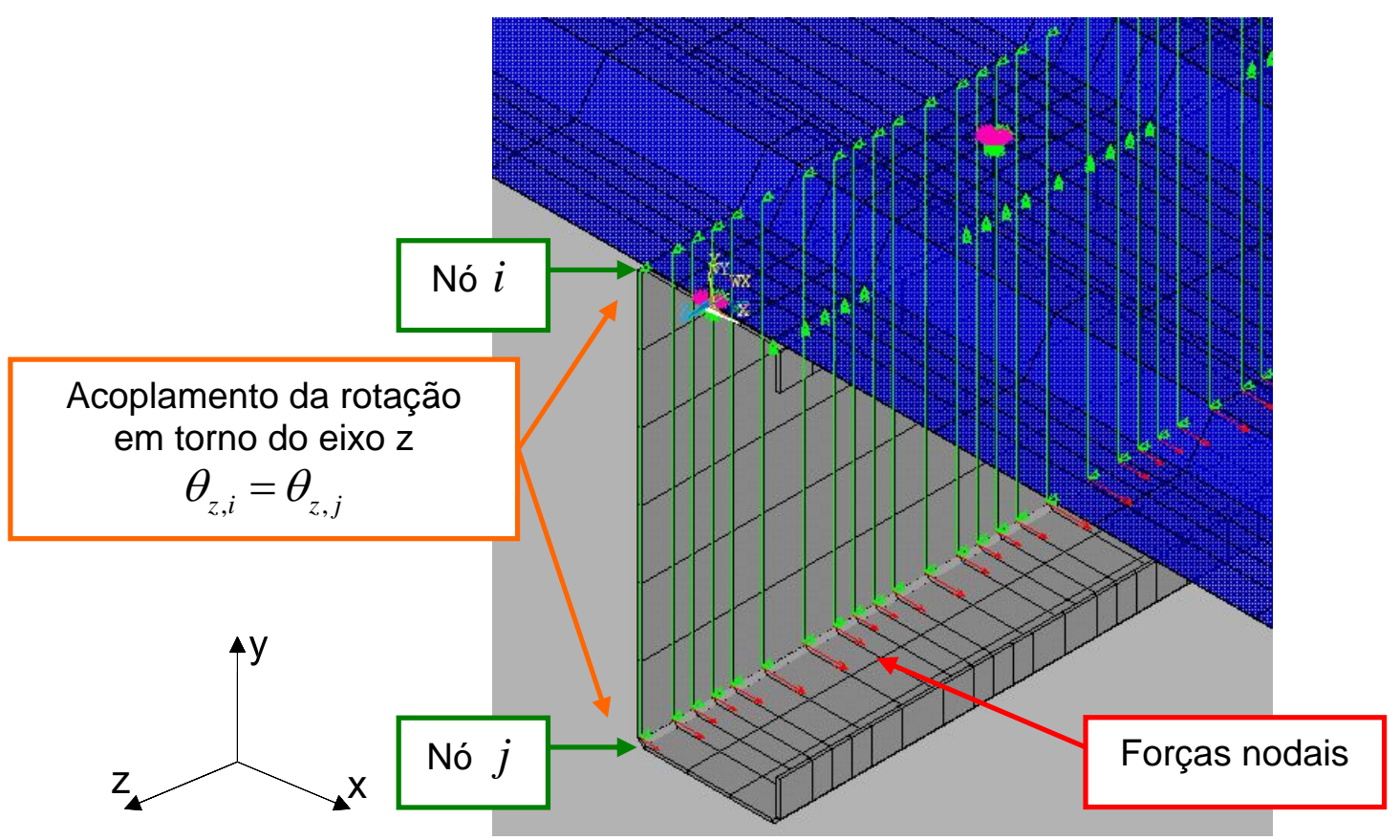

Figura 3.19 - Acoplamento dos nós da alma e aplicação das forças nodais.

Desta forma, $k_{r z}$ é calculado por:

$k_{r z}=\frac{N}{\delta} \cdot h^{2}$

Onde:

$k_{r z}$ : rigidez à rotação em torno do eixo z, como indicado na Figura 3.19;

$N$ : carregamento aplicado por unidade de comprimento da terça;

$\delta$ : é o deslocamento na direção do eixo x;

$h$ : Lucas et al.(1997b) considera $h$ como sendo a altura da terça, no entanto, no presente trabalho foi considerado a distância entre o ponto de aplicação da força e o elemento de mola, $h=b_{w}-2,5 . t$.

\subsubsection{Modelo Proposto 2 (Mola)}

Este modelo visa essencialmente constatar a eficiência do uso das molas simulando a conexão terça-telha baseando-se no modelo descrito por Lucas et al.(1997b). Desta forma, é possível realizar uma análise de estabilidade elástica do perfil pelo programa de faixas finitas CUFSM, uma vez conhecidas as rigidezes das molas. 
O modelo (Figura 3.20) consiste no perfil da terça, nos apoios simulando os parafusos, nas forças nodais, nas molas referentes à rigidez imposta pela conexão terça-telha e no eixo de simetria (apenas meio-vão da terça é simulado). Nesse modelo não é utilizado o elemento de mola para simular a atuação da cantoneira de apoio, já que não seria possível simular este elemento no programa CUFSM (restrições de apoio são apenas vínculos de garfo). Os apoios foram posicionados da mesma forma como nos modelos anteriores, baseados em Baságlia (2004) e Lucas et al.(1997a).

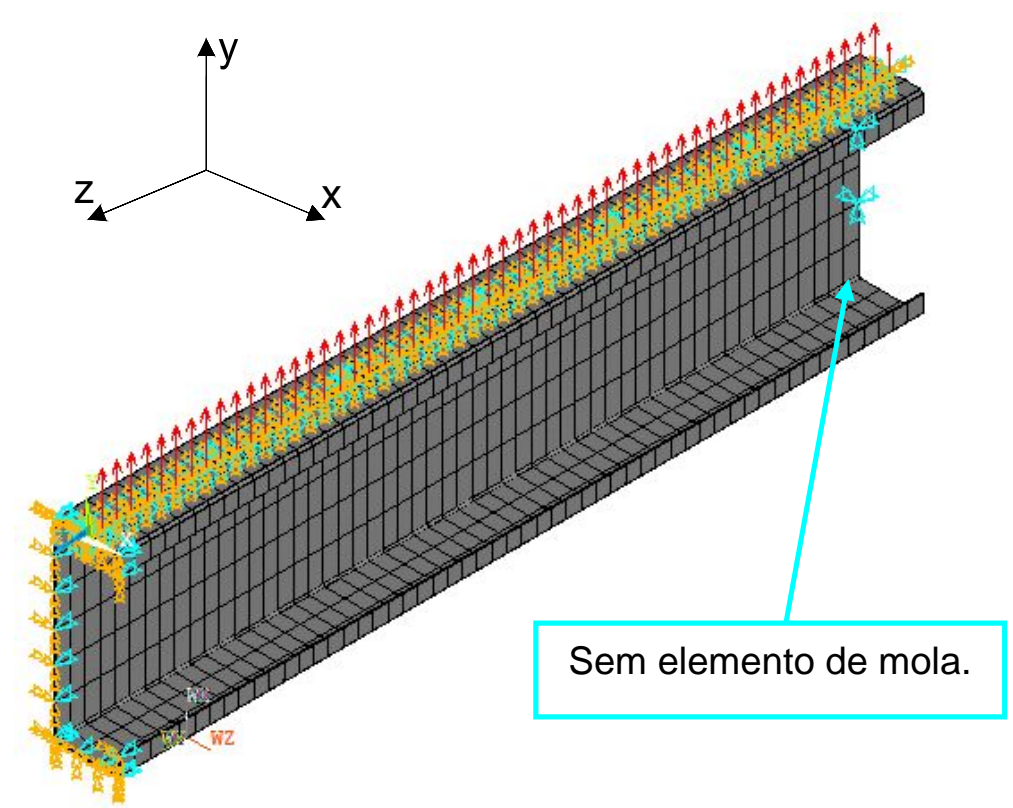

Figura 3.20 - Modelo restrito por elementos de mola.

O carregamento é aplicado no centro da mesa superior incrementalmente por uma força concentrada no nó (Figura 3.21). A força aplicada em cada nó equivale a resultante do carregamento distribuído sobre a área de influência do respectivo nó. Tendo em vista que o programa CUFSM admite que o elemento de mola seja aplicado ao longo de todo o perfil, para a calibração das rigidezes de mola foi utilizado o mesmo conceito. Assim cada nó no centro da mesa superior do perfil dispõe de um elemento de mola rotacional, uma força concentrada e um apoio restringindo o deslocamento na direção do eixo $x$ (Figura 3.21) que irá simular a rigidez lateral da telha. A determinação das rigidezes de mola e o porque de se adotar apoio para simular a rigidez lateral da telha é melhor esclarecido no apêndice $A$. 


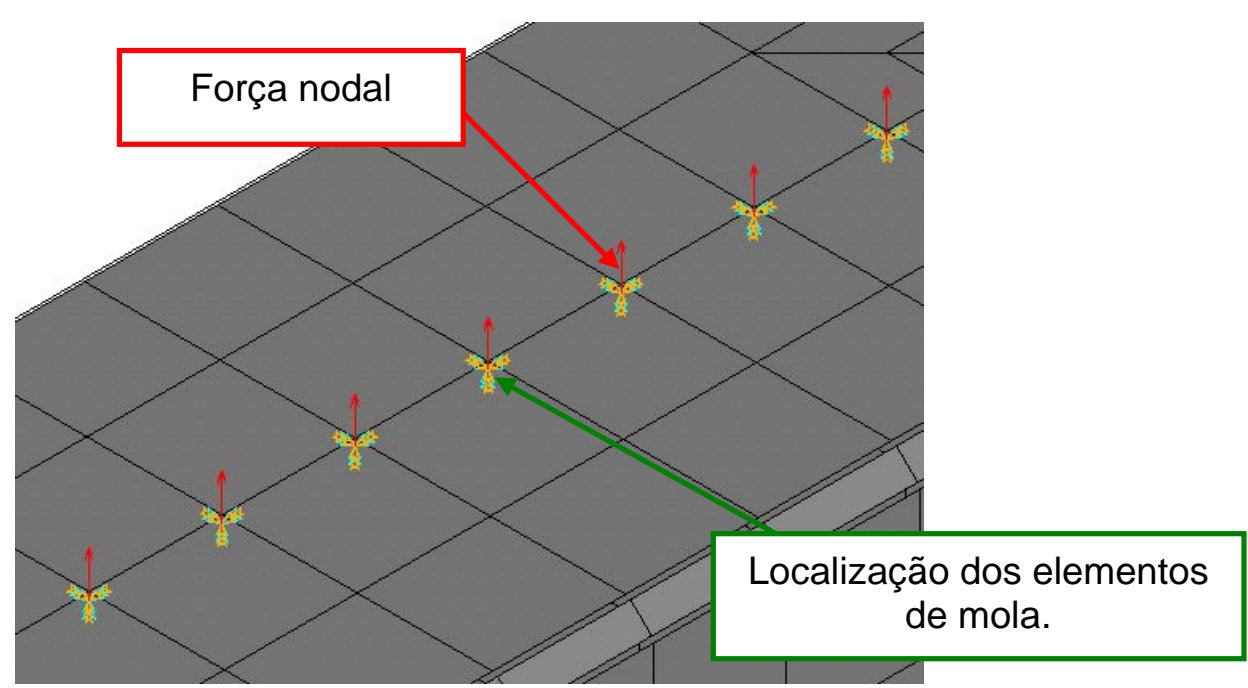

Figura 3.21 - Pontos de aplicação dos elementos de mola e das forças nodais.

\subsection{Validação do Modelo Numérico}

O ensaios em caixa de sucção realizados por Javaroni (1999) (Figura 3.22) foram adotados como referência para as análises numéricas do presente trabalho. Foram realizados quinze ensaios onde apenas três utilizaram o sistema de fixação terçatelha por todas as ondas. Cada ensaio utilizou um tipo de perfil, $U$ simples, $U_{e}$ e $Z_{45}$, e nenhum destes utilizou linhas de corrente.

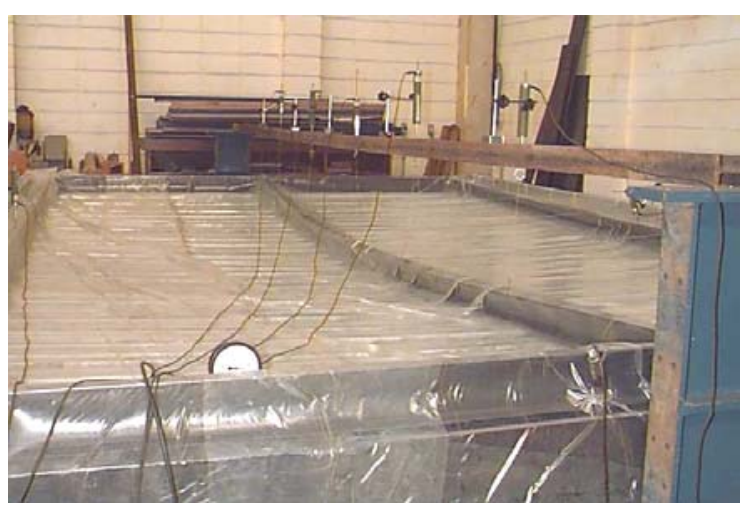

Figura 3.22 - Ensaio do sistema terça-telha em caixa de sucção. (Fonte: Javaroni(1999)) 


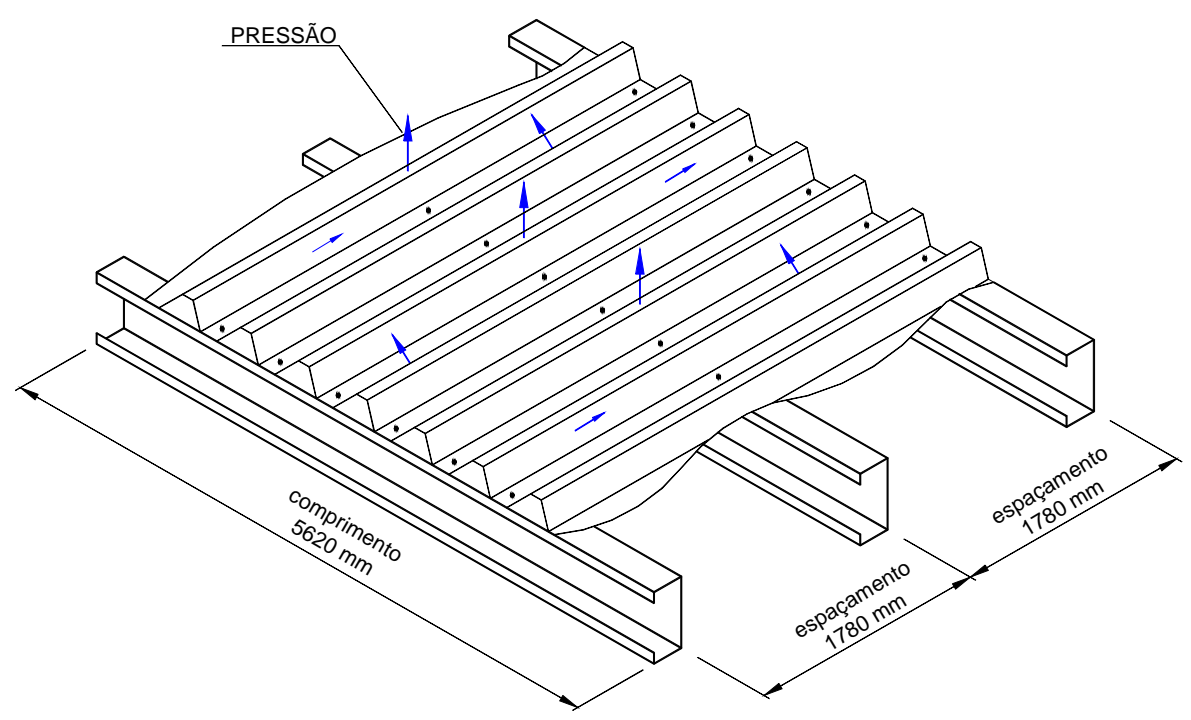

a) Dimensões do sistema terça-telha analisado por Javaroni (1999)

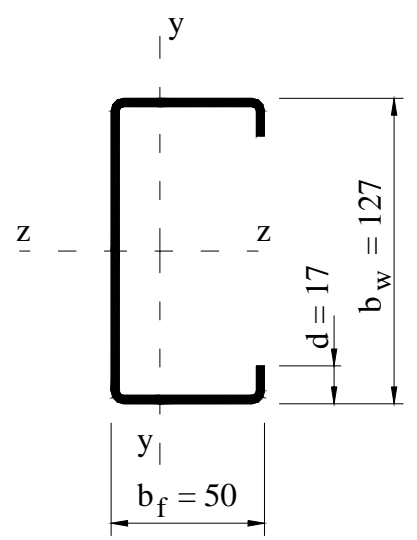

espessura: $\mathrm{t}=3,0 \mathrm{~mm}$

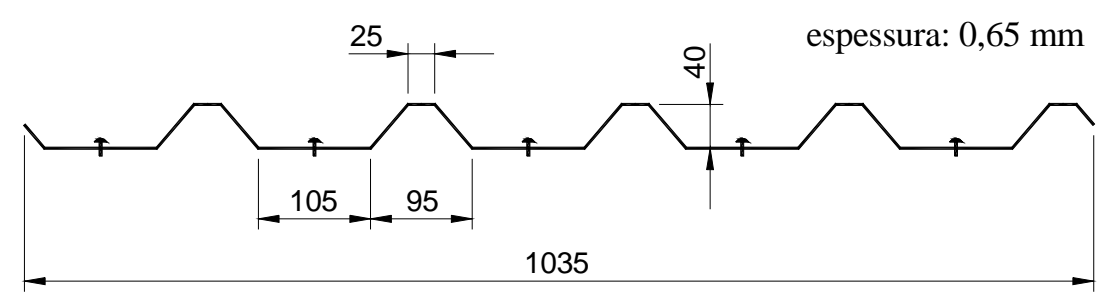

c) Telha analisada

Figura 3.23 - Dimensões utilizadas pelos ensaios de Javaroni (1999). (Fonte: Adapt. Baságlia (2004))

Os protótipos ensaiados foram constituídos por três terças espaçadas por $1780 \mathrm{~mm}$ e com $5620 \mathrm{~mm}$ de comprimento (Figura $3.23 \mathrm{a}$ ) telha com $40 \mathrm{~mm}$ de altura e 0,65mm de espessura (Figura 3.23c). Para a calibração dos modelos numéricos foi considerado o $U_{e} 127 \times 50 \times 17 \times 3,00$ (Figura 3.23b) com as telhas conectadas em todas as ondas.

Javaroni (1999) realizou os ensaios de caracterização do aço para o perfil, as propriedades encontradas são apresentadas na Tabela 3-1. Não foi realizado ensaio de caracterização da telha, portanto foram utilizados os valores nominais informados pelo catálogo do fabricante. 
Tabela 3-1 - Propriedades do material do perfil e da telha. (Fonte: Javaroni(1999))

\begin{tabular}{|c|c|c|c|}
\hline Componente & $\begin{array}{l}\text { Denominação comercial do } \\
\text { aço }\end{array}$ & $\begin{array}{l}\text { Resistência ao } \\
\text { escoamento }\left(f_{y}\right) \\
\text { (MPa) }\end{array}$ & $\begin{array}{l}\text { Resistência à } \\
\text { ruptura }\left(f_{u}\right) \\
(\mathrm{MPa})\end{array}$ \\
\hline Perfil & USI-SAC 41 (Usiminas) ${ }^{1}$ & 343 & 461 \\
\hline Telha & ZAR-230 (CSN) ${ }^{2}$ & 230 & 310 \\
\hline $\begin{array}{ll}\text { Notas: } & 1- \\
& 2-\end{array}$ & $\begin{array}{l}\text { Denominação antiga do USI-SAC } \\
\text { do material (JAVARONI, 1999). } \\
\text { Valores nominais. }\end{array}$ & 300. Valores obtid & a caracterização \\
\hline
\end{tabular}

Para a validação dos modelos numéricos foi utilizado o ensaio intitulado por Javaroni (1999) de Caixa 2. Foram confrontados os resultados no centro do vão da terça intermediária. Os deslocamentos horizontais e verticais foram medidos na junção da mesa inferior e a alma. Os pontos instrumentados para medir as deformações longitudinais são apresentados na Figura 3.24.

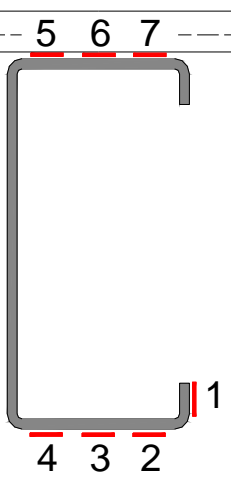

Figura 3.24 - Posicionamento dos extensômetros nas mesas e enrijecedor inferior do perfil. (Fonte: Baságlia (2004))

A Figura 3.25 mostra os gráficos que relacionam os deslocamentos verticais e horizontais com a pressão aplicada na superfície da telha.

Na Figura 3.25a é possível verificar uma concordância satisfatória entre o modelo experimental e todas as análises numéricas, no entanto o modelo proposto 1 , baseado em Baságlia (2004), foi o que apresentou melhor concordância.

$\mathrm{Na}$ Figura 3.25b, referente aos deslocamentos horizontais, percebe-se uma razoável dispersão nos resultados obtidos em cada modelo. O modelo proposto $1 \mathrm{em}$ um primeiro trecho (até a pressão de $0,25 \mathrm{kN} / \mathrm{m}^{2}$ ) apresenta concordância satisfatória, no entanto a partir deste trecho o modelo apresenta-se "mais rígido" que o experimental, possivelmente o contato entre o enrijecedor superior e a telha é mais flexível que o modelado. Tal fato foi constatado analisando-se o modelo da terça restrita por elementos 
de mola. Este modelo é totalmente restringido por apoios na horizontal e por elementos de mola de rotação no centro da mesa superior e apresenta boa concordância com o experimental, sem que sejam colocados elementos de mola que simulem o contato entre a terça e a telha.

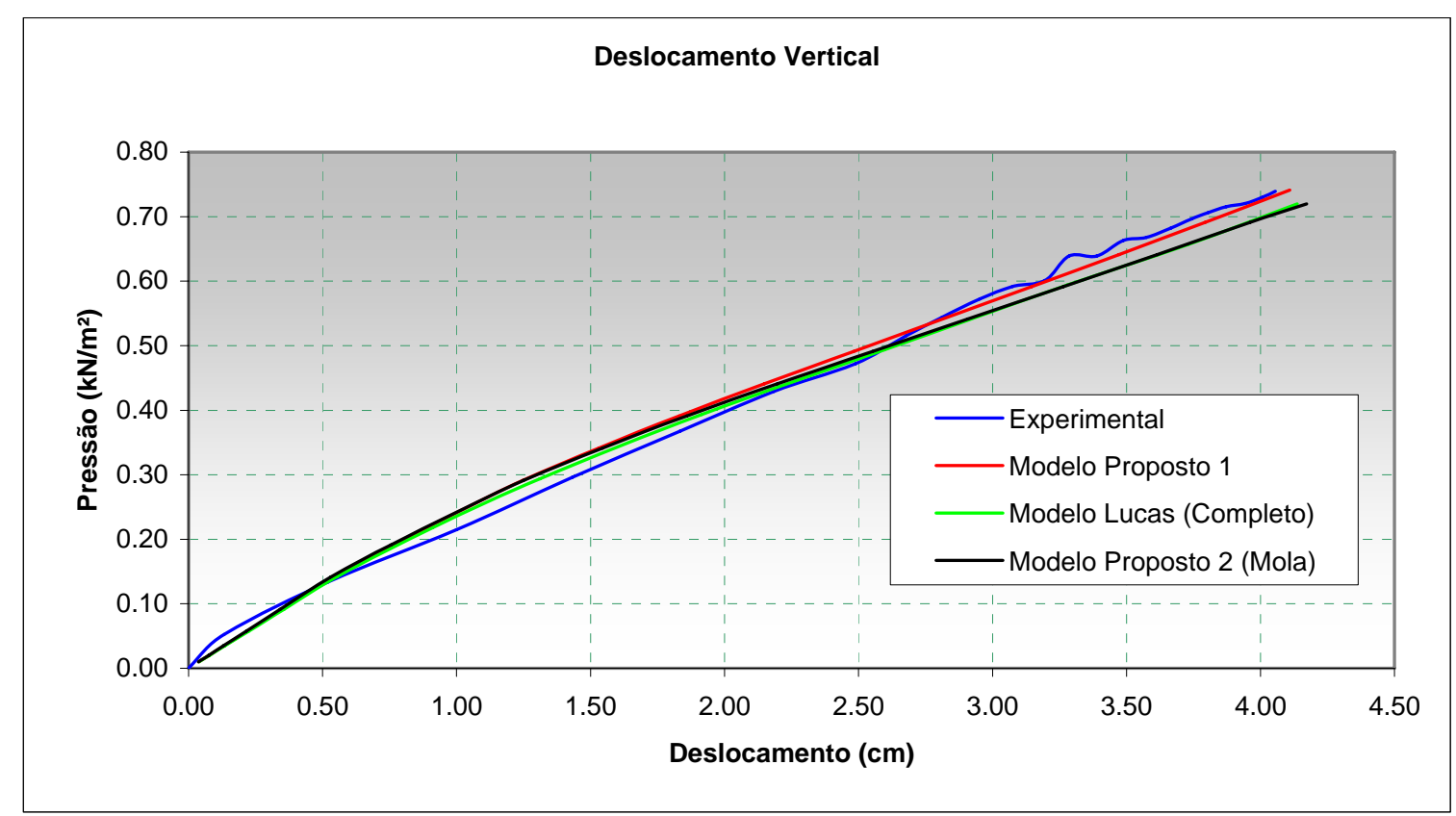

a) Pressão $x$ Deslocamento Vertical

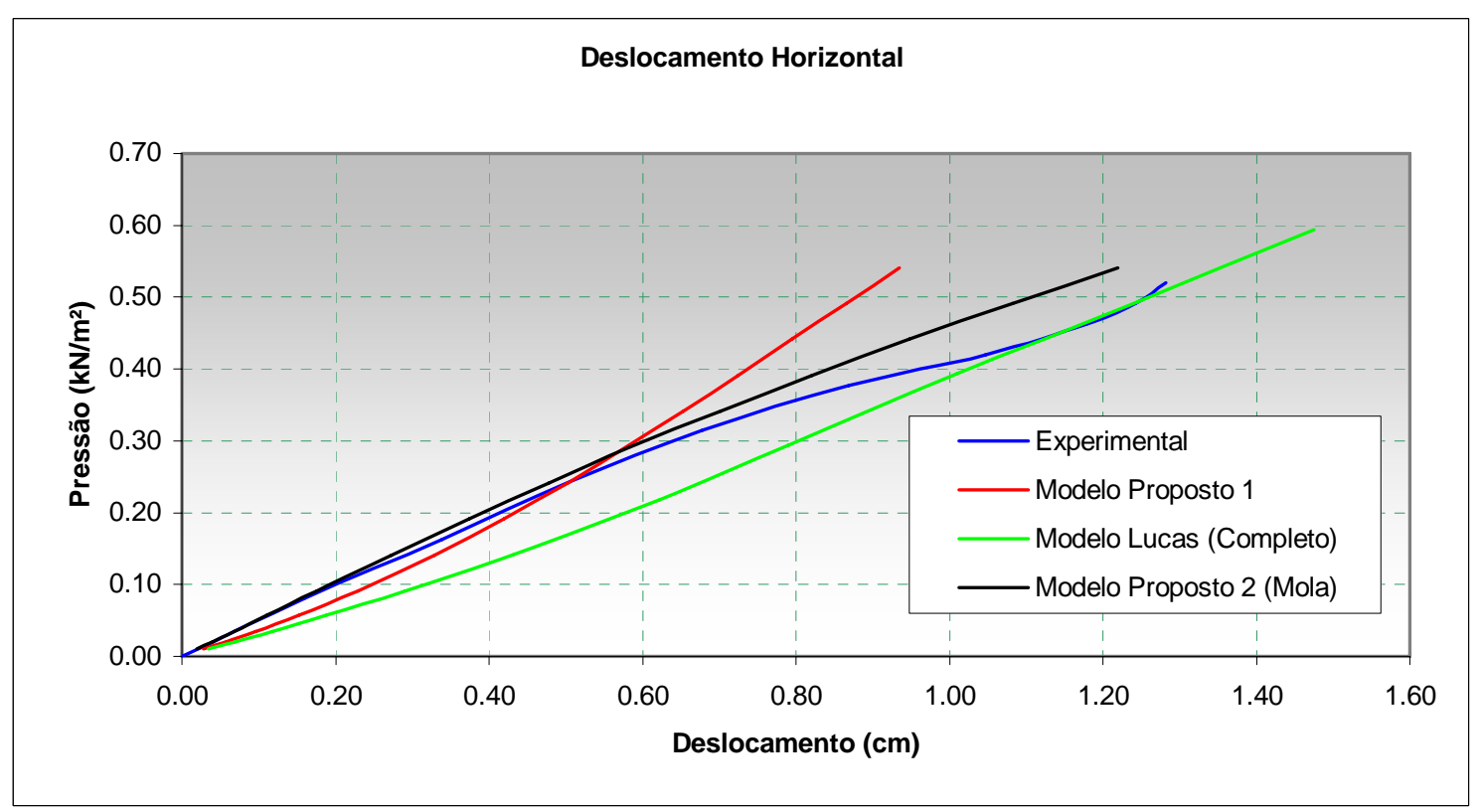

b) Pressão x Deslocamento Horizontal

Figura 3.25 - Gráficos Pressão x Deslocamentos horizontal e vertical.

Já o modelo completo proposto por Lucas et al.(1997a), em um primeiro trecho (até a pressão de $0,4 \mathrm{kN} / \mathrm{m}^{2}$ ), não apresenta boa concordância, resultando 
satisfatório posteriormente.

Alguns fatores que podem influenciar os resultados são: imperfeições iniciais, acomodação dos parafusos e a dificuldade de aquisição experimental dos deslocamentos.

Os Gráficos Pressão x Deformação dos pontos analisados podem ser vistos na Figura 3.26, Figura 3.27 e Figura 3.28.

No ponto 1 tem-se que o modelo proposto 2 (mola) distancia-se a partir de $0,55 \mathrm{kN} / \mathrm{m}^{2}$ das outras curvas. No ponto 2 e 3 a concordância é satisfatória em todos os modelos. No ponto 4 todos os modelos apresentam comportamento semelhante, no entanto, todos apresentam um distanciamento com a curva experimental. No ponto 5, até o a pressão aplicada de $0,55 \mathrm{kN} / \mathrm{m}^{2}$ os comportamento são semelhantes e satisfatório e a partir deste ponto o modelo proposto 2 (mola) começa a distanciar-se. No ponto 6 os modelos apresentam boa concordância e no ponto 7 o modelo proposto 2 (mola) distanciase um pouco mais do modelo experimental.

A análise comparativa das Figuras $3.26,3.27$ e 3.28 demonstra a concordância satisfatória de todos os modelos com o ensaio experimental conduzido por Javaroni (1999).

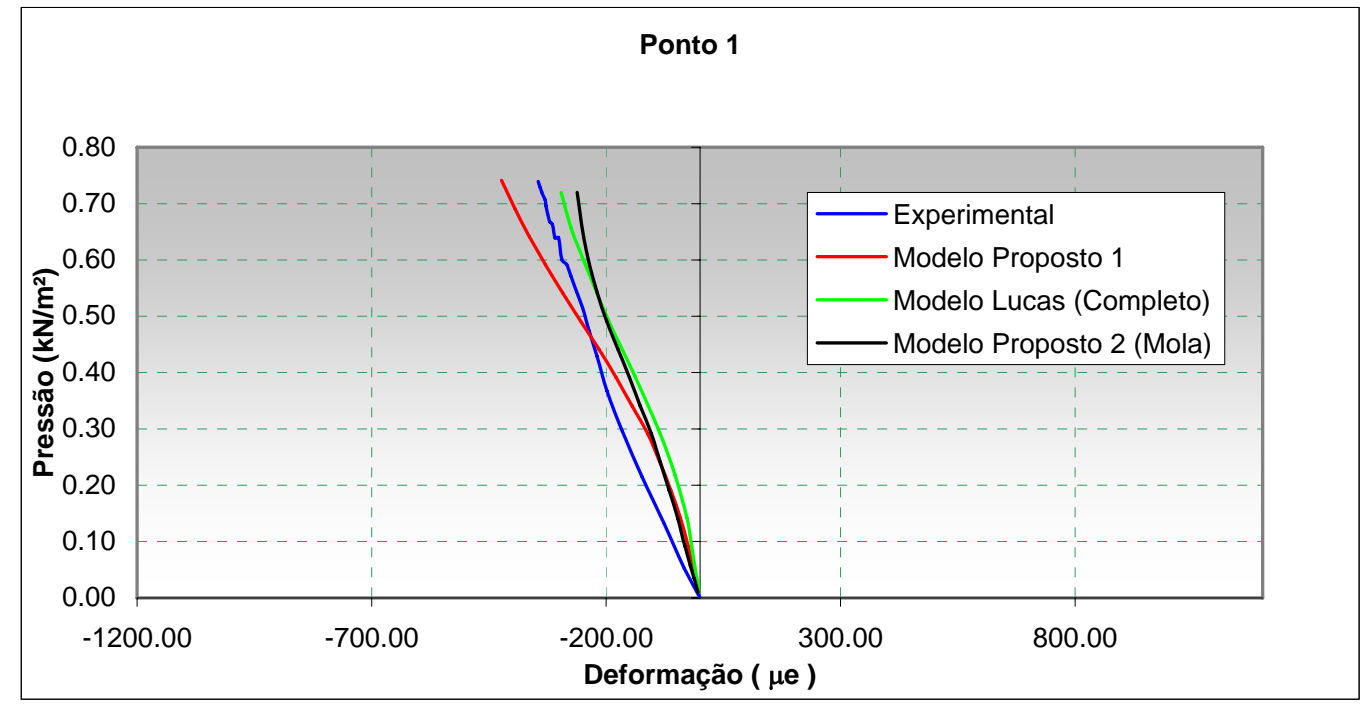

Figura 3.26 - Gráfico Pressão x Deformação do Ponto 1. 


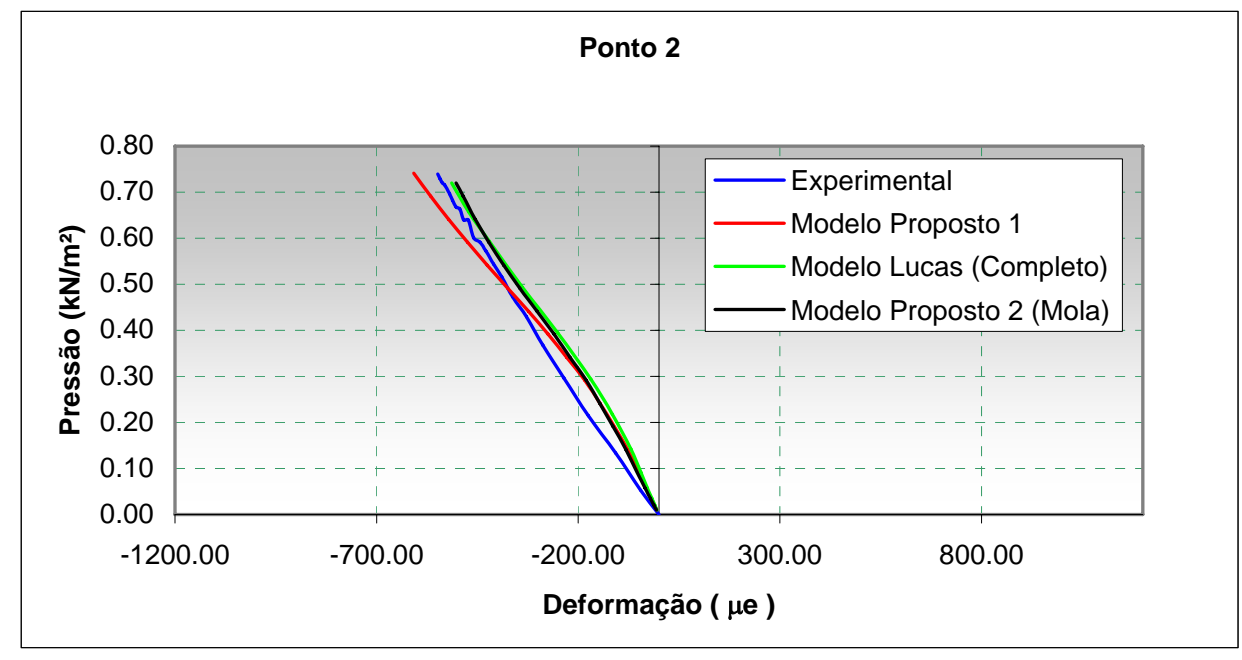

a) Gráfico Pressão x Deformação do Ponto 2

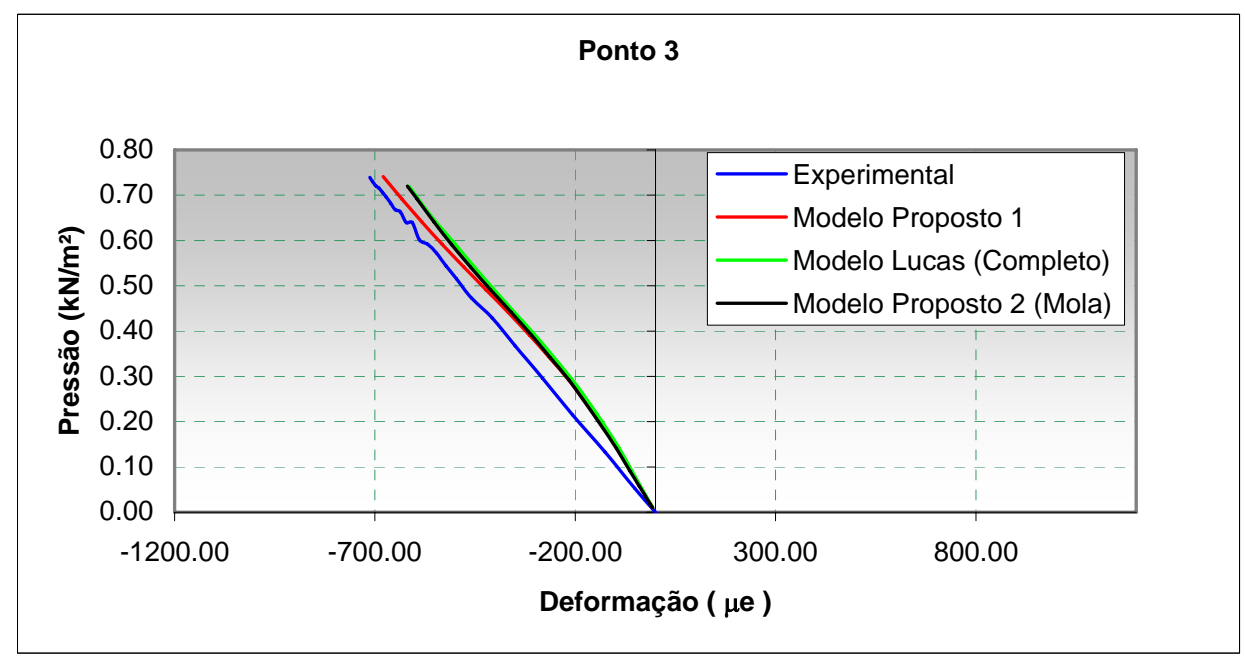

b) Gráfico Pressão x Deformação do Ponto 3

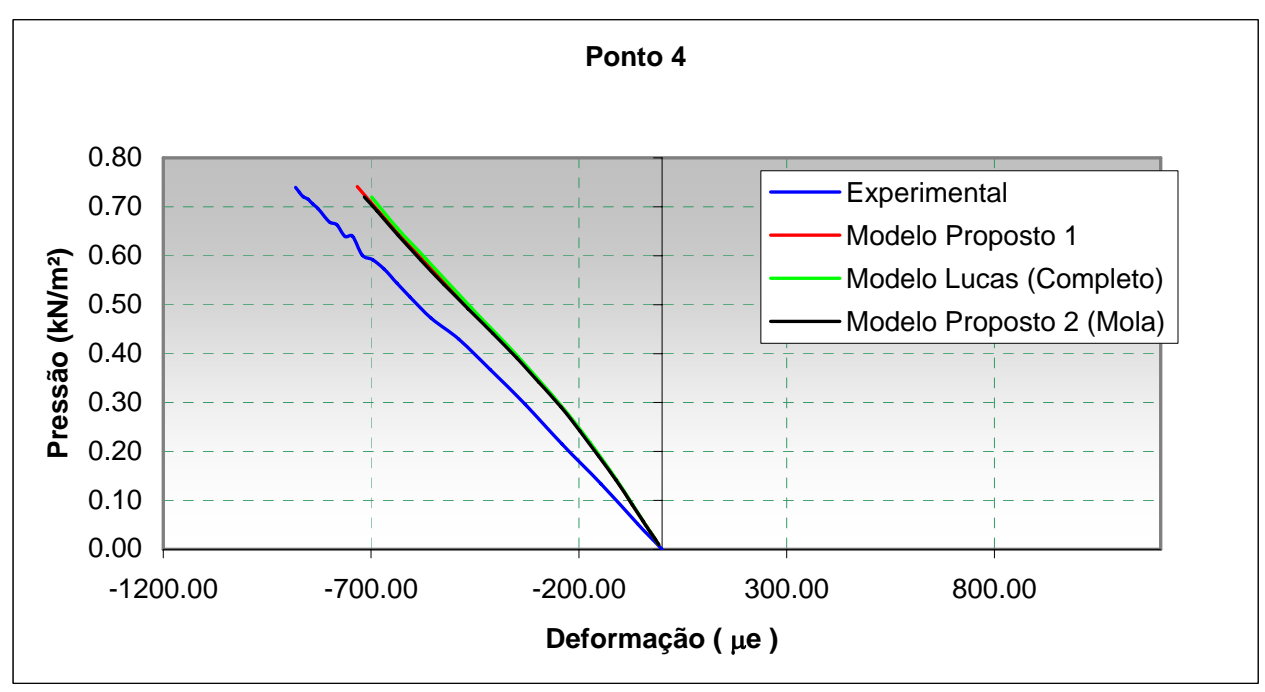

c) Gráfico Pressão x Deformação do Ponto 4

Figura 3.27 - Gráficos Pressão x Deformação dos 2 a 4. 


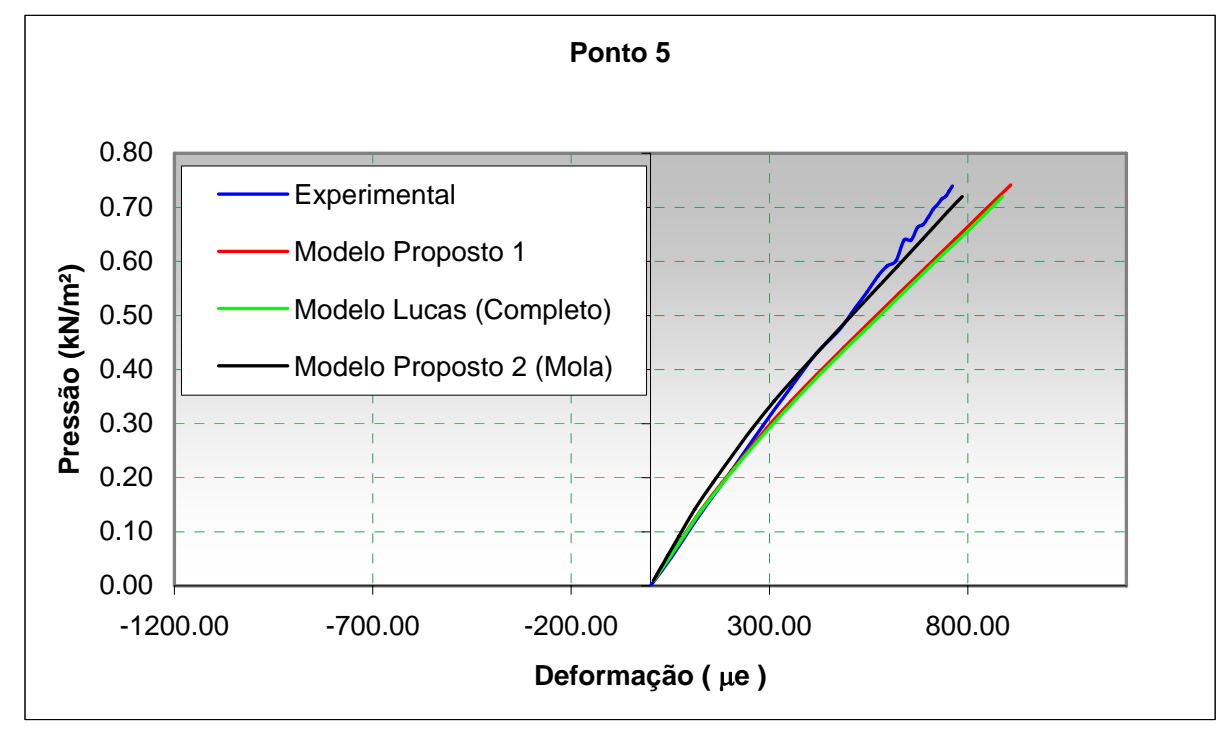

a) Gráfico Pressão x Deformação do Ponto 5

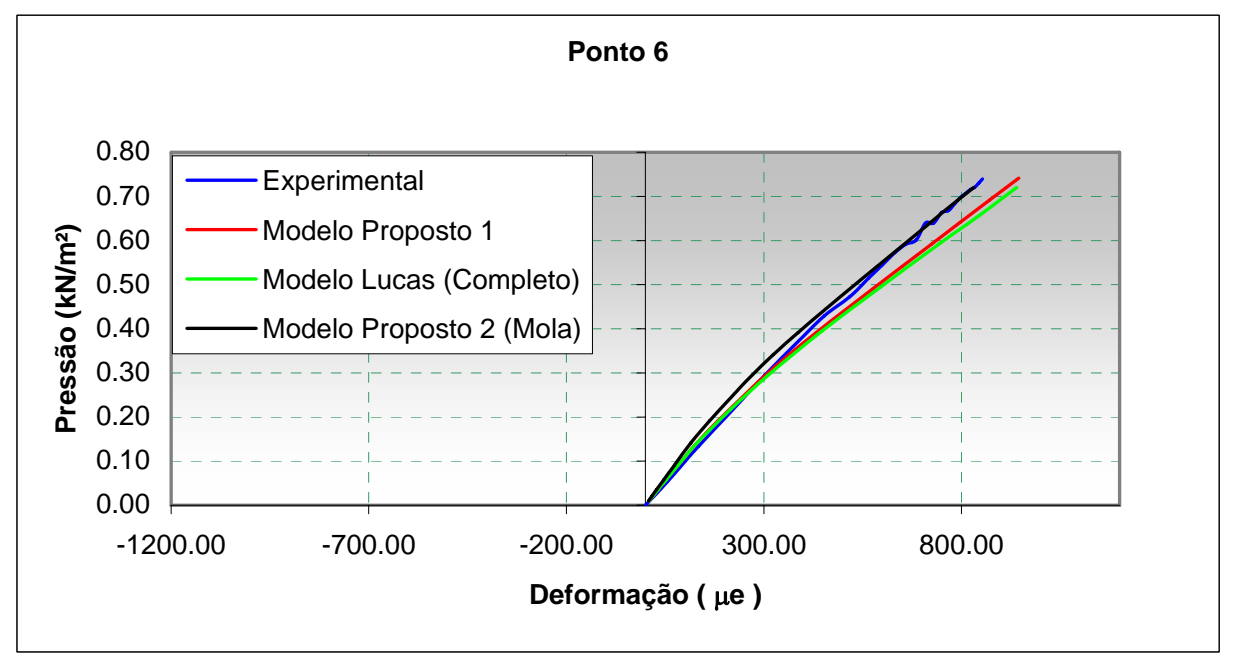

b) Gráfico Pressão x Deformação do Ponto 6

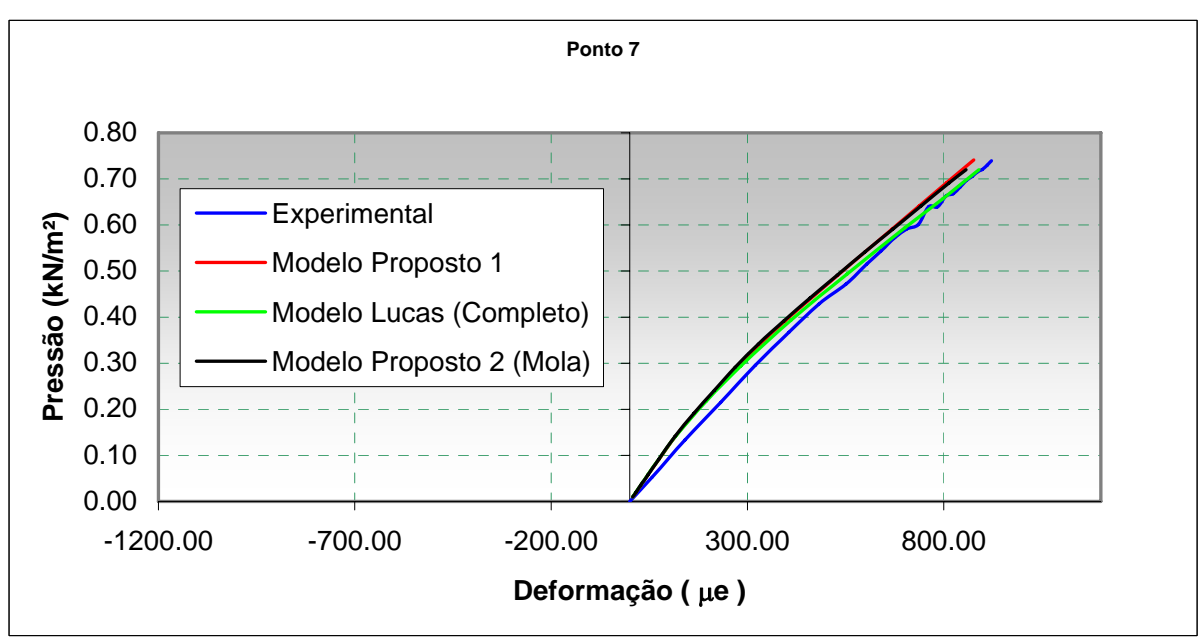

c) Gráfico Pressão x Deformação do Ponto 7

Figura 3.28 - Gráficos Pressão x Deformação dos pontos 5 a 7. 
A Figura 3.29a ilustra pelo gráfico de barras as tensões normais ao plano da seção transversal no meio do vão submetida à pressão de $0,93 \mathrm{kN} / \mathrm{m}^{2}$, esta pressão segundo Javaroni (1999), indica o valor da pressão aplicada nos ensaios experimentais que correspondem a uma flecha igual a 1/100 do vão da terça. Já as Figura 3.29b,c,d,e apresentam o posicionamento e o valor exato das tensões adquiridas.

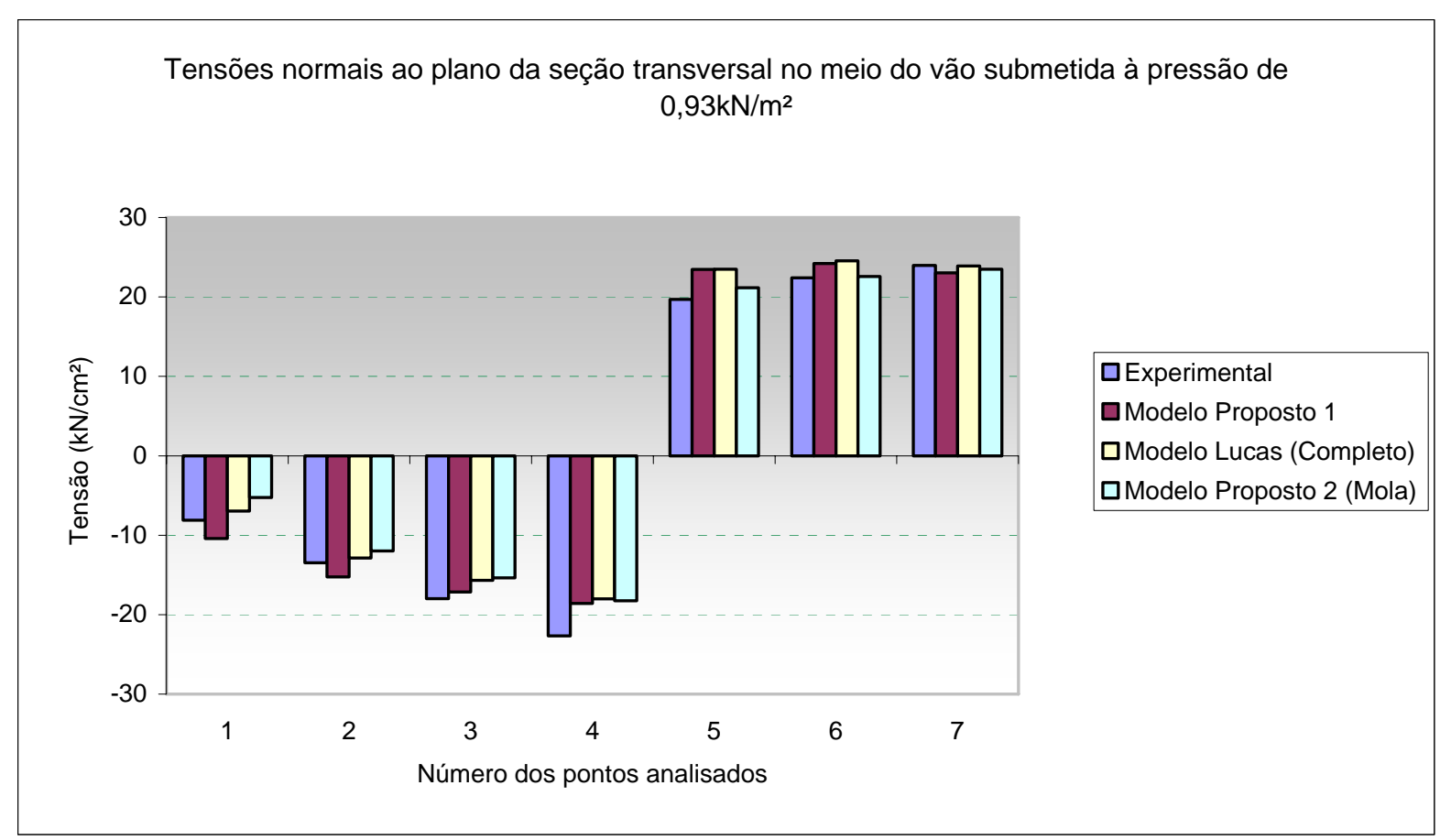

a) Gráfico comparativo das tensões normais ao plano da seção transversal

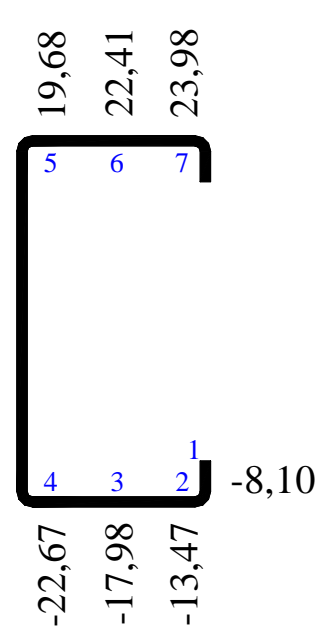

b) Modelo experimental Javaroni (1999)

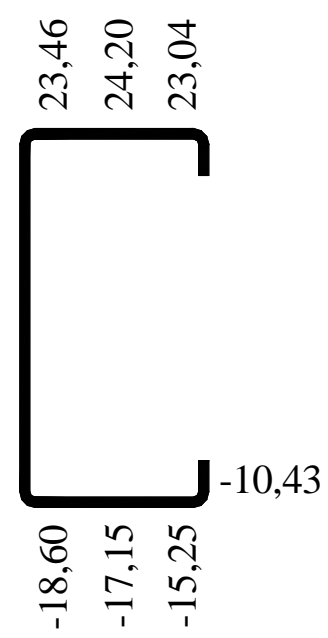

c) Modelo baseado em Baságlia (2004)

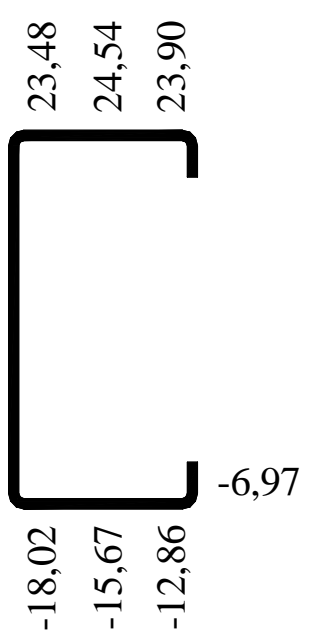

d) Modelo baseado em Lucas (1997a)

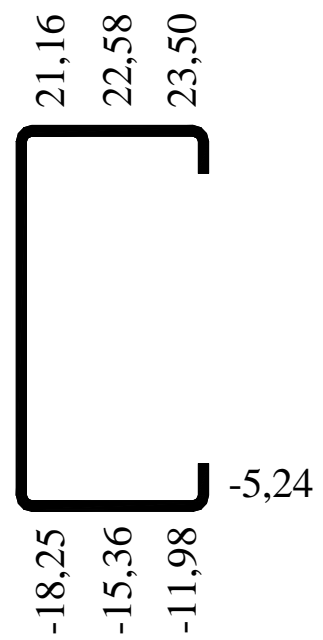

e) Modelo baseado em Lucas (1997b)

Figura 3.29 - Tensões normais ao plano da seção transversal no meio do vão da terça, submetida a uma pressão de $0,93 \mathrm{kN} / \mathrm{m}^{2}$. 
A partir da Figura 3.29 é possível identificar que os modelo proposto 1 e o modelo Lucas (completo) apresentam concordâncias semelhantes com os ensaios experimentais. Já o modelo proposto 2 (mola) apresenta pontos com diferenças significativas e pontos com boa concordância.

O modelo proposto 2 (mola) necessita de tempo de processamento muito inferior aos outros. Em testes realizados o modelo com molas é processado 24 vezes mais rápido que o modelo proposto 1 e 9 vezes mais rápido que o modelo Lucas (completo), isto admitindo-se conhecidas as rigidezes de mola.

A viabilidade dos modelos de mola também depende do ponto de interesse. O ponto 4, junção da mesa inferior com a alma, é de grande interesse pois é o ponto onde tem-se as maiores tensões de compressão e, comparando com os outros modelos, não há diferenças significativas, embora em relação ao ensaio em caixa de sucção a diferença seja de $20 \%$.

Desta forma, pode-se dizer que os modelos apresentam boa concordância com o experimental, sobretudo para a análise de deslocamentos. 


\section{RESULTADOS DA ANÁLISE NUMÉRICA}

A partir do modelo proposto 1 baseado em Baságlia (2004), item 3.3.1, foi desenvolvida uma análise paramétrica para terças biapoiadas em perfil $\cup_{\mathrm{e}}$. Os perfis e vãos adotados refletem as práticas usuais do mercado brasileiro (Tabela 4-1).

Tabela 4-1 - Dimensões dos perfis e vãos adotados na análise paramétrica.

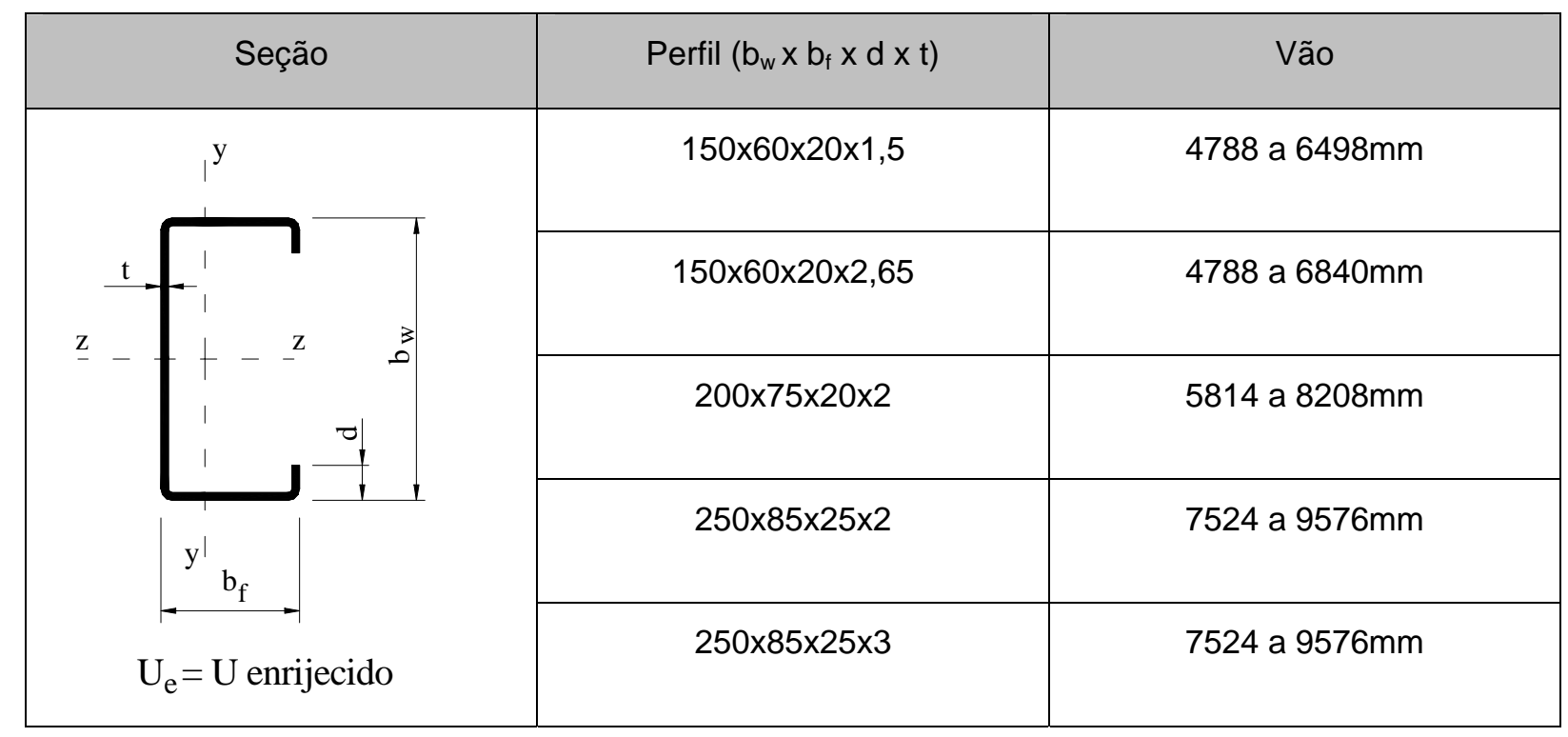

O vão adotado para cada modelo numérico é um número múltiplo da distância entre os parafusos de fixação telha-terça, de tal forma que começa e termina com um parafuso. A Figura 4.1 mostra que a telha de altura $25 \mathrm{~mm}$ tem distância entre ligações igual a $171 \mathrm{~mm}$ e a telha de $40 \mathrm{~mm}$ tem $196 \mathrm{~mm}$. Com isto, os vãos adotados apresentam valores necessários para adaptar a malha dos modelos e sem prejuízos valores como $4788 \mathrm{~mm}$ pode ser aproximado para $4800 \mathrm{~mm}$.

A Tabela 4-2 apresenta as propriedades dos materiais utilizados nos estudos numéricos. 
Tabela 4-2 - Propriedades dos materiais utilizados no estudo numérico.

\begin{tabular}{|c|c|c|c|}
\hline Componente & $\begin{array}{c}\text { Especificação } \\
\text { comercial do aço }\end{array}$ & $\begin{array}{c}\text { Resistência ao } \\
\text { escoamento }\left(\mathbf{f}_{\mathbf{y}}\right) \\
(\mathbf{M P a})\end{array}$ & $\begin{array}{c}\text { Resistência à } \\
\text { ruptura }\left(\mathbf{f}_{\mathbf{u}}\right) \\
(\mathbf{M P a})\end{array}$ \\
\hline Perfil & USI-SAC 300 (Usiminas) $^{(1)}$ & 300 & 400 \\
\hline Telha & ZAR-230 (CSN) ${ }^{(1)}$ & 230 & 310 \\
\hline \multicolumn{2}{|l}{ Nota: 1 - Valores nominais. }
\end{tabular}

A princípio foram analisados modelos com telhas de altura $40 \mathrm{~mm}$ e 25mm, seguindo as dimensões dadas pelo catálogo da empresa Metform (Figura 4.1). Para chapas zincadas, as espessuras apresentadas nos catálogos são as espessuras nominais, ou seja, incluindo a camada de zinco. Nos modelos foi utilizada a espessura real, descontando a camada de zinco de 0,018mm aplicada em cada face, assim em vez de 0,43 e $0,65 \mathrm{~mm}$ considera-se 0,394 e $0,614 \mathrm{~mm}$, respectivamente.

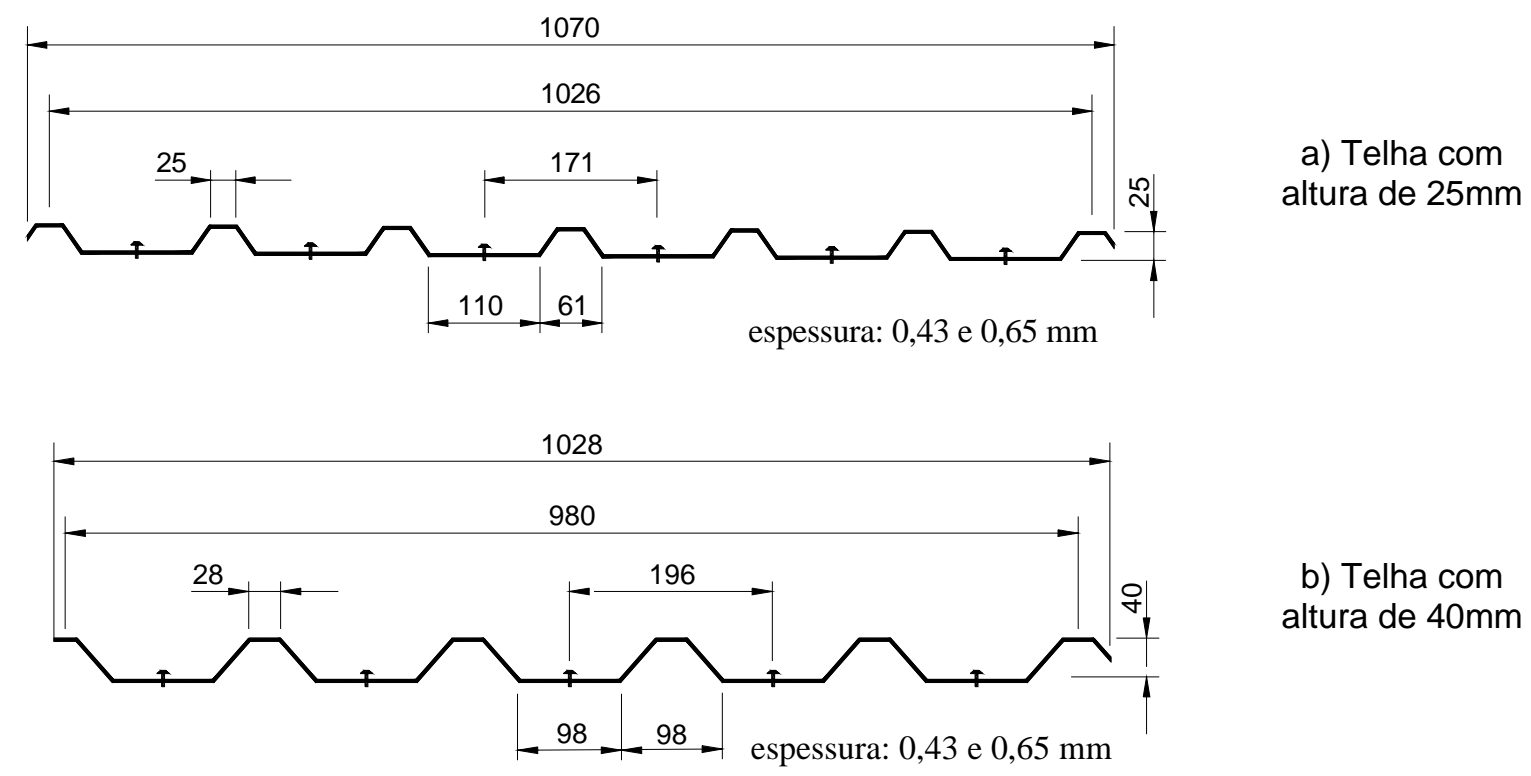

Figura 4.1 - Dimensões das seções transversais de telhas utilizadas nas análises. (Fonte: Catálogo METFORM).

A Figura 4.2 ilustra a comparação dos deslocamentos na junção mesa inferior e alma realizada para o modelo com vão de $7200 \mathrm{~mm}$ e perfil $U_{\mathrm{e}} 200 \times 75 \times 20 \times 2$, variando-se as telhas utilizadas. É possível identificar que para deslocamentos verticais é pequena a diferença, no entanto, para deslocamentos horizontais, os quais refletem indiretamente a distorção do perfil, a espessura é a grandeza que exerce maior influência na resposta do sistema. A partir destes dados optou-se por analisar apenas modelos com 
telha de altura $25 \mathrm{~mm}$ e espessura $0,43 \mathrm{~mm}$, ou seja, a que apresenta menor contribuição ao sistema terça-telha.

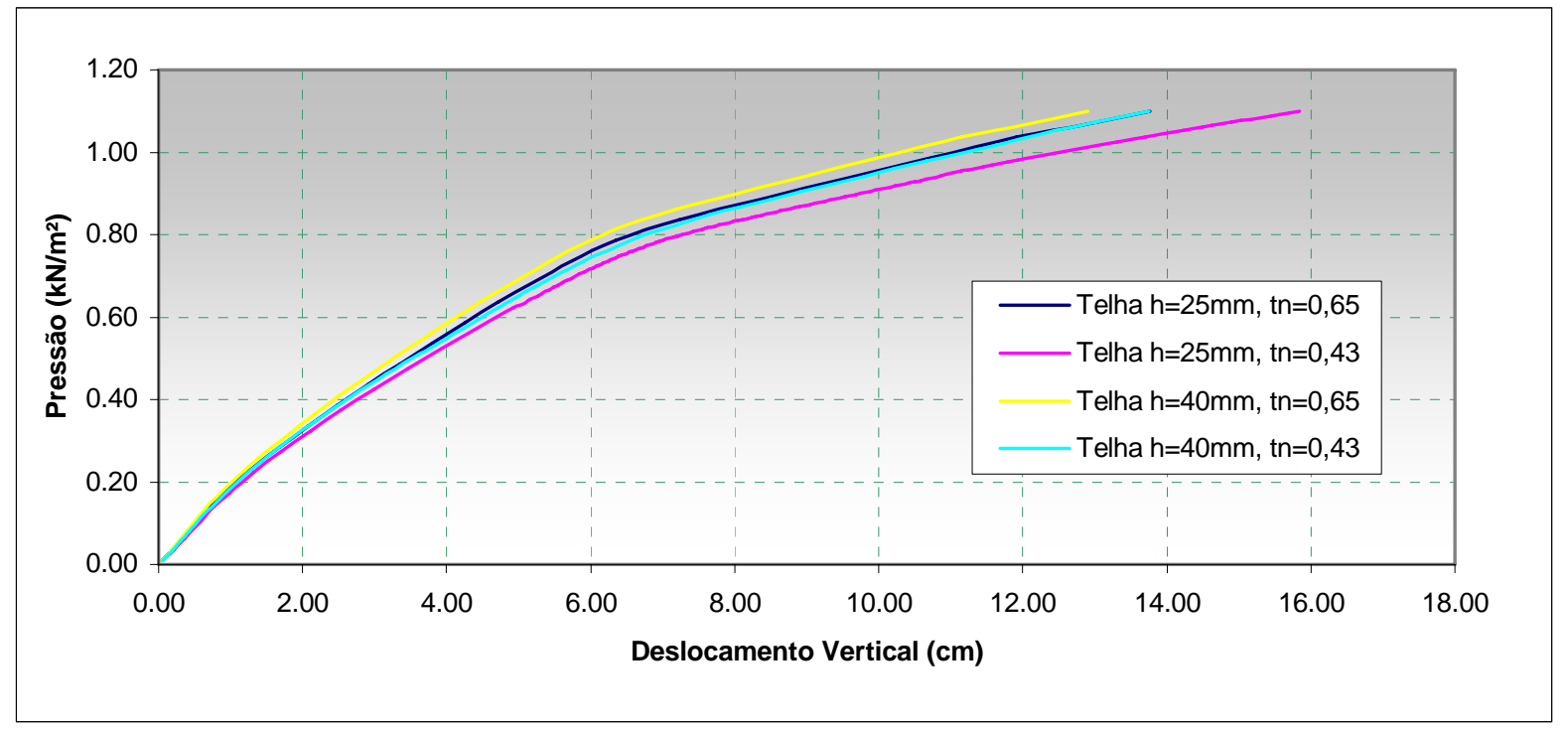

a) Comparação dos deslocamentos verticais

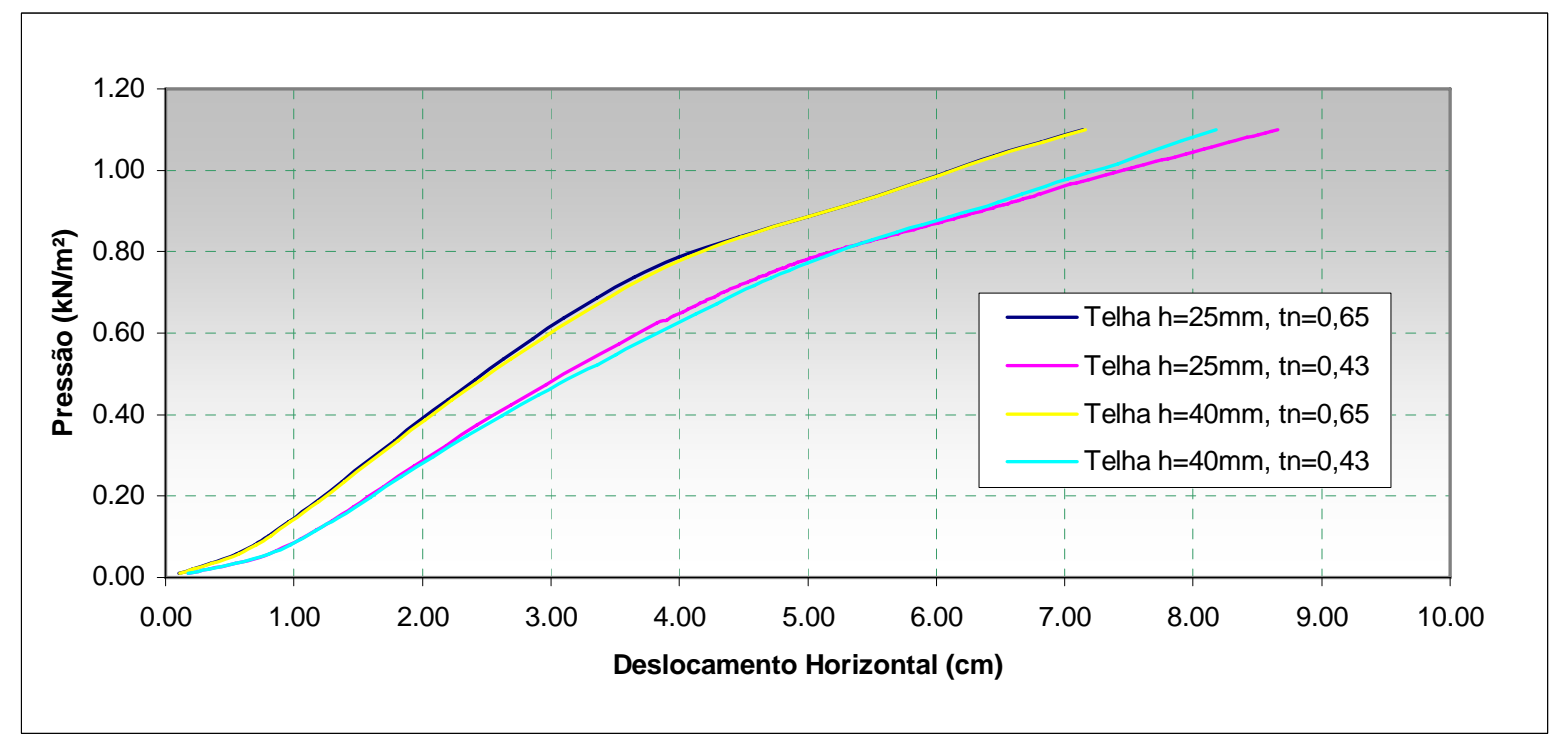

a) Comparação dos deslocamentos horizontais

Figura 4.2 - Comparação entre deslocamentos horizontais e verticais para quatro perfis de telha.

\subsection{Metodologia de Análise dos Resultados}

Para análise de cada modelo foram gerados seis gráficos, uma tabela e duas figuras com as tensões nodais de von Mises e tensões normais ao plano da seção 
transversal, de maneira a permitir avaliar os fenômenos de interesse.

Como exemplo serão mostrados os resultados do modelo $U_{e}$ $250 \times 85 \times 25 \times 2$, com vão de $7524 \mathrm{~mm}$, a telha possui $25 \mathrm{~mm}$ de altura e espessura $0,43 \mathrm{~mm}$. 0 primeiro gráfico (Figura 4.3) permite analisar a eventual distorção do perfil.

No gráfico da Figura 4.3 é plotado o deslocamento relativo na horizontal ( $\beta$ ) entre o nó da alma da seção distorcida (nó $\mathrm{A}, \mathrm{B}, \mathrm{C}, \mathrm{D}, \mathrm{E}$ ) e o nó da seção fictícia (linha vermelha pontilhada) sem ocorrência de distorção (nó A', B', C', D', E'). A seção fictícia é adquirida ligando o primeiro nó da malha da alma ao segundo nó e prolongando-se esta linha até o comprimento da altura da alma. Os nós A', B', C', D' e E' são adquiridos dividindo-se a alma da seção fictícia com o mesmo número de nós da alma distorcida.

Para a Figura 4.3 é adotada a seguinte simbologia:

$\beta$ : parcela do deslocamento horizontal referente à distorção lateral da alma;

$\delta$ : parcela do deslocamento horizontal referente à torção do perfil;

$w$ : deslocamento horizontal total.
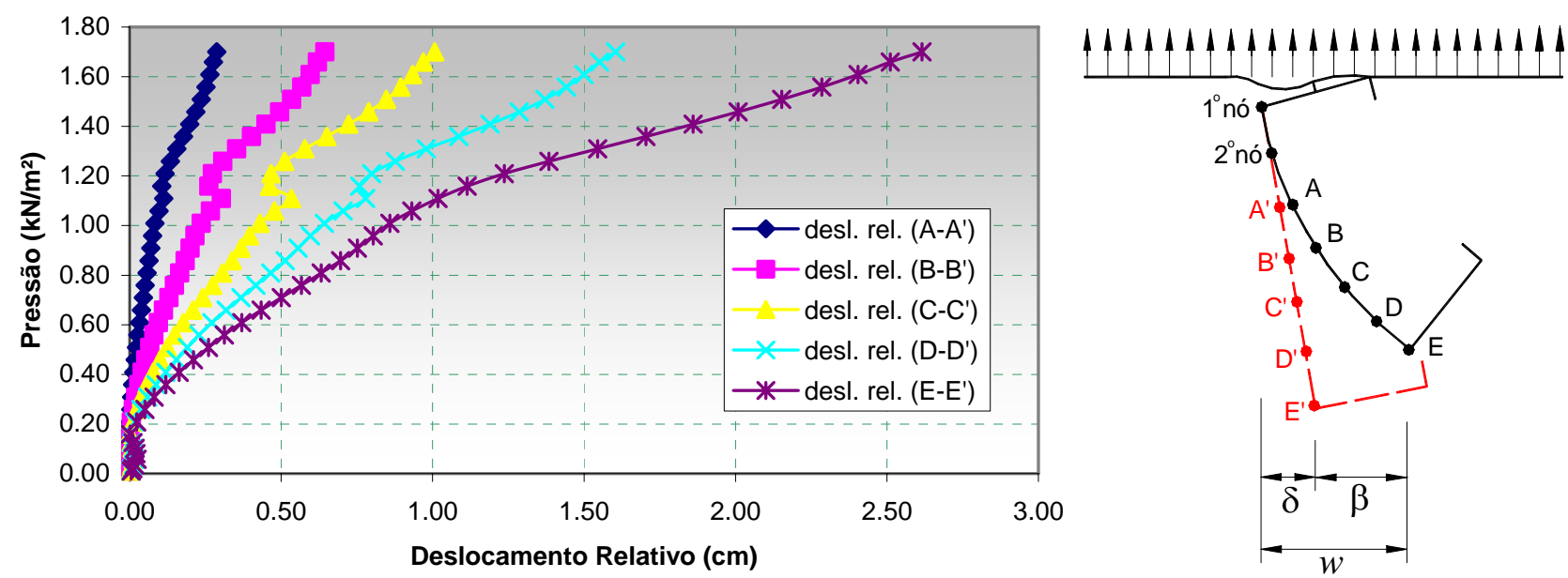

Figura 4.3 - Análise de distorção do perfil.

Analisando a Figura 4.3 pode-se perceber uma descontinuidade das curvas próximo à pressão de $1,10 \mathrm{kN} / \mathrm{m}^{2}$, o que é um indicativo de algum fenômeno nesta pressão.

A Figura 4.4 permite analisar a eventual instabilidade da alma. $O$ procedimento adotado é traçar uma reta imaginária que ligue os pontos extremos da alma e dividi-la no mesmo número de nós que a malha da alma está dividida. No gráfico é então 
registrado o deslocamento relativo ( $\alpha$ ) entre nó da seção (nó $\mathrm{A}, \mathrm{B}, \mathrm{C}, \mathrm{D}, \mathrm{E}$ ) e o respectivo o nó fictício (nó $A^{\prime}, B^{\prime}, C^{\prime}, D^{\prime}, E^{\prime}$ ). No gráfico também é possível verificar a existência de uma descontinuidade das curvas próximo à pressão de 1,10kN/m².

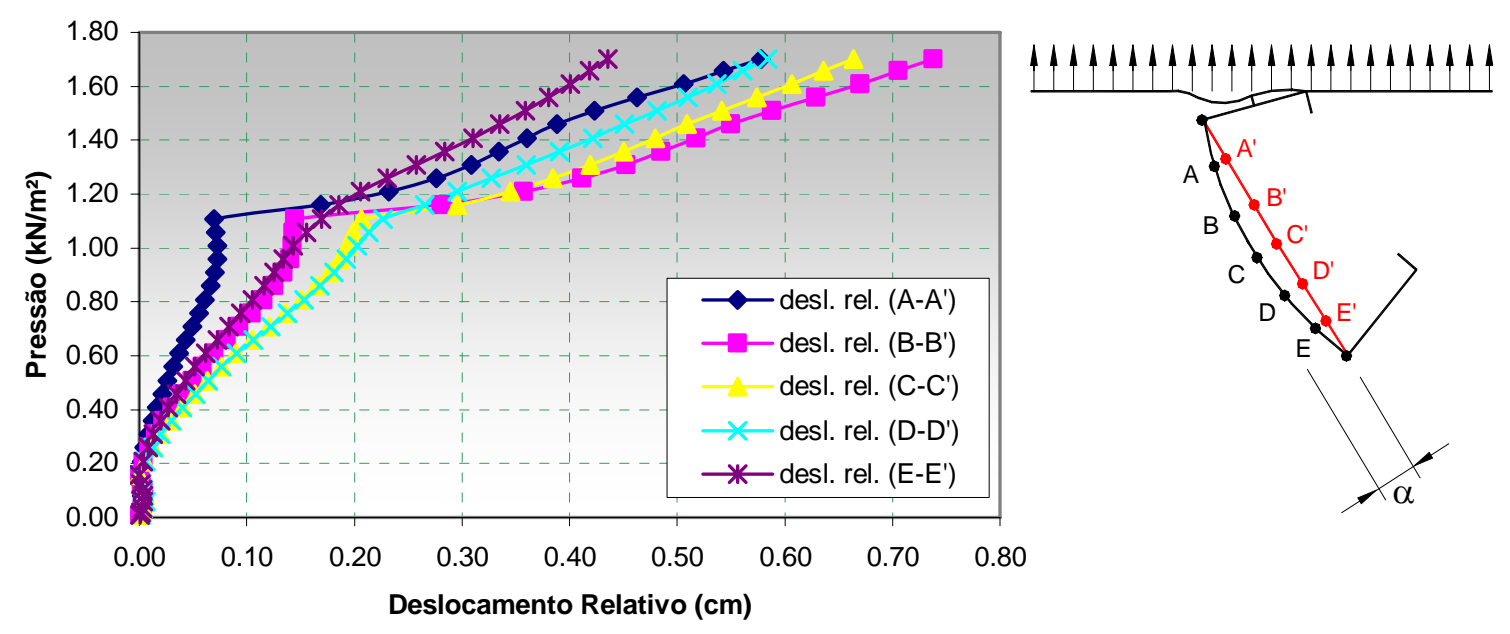

Figura 4.4 - Análise de instabilidade da alma.

O gráfico da Figura 4.5 finaliza a seqüência de gráficos que indicam o deslocamento relativo e o foco de análise passa a ser a mesa inferior. Para realizar a análise da mesa inferior é traçada uma reta fictícia entre os dois pontos extremos da mesa inferior, esta reta é dividida no mesmo número de nós da divisão da malha da mesa inferior do perfil. É então registrado no gráfico a distância, $\gamma$, entre o nó da seção (nó $A$ e B), e o nó fictício (nó A' e B').

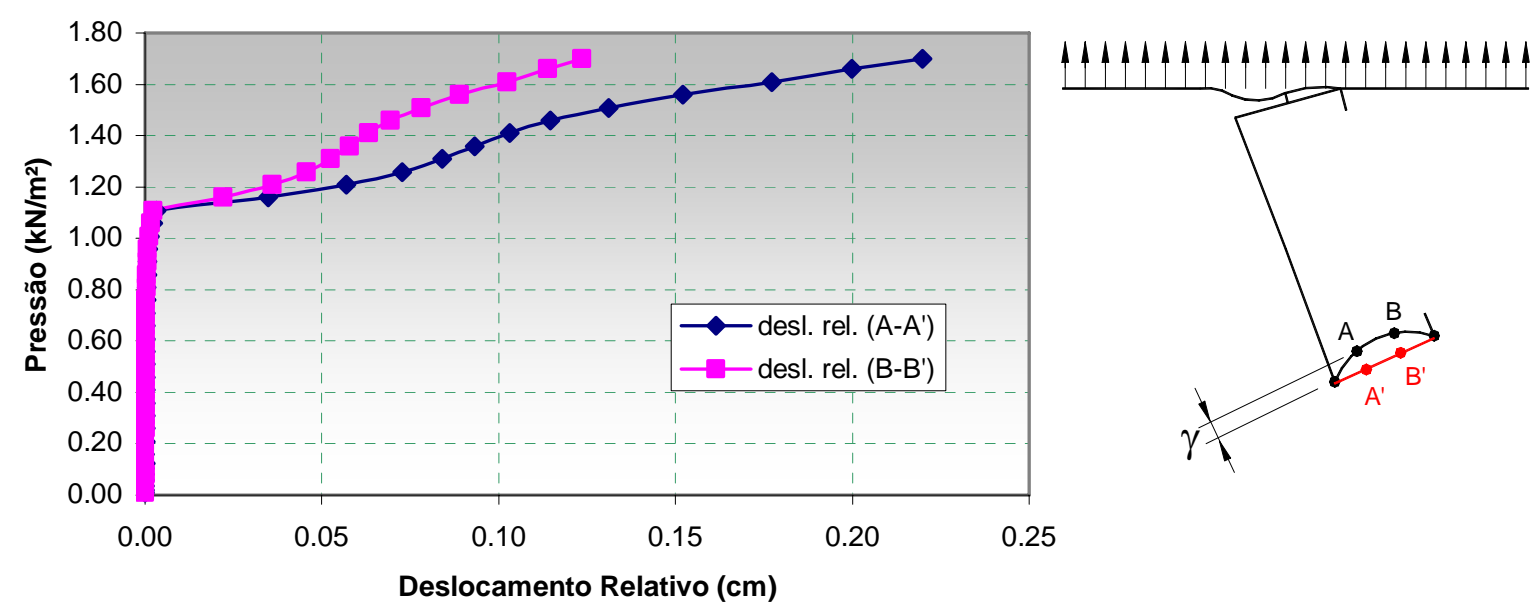

Figura 4.5 - Análise de instabilidade da mesa. 
Os três gráficos já relatados são utéis para distinguir o passo de pressão em que fica caracterizada a ocorrência de algum fenômeno, seja distorção da seção transversal, instabilidade da mesa ou alma, porém é necessário constatar estes fenômenos pela configuração deformada do sistema.

A Figura 4.6 apresenta a configuração deformada nos passos de pressão relativos à pressão de $1,1 \mathrm{kN} / \mathrm{m}^{2}$ e $1,15 \mathrm{kN} / \mathrm{m}^{2}$. A Figura $4.6 \mathrm{a}$ apresenta a posição indeformada e a configuração nos dois passos de pressão analisados, este gráfico necessita de uma escala maior para que seja possível visualizar nitidamente alguma instabilidade, mas pelo ANSYS é possível visualizar a instabilidade da alma a partir da comparação do sistema quando submetido aos dois passos de carga analisados (Figura $4.6 \underline{b}$ e $\underline{c})$.

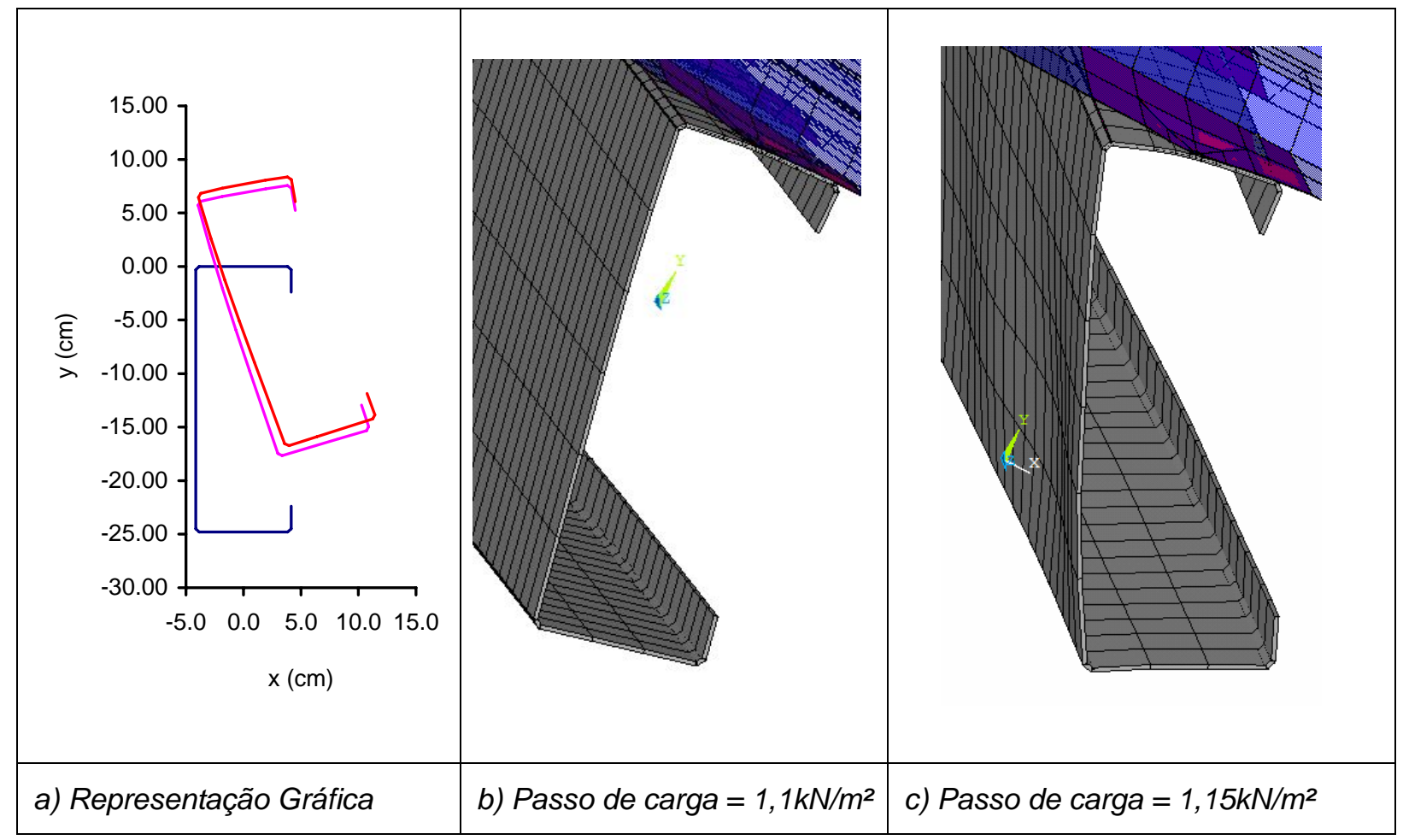

Figura 4.6 - Configuração deformada da seção a meio vão.

Duas tensões são controladas e registradas nos nós da seção a meio vão (Figura 4.7) as tensões do critério de von Mises e as tensões normais ao plano da seção transversal. O registro ocorre sempre que a tensão em um dos nós ultrapassa $\pm 30 \mathrm{kN} / \mathrm{cm}^{2} \mathrm{e}$ um passo de carga anterior. Assim, a pressão associada ao início de escoamento da seção é obtida por interpolação linear considerando os dois passos acima mencionados. 


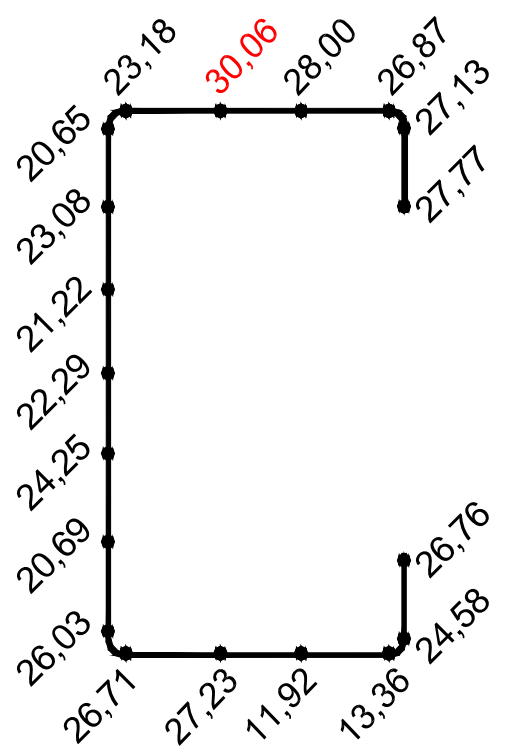

a) Tensões de von Mises (pressão = 1,46kN/m²)

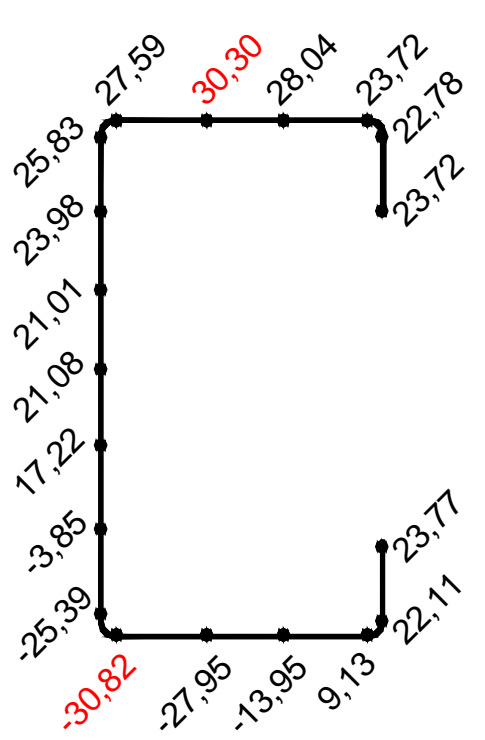

b) Tensões normais ao plano da seção transversal (pressão $=1,21 \mathrm{kN} / \mathrm{m}^{2}$ )

Figura 4.7 - Tensões na seção a meio vão.

Para que haja o controle dos deslocamentos horizontais é plotado o gráfico pressão x deslocamento horizontal da junção alma e mesa inferior (Figura 4.8).

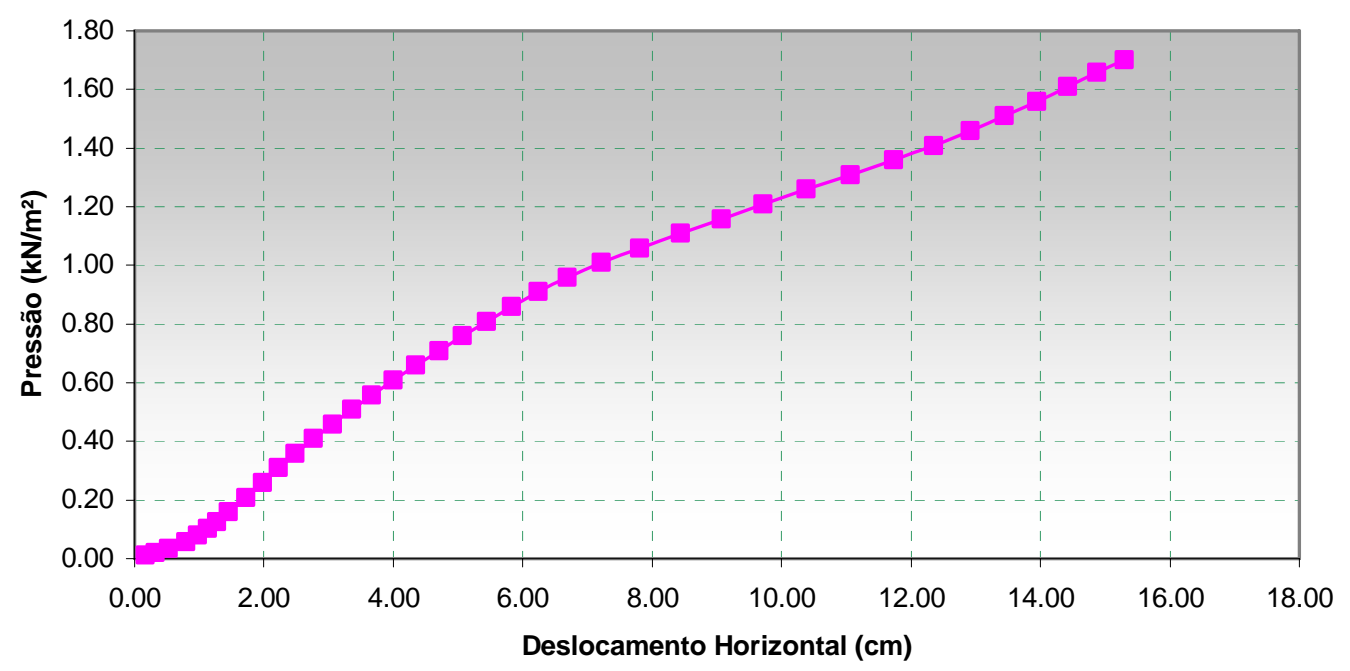

Figura 4.8 - Gráfico pressão x deslocamento horizontal.

Finalmente, é plotado o gráfico da pressão $x$ deslocamento vertical da junção mesa superior e enrijecedor. Optou-se por verificar o deslocamento vertical nesse ponto por ser julgado o deslocamento mais representativo ao analisar a eficiência da vedação, ou seja, o motivo mais relevante para fixar o valor limite para o deslocamento vertical. 
Este gráfico apresenta também o resumo de todos os itens analisados, que também são apresentados numericamente na Tabela 4-3. Estas são as respectivas pressões que provocam cada um dos itens analisados.

É registrado o limite de deslocamento $L / 120$ ( $L$ é o vão da terça) para a análise elástica de terça isolada e a adquirida no modelo numérico, algum fenômeno de instabilidade apresentado, como no exemplo instabilidade da alma, o escoamento longitudinal da seção e o escoamento segundo o critério de von Mises, e a pressão necessária para atingir o momento fletor resistente de cálculo da terça com base no escoamento da seção bruta, $M_{R}=W \cdot f_{y}$, e o escoamento da seção efetiva, $M_{R, e f}=W_{e f} \cdot f_{y}$. Além da reta resultante da análise elástica de deslocamento da terça isolada.

\begin{tabular}{|c|c|c|}
\hline- Modelo & $\longrightarrow$-1/120 no Modelo & $-\leq$ Wef.fy \\
\hline$x-$ W.fy & $\rightarrow$ - Instab. Alma & — Esc. Longit. \\
\hline$\smile$ Esc. Von Mises & _ An. Elást. - Ter & I/120 An. Elást. \\
\hline
\end{tabular}

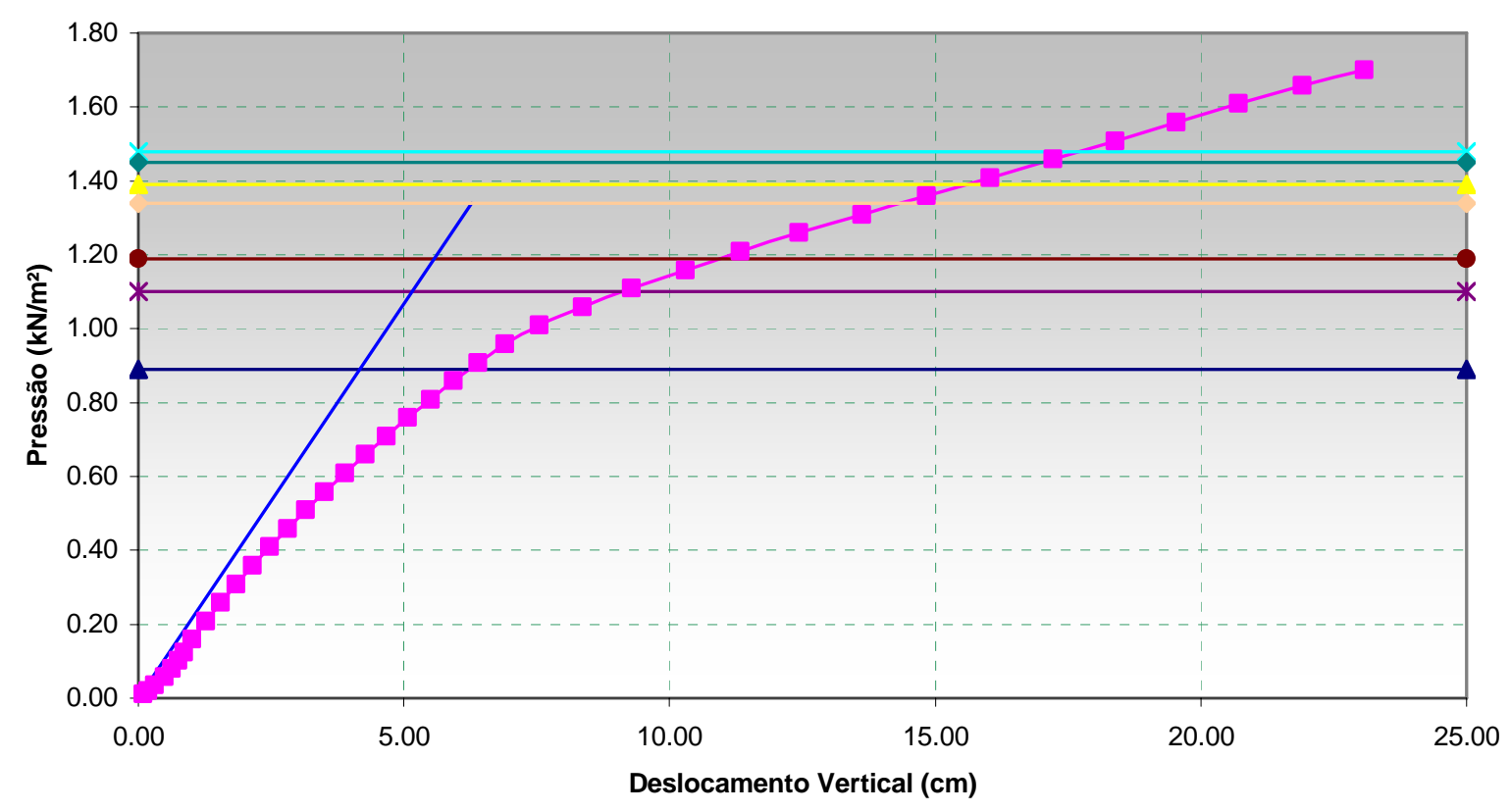

Figura 4.9 - Gráfico pressão x deslocamento vertical e resumo de todos os parâmetros analisados. 
Tabela 4-3 - Pressões associadas à ocorrência de vários estados limites.

\begin{tabular}{|c|r|}
\cline { 2 - 2 } \multicolumn{1}{c|}{ Ocorrência } & $\begin{array}{r}\text { Pressão aplicada } \\
\left(\mathrm{kN} / \mathrm{m}^{2}\right)\end{array}$ \\
\hline Instabilidade da Alma & 1,10 \\
\hline Wef.fy & 1,39 \\
\hline W.fy & 1,48 \\
\hline Escoamento Longitudinal & 1,19 \\
\hline Escoamento de Von Mises & 1,45 \\
\hline L/120, Análise Elástica de Terça Isolada & 1,34 \\
\hline L/120, no Modelo Numérico & 0,89 \\
\hline
\end{tabular}

\subsection{Análise dos Estados Limites}

Dois estados limites devem ser verificados, o estado limite último e o estado limite de serviço. Os estados limites últimos são aqueles associados ao colapso parcial ou total da estrutura, os quais compreendem perda de equilíbrio da estrutura ou parte dela como corpo rígido, deformação excessiva, ruptura ou instabilidade. O estado limite de serviço corresponde a situações além das quais critérios de serviço especificados não são mais atendidos, portanto para as terças consiste em deslocamentos excessivos que venham a prejudicar a estanqueidade, a estética ou provocar danos em componentes a elas vinculados.

Para terças em geral é proposto pela NBR 14762:2001 o limite de deslocamentos de L/180 ( $L$ é o vão da terça). Como a análise será feita em conjunto com casos associados a estados limites últimos, convencionou-se adotar o limite L/120.

A Tabela 4-4 mostra os valores de pressão aplicados à telha para atingir cada um dos itens analisados, os valores são mostrados para os vãos extremos de cada seção transversal analisada. É importante ressaltar que o único modelo dentre os apresentados nesta tabela em que foi identificada instabilidade e escoamento da seção, seja pelo critério de von Mises ou escoamento longitudinal foi o modelo com perfil $U_{e}$ 250x85x25x2 e vão: $7524 \mathrm{~mm}$, no entanto a pressão limite também é referente a atingir o deslocamento excessivo, os dados deste modelo foram propositalmente indicados no item anterior, na Tabela 4-3.

$\mathrm{Na}$ Tabela 4-4 é mostrada a grande diferença entre atingir o limite de deslocamentos identificado pela análise elástica de terça biapoiada e pela análise numérica, as diferenças chegam a $60 \%$ como no modelo $\cup_{\mathrm{e}} 200 \times 75 \times 20 \times 2$ e vão: $5814 \mathrm{~mm}$. 
Outra questão a salientar são os valores resultantes dos processos normativos que ora está muito a favor da segurança, $U_{e} 250 \times 85 \times 25 \times 2$ e vão:9576mm, e ora está contra a segurança, $\cup_{e} 250 \times 85 \times 25 \times 3$ e vão:7524mm.

Também é apresentado na Tabela 4-4 na última coluna o fator $\mathrm{R}$ necessário para limitar os deslocamentos excessivos. Pelos valores encontrados é possível simplificadamente adotar $\mathrm{R}=0,6$ para terças biapoiadas em perfil $\mathrm{U}_{\mathrm{e}}$.

Tabela 4-4 - Valores de pressão $\left(\mathrm{kN} / \mathrm{m}^{2}\right)$, para os itens analisados nos modelos extremos de cada faixa de vão estudada.

\begin{tabular}{|c|c|c|c|c|c|c|c|c|}
\hline \multirow{2}{*}{$\begin{array}{c}\text { Seção } \\
\text { transversal } U_{e}\end{array}$} & \multirow{2}{*}{ vão } & \multicolumn{6}{|c|}{ Pressão* $\left(\mathrm{kN} / \mathrm{m}^{2}\right)$} & \multirow{2}{*}{$\mathrm{R}^{\star \star}$} \\
\hline & & P1 & P2 & P3 & P4 & P5 & P6 & \\
\hline \multirow{2}{*}{$150 \times 60 \times 20 \times 1,5$} & 4788 & 1,06 & 1,11 & 0,95 & 0,65 & 0,42 & 0,74 & 0,61 \\
\hline & 6498 & 0,58 & 0,60 & 0,38 & 0,35 & 0,23 & 0,41 & 0,60 \\
\hline \multirow{2}{*}{$150 \times 60 \times 20 \times 2,65$} & 4788 & 1,86 & 1,86 & 1,60 & 1,13 & 0,74 & 1,30 & 0,61 \\
\hline & 6840 & 0,92 & 0,92 & 0,55 & 0,54 & 0,37 & 0,64 & 0,59 \\
\hline \multirow{2}{*}{$200 \times 75 \times 20 \times 2$} & 5814 & 1,58 & 1,62 & 1,56 & 0,98 & 0,63 & 1,03 & 0,62 \\
\hline & 8208 & 0,83 & 0,87 & 0,58 & 0,50 & 0,33 & 0,54 & 0,60 \\
\hline \multirow{2}{*}{$250 \times 85 \times 25 \times 2$} & 7524 & 1,39 & 1,48 & 1,34 & 0,89 & 0,56 & 0,56 & 0,64 \\
\hline & 9576 & 0,86 & 0,91 & 0,65 & 0,57 & 0,34 & 0,34 & 0,66 \\
\hline \multirow{2}{*}{$250 \times 85 \times 25 \times 3$} & 7524 & 2,12 & 2,12 & 1,95 & 1,31 & 0,85 & 0,85 & 0,62 \\
\hline & 9576 & 1,33 & 1,33 & 0,95 & 0,83 & 0,53 & 0,53 & 0,62 \\
\hline
\end{tabular}

Onde:

P1: Pressão correspondente ao $\mathrm{M}_{\mathrm{R}}=\mathrm{W}_{\mathrm{ef}} \mathrm{f}_{\mathrm{y}}$;

P2: Pressão correspondente ao $M_{R}=W . f_{y}$;

P3: Pressão correspondente a atingir L/120 na análise elástica de deslocamento;

P4: Pressão correspondente a atingir L/120 no modelo numérico;

P5: Pressão correspondente ao $M_{R}=R . W_{\text {ef }} f_{y}$ como definido pela NBR 14762:2001;

P6: Pressão correspondente ao $M_{R}=R$. $W_{\text {ef. }} . f_{y}$ como definido pelo AISI (2001).

Nota: * Valores de pressão para terças com largura de influência de 2 metros.

** Valor do fator $\mathrm{R}$ necessário se considerado como limite o limite de deslocamento L/120 definido na modelagem numérica.

\subsubsection{Estado Limite de Serviço}

Devido à significativa resposta não-linear do sistema telha-terça, os resultados da análise paramétrica permitiram determinar uma expressão para avaliar o deslocamento em função dos demais parâmetros envolvidos.

Para isto foi empregado o programa Table Curve 3D, onde após várias 
simulações optou-se por considerar um eixo relativo parâmetro $L^{3} / W$, sendo $L$ o vão da terça e $W$ o módulo de resistência elástico da seção bruta, o outro eixo relativo à força uniformemente distribuída na terça $(p)$, ou seja, o produto da pressão aplicada na telha pela largura de influência e o outro eixo com a incógnita, o deslocamento vertical, representado por $d$.

Diversas expressões são fornecidas pelo programa e somente as mais expressivas são listadas. Foram selecionadas as que fossem de fácil aplicação e que proporcionaram boa concordância com a análise numérica. A concordância foi avaliada pelo fator $r^{2}$, o fator tende ao valor 1 quanto melhor a aproximação.

As expressões (4.1) e (4.2) são relativamente simples e apresentam $r^{2}=0,9629$ e 0,93 , respectivamente, portanto refletindo um ajuste satisfatório.

$$
\begin{aligned}
& \ln (d)=-17,59+1,20 \cdot \ln \left(\frac{L^{3}}{W}\right)+1,41 \cdot \ln (p) \\
& d=1 /\left(24,63 \cdot 10^{-3}-7,87 \cdot \sqrt{\frac{L^{3}}{W}}+40,85 \cdot 10^{-2} /(\sqrt{p})\right)
\end{aligned}
$$

A Figura 4.10 apresenta as superfícies ajustadas pelas expressões (4.1) e (4.2), na figura a superfície é apresentada por mapa de cores e os pontos são plotados, sendo que os pontos vermelhos são os que se encontram mais distanciados.

Já a Figura 4.11 apresenta uma comparação qualitativa entre a equação (4.1) e a superfície delimitada pelas análises numéricas, ficando evidente o distanciamento em alguns pontos, no entanto, uma boa aproximação ao se considerar a superfície como um todo. 


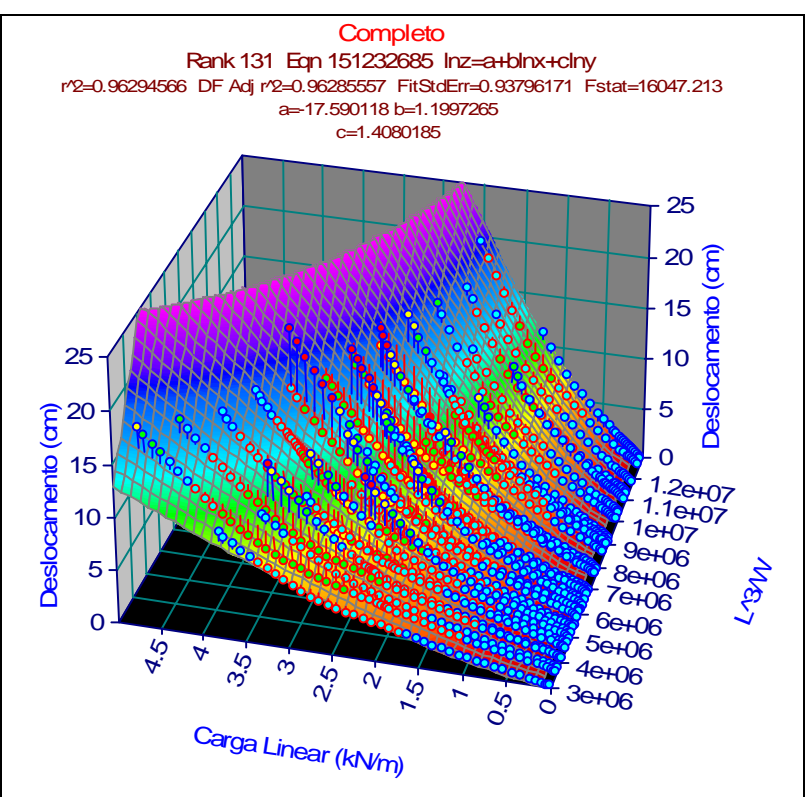

a) Superfície aproximada por equação composta por logaritmo neperiano

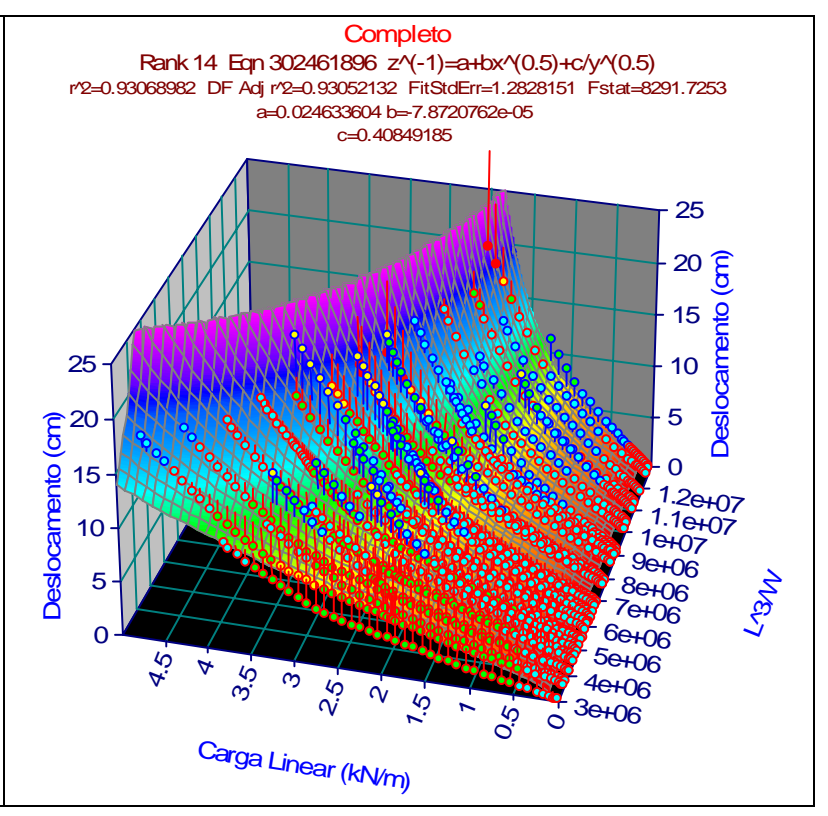

b) Superfície aproximada por equação composta por raiz quadrática

Figura 4.10 - Aproximação dos deslocamentos verticais por superfícies.

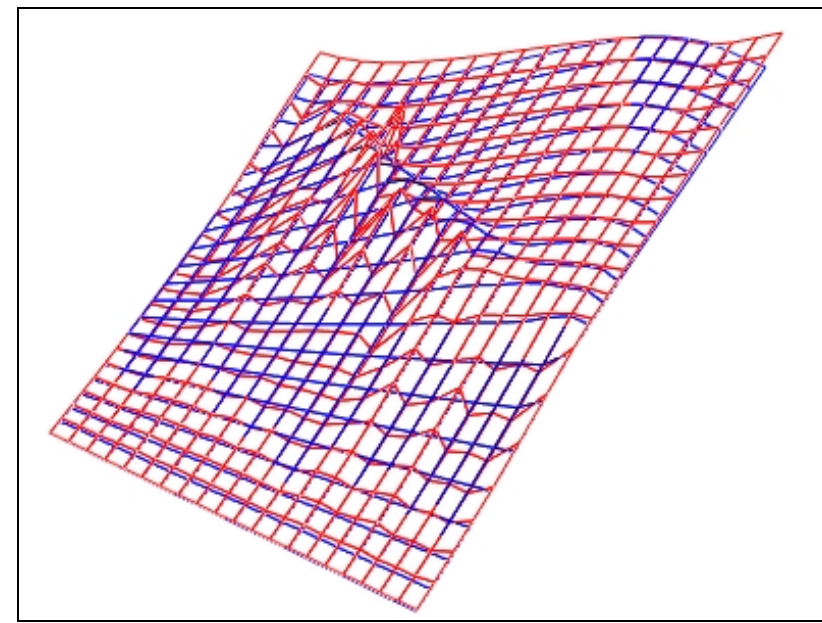

a) Comparação entre a superfície dos modelos, vermelha, e a superfície aproximada, azul

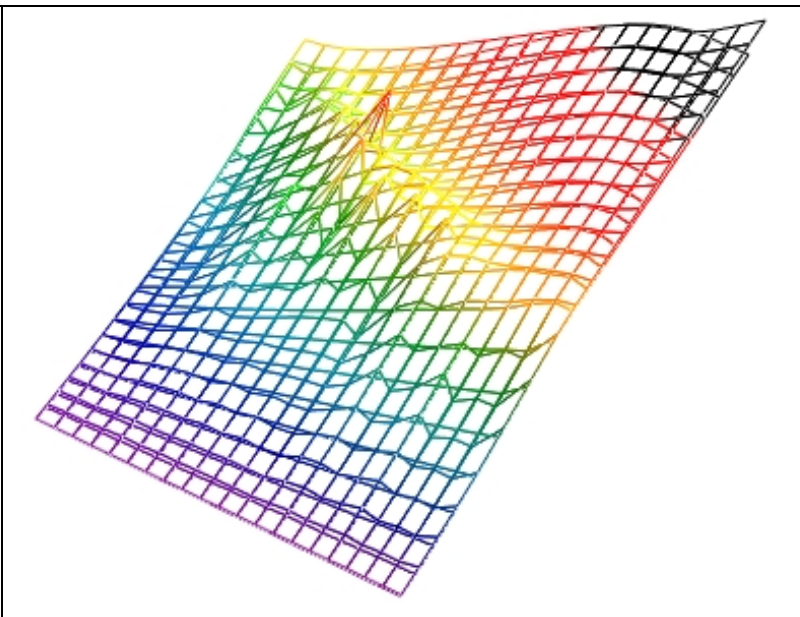

b) Comparação entre as superfícies ambas em mapa de cores

Figura 4.11 - Comparação qualitativa da superfície gerada pelos dados dos modelos e a gerada pela superfície composta por equação logarítmica neperiana.

Outra aproximação que resultou em bons resultados foi restringir os valores de entrada somente em deslocamentos entre L/100 e L/150. A equação (4.3) é plotada na Figura 4.12 e o fator $r^{2}$ resultante é igual a 0,9825. Assim a equação encontrada apesar de não prever satisfatoriamente todo o comportamento do modelo, apresenta a melhor concordância. 


$$
\ln (d)=-6,98+33,47 \cdot 10^{-3} \cdot\left(\ln \left(\frac{L^{3}}{W}\right)\right)^{2}+1,09 \cdot \ln (q)
$$

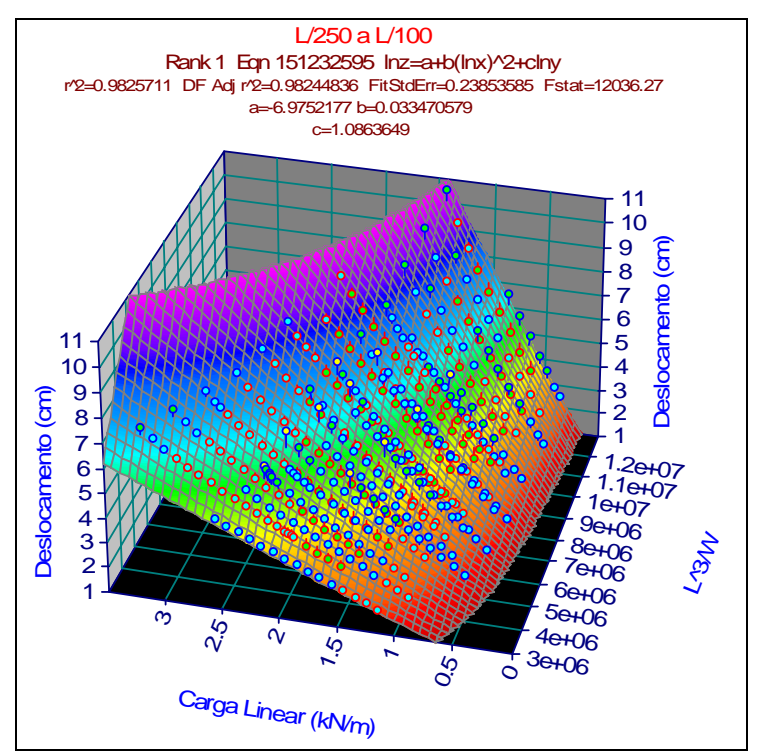

Figura 4.12 - Aproximação dos deslocamentos verticais somente nos trechos entre l/100 e I/250.

A Figura 4.13 mostra a comparação ao se utilizar as equações propostas. Dois modelos são apresentados o primeiro, Figura 4.13a, apresentou diferenças pequenas a partir da utilização de todas as equações, já a Figura 4.13b, foi um dos modelos que apresentou maiores diferenças. O ponto de análise das diferenças é aquele correspondente a um deslocamento de L/180.

Na Figura 4.13 em ambos os modelos constata-se que a equação (4.3) apresenta diferença muito pequena, enquanto a equação (4.1) apresenta menor exatidão apesar de não possuir limite de deslocamentos para ser empregada, já a equação (4.2) mostra que as diferenças são muito grandes e que não é interessante utilizar equações ainda mais simplificadas.

$\mathrm{Na}$ Figura 4.14 fica clara a comparação ao se utilizar a equação (4.1) e (4.3), é plotada a superfície resultante das diferenças entre as superfícies geradas por cada equação, sendo que as diferenças ficam mais acentuadas onde o domínio da equação (4.3) não é mais válido. 


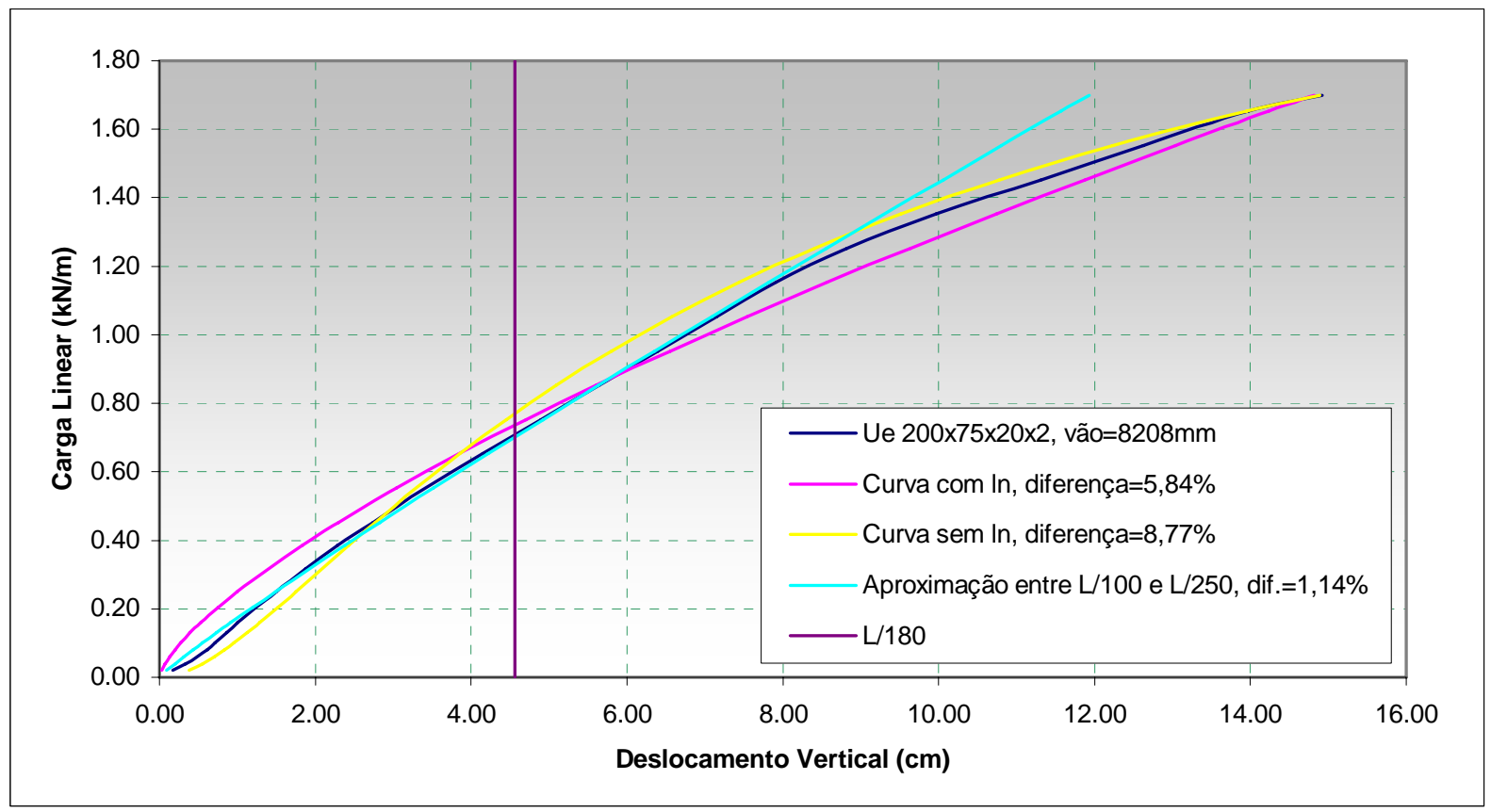

a) Modelo que obteve boa aproximação por todas as curvas analisadas

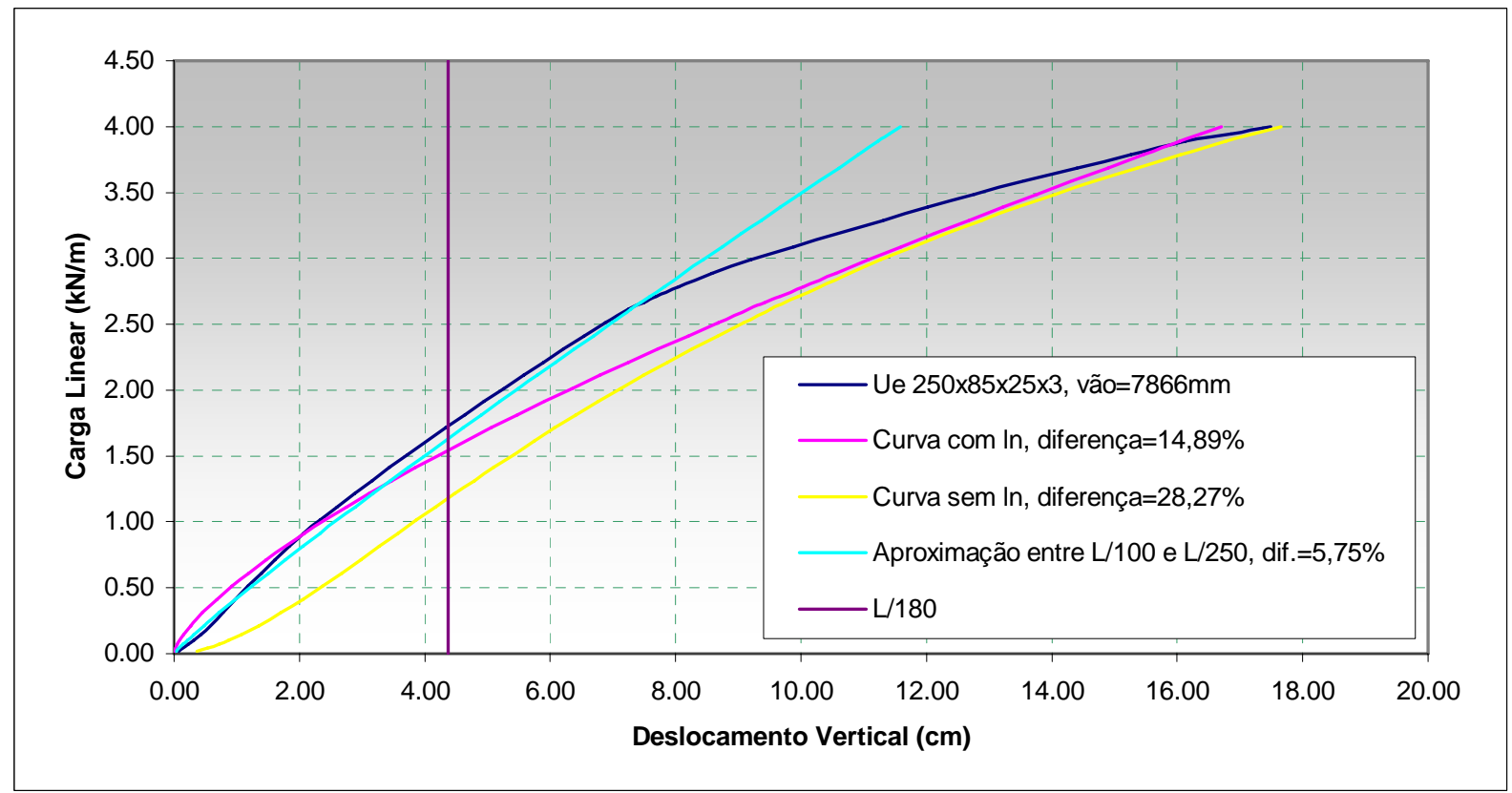

b) Modelo apresentando diferenças maiores

Figura 4.13 - Comparação entre curvas analisadas em dois modelos. 


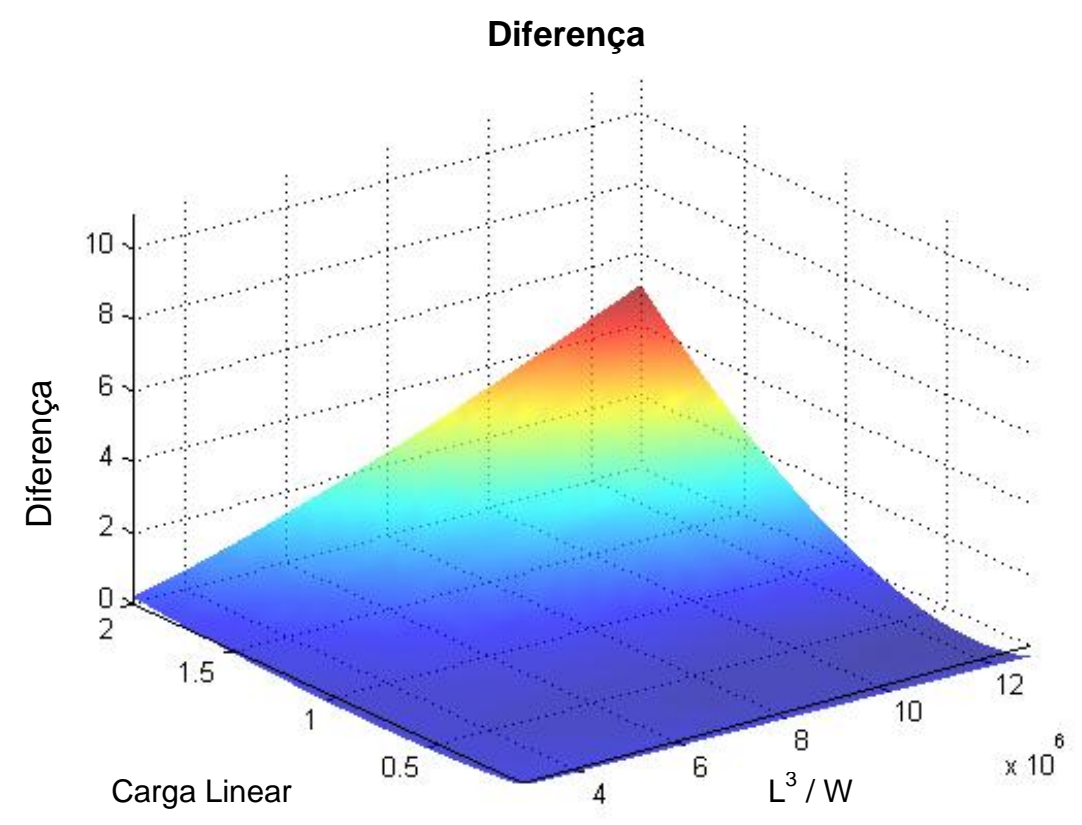

Figura 4.14 - Diferença de utilização entre a equação 4.1 e 4.3.

\subsubsection{Estado Limite Último}

Dos modelos analisados no programa ANSYS cinco apresentaram instabilidade de alma, sendo todos em perfil $U_{e} 250 \times 85 \times 25 \times 2$ e vãos $7524,7866,8208$, $8550,8892 \mathrm{~mm}$. O estudo mais detalhado de como pode ser determinado o momento resistente da terça é realizado no próximo capítulo.

Os resultados de instabilidade de alma apresentados pelo programa ANSYS devem ser analisados com cautela, lembrando que o ensaio ao qual o modelo numérico foi calibrado não apresentou instabilidade de nenhuma natureza, sendo o deslocamento excessivo o fator limitante.

Assim, dá-se por necessário antes de qualquer afirmação, que o modelo numérico seja comparado a ensaios em que fique evidente o fenômeno de instabilidade. Deve-se atentar particularmente às imperfeições iniciais, ao grau de restrição que os apoios laterais (simulação dos parafusos) oferecem e às plastificações que acontecem nas regiões de ligação. 



\section{MÉTODO DA RESISTÊNCIA DIRETA (MRD) APLICADO AO SISTEMA TERÇA- TELHA}

O presente capítulo foi desenvolvido basicamente durante dois meses de estágio na Jonhs Hopkins University em Baltimore, EUA sob a orientação dos Professores Maximiliano Malite e Benjamin W. Schafer.

Os métodos adotados pelas normas e procedimentos de cálculo para o dimensionamento de terças até então concentram-se na utilização do fator $\mathrm{R}$ (Norma Brasileira (NBR 14762:2001) e AISI (2001)) e o método desenvolvido por Peköz e Soroushian (1982) (Eurocode 3 - parte 1.3 (1996)). Apesar de, a partir de 2001, a especificação do AISI apresentar o método da resistência direta como alternativa de cálculo, terça conectada à telha ainda não é um tópico claramente abrangido pelo método devido à necessidade de mais pesquisas.

Desta forma, no presente capítulo apresenta-se o estudo dos perfis analisados no trabalho utilizando o MRD. O MRD é aplicado considerando que a seção está restringida por vinculações que simulam o efeito da conexão à telha (Figura 5.1a). Já as tensões à que a seção está submetida é considerada de duas formas: (i) tensões geradas apenas pela flexão $\left(\sigma_{M}\right)$ (item 5.1) e (ii) tensões combinadas da flexão $\left(\sigma_{M}\right)$ e da flexotorção $\left(\sigma_{B}\right)$ (item 5.3). 


\subsection{Prática Atual para o Cálculo de Terças utilizando o Método da Resistência Direta}

O presente item visa mostrar os resultados da utilização do método da resistência direta, tal como ele é utilizado pelos escritórios de cálculo nos EUA, para o dimensionamento de terças restringidas pelas telhas.

Para a utilização do método da resistência direta é necessário proceder a uma análise geral de estabilidade elástica do perfil, de modo a se obter tensões críticas e os respectivos modos de flambagem. Para tal, será empregado o programa CUFSM, via faixas finitas, desenvolvido por Schafer, o qual permite considerar restrições elásticas.

Foi adotado módulo de elasticidade (E) igual a $20500 \mathrm{kN} / \mathrm{cm}^{2}$ e tensão de referência $\mathrm{f}_{\mathrm{y}}=300 \mathrm{MPa}$, com distribuição de tensões correspondentes à flexão em torno do eixo principal perpendicular à alma (Figura 5.1b). Foi admitida restrição no centro da mesa tracionada por um apoio que bloqueia totalmente o deslocamento horizontal e uma mola rotacional na mesma posição (Figura 5.1a). Os apoios simulam a contribuição da telha, ou seja, considera-se que a telha irá restringir completamente o deslocamento horizontal e a mola de rotação simula a rigidez à rotação imposta pela telha.

Cabe salientar que a convenção de sinais utilizada daqui em diante é a mesma do programa CUFSM, sendo o sinal positivo referente à compressão e negativo à tração (Figura 5.1b).

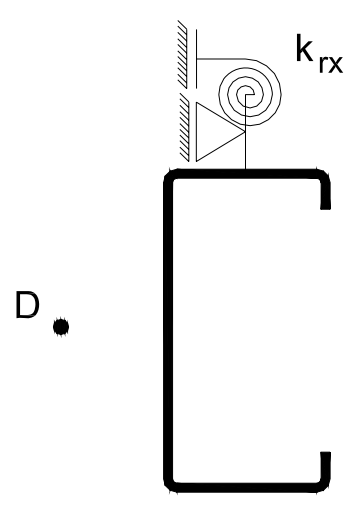

a) Vinculação

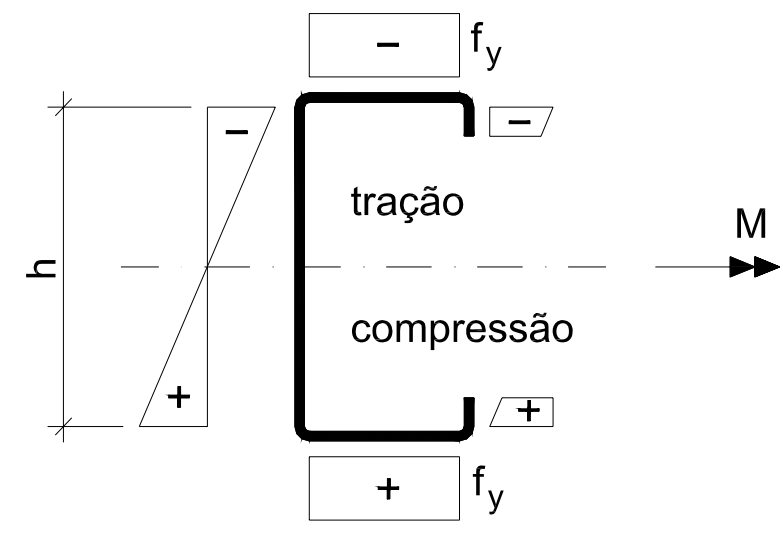

b) Distribuição de tensões adotada

Figura 5.1 - Vinculação e distribuição de tensões para o CUFSM.

A Figura 5.2 mostra os resultados apresentados pelo programa CUFSM para a análise do perfil $U_{e} 250 \times 85 \times 25 \times 2$, utilizando a rigidez de mola $\left(k_{r x}\right)$ igual a 0,68 $\mathrm{kN} . \mathrm{m} / \mathrm{rad} / \mathrm{m}$, determinada pelo procedimento proposto no apêndice A. Como é mostrado, a 
análise de auto-valor leva a três pontos de mínimo bem nítidos, sendo o primeiro referente à flambagem local $\left(M_{c r} / M_{y}=1,18\right)$, o segundo flambagem distorcional $\left(M_{c r d} / M_{y}=1,20\right)$ e 0 terceiro flambagem lateral distorcional ${ }^{*}\left(\mathrm{M}_{\mathrm{cr}} / \mathrm{M}_{\mathrm{y}}=0,56\right)$.

A faixa de vãos considerada (7524 a 9576mm) situa-se após o terceiro mínimo. Segundo a prática atual de cálculo o modo "distorção lateral" é analisado como um modo global, assim sendo para todos os vãos o valor de $M_{c r} / M_{y}$ será igual a 0,56 e emprega-se na análise de momento crítico a curva estabelecida para flambagem lateral com torção (FLT). Da mesma forma, apesar do fenômeno apresentado ser flambagem lateral distorcional o momento crítico é corrigido pelo coeficiente de equivalência de momentos na flexão $\left(\mathrm{C}_{\mathrm{b}}\right)$ que é associado apenas ao modo global (FLT).

O parâmetro $C_{b}$ é calculado segundo a expressão apresentada na NBR 14762:2001 e irá mudar para cada vão analisado. Para a utilização da equação é necessário o máximo valor do momento fletor que não é alterado e coincide com o momento no centro da viga e o momento no primeiro e último quarto do vão, o qual é alterado para cada vão analisado e portanto o valor de $C_{b}$ varia.

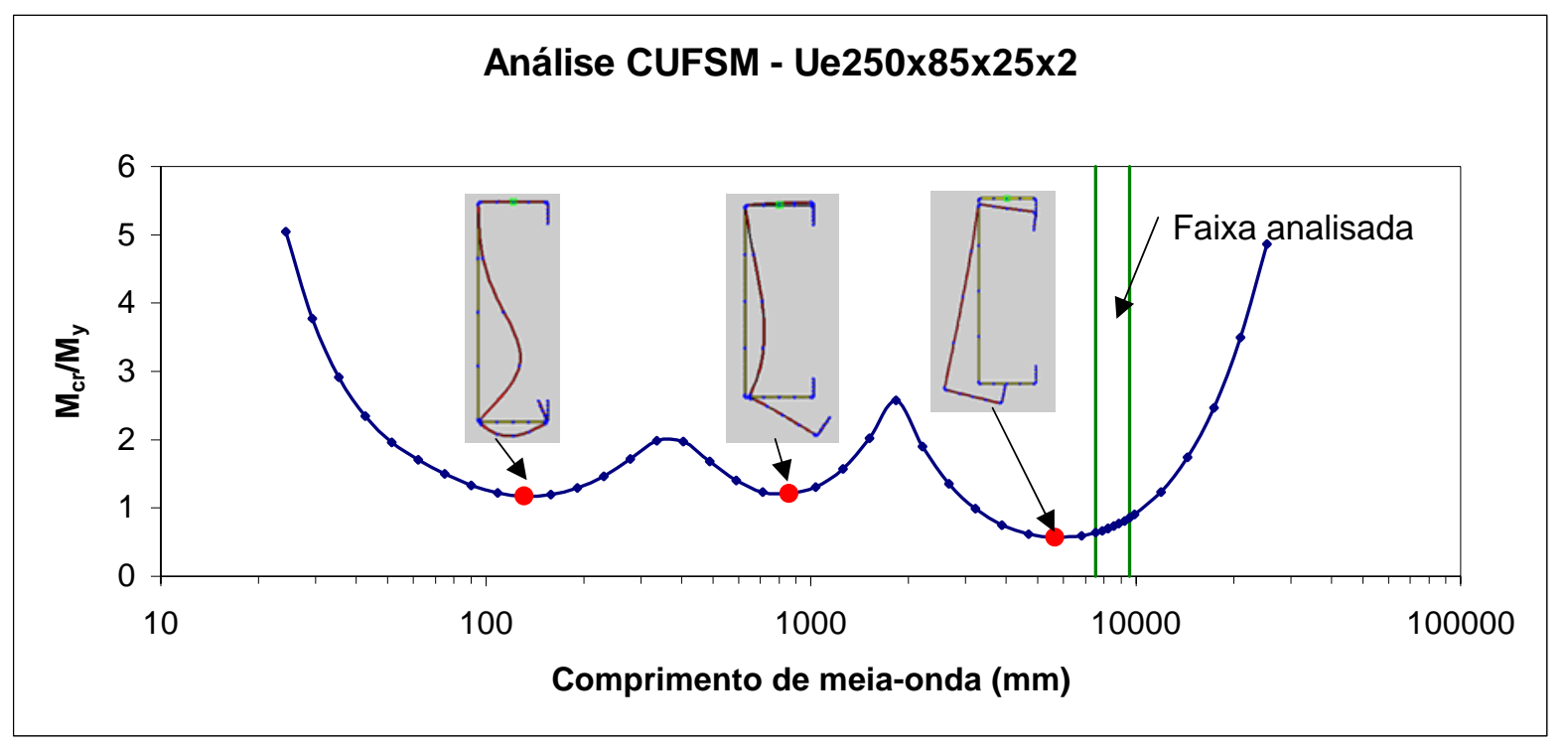

Figura 5.2 - Resultado da análise no programa CUFSM

Seguindo as mesmas diretrizes foram processadas todas as seções e vãos analisados (Figura 5.3) na mesma figura também foram plotadas as curvas associadas ao modo global, $\mathrm{M}_{\mathrm{g}}$, e ao modo local, $\mathrm{M}_{\mathrm{l}}$.

\footnotetext{
* O termo flambagem lateral distorcional provém da tradução direta do termo em inglês: "Iateral distortional buckling".
} 


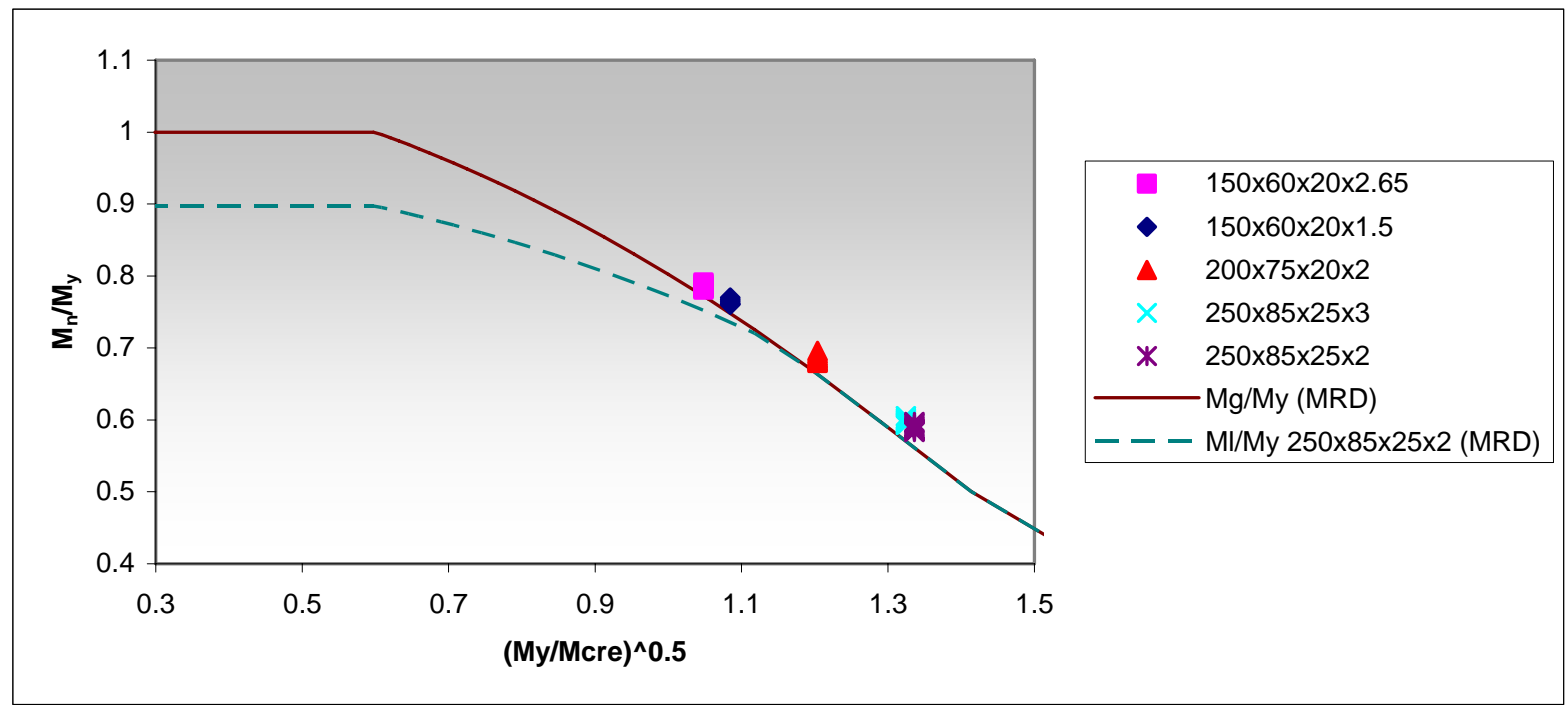

Figura 5.3- Gráfico de resultados para todas as seções analisadas.

O gráfico apresentado na Figura 5.3 mostra a relação estabelecida entre a esbeltez reduzida das barras analisadas e o momento resistente. O gráfico também evidencia a predominância do momento resistente global $\left(\mathrm{M}_{\mathrm{g}}\right)$ sobre o momento resistente local $\left(M_{1}\right)$, já que, somente para o perfil $U_{e} 250 \times 85 \times 25 \times 2$, a curva definida pela equação do momento resistente local $\left(\mathrm{M}_{\mathrm{I}} / \mathrm{M}_{\mathrm{y}}\right)$ não coincide completamente com a curva definida pela equação do momento resistente global $\left(M_{g} / M_{y}\right)$.

Nota-se que as curvas definidas pelo modo global $\left(M_{g}\right)$ e o modo local $\left(\mathrm{M}_{\mathrm{l}}\right)$, comparadas aos valores das simulações é satisfatória. Para perfis mais esbeltos, os resultados encontram-se ligeiramente mais afastados da curva definida para o modo global, já para os perfis mais compactos os resultados das simulações ficam um pouco mais próximos da curva do modo global. Contudo, todos os valores encontram-se acima da curva definida, ou seja, os resultados estão a favor da segurança.

\subsection{Estudo das Tensões Atuantes na Seção Transversal}

Apesar da prática de cálculo ser considerar o carregamento atuante no centro de cisalhamento do perfil (Figura 5.4a) a posição real de aplicação do carregamento é a mesa do perfil (Figura 5.4b) na mesma posição da vinculação estabelecida pela telha simbolizada na figura pelo apoio e a mola rotacional. 


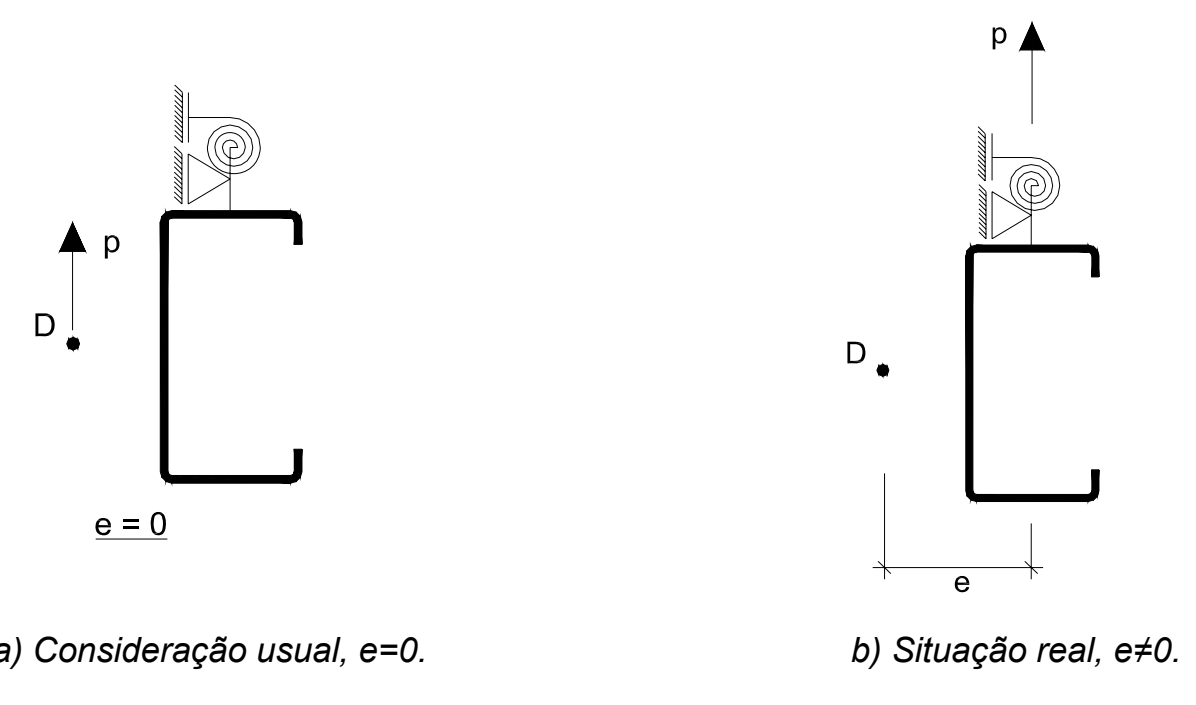

Figura 5.4 - Posicionamento do carregamento aplicado.

Cabe neste momento explicar detalhadamente o gráfico que será utilizado em figuras subseqüentes. A Figura 5.5 apresenta as tensões normais ao longo da seção transversal. $\mathrm{Na}$ figura, o ponto $0 \mathrm{~mm}$ é referente ao início do enrijecedor e consequentemente o último ponto refere-se ao fim do comprimento desenvolvido ao longo da seção transversal, ou seja, o final do outro enrijecedor da seção.

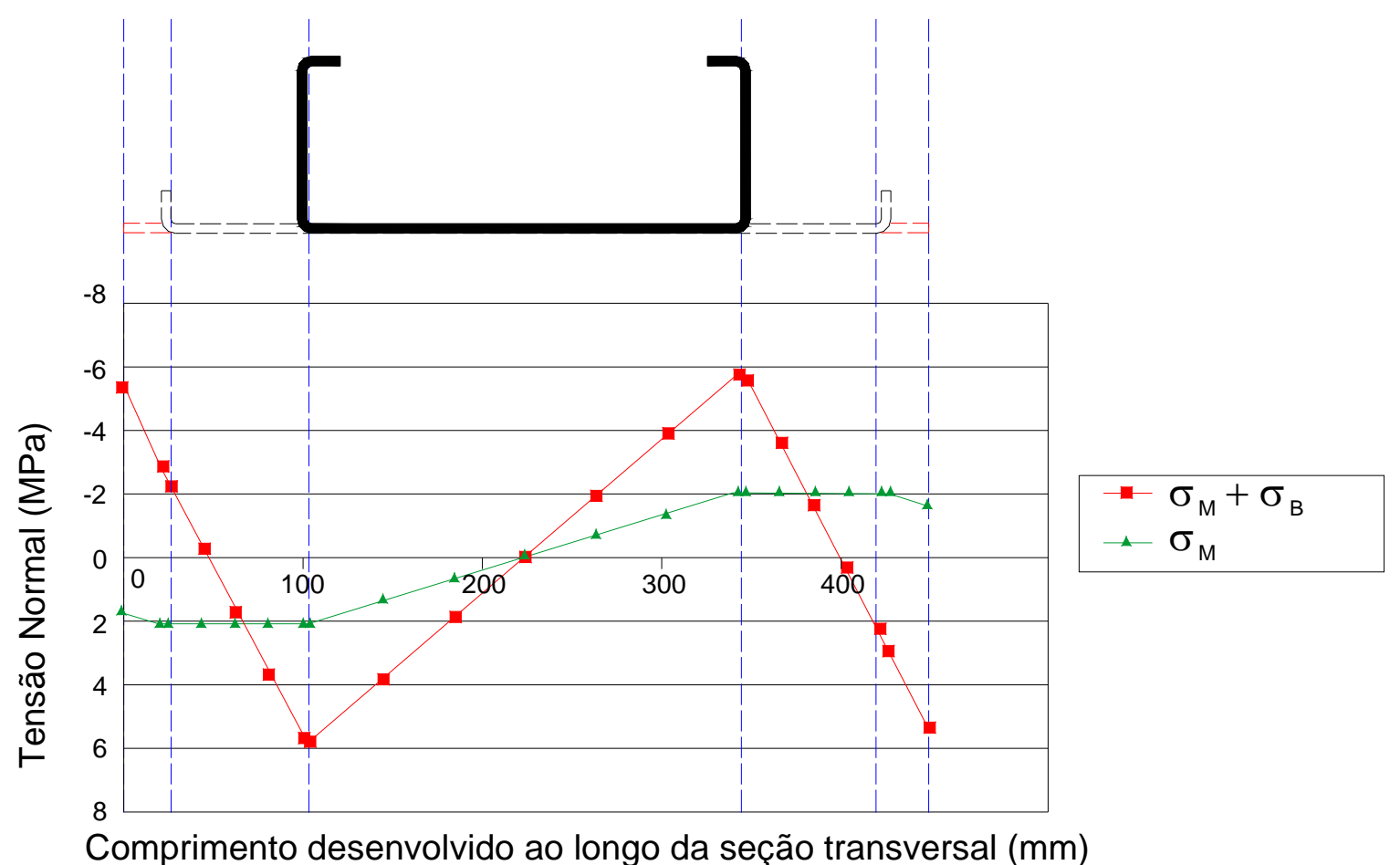

Figura 5.5 - Gráfico de distribuição de tensões ao longo da seção transversal.

A posição de aplicação do carregamento afeta consideravelmente a distribuição e o valor das tensões longitudinais atuantes na seção transversal. Para a 
definição das tensões normais atuantes na seção transversal optou-se por utilizar a teoria de Vlasov.

Na Figura 5.5 são plotados os valores de tensão normal ao longo da seção transversal para o carregamento distribuído de $0,02 \mathrm{~N} / \mathrm{mm}$, aplicado no perfil $U_{e}$ $250 \times 85 \times 25 \times 2$, sem restrição no plano da seção transversal e considerando apoio de vínculo de garfo em ambas as extremidades. É comparada no gráfico a distribuição de tensões considerando-se o carregamento distribuído aplicado no centro de cisalhamento e no centro da mesa superior.

Para carregamento aplicado no centro de cisalhamento o perfil estará sujeito à flexão normal e a distribuição de tensões obedece à equação $\left(\sigma_{M}=\sigma_{z}=M_{x} \cdot y / I_{x}\right)$. No entanto, sendo o carregamento aplicado no centro da mesa superior o perfil estará sujeito não somente a flexão como também à torção (flexo-torção $\left.\sigma_{B}\right)$. Na legenda do gráfico apresentado na Figura $5.5, \sigma_{M}$ representa a tensão proveniente do momento fletor, enquanto, $\sigma_{B}$ representa a tensão normal de flexo-torção, oriunda do bimomento.

O fato de se mudar a posição de aplicação do carregamento amplia consideravelmente o valor das tensões longitudinais atuantes além de alterar a distribuição das tensões. Para a flexão simples, o máximo valor das tensões encontra-se nas mesas, enquanto para o perfil sujeito à flexo-torção, as máximas tensões atuam na junção das mesas com a alma.

\subsubsection{Modelo de Winter para Determinação das Tensões Atuantes em Fase Elástica}

Winter (1950) propôs um modelo simplificado para a determinação das tensões longitudinais atuantes em um perfil sujeito à flexo-torção. O modelo de Winter continua a ser empregado no AISI (2004b).

Na Figura 5.6a tem-se a configuração inicial do problema, carregamento aplicado no centro da mesa superior. Para a determinação das tensões longitudinais o problema é divido em duas partes: (i) o carregamento é aplicado no centro de cisalhamento (D) (Figura 5.6b) e as tensões resultam da teoria de flexão, (ii) o perfil é dividido em duas partes (Figura 5.6d) onde cada parte corresponde a $1 / 4$ da altura da alma (h), mesa e 
enrijecedor, e é aplicada uma força fictícia $p_{f}=\frac{p \cdot e}{h}$ horizontalmente em cada uma das partes. Novamente é utilizada a teoria de flexão para determinar a distribuição de tensões em cada parte.

Finalmente, admite-se a distribuição linear de tensões na alma e procedese à superposição dos efeitos. Tendo-se a distribuição de tensões em cada parte (Figura 5.6d) está determinada para esta parte do modelo a tensão nas mesas e enrijecedores. A tensão na alma ainda não está definida, porém os máximos e mínimos já estão e basta ligalos definindo a distribuição triangular na alma, linha pontilhada na (Figura 5.6e). De posse destas duas distribuições Figura 5.6c e Figura 5.6e o resultado da distribuição das tensões longitudinais é a sobreposição destas duas distribuições.

(+) compressão

$(-)$ tração

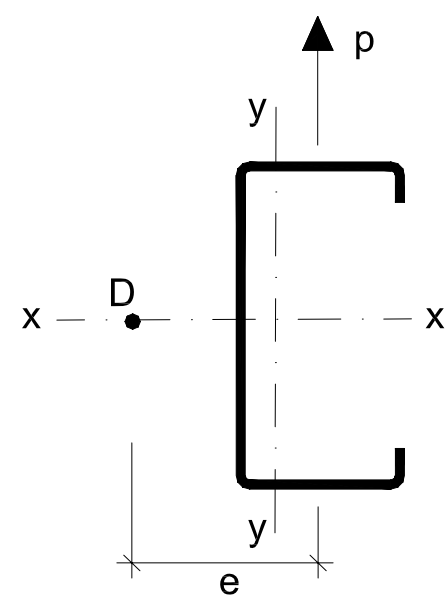

a) Configuração real e convenção de sinais.

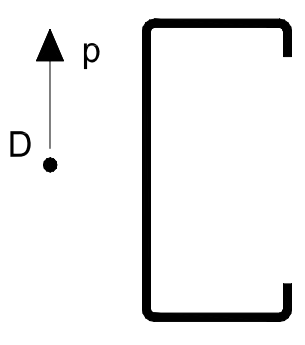

b) Carregamento aplicado em D.
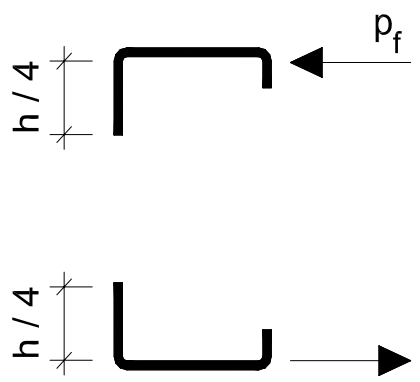

$p_{f}$

d) Proposta de Winter para aplicação do carregamento fictício.

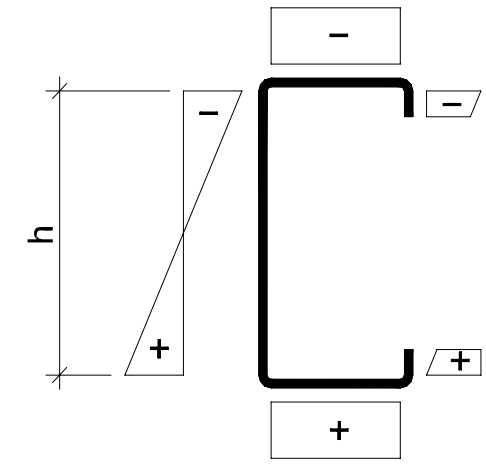

c) Distribuição de tensões para o carregamento aplicado em $D$.

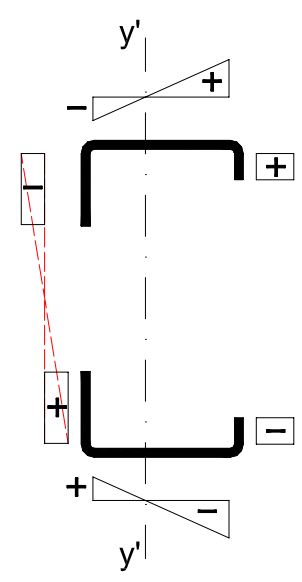

e) Distribuição das tensões para o carregamento fictício e definição da distribuição triangular na alma.

Figura 5.6 - Ilustração do modelo proposto por Winter para flexo-torção (1950). 
Como exemplo, foi analisado o perfil $U_{e} 250 \times 85 \times 25 \times 2$, vão igual a $7524 \mathrm{~mm}$ e carga distribuída (p) igual a $0,02 \mathrm{~N} / \mathrm{mm}$. As tensões obtidas pelo modelo de Winter foram comparadas às tensões calculadas com base na teoria de flexo-torção (Vlasov), teoria de flexão e também às tensões provenientes da análise via MEF. Os resultados são apresentados na Figura 5.7.

O modelo definido por Winter, apesar de sua simplicidade, apresentou ótima concordância com a teoria de flexo-torção (Vlasov) e a análise via MEF, enquanto o mesmo não pode ser dito se considerar apenas os efeitos da flexão.

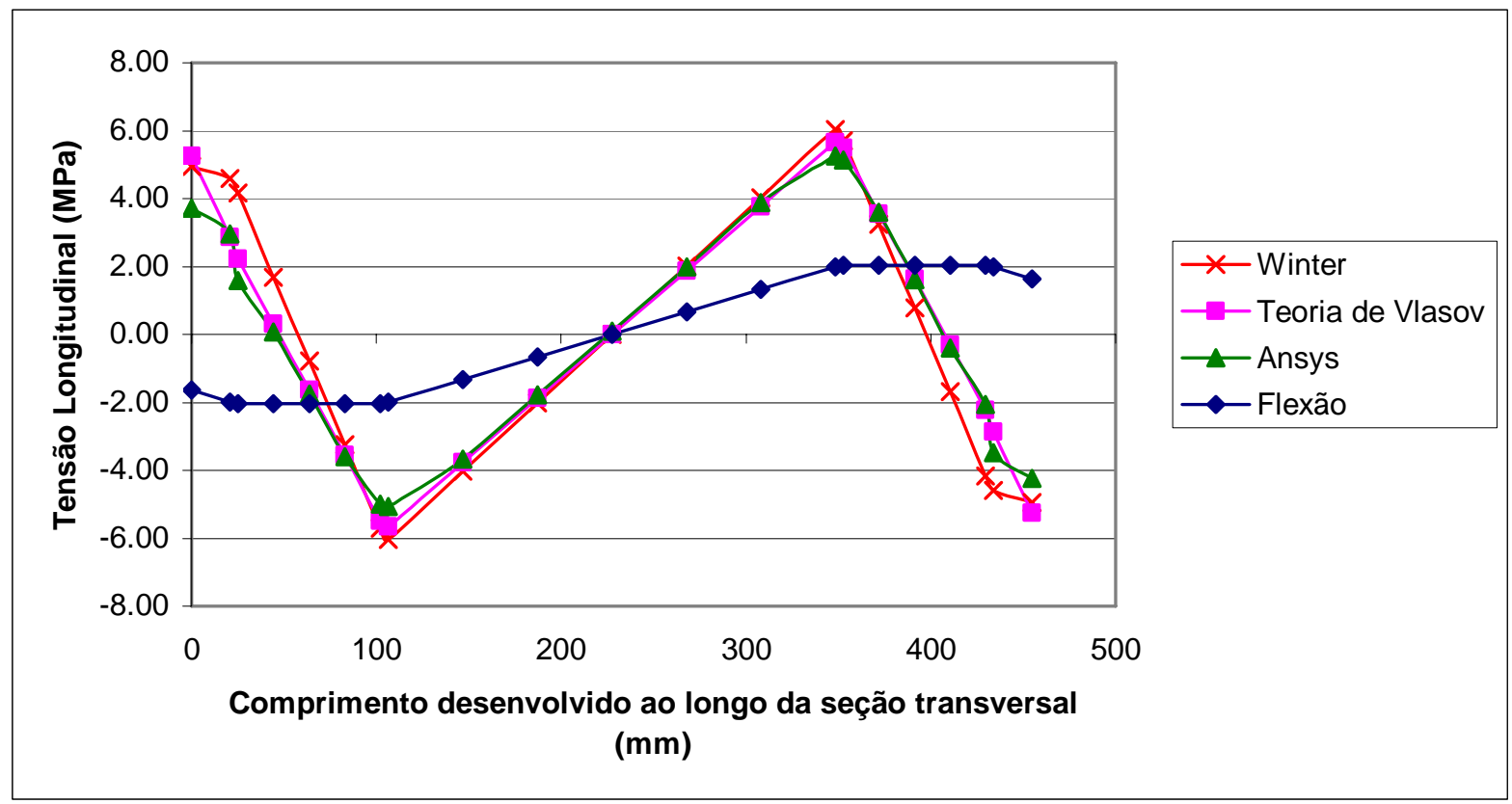

Figura 5.7 - Comparação entre o modelo de Winter, Teoria de Flexo-Torção (Vlasov), ANSYS e

Flexão Simples para perfil vinculado em ambas as extremidades por vínculo de garfo.

\subsubsection{Modelo Proposto para a Distribuição de Tensões Considerando as Restrições Impostas pela Telha (Modelo de Winter Modificado)}

Nesse item será apresentada uma proposta para avaliar a distribuição de tensões na seção, considerando as restrições impostas pela telha.

Antes de prosseguir é necessário entender as alterações impostas à distribuição das tensões longitudinais em fase elástica quando consideradas as restrições devido à fixação da telha à terça. 


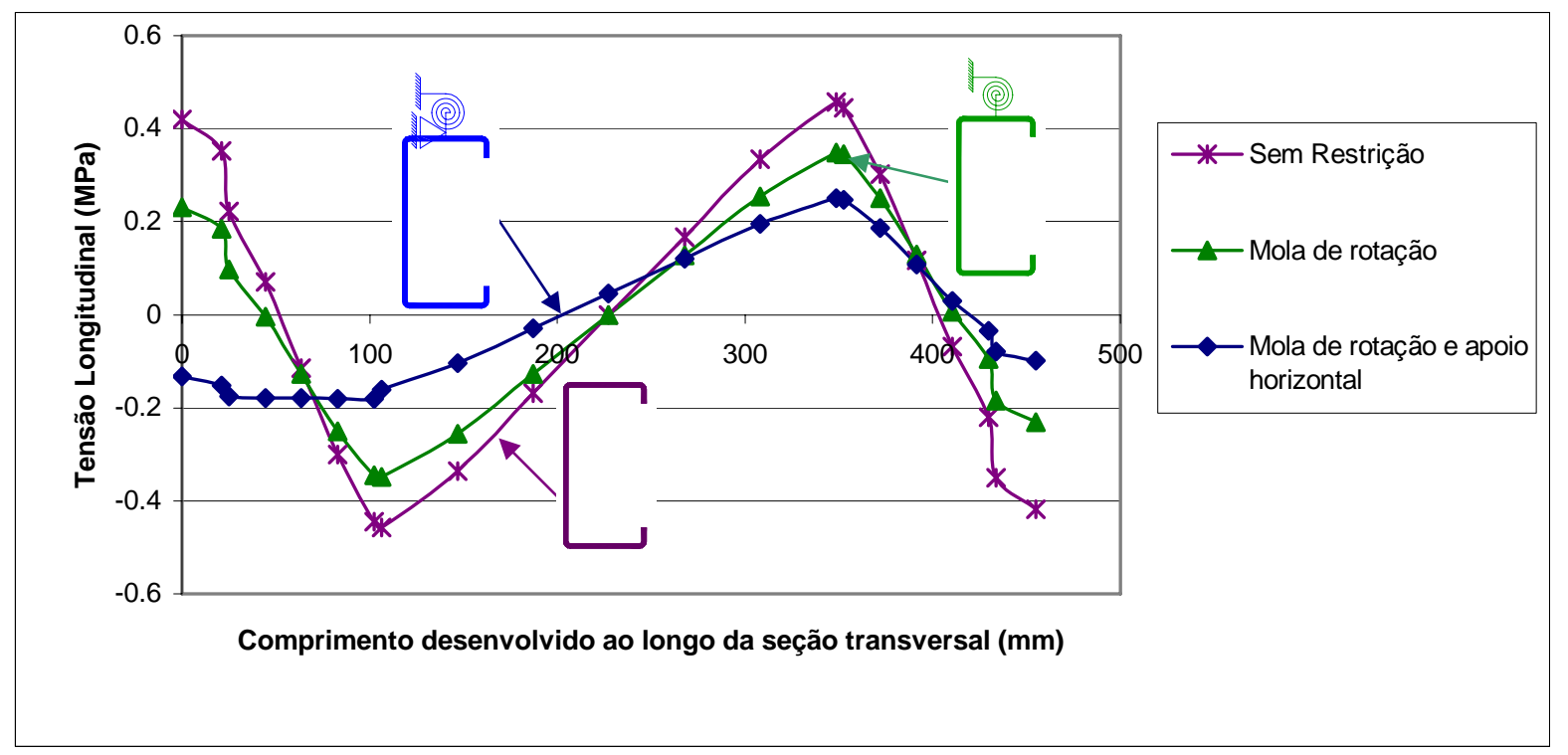

Figura 5.8 - Distribuição de tensões para diferentes configurações de vinculação.

$\mathrm{Na}$ Figura 5.8 foram plotados os resultados de modelos processados no programa Ansys. A distribuição das tensões para o perfil sem restrições na mesa é a mesma apresentada no item anterior. Quando é colocada a mola de rotação no centro da mesa superior há redução das tensões, no entanto, a distribuição das tensões continua com a mesma configuração.

Ao se colocar o apoio que restringe os deslocamentos na horizontal a mesa que recebe o apoio apresenta valores de tensões constantes (patamar) como se fosse solicitada somente à flexão. Já nas outras partes do perfil, alma e mesa não conectada, há redução dos valores de tensão, porém com a mesma configuração de distribuição.

Pode-se resumir que a mola de rotação reduz o efeito da torção em toda a seção transversal e o apoio horizontal inibe completamente o efeito da torção na mesa conectada e reduz o efeito da torção nas demais partes da seção transversal.

A Figura 5.9 apresenta o modelo proposto nesse trabalho, baseado no modelo de Winter, para determinar as tensões longitudinais na seção a meio vão em terças com restrições na mesa tracionada.

A Figura 5.9a mostra o esquema geral do problema, perfil $U_{e}$ (biapoiado) restrito na mesa por uma mola rotacional e um apoio horizontal sujeito a um carregamento distribuído aplicado no centro da mesa, no caso tracionada. Da mesma forma do modelo de Winter original, o problema é subdividido em duas partes e as tensões encontradas serão em seguida superpostas para definir as tensões longitudinais. A primeira parcela, Figura 
$5.9 b$, consiste em considerar o perfil $U_{e}$ sujeito ao carregamento distribuído aplicado no centro de cisalhamento, as tensões provocadas por esse carregamento são ilustradas na Figura 5.9c proveniente da teoria de flexão.

A segunda parcela consiste da análise dos efeitos da flexo-torção. O carregamento $p_{h}\left(p_{h}=p \cdot e / h\right)$ é admitido aplicado no ponto em que é conectada a mola de rotação e o apoio horizontal, Figura 5.9a.

A seção transversal fictícia, Figura 5.9e, consiste na alma, mesa inferior e enrijecedor, onde é aplicada o carregamento $p_{h}$ que solicita a seção ao momento fletor $M_{y^{\prime}}=p_{h} . l^{2} / 8$ em torno do eixo paralelo à alma, eixo $y^{\prime}$.

As tensões resultantes adotando este procedimento são ilustradas na Figura 5.9e. De posse desta distribuição, basta traçar uma linha do ponto de máximo localizado na junção da mesa inferior e alma ao centro da alma. Desta forma, a parcela que será superposta está definida, Figura 5.9f.

(+) compressão

(-) tração

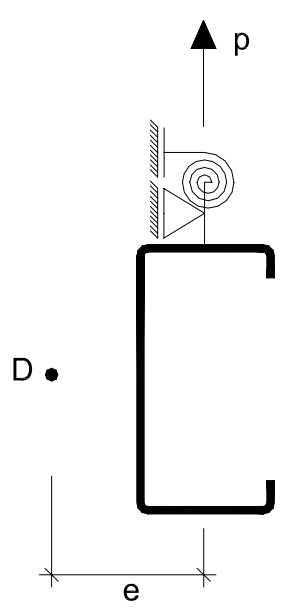

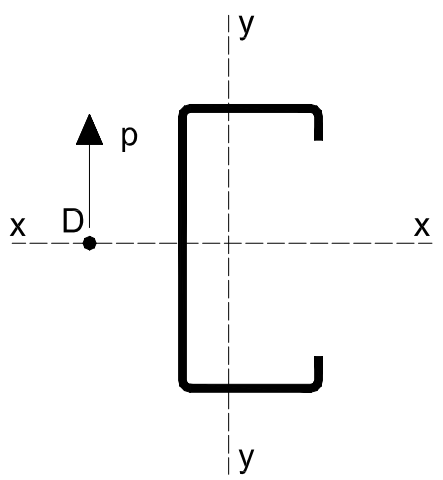

b) Carregamento aplicado em $D$

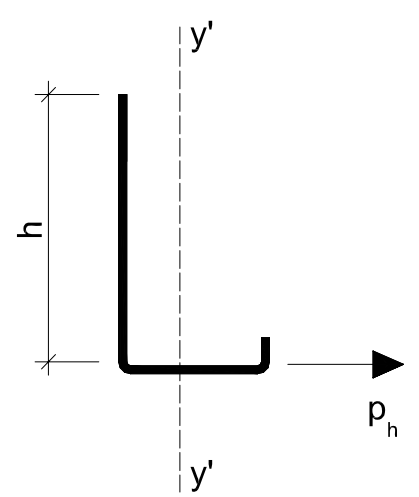
aplicação do carregamento em $D$ c) Distribuição das tensões devido à
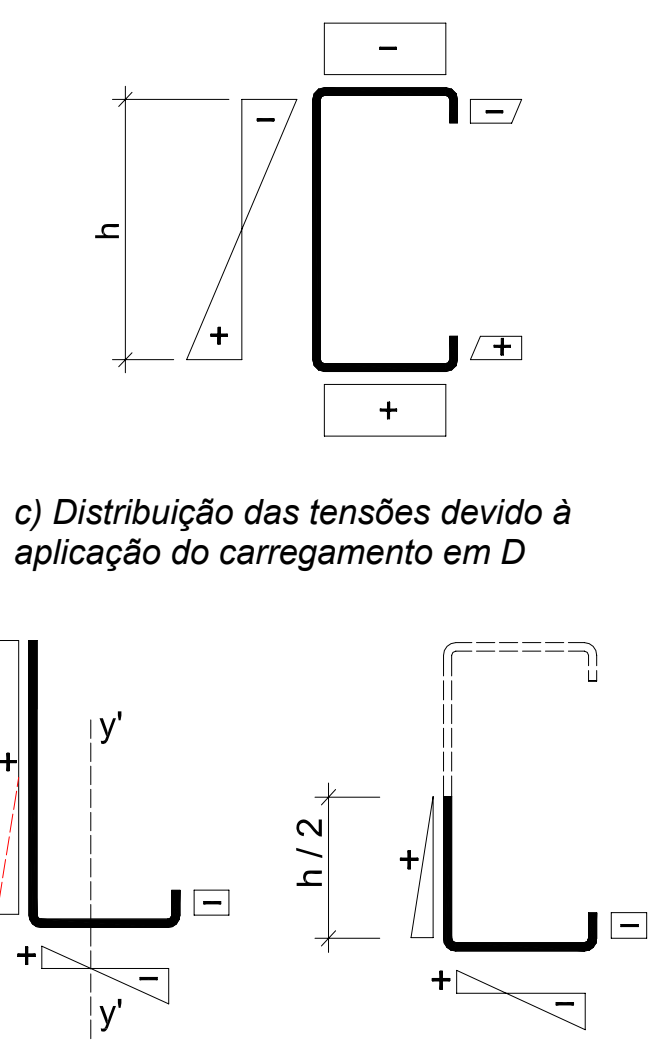

f) Parcela que será superposta d) Aplicação do carregamento $p_{h}$ na seção fictícia
e) Distribuição das tensões devido à aplicação de $p_{h}$


No entanto, não basta apenas superpor as tensões indicadas na Figura 5.9c e Figura 5.9f. As tensões devem ser multiplicadas por um coeficiente redutor. As tensões da Figura 5.9c devem ser multiplicadas por $\alpha_{M}$, coeficiente de redução para o momento em torno do eixo de maior inércia, eixo x. As tensões da Figura 5.9f devem ser multiplicadas por $\alpha_{B}$, o índice $\mathrm{B}$ maiúsculo é sugerido devido à relação destas tensões com o bimomento. Desta forma, as tensões podem ser representadas pela equação (5.1). A convenção de eixos é a mesma apresentada nas figuras $5.14 \underline{b}$ e $\underline{d}$.

$$
\sigma=\alpha_{M} \cdot \frac{M_{x} \cdot y}{I_{x}}+\alpha_{B} \cdot \frac{M_{y^{\prime}} \cdot x}{I_{y^{\prime}}}
$$

Onde:

$\alpha_{M}=$ Coeficiente de redução das tensões relativas à flexão em torno do eixo $\mathrm{x}$;

$M_{x}=$ Momento fletor em torno do eixo x;

$y=$ Distância da fibra considerada ao eixo $\mathrm{x}$;

$I_{x}=$ Momento de inércia em torno do eixo $\mathrm{x}$;

$\alpha_{B}=$ Coeficiente de redução das tensões na seção fictícia;

$M_{y^{\prime}}=$ Momento fletor na seção fictícia em torno do eixo y';

$x=$ Distância da fibra considerada ao eixo y;

$I_{y^{\prime}}=$ Momento de inércia da seção fictícia em torno do eixo y'.

É considerada pelo autor a maior importância deste método desenvolvido a capacidade de desmembrar os efeitos provocados pelo momento fletor e pelo momento torçor e assim analisar o que interfere na magnitude de cada um destes.

A Figura 5.10 mostra a comparação entre o modelo processado pelo ANSYS e os resultados do modelo proposto. O exemplo consiste da análise da seção $U_{e}$ $250 \times 85 \times 25 \times 2$, vão de $7524 \mathrm{~mm}$, mola rotacional de rigidez $\mathrm{k}_{\mathrm{rx}}$ igual a $0,68 \mathrm{kN} . \mathrm{m} / \mathrm{rad} / \mathrm{m}$ e carregamento $p=0,02 \mathrm{~N} / \mathrm{mm}$. O reduzido valor da força é para assegurar que a estrutura se comporta em regime elástico na análise via ANSYS. Pela Figura 5.10 é possível concluir que o modelo proposto apresenta concordância satisfatória, desde que, utilizando os devidos coeficientes $\alpha_{M}$ e $\alpha_{B}$. 


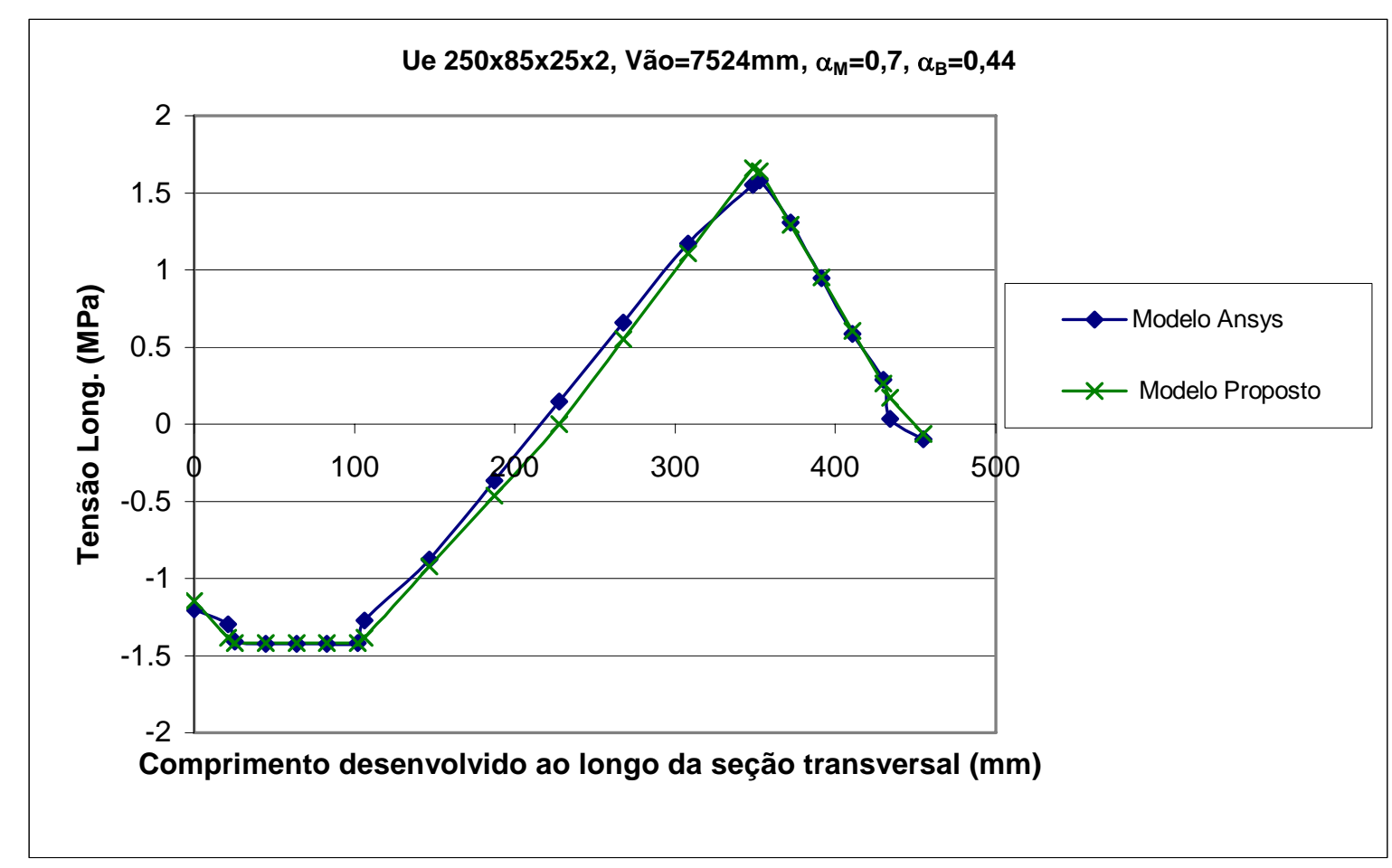

Figura 5.10 - Modelo de Winter modificado versus resultados do Ansys.

\subsubsection{Estudo dos Coeficientes de Redução $\alpha_{B}$ e $\alpha_{M}$ do Modelo Proposto}

No modelo proposto é necessário que sejam utilizadas os coeficientes de redução $\alpha_{M}$ e $\alpha_{B}$. Por meio de diversas análises via MEF conclui-se que $\alpha_{M}$ é uma função dependente das condições de contorno, do vão analisado e do momento de inércia em torno do eixo x. Já $\alpha_{B}$ é uma função dependente das condições de contorno, do vão analisado, da rigidez rotacional da mola conectada à mesa e do momento de inércia em torno do eixo y' da seção fictícia.

A Figura 5.11 ilustra a influência da rigidez de mola no coeficiente $\alpha_{B}$ para a análise do perfil $U_{e} 250 \times 85 \times 25 \times 2$ e vão de $7524 \mathrm{~mm}$. A faixa usual de valores de $\mathrm{k}_{\mathrm{rx}}$ (kN.m/rad/m), segundo Lucas (1997), está destacada na figura. Na figura também é destacada a faixa utilizada no presente trabalho, podendo ser considerados valores de baixa rigidez rotacional. A baixa rigidez rotacional está relacionada com a telha utilizada (altura de $25 \mathrm{~mm}$ e espessura 0,43mm).

É importante ressaltar na Figura 5.11 que para, pequenas rigidezes de mola, ou seja, perfil muito próximo da consideração de não restrito, os valores de $\alpha_{B}$ 
convergem para 1, ou seja, as tensões provenientes do momento torçor não necessitam de redução. Ao se aumentar muito a rigidez rotacional $\mathrm{k}_{\mathrm{rx}}$ os valores de $\alpha_{B}$ atingem um patamar em torno de 0,1 e por mais que seja aumentada a rigidez de mola as tensões atuantes serão as mesmas.

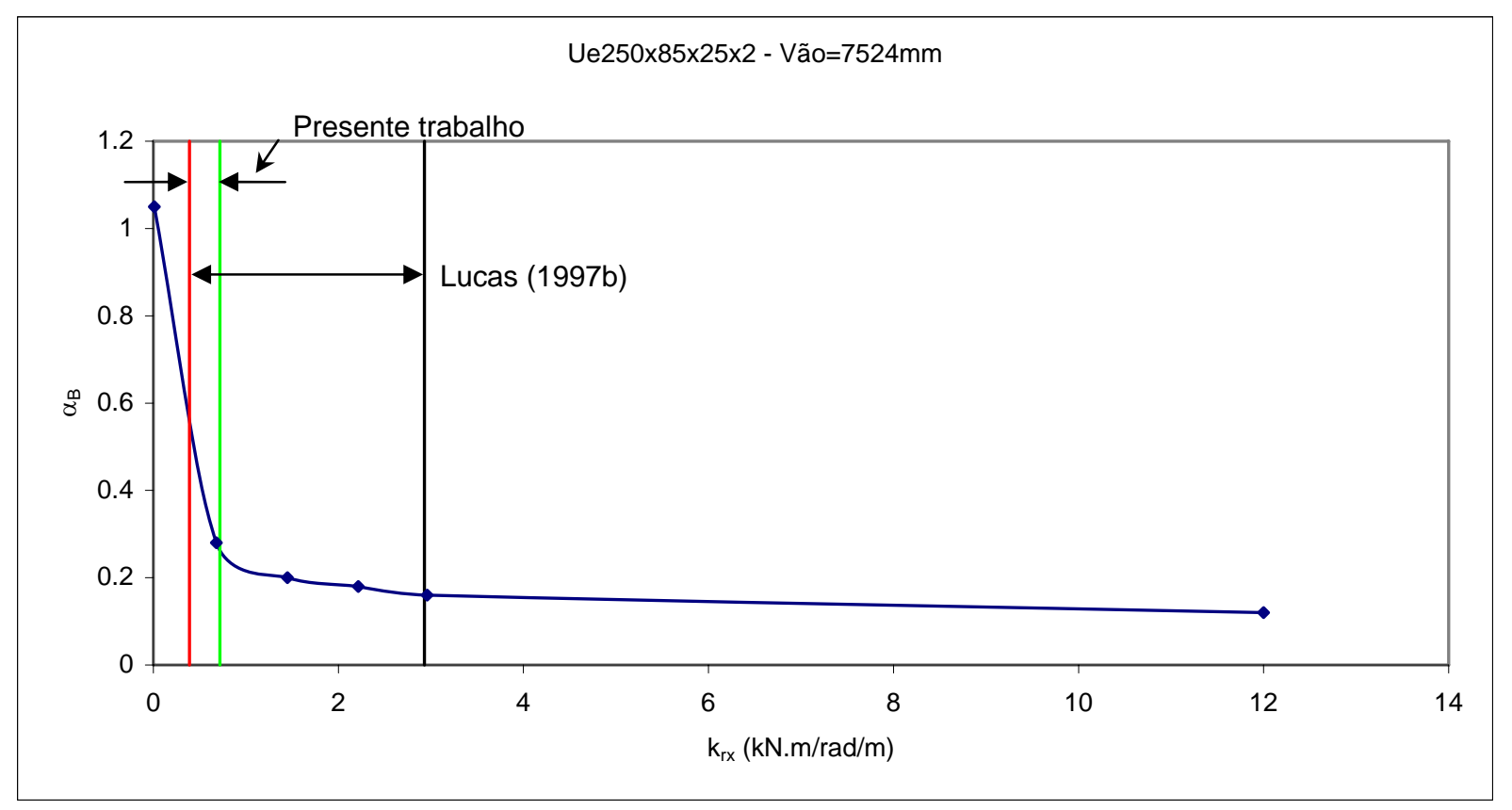

Figura 5.11 - Influência da rigidez de mola, $k_{r x}$, sobre $\alpha_{B}$.

A análise dos coeficientes $\alpha_{B}$ e $\alpha_{M}$ foram estendidas para quatro diferentes tipos de seções transversais, cada seção transversal apesar de ser conectada à mesma telha apresenta diferentes valores de rigidez rotacional a serem considerados, tabela 5.1. Para a determinação destes coeficientes foi utilizado o método descrito no Apêndice A.

Tabela $5.1-k_{r x}$ encontrado para diferentes seções transversais.

\begin{tabular}{c|c}
\hline Seção Transversal & $k_{r \times}(\mathrm{kN} . \mathrm{m} / \mathrm{rad} / \mathrm{m})$ \\
\hline$U_{\mathrm{e}} 150 \times 60 \times 20 \times 1,5$ & 0,39 \\
\hline$U_{\mathrm{e}} 200 \times 75 \times 20 \times 2$ & 0,58 \\
\hline$U_{\mathrm{e}} 250 \times 85 \times 25 \times 2$ & 0,68 \\
\hline$U_{\mathrm{e}} 250 \times 85 \times 25 \times 3$ & 0,72 \\
\hline
\end{tabular}


Os valores de $\alpha_{M}$ são plotados na Figura 5.17. Pode-se notar que os valores convergem para um único ponto com o aumento do vão e definem um patamar em torno de $\alpha_{M}=0,5$, já para valores pequenos de vão o coeficiente tende ao valor unitário. Foram também analisados vãos menores que $2700 \mathrm{~mm}$, ou seja, vãos muito pequenos sem caráter de aplicação prática para terças. Para estes valores $\alpha_{M}$ pode assumir valores maiores que 1 e também encontra-se maiores dificuldades de se adaptar o modelo proposto à análise numérica, isto deve-se ao fato de para pequenos vãos as tensões longitudinais sofrerem acréscimos devido a influência dos esforços cortantes.

Algumas simulações mostraram que as curvas dos valores de $\alpha_{M}$ poderiam ser facilmente ajustadas por funções polinomiais em função da esbeltez e do vão do perfil, desta forma, os valores de $\alpha_{M}$ poderiam ser previstos para cada vão e esbeltez analisada.

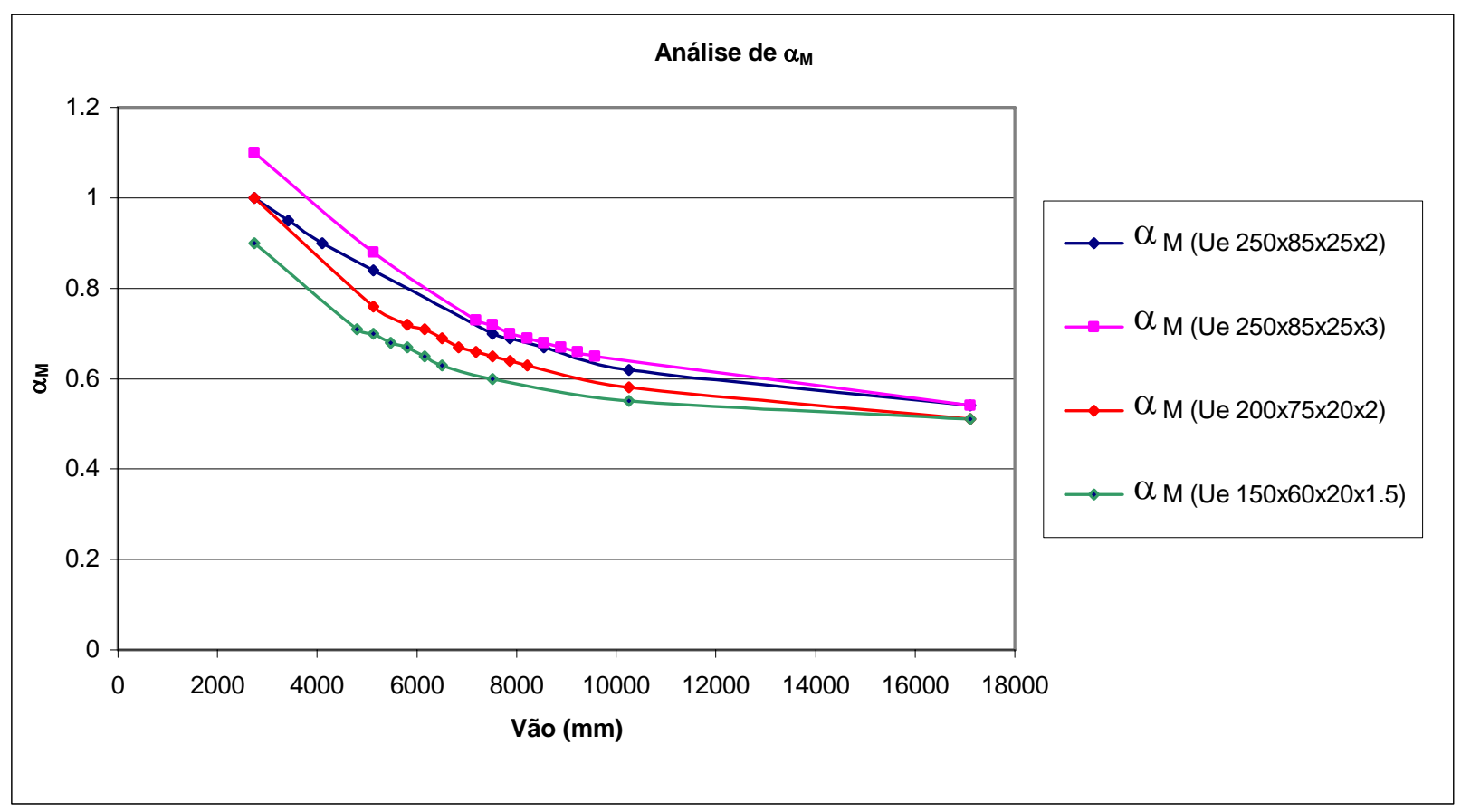

Figura 5.12 - Análise de $\alpha_{M}$ para diferentes vãos.

A análise de $\alpha_{B}$ é ilustrada na Figura 5.13, onde se pode notar que, para pequenos vãos $\alpha_{B}$ tende a 1 , sendo que da mesma forma para $\alpha_{M}$ a precisa análise das tensões longitudinais para pequenos vãos, menores que $2700 \mathrm{~mm}$, possivelmente deveria considerar a influência dos esforços cortantes. Já para grandes vãos, a influência do momento torçor nas tensões longitudinais é desprezível $\left(\alpha_{B}=0\right)$. 
É mostrada na Figura $5.13 \underline{b}$ e $\underline{c}$ a comparação entre as tensões longitudinais para o vão de $2736 \mathrm{~mm}$ e para o vão de $17100 \mathrm{~mm}$. Pode se notar que para o vão de $2736 \mathrm{~mm}$ é grande a influência do momento torçor na distribuição das tensões, sendo que no enrijecedor inferior e parcela da alma chegam a atuarem tensões negativas, ou seja, tração. Já para o vão de 17100mm a distribuição de tensões é semelhante à de solicitação somente por flexão e coincide com a afirmação de que para grandes vãos as tensões longitudinais provenientes do momento torçor são desprezíveis.

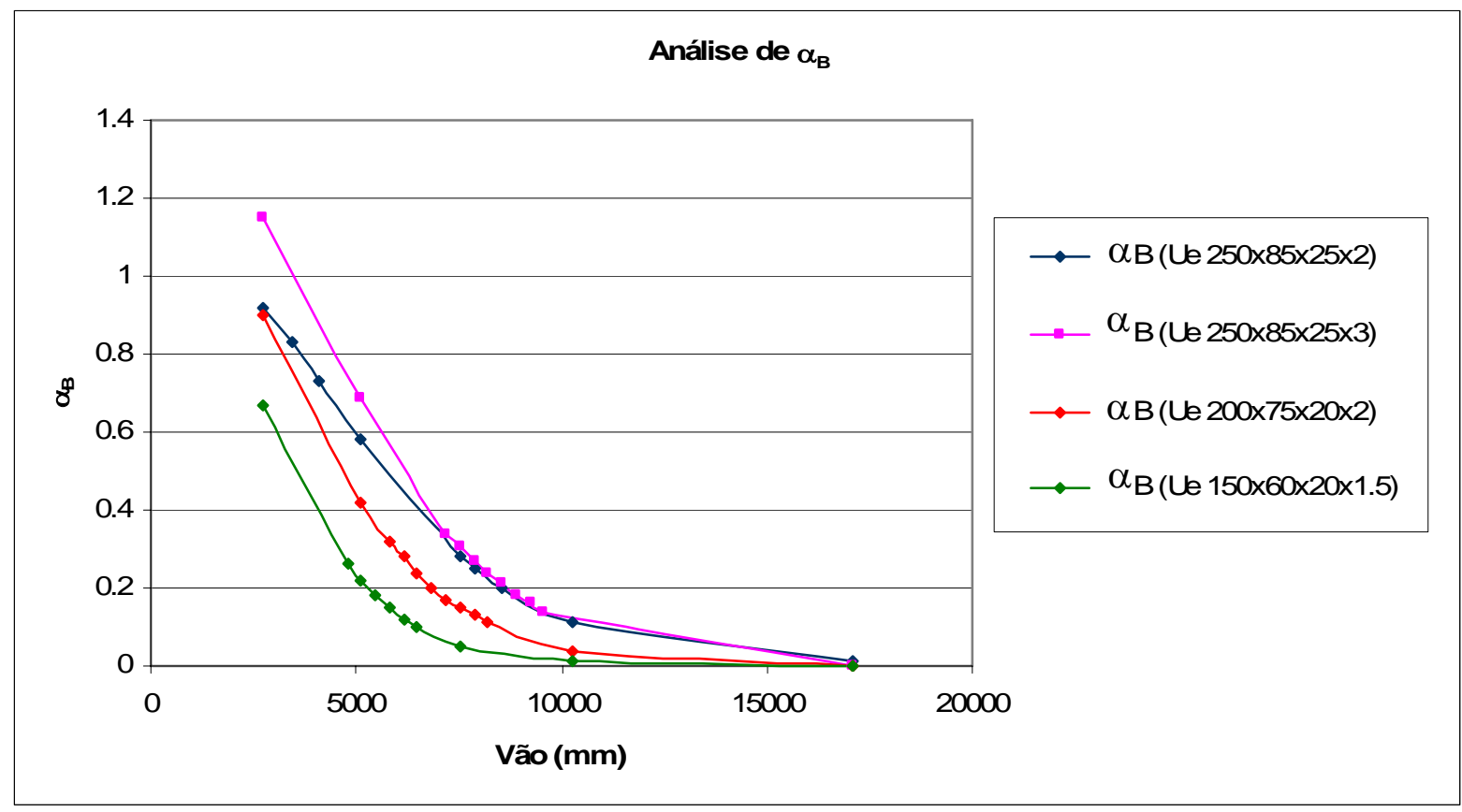

a) Análise de $\alpha_{B}$ para diferentes vãos.

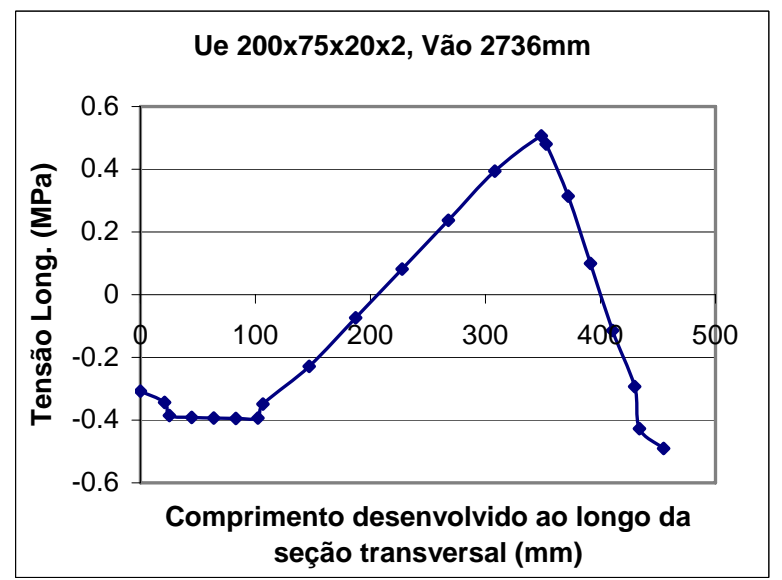

b) Tensão Longitudinal para vão igual a $2736 \mathrm{~mm}$

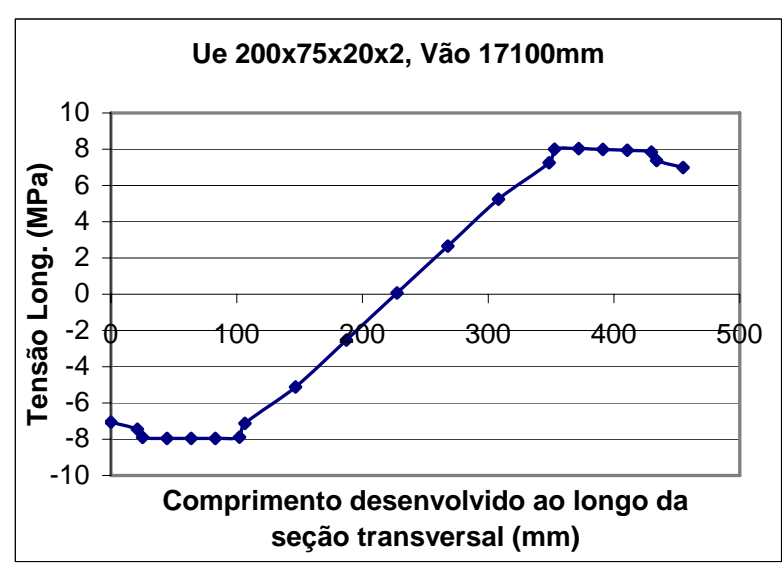

c) Tensão Longitudinal para vão igual a $17100 \mathrm{~mm}$

Figura 5.13-Análise de $\alpha_{B}$. 
Como dito anteriormente, $\alpha_{M}$ poderia ser aproximado por uma função polinomial com bons resultados, entretanto, a curva de $\alpha_{B}$ quando aproximada por polinômios não apresenta resultados satisfatórios. A partir de uma análise mais criteriosa da teoria de Vlasov pode-se concluir que as funções que conduzem a teoria de flexo-torção são funções hiperbólicas.

As curvas hiperbólicas foram analisadas e chegou-se a uma excelente aproximação utilizando-se a função cossecante hiperbólica (1/senh(x)) (Figura 5.14) veja que para os perfis analisados as equações variam de $1 / \operatorname{senh}(L / 2200)$, aproximação para $U_{e}$ $150 \times 60 \times 20 \times 1,5$, a 1/senh(L/4000), aproximação para $U_{e} 250 \times 85 \times 25 \times 3$. O divisor do vão $L$ está diretamente relacionado à esbeltez do perfil, quanto maior a esbeltez maior o divisor.

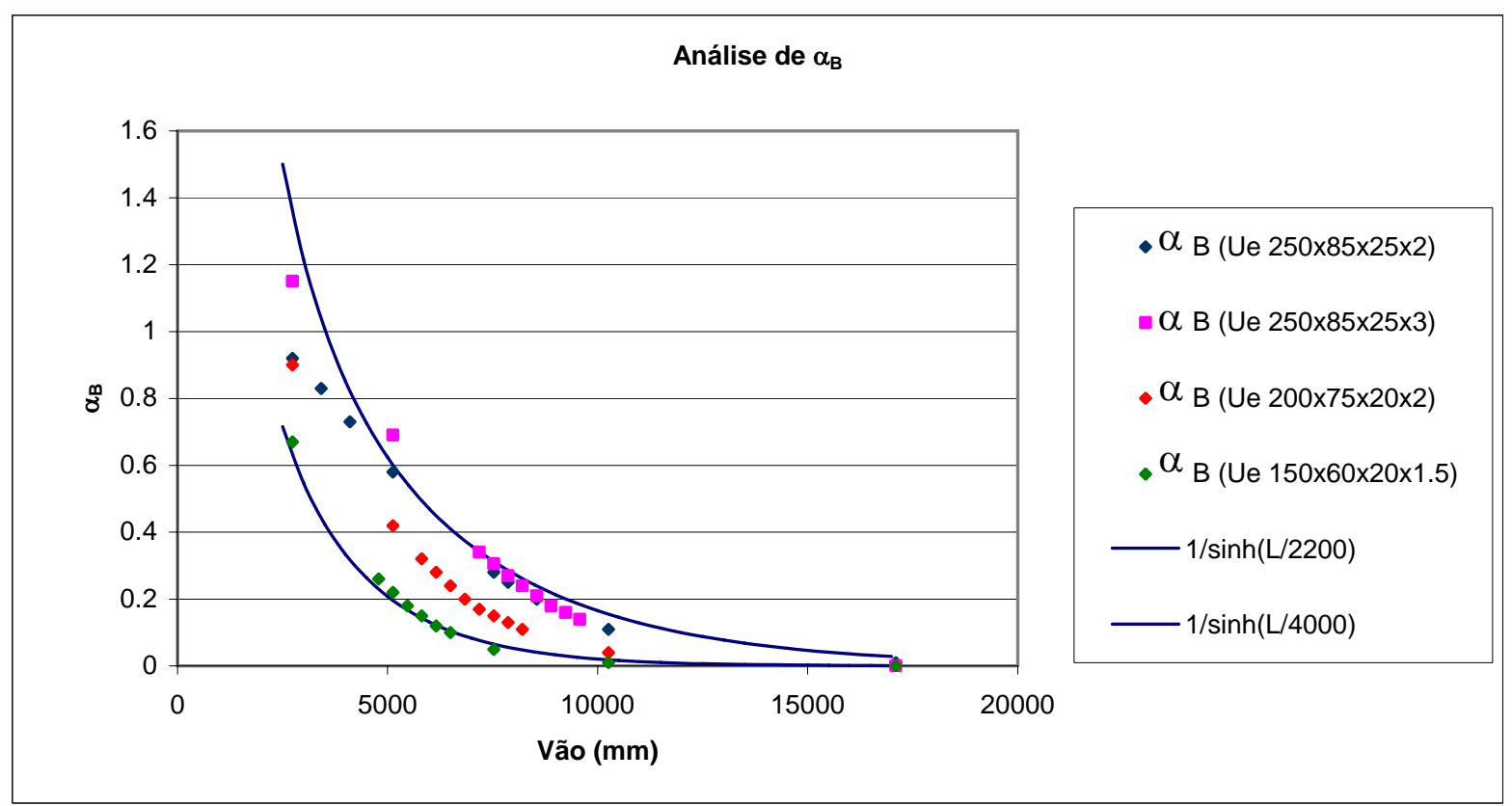

Figura 5.14 - Análise das equações para aproximação de $\alpha_{B}$.

\subsection{Aplicação do Método da Resistência Direta com Base nas Tensões $\sigma_{M}$ e $\sigma_{B}$}

Sabendo-se como avaliar as tensões em fase elástica basta carregar a estrutura até que a fibra mais solicitada atinja a tensão de escoamento como ilustrado na Figura 5.15 no exemplo do perfil $U_{e} 250 \times 85 \times 25 \times 2$ e vão de $7524 \mathrm{~mm}$. Estas serão as tensões longitudinais (tensões de referência) que serão fornecidas ao programa CUFSM, vale lembrar que a análise de auto-valor somente tem sentido quando feita utilizando as 
tensões encontradas devido à análise elástica. Deve-se também inserir como dado $\mathrm{k}_{\mathrm{rx}} \mathrm{e}$ restringir os deslocamentos horizontais (Figura 5.9a).

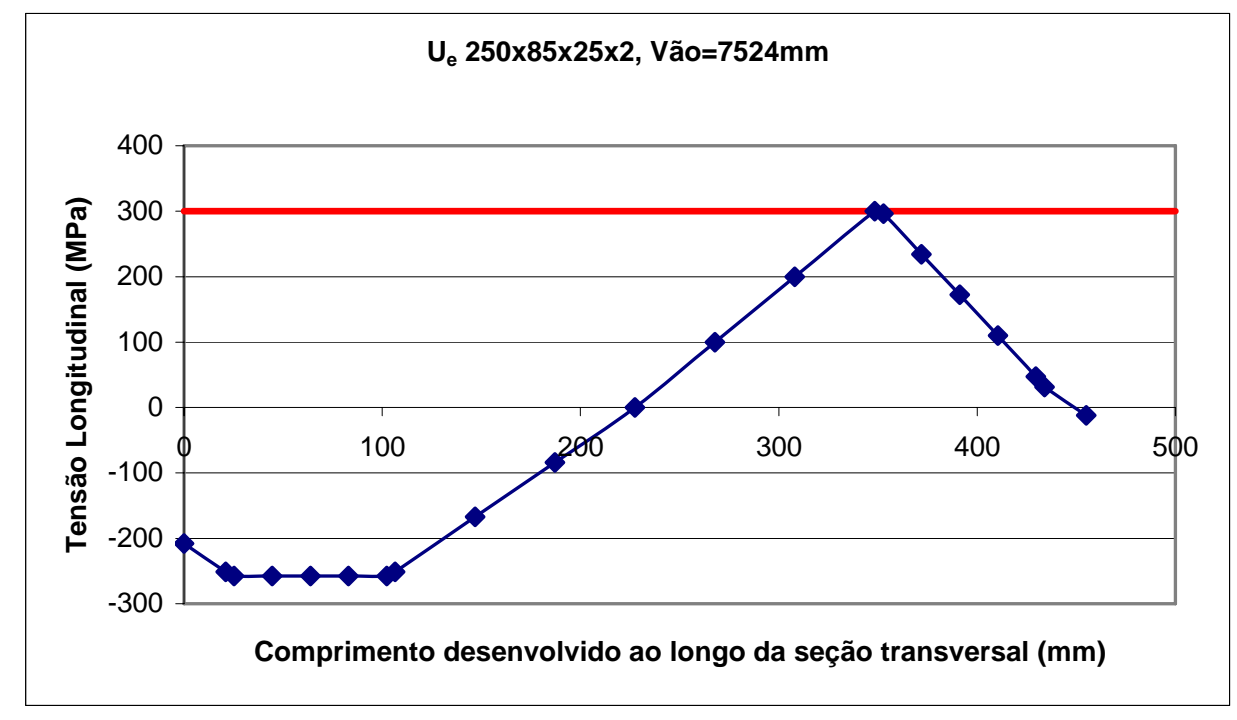

Figura 5.15 - Tensões fornecidas ao programa CUFSM.

Desta forma, basta processar o modelo e encontrar os auto-valores. Os resultados obtidos pelo programa CUFSM são plotados no gráfico da Figura 5.16. Dois mínimos evidentes podem ser notados: o primeiro refere-se à flambagem local e o segundo à flambagem lateral distorcional. O mínimo para flambagem distorcional não fica claro nesta análise, porém, não é regra, geral apesar deste mínimo ser sempre um valor muito superior aos dos outros modos de flambagem, de tal forma que o modo distorcional não será predominante no dimensionamento.

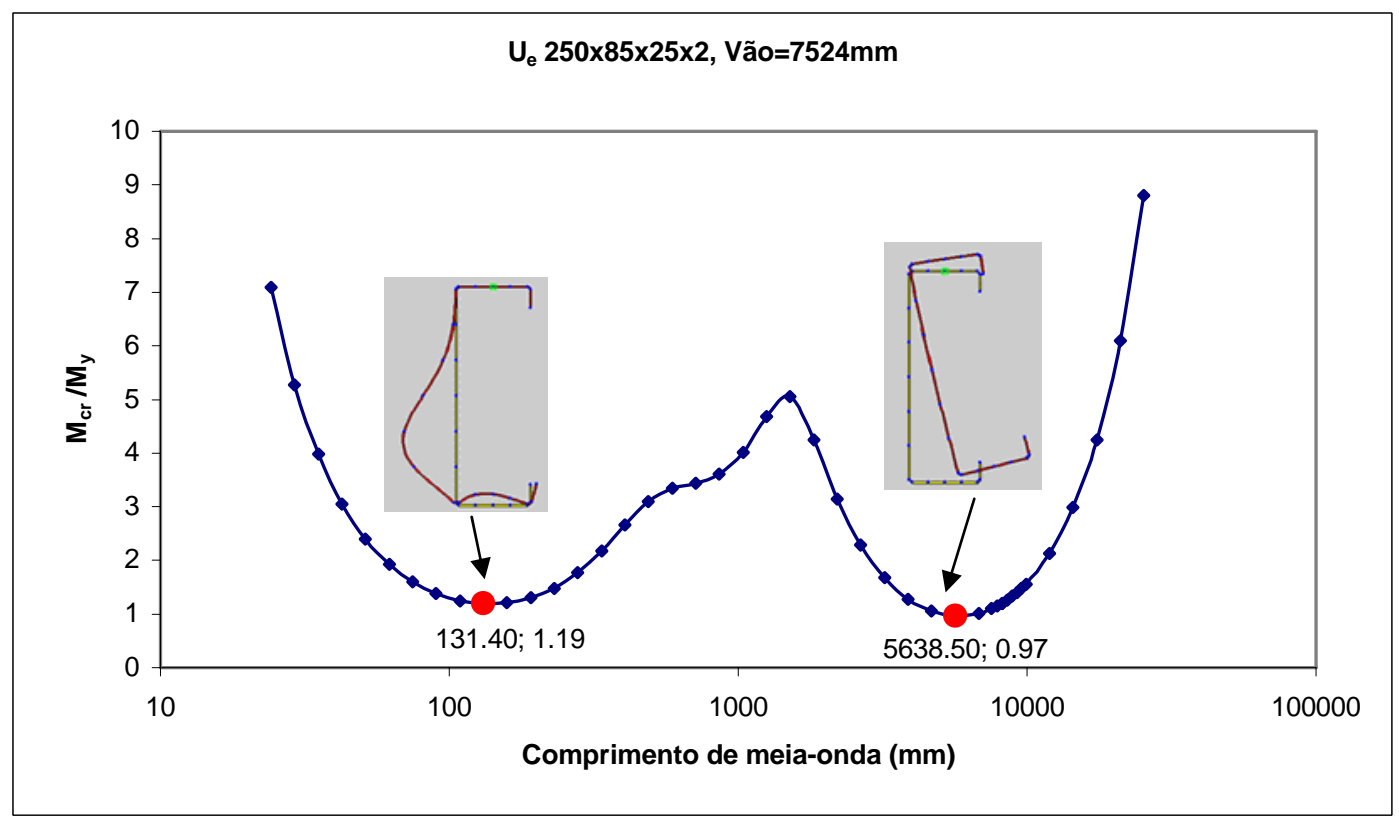

Figura 5.16-Resultados obtidos pelo CUFSM. 
De posse da análise realizada no CUFSM é possível utilizar o método da resistência direta parametrizando todos os resultados em função de $M_{y}$. Observa-se que, $M_{y}$ é uma variável que representa a distribuição de tensões apresentada na Figura 5.15 e não é associado diretamente a um número de tal forma que os momentos nominais ficam em função da variável $M_{y}$.

$$
\begin{aligned}
& \text { A partir da análise anteriormente apresentada para o perfil } U_{\mathrm{e}} \\
& 250 \times 85 \times 25 \times 2 \text { e vão de } 7524 \mathrm{~mm} \text {, obteve-se } M_{g}\left(M_{y}\right)=0,814 \cdot M_{y} \text { e } \\
& M_{l}\left(M_{y}\right)=0,782 \cdot M_{y} \text {, assim } M_{n}\left(M_{y}\right)=M_{l}\left(M_{y}\right)=0,782 \cdot M_{y} .
\end{aligned}
$$

Para que o perfil seja solicitado a $78,2 \%$ de $M_{y}$ é necessário que seja aplicado a pressão de $1,42 \mathrm{kN} / \mathrm{m}^{2}$, no entanto, a análise numérica via ANSYS indicou instabilidade da alma à pressão de $1,10 \mathrm{kN} / \mathrm{m}^{2}$, e por mais que a simulação seja refinada considerando imperfeições iniciais e apoios simulados por mola o valor de pressão aplicada para provocar a instabilidade somente irá diminuir.

Assim sendo, pode-se concluir que como já comentado no item 4.2.2 são necessários ensaios para que se possa calibrar adequadamente os modelos via MEF em que ocorra instabilidade. Nota-se que, a utilização da equação para a determinação do momento resistente global assim como concebida para a análise de perfis submetidos à flambagem lateral com torção (perfis isolados), considerando os resultados do modelo via ANSYS como referência, não deve ser utilizada para a análise de perfis submetidos à flambagem lateral distorcional, pois conduzirá a valores contrários à segurança.

É importante ressaltar que o mesmo perfil quando dimensionado pelo AISI (2001), fator $R$, resulta na pressão máxima de $0,56 \mathrm{kN} / \mathrm{m}^{2}$ e dimensionando pelo $M R D$, no entanto considerando a distribuição tensões relativas à flexão em torno do eixo de maior inércia, prática americana atual, a pressão máxima resulta em $0,88 \mathrm{kN} / \mathrm{m}^{2}$, ou seja, ambos os procedimentos conduzem a resultados inferiores.

\subsubsection{Apresentação dos Resultados de Todas as Simulações pelo MRD}

O mesmo estudo apresentado no item anterior para uma seção e vão específico foi realizado para todas as seções e vãos em análise (Figura 5.17). Nesta figura são comparados os resultados encontrados utilizando-se o modelo usual de dimensionamento pelo MRD (Modelo Simplificado - M.S. - símbolos cheios), aos resultados provenientes do modelo proposto (Modelo Completo - M.C. - símbolos 
vazados). Lembre-se que a diferença entre os dois modelos está em como são consideradas as tensões atuantes, enquanto no modelo simplificado são consideradas somente as tensões devido à flexão, no modelo completo são consideradas também as tensões provenientes da flexo-torção.

A Figura 5.17 evidencia a grande diferença encontrada entre os modelos considerados. Por exemplo, para a seção $U_{e} 250 \times 85 \times 25 \times 2$, enquanto para o modelo simplificado $M_{n} / M_{y}$ resulta por volta de 0,6 , no modelo completo $M_{n} / M_{y}$ varia de 0,7 a 0,8 , veja que esta grande diferença é mantida para todas as seções analisadas. Outro fato a ser notado é a devida correlação entre as simulações e as curvas do MRD definidas. É importante observar que, para o perfil $U_{e} 250 \times 85 \times 25 \times 2$, o momento resistente é governado pelo modo local.

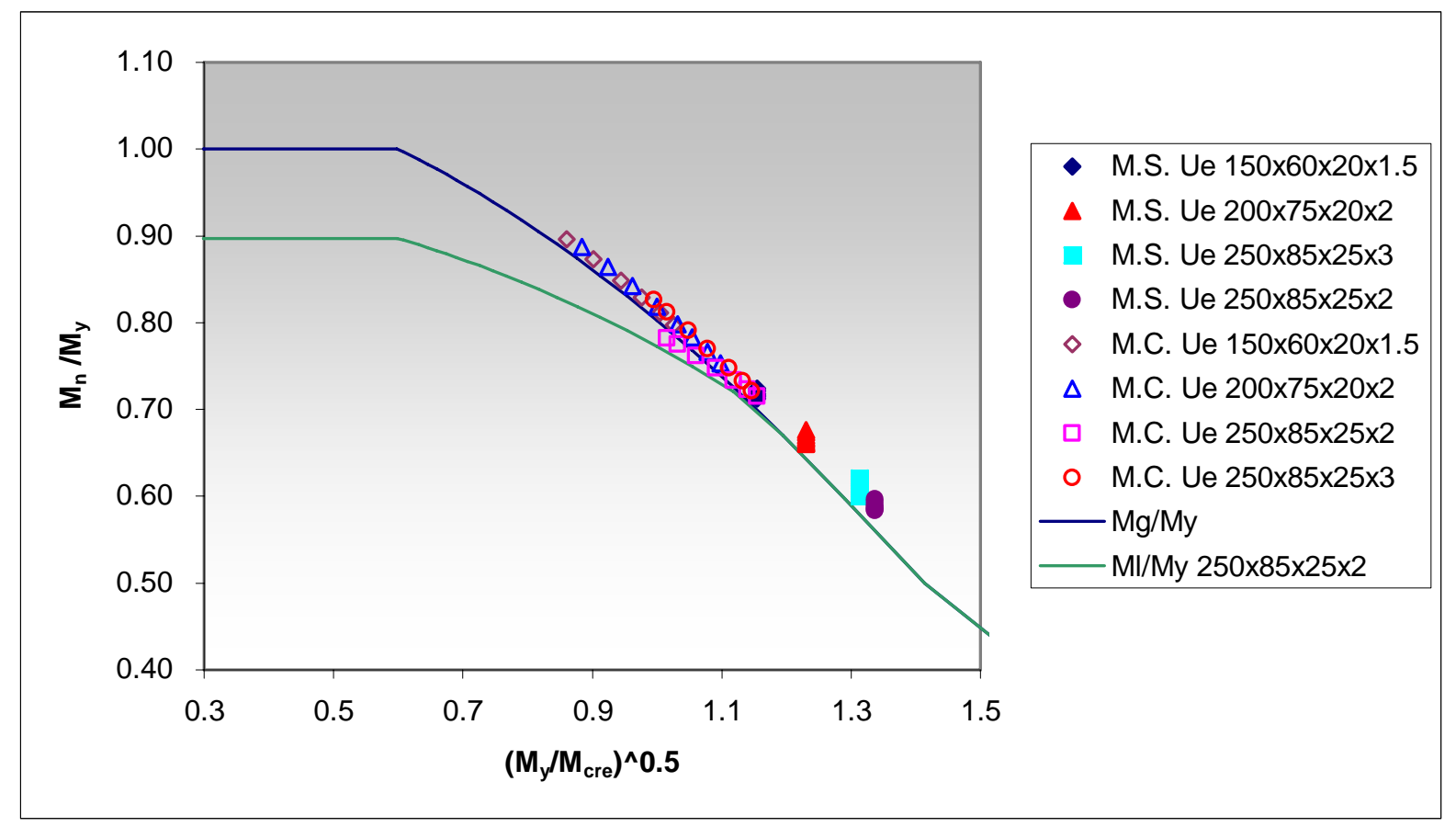

Figura 5.17 - Comparação dos resultados utilizando-se a prática atual de dimensionamento pelo MRD (M.S.) e o modelo completo proposto (M.C.).

Na Tabela 5.2 são comparados os valores de pressão resultantes do dimensionamento segundo a NBR 14762:2001, o AISI (2001) e o MRD (M.S. e M.C.). Notase que os valores de pressão admissível pelo MRD são sempre superiores ao dimensionamento pelas normas analisadas. Pode-se concluir também que é considerável a diferença no dimensionamento de terças conectadas a telha pelos dois métodos M.S. e M.C. e que certamente, apesar de maior dificuldade de implementação, o M.C. conduz ao dimensionamento mais econômico. 
Tabela 5.2 - Valores de pressão máxima obtidas pelos métodos de dimensionamento analisados.

\begin{tabular}{|c|c|c|c|c|c|}
\hline \multirow{2}{*}{$\begin{array}{c}\text { Seção transversal } \\
\cup_{\mathrm{e}}\end{array}$} & \multirow[b]{2}{*}{ vão (mm) } & \multicolumn{4}{|c|}{ Pressão* $\left(k N / m^{2}\right)$} \\
\hline & & $\mathrm{P} 1$ & $\mathrm{P} 2$ & $\mathrm{P} 3$ & $\mathrm{P} 4$ \\
\hline \multirow{6}{*}{$150 \times 60 \times 20 \times 1,5$} & 4788 & 0,42 & 0,74 & 0,81 & 1,18 \\
\hline & 5130 & 0,37 & 0,65 & 0,71 & 1,04 \\
\hline & 5472 & 0,32 & 0,57 & 0,62 & 0,94 \\
\hline & 5814 & 0,29 & 0,50 & 0,55 & 0,84 \\
\hline & 6156 & 0,26 & 0,45 & 0,49 & 0,77 \\
\hline & 6498 & 0,23 & 0,41 & 0,44 & 0,71 \\
\hline \multirow{8}{*}{$200 \times 75 \times 20 \times 2$} & 5814 & 0,63 & 1,03 & 1,13 & 1,69 \\
\hline & 6156 & 0,56 & 0,92 & 1,00 & 1,53 \\
\hline & 6498 & 0,51 & 0,83 & 0,90 & 1,40 \\
\hline & 6840 & 0,46 & 0,74 & 0,81 & 1,30 \\
\hline & 7182 & 0,42 & 0,68 & 0,73 & 1,19 \\
\hline & 7524 & 0,38 & 0,61 & 0,66 & 1,09 \\
\hline & 7866 & 0,34 & 0,56 & 0,60 & 1,00 \\
\hline & 8208 & 0,32 & 0,51 & 0,55 & 0,93 \\
\hline \multirow{7}{*}{$250 \times 85 \times 25 \times 2$} & 7524 & 0,56 & 0,56 & 0,89 & 1,41 \\
\hline & 7866 & 0,51 & 0,51 & 0,81 & 1,33 \\
\hline & 8208 & 0,47 & 0,47 & 0,74 & 1,22 \\
\hline & 8550 & 0,43 & 0,43 & 0,68 & 1,14 \\
\hline & 8892 & 0,40 & 0,40 & 0,62 & 1,08 \\
\hline & 9234 & 0,37 & 0,37 & 0,58 & 1,01 \\
\hline & 9576 & 0,34 & 0,34 & 0,54 & 0,95 \\
\hline \multirow{7}{*}{$250 \times 85 \times 25 \times 3$} & 7524 & 0,86 & 0,86 & 1,34 & 2,16 \\
\hline & 7866 & 0,79 & 0,79 & 1,22 & 2,03 \\
\hline & 8208 & 0,72 & 0,72 & 1,11 & 1,87 \\
\hline & 8550 & 0,67 & 0,67 & 1,02 & 1,73 \\
\hline & 8892 & 0,62 & 0,62 & 0,94 & 1,60 \\
\hline & 9234 & 0,57 & 0,57 & 0,90 & 1,50 \\
\hline & 9576 & 0,53 & 0,53 & 0,81 & 1,40 \\
\hline
\end{tabular}

Onde:

P1: Pressão correspondente ao $\mathrm{M}_{\mathrm{R}}=\mathrm{R} . \mathrm{W}_{\mathrm{ef}} \cdot \mathrm{f}_{\mathrm{y}}$ como definido pela NBR 14762:2001;

P2: Pressão correspondente ao $\mathrm{M}_{\mathrm{R}}=\mathrm{R} . \mathrm{W}_{\mathrm{ef}} \cdot \mathrm{f}_{\mathrm{y}}$ como definido pelo AISI (2001);

P3: Pressão correspondente ao dimensionamento pelo MRD de acordo com a prática atual americana (M.S.);

P4: Pressão correspondente ao dimensionamento pelo MRD utilizando a distribuição de tensões normais correta (M.C.).

* Nota: Valores de pressão para terças com largura de influência de 2 metros.

Diante das simulações geradas no presente capítulo pode-se concluir que os valores calculados pelos processos normativos estão sempre muito aquém dos valores encontrados pelo método da resistência direta. Vale lembrar, que como ressaltado no capítulo 4, são grandes as evidências de que os valores determinados pelos processos 
normativos (fator $\mathrm{R}$ ) ao serem calibrados pelos ensaios em caixa de sucção tiveram como limitante deslocamento excessivo e não escoamento do material ou algum tipo de instabilidade. Sendo assim, são necessários ensaios destinados a determinar curvas de resistências do MRD para o fenômeno de flambagem lateral distorcional.

Tendo-se os resultados experimentais para determinar as curvas de resistência deve-se optar por como as tensões devem ser consideradas na análise de estabilidade elástica: (i) tensões oriundas somente da flexão, prática atual americana - item 5.1 ou (ii) tensões oriundas da flexão e torção, modelo proposto no item 5.2.2.

O método mais simples e prático de considerar a distribuição de tensões é o caso (i) e seria necessário averiguar se a curva de resistência ajustada considerando somente a distribuição das tensões da flexão conduz a resultados satisfatórios. Caso contrário, as curvas também podem ser ajustadas pelo caso (ii) o qual possui maior dificuldade de aplicação, no entanto trata as tensões de forma mais realista e talvez conduza a um melhor ajuste das curvas de resistência. 



\section{CONCLUSÕES}

Três modelos numéricos foram estudados via MEF: (i) modelo proposto 1, onde são utilizados eixos de simetria para simular a continuidade da terça e telha, (ii) modelo proposto por Lucas (1997a), onde são utilizados diversos acoplamentos de nós para simular o contato e a continuidade das telhas e (iii) modelo proposto 2, onde utiliza-se elementos de mola para representar a telha e um eixo de simetria a meio vão da terça. Todos os modelos apesar da seqüência de simplificações adotadas apresentaram ótimas correlações com os ensaios desenvolvidos por Javaroni (1999), sobretudo quando comparado o deslocamento vertical.

Por meio de um estudo paramétrico foi possível gerar equações de superfície para determinar os deslocamentos verticais, tendo-se como variáveis o vão da terça, o módulo de resistência elástico da seção bruta e o carregamento aplicado. As equações apresentadas são importantes para uma avaliação mais realista do estado limite de serviço, uma vez que os deslocamentos obtidos com base em análise elástica de primeira ordem, em geral não conduzem a resultados satisfatórios, em vista da resposta fortemente não-linear do sistema.

Nas análises numéricas via MEF, em muitos casos o estado limite último não ficou caracterizado, dificultando assim o emprego desses modelos para a avaliação do momento fletor resistente. Para alguns casos de terças de maior esbeltez local $\left(U_{e}\right.$ 250x85x25x2), a análise numérica indicou a ocorrência de instabilidade local na alma, entretanto não é possível extrair conclusões consistentes uma vez que a análise experimental empregada para a calibração dos modelos não indicou tal ocorrência (terças com menor esbeltez local).

A análise de viabilidade do emprego do método da resistência direta (MRD) foi feita com base em um estudo paramétrico admitindo dois casos de distribuição de tensões: (i) tensões oriundas somente da flexão, que correspondem a atual prática nos EUA e (ii) tensões oriundas da flexão e torção. Em ambos casos foi empregada a curva de 
resistência associada à flambagem lateral com torção (FLT) uma vez que o MRD não prevê curva de resistência específica para a distorção lateral.

Diante da dificuldade de determinação das tensões normais elásticas para perfis restringidos o presente trabalho apresenta um método para a determinação das mesmas. Neste método as tensões provocadas pela flexão e torção são desacopladas e corrigidas pelos fatores $\alpha_{M}$ (coeficiente de redução do momento fletor) e $\alpha_{B}$ (coeficiente de redução dos efeitos da torção).

Pode-se concluir que $\alpha_{M}$ e $\alpha_{B}$ dependem do vão analisado e $\alpha_{B}$ depende também da rigidez de mola $k_{r x}$ a ser empregada. Determinou-se por meio da análise dos coeficientes de redução que quanto maior o vão menores são os efeitos da flexão e torção e que quanto maior $k_{r x}$ menor o efeito da torção. Por meio de estudos paramétricos é possível gerar curvas para a determinação de $\alpha_{M}$ e $\alpha_{B}$, sendo que no presente trabalho observou-se que aproximar $\alpha_{M}$ por equações polinomiais e $\alpha_{B}$ por equações hiperbólicas corresponde a uma satisfatória solução.

Os resultados do MRD quando comparados aos procedimentos do AISI (2001) e NBR 14762:2001 apresentaram grande diferença. Ambos os casos indicaram momentos resistentes superiores aos obtidos pelo método do fator $R$, sendo que o caso (i) apresentou resultados mais próximos. Tomando como referência o método do fator $R$, proposto com base em ensaios experimentais (caixa de sucção), pode-se concluir que não é adequado empregar a curva de resistência associada à flambagem lateral com torção para o modo de distorção lateral. Assim, será necessário calibrar o MRD de modo a permitir a análise de terças restringidas pelas telhas. 


\section{REFERÊNCIAS BIBLIOGRÁFICAS}

AMERICAN IRON AND STEEL INSTITUTE (1991). Cold-Formed Steel Design Manual. Washington: AISI.

AMERICAN IRON AND STEEL INSTITUTE (1996). Cold-Formed Steel Design Manual. Washington: AISI.

AMERICAN IRON AND STEEL INSTITUTE (2001). North American Specification for the Design of Cold-Formed Steel Structural Members. Washington: AISI.

AMERICAN IRON AND STEEL INSTITUTE (2004a). Appendix 1 - Design of cold-formed steel structural members using the direct strength method. North American Specification for the Design of Cold-Formed Steel Structural Members. Washington: AISI.

AMERICAN IRON AND STEEL INSTITUTE (2006). Direct Strength Method Design Guide. American Iron and Steel Institute, Washington, DC. (Approved, to be published in 2006).

AMERICAN IRON AND STEEL INSTITUTE (2004b) Appendix C - Cold-Formed Steel Framing Design Guide - Simplified Approximate Method for the Calculation of Warping Torsional Stresses. Washington: AISI.

ANSYS (1997). Structural nonlinearities: user's guide for revision 5.5. Houston. v.1. 
ASSOCIAÇÃO BRASILEIRA DE NORMAS TÉCNICAS (2001). NBR 14762: Dimensionamento de estruturas de aço constituídas por perfis formados a frio. Rio de Janeiro: ABNT.

AUSTRALIAN/NEW ZEALAND STANDARD (1996). AS/NZS 4600:1996 : Cold-formed steel structures.

CHODRAUI, G.M.B. (2006). Análise Teórica e experimental de perfis de aço formados à frio submetidos à compressão. 294p. Tese (Doutorado) - Escola de Engenharia de São Carlos, Universidade de São Paulo, São Carlos. 2006.

BASÁGLIA, C.D. (2004). Sobre o comportamento estrutural de terças de aço considerando a interação com as telhas. 117p. Dissertação (Mestrado) - Escola de Engenharia de São Carlos, Universidade de São Paulo, São Carlos. 2004.

EUROPEAN COMMITTEE FOR STANDARDISATION (1996). Eurocode 3: Design of steel structures. Part 1.3: General rules. Suplementary rules for cold formed thin gauge members and sheeting. Brussels: CEN. (ENV 1993-1-3: 1996).

HANCOCK, G. J.; JOHNSTON, N. (1994). Calibration of the AISI R-factor design approach for purlins using Australian test data. Engineering, v.16, n.5, p.342-347.

HANCOCK, G.J., MURRAY, T.M.; ELLIFRITT, D.S. (2001). Cold-formed steel structures to the AISI specification. New York: Marcel Dekker, Inc.

JAVARONI, C.E. (1999). Perfis de aço formados a frio submetidos à flexão: análise teóricoexperimental. 258p. Tese (Doutorado) - Escola de Engenharia de São Carlos, Universidade de São Paulo, São Carlos. 1999.

LaBOUBE, R.A. (1988). Behavior of Continuous Span Purlin System. In: Ninth International Conference on Cold-Formed Steel Structures, 11.,1988, St. Louis, Missouri, USA. p.191- 
LaBOUBE, R.A. (1991). Uplift capacity of Z-purlins. Journal of Structural Engineering, v.117, n.4, p.1159-1166.

LaBOUBE, R.A. (1992). Estimating uplift capacity of ligth steel roof system. Journal of Structural Engineering, v.118, n.3, p.848-852.

LOURENÇO, P. B. (1999). Métodos computacionais na mecânica dos sólidos não-linear. Departamento de engenharia civil. Universidade do Minho.

LUCAS, R.M.; AL-BERMANI, F.G.A; KITIPORNCHAI, S. (1997a). Modelling of cold-formed purlin-sheeting systems - part 1: full model. Thin Walled Structures. v.27, n.3, p.223-243.

LUCAS, R.M.; AL-BERMANI, F.G.A; KITIPORNCHAI, S. (1997b). Modelling of cold-formed purlin-sheeting systems - part 2: simplified model. Thin Walled Structures. v.27, n.4, p.263286.

PEKÖZ, T.; SOROUSHIAN, D. (1982). Behavior of C- and Z-purlins under wind uplift. In: International Specialty Conference on Cold-Formed Steel Structures, 6., 1982, St Louis, Missouri, USA. p.409-429.

SCHAFER, B. W. CUFSM 2.6 - Users Manual and Tutorials. Available at www.ce.jhu.edu/bschafer/cufsm, 2006.

VLASOV, V. Z. (1961). Thin-walled elastic beams. Trad. Y. Schechtman (Israel Program for Scientific Translation, Jerusalem). 2 ed. Washington: Published for the National Science Foundation.

WINTER G.; LANSING W.; McCALLEY R. B. (1950). Performance of Laterally Loaded 
Channel Beams. Four papers on the performance of thin walled steel structures, Cornell University, Engineering Experiment Station, Reprint No. 33.

YE, Z.; KETTLE, R.J.; LI, L.; SCHAFER, B.J. (2002). Buckling behavior of cold-formed zedpurlins partially restrained by steel sheeting. Thin Walled Structures. v.40, p.853-864.

YE, Z.; KETTLE, R.J.; LI, L. (2004). Analysis of cold-formed zed-purlins partially restrained by steel sheeting. Computers \& Structures. v.82, p.731-739. 


\section{Apêndice A}

\section{Calibração dos Valores de Rigidez de Mola}

Nesse apêndice descreve-se o procedimento empregado para avaliação da rigidez de mola adotada na análise numérica. Para exemplificação são mostrados os valores adquiridos para deslocamentos e rotações dos nós da análise numérica (modelo proposto 1 - item 3.3.1) que simula o ensaio realizado por Javaroni (1999) intitulado de Caixa 2. Os nós analisados são aqueles onde serão aplicados os elementos de mola. As direções dos deslocamentos e rotações são as mesmas ilustradas na figura A-1.

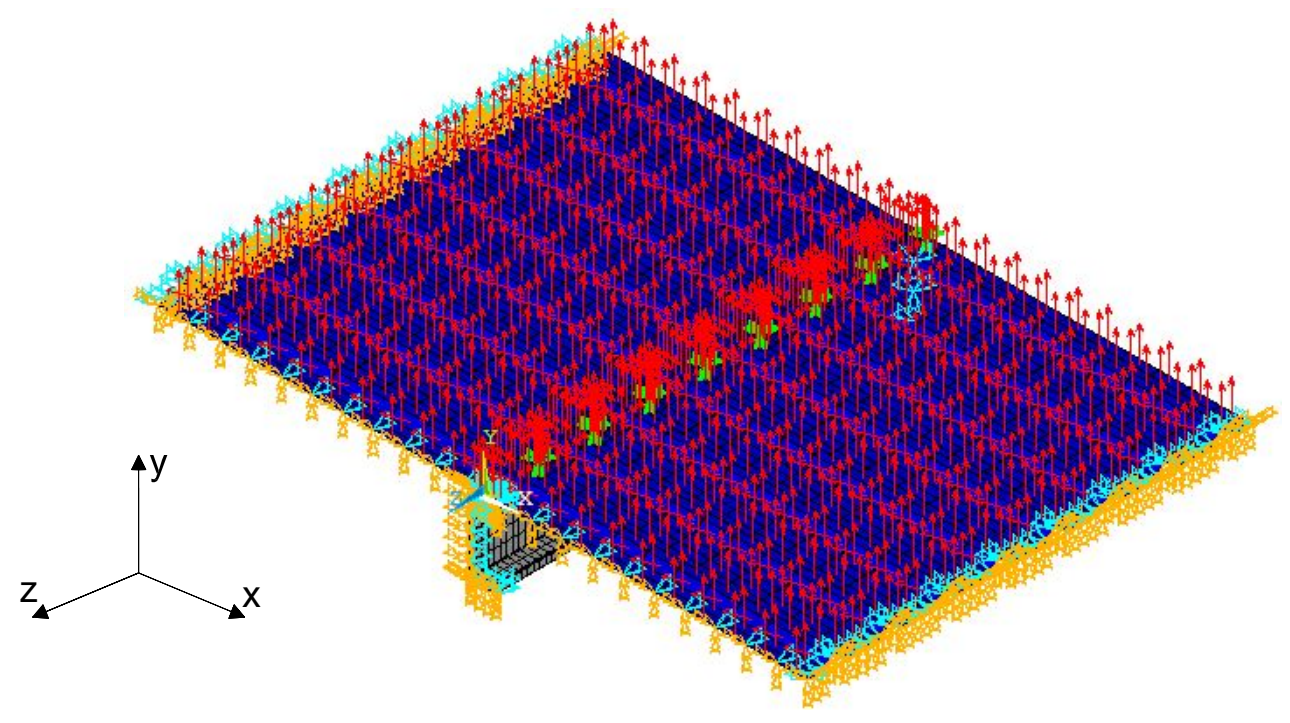

Figura A-1 - Eixo utilizado na determinação de rotações e deslocamentos.

A tabela A-2 mostra a razão entre os resultados adquiridos pela análise da terça isolada e os resultados da tabela $A-1$, as lacunas tracejadas referem-se aos valores por divisão por zero já que tanto em um modelo como no outro estes valores são iguais a zero devido ao eixo de simetria.

Tendo em vista os pequenos valores de deslocamento na direção do eixo $x$, foram utilizados apoios que restringem totalmente a translação na direção do eixo $x$.

É importante salientar a pressão na qual deve ser determinada a rigidez de mola, para o modelo exemplificado, a pressão última adotada foi de $0,72 \mathrm{kN} / \mathrm{m}^{2}$. No entanto, para os outros modelos foi adotado o carregamento último, seja por instabilidade, deslocamentos excessivos ou o momento fletor de início de escoamento $\left(M_{R}=W . f_{y}\right)$. 
Tabela A-1 - Deslocamentos e rotações do modelo proposto 1.

\begin{tabular}{|r|r|r|r|r|r|r|}
\hline \multicolumn{7}{|c|}{ Modelo Proposto 1 - Pressão=0,72kN/m } \\
\hline NODE & UX $(\mathrm{cm})$ & UY $(\mathrm{cm})$ & $\mathrm{UZ}(\mathrm{cm})$ & ROTX $(\mathrm{rad})$ & ROTY $(\mathrm{rad})$ & ROTZ $(\mathrm{rad})$ \\
\hline 104 & 0,0142 & 4,3415 & 0,0000 & 0,0000 & 0,0000 & 0,1373 \\
\hline 60 & 0,0136 & 4,3144 & $-0,0161$ & $-0,0027$ & 0,0002 & 0,1366 \\
\hline 127 & 0,0116 & 4,2336 & $-0,0318$ & $-0,0054$ & 0,0004 & 0,1343 \\
\hline 450 & 0,0083 & 4,0999 & $-0,0469$ & $-0,0080$ & 0,0005 & 0,1304 \\
\hline 646 & 0,0040 & 3,9146 & $-0,0611$ & $-0,0105$ & 0,0007 & 0,1250 \\
\hline 842 & $-0,0011$ & 3,6798 & $-0,0740$ & $-0,0129$ & 0,0008 & 0,1181 \\
\hline 1038 & $-0,0068$ & 3,3980 & $-0,0854$ & $-0,0152$ & 0,0008 & 0,1097 \\
\hline 1234 & $-0,0128$ & 3,0725 & $-0,0951$ & $-0,0173$ & 0,0009 & 0,0998 \\
\hline 1430 & $-0,0187$ & 2,7072 & $-0,1028$ & $-0,0192$ & 0,0009 & 0,0885 \\
\hline 1626 & $-0,0242$ & 2,3069 & $-0,1085$ & $-0,0208$ & 0,0008 & 0,0761 \\
\hline 1822 & $-0,0293$ & 1,8772 & $-0,1118$ & $-0,0221$ & 0,0007 & 0,0626 \\
\hline 2018 & $-0,0338$ & 1,4250 & $-0,1128$ & $-0,0230$ & 0,0006 & 0,0484 \\
\hline 2214 & $-0,0373$ & 0,9581 & $-0,1114$ & $-0,0236$ & 0,0004 & 0,0339 \\
\hline 2410 & $-0,0395$ & 0,4876 & $-0,1078$ & $-0,0234$ & 0,0003 & 0,0207 \\
\hline 2606 & $-0,0407$ & 0,0270 & $-0,1027$ & $-0,0232$ & 0,0013 & 0,0109 \\
\hline
\end{tabular}

Tabela A-2 - Razão dos deslocamentos e rotações do modelo de terça isolada e tabela A-1.

\begin{tabular}{|c|c|c|c|c|c|c|}
\hline \multicolumn{7}{|c|}{ Terça Isolada - Pressão=0,72kN/m² } \\
\hline NODE & UX & UY & UZ & ROTX & ROTY & ROTZ \\
\hline 104 & $-100,72$ & 1,27 & - & - & - & 3,58 \\
\hline 60 & $-105,93$ & 1,27 & 1,00 & 1,28 & 4,87 & 3,58 \\
\hline 127 & $-124,81$ & 1,27 & 1,00 & 1,28 & 4,63 & 3,58 \\
\hline 450 & $-174,23$ & 1,27 & 0,99 & 1,28 & 4,33 & 3,59 \\
\hline 646 & $-361,98$ & 1,27 & 0,99 & 1,28 & 3,92 & 3,60 \\
\hline 842 & 1302,45 & 1,27 & 0,98 & 1,28 & 3,35 & 3,61 \\
\hline 1038 & 211,36 & 1,28 & 0,98 & 1,27 & 2,54 & 3,64 \\
\hline 1234 & 110,46 & 1,28 & 0,97 & 1,27 & 1,41 & 3,67 \\
\hline 1430 & 72,56 & 1,29 & 0,96 & 1,28 & $-0,14$ & 3,71 \\
\hline 1626 & 52,33 & 1,31 & 0,94 & 1,28 & $-2,39$ & 3,78 \\
\hline 1822 & 39,03 & 1,32 & 0,92 & 1,29 & $-5,86$ & 3,86 \\
\hline 2018 & 29,02 & 1,35 & 0,90 & 1,31 & $-12,07$ & 3,98 \\
\hline 2214 & 20,68 & 1,39 & 0,87 & 1,33 & $-24,91$ & 4,15 \\
\hline 2410 & 13,27 & 1,46 & 0,83 & 1,35 & $-46,25$ & 4,28 \\
\hline 2606 & 5,82 & 4,54 & 0,75 & 1,22 & $-11,46$ & 4,89 \\
\hline Média & 65,95 & 1,52 & 0,93 & 1,29 & $-5,57$ & 3,83 \\
\hline Desv. Padrão & 368,145 & 0,837 & 0,074 & 0,029 & 14,520 & 0,368 \\
\hline
\end{tabular}

Ao restringir o deslocamento na direção do eixo $x$ a relação entre os resultados passa a assumir os valores dados na tabela A-3. No entanto a rotação em torno do eixo z e o deslocamento na direção do eixo y continuam apresentando grandes diferenças, desta forma adota-se o modelo mostrado na figura A-2, que além do apoio restringindo o deslocamento em $\mathrm{x}$, possui uma mola de rotação em torno do eixo $\mathrm{z}$, com 
rigidez $k_{r z}$ (modelo proposto 2 - item 3.3.4).

Tabela A-3 - Razão dos deslocamentos e rotações do modelo de terça restrita em x e tabela A-1.

\begin{tabular}{|c|c|c|c|c|c|c|}
\hline \multicolumn{7}{|c|}{ Terça Restrita Somente em X - Pressão $=0,72 \mathrm{kN} / \mathrm{m}^{2}$} \\
\hline NÓ & UX & UY & UZ & ROTX & ROTY & ROTZ \\
\hline 104 & 0,00 & 1,21 & - & - & - & 2,97 \\
\hline 60 & 0,00 & 1,21 & 1,00 & 1,21 & 3,25 & 2,96 \\
\hline 127 & 0,00 & 1,21 & 1,00 & 1,21 & 3,17 & 2,95 \\
\hline 450 & 0,00 & 1,21 & 1,00 & 1,21 & 3,12 & 2,93 \\
\hline 646 & 0,00 & 1,21 & 0,99 & 1,21 & 3,07 & 2,90 \\
\hline 842 & 0,00 & 1,21 & 0,99 & 1,21 & 3,01 & 2,86 \\
\hline 1038 & 0,00 & 1,21 & 0,99 & 1,21 & 2,93 & 2,82 \\
\hline 1234 & 0,00 & 1,21 & 0,98 & 1,21 & 2,82 & 2,77 \\
\hline 1430 & 0,00 & 1,21 & 0,98 & 1,21 & 2,72 & 2,72 \\
\hline 1626 & 0,00 & 1,21 & 0,97 & 1,21 & 2,63 & 2,66 \\
\hline 1822 & 0,00 & 1,22 & 0,97 & 1,21 & 2,56 & 2,61 \\
\hline 2018 & 0,00 & 1,22 & 0,96 & 1,21 & 2,56 & 2,55 \\
\hline 2214 & 0,00 & 1,22 & 0,95 & 1,21 & 2,63 & 2,47 \\
\hline 2410 & 0,00 & 1,22 & 0,97 & 1,25 & 2,25 & 2,14 \\
\hline 2606 & 0,00 & 0,51 & 0,91 & 1,27 & $-0,59$ & 0,68 \\
\hline Média & 0,00 & 1,17 & 0,98 & 1,22 & 2,58 & 2,60 \\
\hline Desv. Padrão & 0,0000 & 0,1810 & 0,0245 & 0,0178 & 0,9565 & 0,5772 \\
\hline
\end{tabular}

$$
k_{r z}
$$

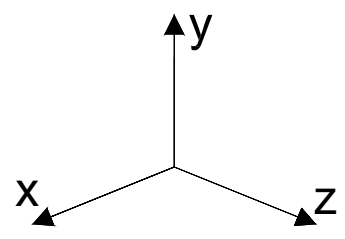

Figura A-2 - Modelo adotado utilizando elementos de mola.

O modelo proposto em Lucas (1997b), "Rotational Restraint Model", é então analisado, o gráfico pressão $x$ deslocamento horizontal é mostrado na figura A-3. O gráfico mostra uma tendência linear e assim podendo ser aproximado por uma reta. 


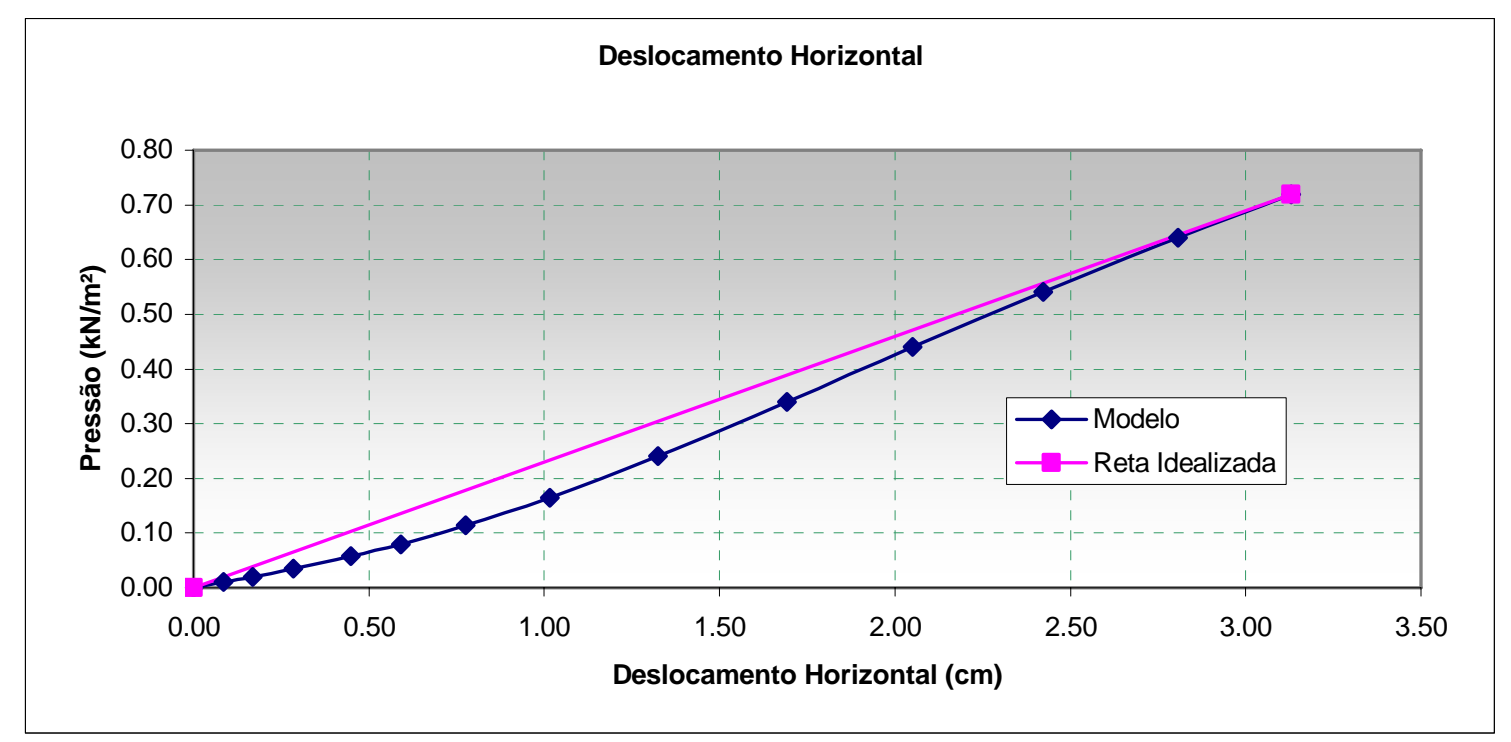

Figura A-3 - Gráfico pressão x deslocamento horizontal, do modelo proposto por Lucas (1997a), "Rotational Restraint Model".

Sabendo-se que o carregamento aplicado, $N$, é igual à pressão aplicada na telha de $7,2 \times 10^{-5} \mathrm{kN} / \mathrm{cm}^{2}$, multiplicada pela largura de influência de $178 \mathrm{~cm}$, tem-se que $\mathrm{N}=1,28 \times 10^{-2} \mathrm{kN} / \mathrm{cm}$. O deslocamento horizontal encontrado é de $3,12 \mathrm{~cm}$, como ilustrado na figura A-3. Foi adotado $h=b_{w}-2,5 . t$ que resulta em $h=11,95 \mathrm{~cm}$. Com estes dados é possível calcular a rigidez de mola $k_{r z}$ segundo Lucas (1997b), sendo:

$k_{r z}=\frac{N}{\delta} \cdot h^{2}=\frac{1,28 \times 10^{-2}}{3,12} \cdot 11,95^{2}=0,586 \mathrm{kN} / \mathrm{rad}=586 \mathrm{~N} / \mathrm{rad}$

As razões entre os resultados encontrados com a utilização deste coeficiente de mola e o modelo simplificado são mostradas na tabela A-4, no entanto, as rotações em z não apresentam resultados satisfatórios.

Diante disto é necessário realizar simulações até que os resultados apresentem a relação mais próxima do valor 1 . No exemplo constatou-se que um valor ideal seria $k_{r z}=0,35 \mathrm{kN} / \mathrm{rad}$, como mostrado na tabela A-4.

No presente trabalho foi adotada a mesma nomenclatura do CUFSM para a rigidez à rotação, onde $k_{r z}=k_{r x}$ e as unidades ao invés de N/rad utiliza-se kN.m/rad/m. 
Tabela A-3 - Razão dos deslocamentos e rotações do modelo de terça restrita em x com mola $k_{r z}=0,586 \mathrm{kN} \cdot \mathrm{m} / \mathrm{rad} / \mathrm{m}$ (modelo proposto 2) e da tabela A-1.

\begin{tabular}{|c|c|c|c|c|c|c|}
\hline \multicolumn{7}{|c|}{ Modelo Proposto 2 - Pressão $=0,72 \mathrm{kN} / \mathrm{m}^{2}-\mathrm{krz}=0,586 \mathrm{kN} . \mathrm{m} / \mathrm{rad} / \mathrm{m}$} \\
\hline NÓ & UX & UY & UZ & ROTX & ROTY & ROTZ \\
\hline 104 & 0,00 & 0,95 & - & - & - & 0,63 \\
\hline 60 & 0,00 & 0,95 & 0,98 & 0,98 & 1,09 & 0,62 \\
\hline 127 & 0,00 & 0,95 & 0,98 & 0,98 & 1,06 & 0,62 \\
\hline 450 & 0,00 & 0,95 & 0,98 & 0,98 & 1,04 & 0,62 \\
\hline 646 & 0,00 & 0,95 & 0,98 & 0,98 & 1,03 & 0,61 \\
\hline 842 & 0,00 & 0,95 & 0,98 & 0,98 & 1,01 & 0,60 \\
\hline 1038 & 0,00 & 0,95 & 0,98 & 0,97 & 0,98 & 0,59 \\
\hline 1234 & 0,00 & 0,95 & 0,98 & 0,97 & 0,93 & 0,57 \\
\hline 1430 & 0,00 & 0,94 & 0,98 & 0,96 & 0,89 & 0,55 \\
\hline 1626 & 0,00 & 0,94 & 0,98 & 0,96 & 0,83 & 0,52 \\
\hline 1822 & 0,00 & 0,94 & 0,98 & 0,96 & 0,78 & 0,49 \\
\hline 2018 & 0,00 & 0,93 & 0,98 & 0,95 & 0,71 & 0,44 \\
\hline 2214 & 0,00 & 0,92 & 0,98 & 0,95 & 0,59 & 0,35 \\
\hline 2410 & 0,00 & 0,90 & 0,99 & 0,94 & 0,41 & 0,21 \\
\hline 2606 & 0,00 & 0,21 & 0,99 & 0,92 & 0,01 & 0,06 \\
\hline Média & 0,00 & 0,89 & 0,98 & 0,96 & 0,81 & 0,50 \\
\hline Desv. Padrão & 0,0000 & 0,1893 & 0,0024 & 0,0169 & 0,3021 & 0,1687 \\
\hline
\end{tabular}

Tabela A-4 - Razão dos deslocamentos e rotações do modelo de terça restrita em x com mola $k_{r z}=0,35 \mathrm{kN} \cdot \mathrm{m} / \mathrm{rad} / \mathrm{m}$ (modelo proposto 2 ) e da tabela A-1.

\begin{tabular}{|c|c|c|c|c|c|c|}
\hline \multicolumn{7}{|c|}{ Modelo Proposto 2 - Pressão=0,72kN/m² $-\mathrm{krz}=0,35 \mathrm{kN} . \mathrm{m} / \mathrm{rad} / \mathrm{m}$} \\
\hline NÓ & UX & UY & UZ & ROTX & ROTY & ROTZ \\
\hline 104 & 0,00 & 1,01 & - & - & - & 0,99 \\
\hline 60 & 0,00 & 1,01 & 1,01 & 1,04 & 1,52 & 1,00 \\
\hline 127 & 0,00 & 1,01 & 1,00 & 1,05 & 1,48 & 0,98 \\
\hline 450 & 0,00 & 1,01 & 1,00 & 1,04 & 1,45 & 0,97 \\
\hline 646 & 0,00 & 1,00 & 1,00 & 1,04 & 1,43 & 0,96 \\
\hline 842 & 0,00 & 1,00 & 1,00 & 1,04 & 1,39 & 0,94 \\
\hline 1038 & 0,00 & 1,00 & 1,00 & 1,03 & 1,34 & 0,92 \\
\hline 1234 & 0,00 & 1,00 & 1,00 & 1,03 & 1,28 & 0,90 \\
\hline 1430 & 0,00 & 0,99 & 1,00 & 1,02 & 1,21 & 0,87 \\
\hline 1626 & 0,00 & 0,99 & 0,99 & 1,01 & 1,15 & 0,83 \\
\hline 1822 & 0,00 & 0,98 & 0,99 & 1,01 & 1,08 & 0,79 \\
\hline 2018 & 0,00 & 0,98 & 0,99 & 1,00 & 1,01 & 0,72 \\
\hline 2214 & 0,00 & 0,97 & 0,99 & 1,00 & 0,91 & 0,63 \\
\hline 2410 & 0,00 & 0,95 & 0,99 & 0,99 & 0,66 & 0,45 \\
\hline 2606 & 0,00 & 0,22 & 0,99 & 0,98 & 0,00 & 0,12 \\
\hline Média & 0,00 & 0,94 & 1,00 & 1,02 & 1,14 & 0,80 \\
\hline Desv. Padrão & 0,0000 & 0,2002 & 0,0065 & 0,0222 & 0,4093 & 0,2447 \\
\hline
\end{tabular}

